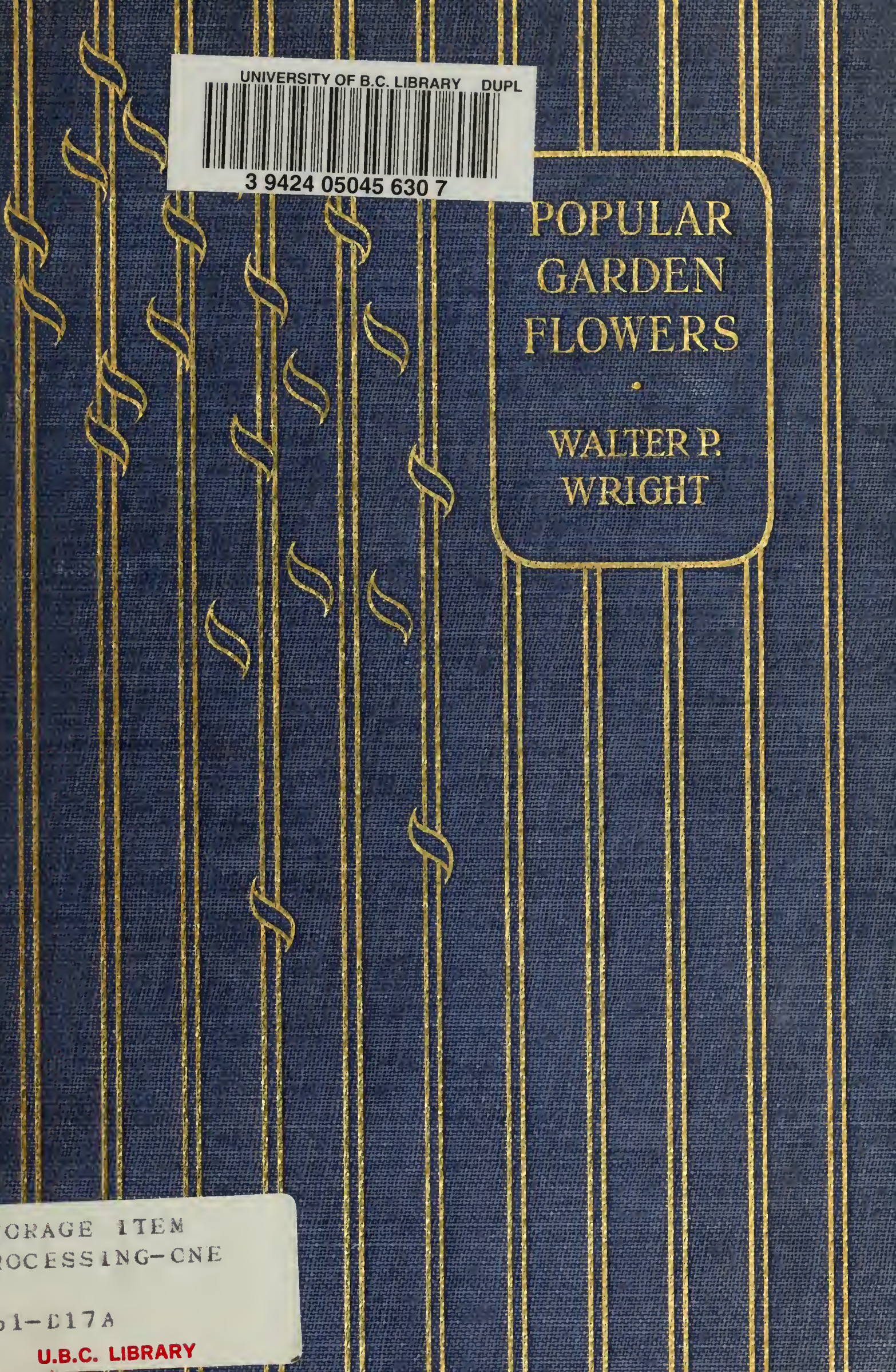




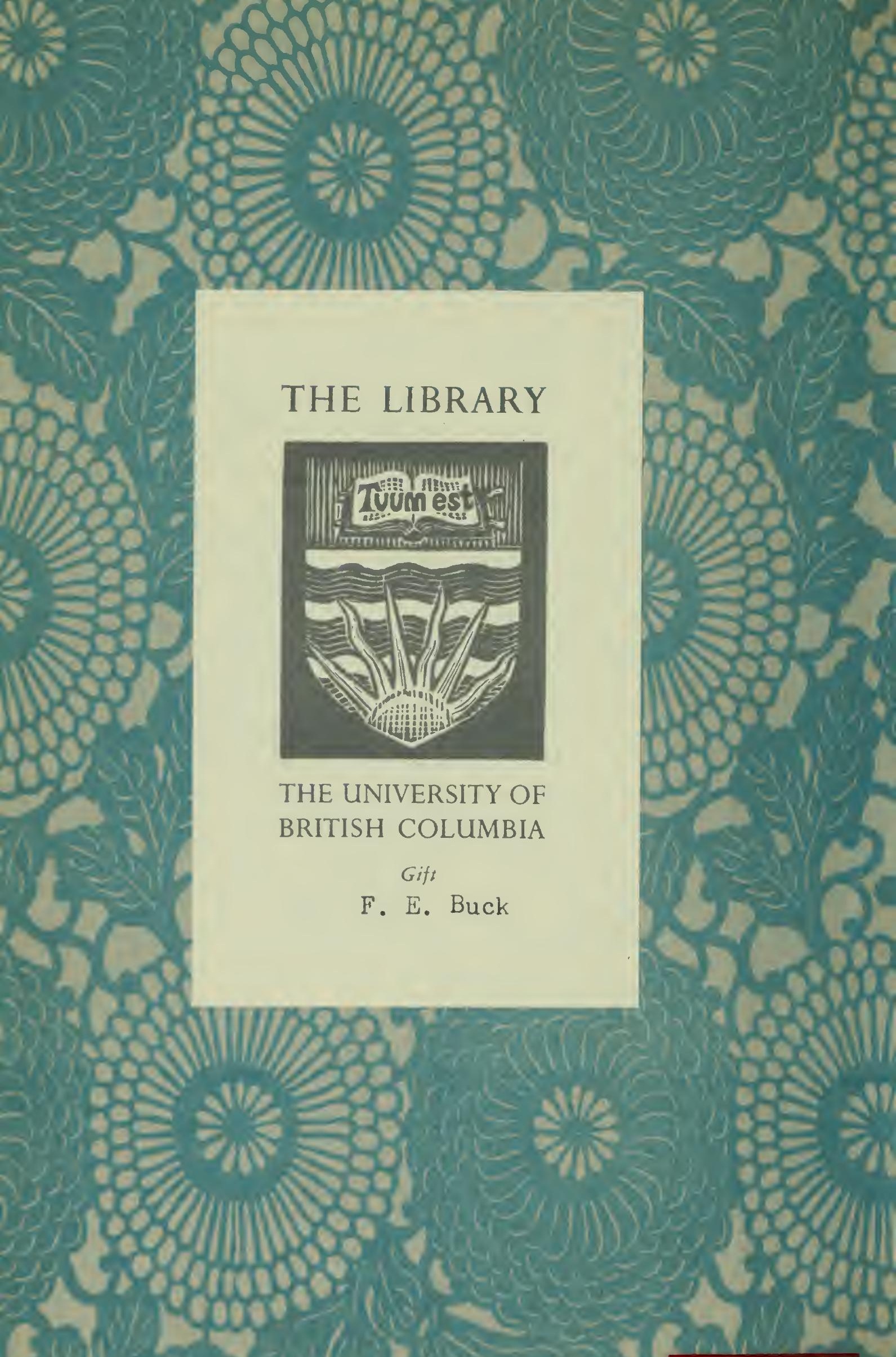


F.b. Buck,

1912

POPULAR GARDEN FLOWERS 
BY THE SAME AUTHOR

Uniform with this Volume

THE GARDEN WEEK BY IVEEK

THROUGHOUT THE YEAR

A Practical Handbook to Gardening OPERATIONS FOR EVERY WEEK IN THE

Year and to THE Culture of all Important Plants

With Coloured Plates and Engravings and One Hundred Practical Illustrations

Price 6s. net

THE PERFECT GARDEN :

How to Keep it Beautiful and Fruitful

With Coloured Plates and Engravings, and with ig Plans for Gardens, etc.

Price 6s. net 
Digitized by the Internet Archive in 2010 with funding from

University of British Columbia Library

http://www.archive.org/details/populargardenflo00wrig 


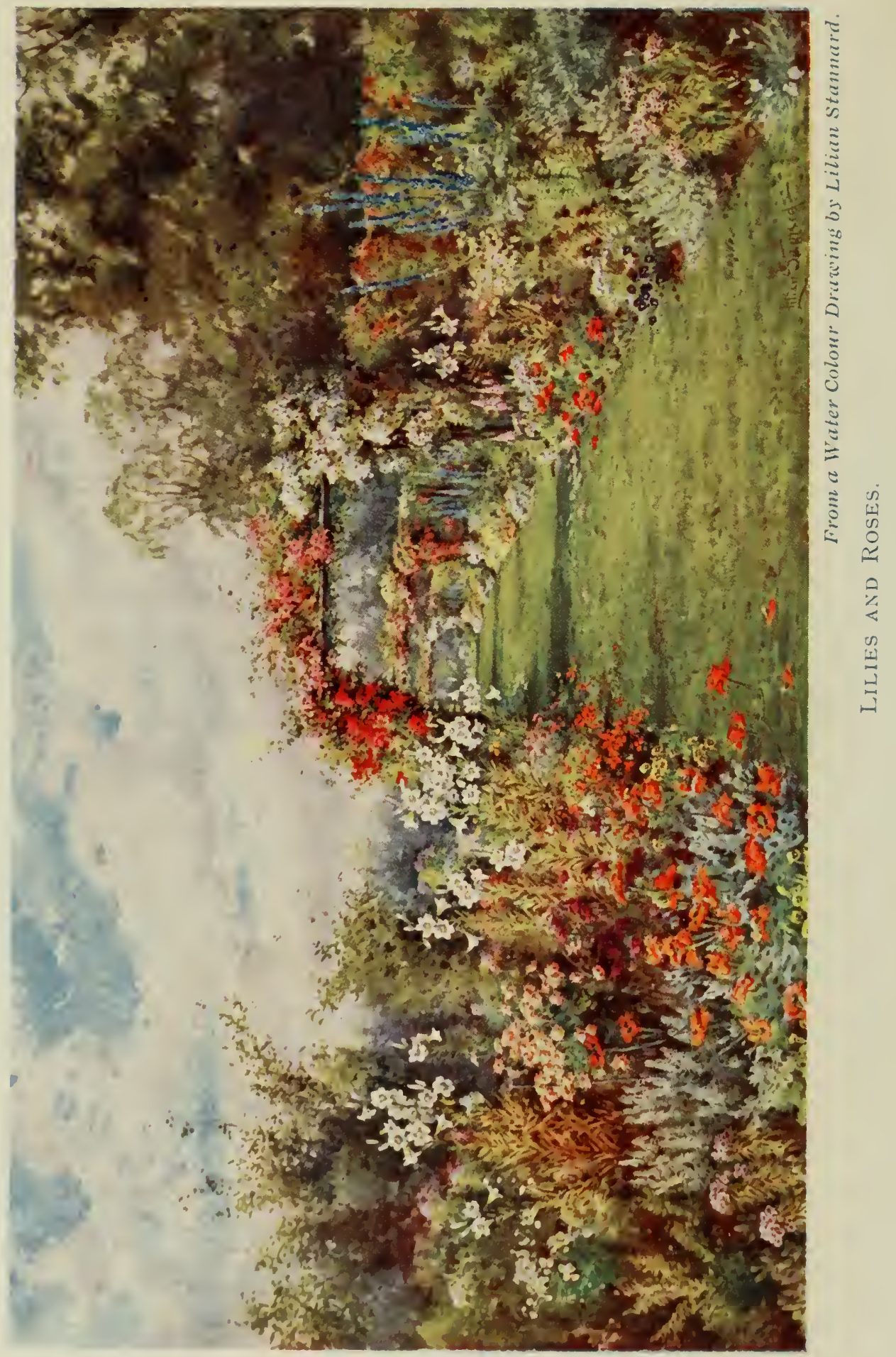




\section{POPULAR GARDEN FLOWERS}

ANEMONES : ASTERS : BEGONIAS : CARNATIONS : CHRYSANTHEMUMS : CROCUSES : DAFFODILS :

DAHLIAS : GERANIUMS : GLADIOLI : HOLLYHOCKS : HYACINTHS : IRISES :

LILIES : PANSIES : PHLOXES : PRIMULAS : SWEET PEAS :

STOCKS : TULIPS :

ROSES

धृ ${ }^{c}$

BY

WALTER P. WRIGHT

AUTHOR OF "THE PERFECT GARDEN"

"THE GARDEN WEEK BY WEEK," ETC.

WITH SIX ILLUSTRATIONS IN COLOUR

AND FORTY.EIGHT REPRODUCTIONS

FROM PHOTOGRAPHS

\section{LONDON}

GRANT RICHARDS LTD

PUBLISHERS 
Printed by Batlantyne, Hanson \& Co. At the Biallantyne Press, Edinburgh I9II 


\section{PREFACE}

Systems of gardening are not of much use unless supported by good plants, of which the best varieties are selected for thorough cultivation.

Many amateurs grow too many kinds of plants. They crowd their beds, borders, and rockeries with a heterogeneous assembly of genera, many of which are of no special value. They would find gardening equally interesting, and far more effective, if they selected a few of the great flowers which have been developed by florists, studied the habit and requirements of the plants, and made themselves acquainted with the best varieties.

By making good use of such great bulbous flowers as Daffodils, Tulips, and Hyacinths for spring; Begonias, Roses, Sweet Peas, Zonal Geraniums, Asters, Carnations, Hollyhocks, Irises, Lilies, Pæonies, and Pansies for summer; and Dahlias, Chrysanthemums, Phloxes, Michaelmas Daisies, Japanese Anemones, and Gladioli for late summer and autumn, it is possible to have a garden full of beauty and interest for the greater part of the year.

In "The Perfect Garden" I dealt with systems of gardening and plans of gardens. In a second work, "The Garden Week by Week," I described the routine of garden operations throughout the year. In the present one, which completes the trilogy, I take all the most important plants and deal with them fully, showing 
their history, the origin and pronunciation of their names, their position in literature and folklore, their value as modern garden plants, their culture, and the best varieties of them.

Garden interests are kept clearly in view throughout, and the book is not the less practical because literary associations are referred to. Every important cultural item has received attention. I feel sure that gardenlovers will not grow their favourite flowers with less of either interest or thoroughness for knowing something of their place in history and literature.

Although the various plants are dealt with primarily as garden flowers, I have thought it wise to refer briefly to the indoor as well as the outdoor culture of such as are used for both greenhouse and garden adornment, and even to offer hints for the guidance of exhibitors. This has been done for the sake of completeness.

In the case of such particularly important plants as Carnations, Chrysanthemums, and Roses, which are specialised by thousands of people, I have supplemented the practical information with a summary in the form of a monthly calendar of cultural operations, which will guard the amateur from the ill effects of neglecting important operations or performing them out of season.

WALTER P. WRIGHT.

March, 19II. 


\section{CONTENTS}

CHAP. T'AGE

I. ANEMONES (WindFlOWERS) • • • • • I

II. Asters, China AND Perennial . • . . 13

III. BEgONIAS • • • • • . • • 24

IV. Bell-Flowers (CAMPANulas) AND CANTERBURY BELLS • • • • • • • • 32

V. Shrubby Border and Bedding Calceolarias . $3 S$

VI. Canary Creeper and other Nasturtiums and

TROPEOLUMS • • • • • • • 42

VII. Candytufts AND OTher AnNuAls • • 47

ViII. Carnations, Picotees, and Pinks • • . 51

IX. Christmas and Lenten Roses (Hellebores) • 77

X. Chrysanthemums . . . . . . $\quad . \quad 84$

XI. Clematises $\quad$ • • • • • • . III

XII. Columbines (Aquilegias) . • • • . . . I I

XIII. CROCUSES • • • • • • • • • 126

XIV. DAFFODILS AND NARCISSI . . . . . I 34

XV. Dahlias . . . . . . . . . . . 150

XVI. FEVERFEIS (PYRETHRUMS) . . . . . ${ }^{1} 6_{3}$

XVII. FORGET-ME-NOTS (MyOSOTIS) • . . . . 167

XVIII. FoxglOVES . . . . . . . . . I7I

XIX. Geraniums . . . . . . . . . . 176

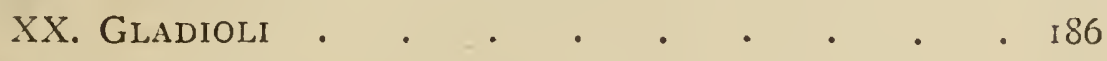

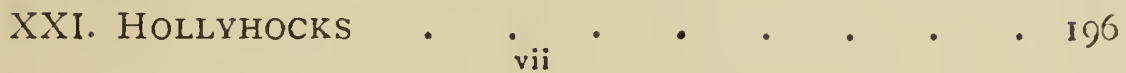


CIIA:.

XXil. Honeysuckle . . . • . • . . 202

XXIII. Hyacinths . . . . . . . . . 208

XXIV. IRISES . • . . • . • . . . 218

XXV. JASMINF, • • • • • • • • • • 232

KXVI. Perennial Larkspurs (Delphiniums) • . 237

XXVII. Lilies . • • . . . • . . . 243

XXVIII. PÆONIES . . . . . . . . . 263

XXIX. Pansies, Violas, and Sweet Violets . . . 270

XXX. Phloxes . . . . • • • . . 285

XXXi. Primulas-Auriculas, Oxlips, Polyanthuses, and Primiroses . . . . . . . . 294

XXXII. ROSES . . . . . . . . . . . 303

XXXIII. Snapdragons and Siveet Williams • • . 339

XXXIV. SweEt Peas • • . . . . • • 345

XXXV. Stocks ani Wallflowers . • • • • 355

XXXVI. TULIPS . • • . • • • • • • 362

$\operatorname{INDEX} \cdot \cdot \cdot \cdot \cdot \cdot \cdot 371$ 


\title{
LIST OF ILLUSTRATIONS
}

\author{
IN COLOUR
}

Lilies and Roses

Frontispiece

Hollyhocks and Herbaceous Phloxes . . . Facing page I96

Perennial Larkspurs • • . • . . " " 236

White Lilies . . . . . . . . " " 242

Rose Borders . . . . . . . . " " 304

Sweet Peas . . . . . . . . "

\section{BLACK AND WHITE}

Hepaticas . . . . . . . . . .

A bed of Japanese Anemones . . . . . . "

Annual Asters . . . . . . . . . .

Double Begonias . . . . . . . . . . 2 26

Canterbury Bells . . . . . . . . " " 12

A bed of the Peach-leaved Campanula persicifolia . " " 36

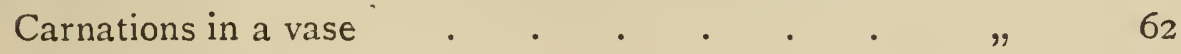

Double Pinks . . . . . . . . . $\quad$ " . 46

Double Indian Pinks . . . . . . . . $\quad$, 68

Single Chrysanthemums as cut flowers . . . . $\quad \% \quad 84$

Prize Japanese Chrysanthemums . . . . . " . $\quad 94$

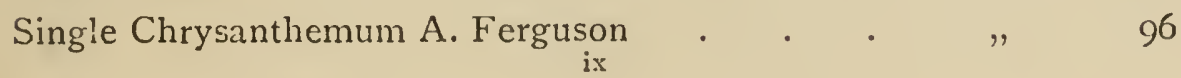


Decorative Chrysanthemums . . . . . Facing page 98

Double white annual Chrysanthemums . . . " " 100

Chrysanthemum (Pyrethrum) uliginosum . . " " 104

Clematis Montana . . . . . . . " "

Columbines . . . . . . . . . " . 120

Crocuses in grass under trees . . . . . . " $\quad$. 132

Narcissus Emperor . . . . . . . " "

Cactus Dahlias . . . . . . . . $\quad$ " 160

A bed of Dahlias . . . . . . . . $\quad$. $\quad 162$

Alpine Forget-me-not (Myosotis dissitiflora) . . " $\quad 168$

Foxgloves in the wild garden . . . . . $\quad " \quad 172$

Gladioli . . . . . . . . . . . .

A well-bloomed Hollyhock . . . . . . " $\quad 198$

Honeysuckle on an arch . . . . . . . " " 204

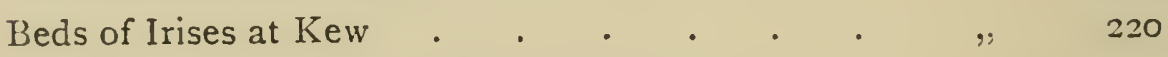

Iris Sibirica massed for effect on the margin of a pond at Kew . . . . . . . . . . . . 226

A border of Irises . . . . . . . . .

A bed of Delphinium (perennial Larkspur) Belladonna

Lilium auratum

238

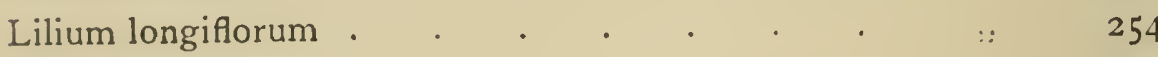

Lilium speciosum . . . . . . . . . . .

Belladonna Lilies . . . . . . . . " . 260

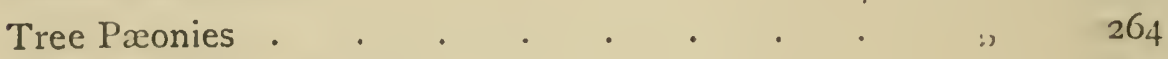

Violas or Tufted Pansies . . . . . . . . . . . 276

Perennial Phloxes . . . . . . . " . 286

Primroses . . . . . . . . . $\quad$ " 294

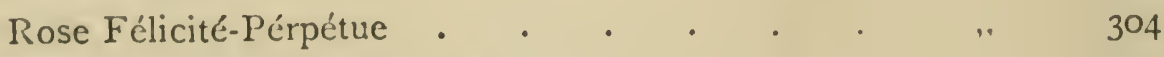

$\Lambda$ bed of the beautiful Rose Electra . . . . . 324

A Rose Pergola in the Royal Gardens, Kew . . . " $\quad 332$ 


\section{LIST OF ILLUSTRATIONS}

$\mathrm{xi}$

Pentstemons

Sweet Peas

Ten-week Stock

Tulips and Arabis (White Rock Cress)

Beds of Tulips at Kew

- Facing page 340

A border of Tulips with Lilac above . . .

Cannas

$\begin{array}{ll}" & 348 \\ " & 358 \\ " & 362 \\ " & 364 \\ " & 368 \\ " & 370\end{array}$





\section{I}

ON ANEMONES (WINDFLOWERS) AS ALL-THE-YEARROUND PLANTS

To many lovers of flowers the Anemone is merely a charming denizen of the woodlands. When it is mentioned, radiant pictures of the shady undergrowth of the forest rise into memory. The listener recalls bright spring mornings in the secluded forest dales, when the first note of the cuckoo was heard, and the startled rabbits scurried at the sound of his footsteps. The Windflowers spread in sheets at his feet, the white or tinted flowers rising a few inches from the pretty green leaves.

But the Anemone is also a garden plant of outstanding beauty and value. There are many species of it, and these have their varieties, differing to some extent in form and colour. Many bear little resemblance to the Wood Anemone. They are of larger growth, the flowers are many times the size, and the colours are rich and varied. With culture, we can have some of them in flower every month of the year. It is these beautiful Anemones that I now propose to consider.

Garden-lovers who trace the folk-lore and literary association of flowers, grow them with a deeper interest from the knowledge that they have become the subject of tradition or rite with the multitude, or have come under the special observation of great writers. Research is carried to excess if the flower-lover deteriorates as 
a gardener in proportion to his development as an antiquarian, but most people find no difficulty in maintaining their cultural standard, while learning all that there is to know about the plants which they grow.

A beautiful flower is worth studying from two points of view-its value as a garden object, and the part that it has played in life and literature. In the former capacity it adds to the pleasure of the present, in the latter it links us with the past.

The brilliant Anemone, the first of our list of popular garden flowers, is a typical example of a flower that has the double interest of garden beauty and legendary association. In its different species and varieties it is a garden plant of great value, owing to its hardiness, the long period over which it blooms, and its brilliant colours. The flower gardener loves it, because it gives beautiful flowers for practically every month of the year, and is particularly generous in winter and spring. The litterateur regards it with special interest as the flower referred to by Shakespeare in "Venus and Adonis" :

"By this, the boy that by her side lay killed

Was melted like a vapour from her sight, And in his blood that on the ground lay spilled, A purple flower sprang up chequered with white."

The gardener might object that the flower which Shakespeare had in view when he wrote these lines could not have been the Anemone, inasmuch as it was neither purple nor chequered. But it has to be remembered that with the mediaeval writers "purple" had a much wider application than it has at the present time. In the Latin purpureus it was used to describe the Poppy. And with respect to chequering, it was 
applied as freely to spots of various shape as it was to square markings. A red flower with any kind of white markings might easily be "purple chequered with white" in Shakespeare's time.

The Adonis Flower of his day was certainly the Anemone-note Ross's statement in 1647 that "Adonis was turned into a red flower called Anemone."

The Anemone is the flower of the wind. The name comes from the Greek anemos-wind. What was the Greek idea? Pliny says that the plant was so named because "the flower hath the propertie to open but when the wind doth blow"; but as this does not conform to the habit of the Anemone, it can only be supposed that he had some other flower in mind. Our Anemone became the Windflower because several species inhabited exposed, wind-swept places.

That the early classical writers had another Anemone than ours is shown by Sir William Jones's lines:

"Youth, like a thin Anemone, displays
His silken leaf, and in a morn decays."

The modern Anemone is not a fleeting (fugacious) flower, and this figure could not be used correctly in reference to it.

We have anglicised the name by adopting an accentuation of our own. We ought to make it An-e-mo'-ne ; we make it A-nem'-o-ne. It is interesting to note that the scansion of the lines quoted above point to our method of pronunciation being held in the days of the old poet, but it is possible that he introduced an arbitrary pronunciation for the sake of his metre.

The Windflower has its popular names. There is the "Poppy" Anemone (coronaria), and there is the "Star" Anemone (hortensis). These represent two 


\section{4 \\ POPULAR GARDEN FLOWERS}

great sections of early bloomers. The popular name of one of our native Anemones comes from its season of flowering: it is pulsatilla-the Pasque or Passe Flower - the Easter Flower. Then there is the Japanese Anemone $(A$. Japonica) a later bloomer, and likewise a taller grower, than most other species.

Several of the most important species have a bevy of beautiful daughters, but before considering these we might tabulate the most important kinds, and show their normal period of flowering outdoors :-

\begin{tabular}{|c|c|c|c|c|c|}
\hline \multicolumn{4}{|c|}{ Species. } & \multirow{2}{*}{$\begin{array}{c}\begin{array}{c}\text { Flowering Season } \\
\text { Outdoors. }\end{array} \\
\text { Spring }\end{array}$} & \multirow{2}{*}{$\begin{array}{l}\text { When to Sow or Plant. } \\
\text { Plant in autumn. }\end{array}$} \\
\hline Apennina & . & - & & & \\
\hline Blanda . & & . & & $\begin{array}{l}\text { Late winter and } \\
\text { early spring }\end{array}$ & Plant in autumn. \\
\hline Coronaria & - & - & - & April to June & $\begin{array}{l}\text { Sow seed the pre- } \\
\text { vious spring, or } \\
\text { plant tubers in } \\
\text { autumn. }\end{array}$ \\
\hline Fulgens . & - & - & - & April & $\begin{array}{l}\text { Sow seed previous } \\
\text { spring, or plant } \\
\text { tubers in autumn. }\end{array}$ \\
\hline \multirow{2}{*}{\multicolumn{3}{|c|}{$\begin{array}{l}\text { Hepatica } \\
\text { Hortensis (stellata) }\end{array}$}} & & February, March & Plant previous March. \\
\hline & & & & April & $\begin{array}{l}\text { Plant tubers in } \\
\text { autumn. }\end{array}$ \\
\hline Japonica & - & - & & $\left\{\begin{array}{c}\text { August to } \\
\text { October }\end{array}\right\}$ & $\begin{array}{l}\text { Plant early in pre- } \\
\text { vious spring. }\end{array}$ \\
\hline $\begin{array}{l}\text { Narcissiflora } \\
\text { Nemorosa }\end{array}$ & . & : & & $\begin{array}{l}\text { April } \\
\text { April }\end{array}$ & $\begin{array}{l}\text { Plant previous spring. } \\
\text { Plant previous au- } \\
\text { tumn. }\end{array}$ \\
\hline Pulsatilla & - & - & & March, April & Plant previous spring. \\
\hline Sylvestris & & . & & April & Plant previous spring. \\
\hline
\end{tabular}

The gardener extends the flowering season of some of these, as we shall see in our consideration of the different species.

Anemone Apennina, sometimes called the Italian Windflower, owing to its being a native of the Apen- 
nines, is a pretty blue species with creeping, tuberous roots. It may grow on rockwork, or naturalised in the woodland. There is a double light blue form (florepleno), a white (alba), and a mauve (purpurea). All grow about six inches high.

Blanda is a charming Windflower often in flower in January in sheltered places. It is blue, varying in shade, but also produces white and pink flowers. There are two exceptionally desirable varieties, namely, atrocærulea, dark blue, and scythinica, white and blue. Like Apennina, the Blandas have creeping, semi-tuberous roots. They grow about four inches high, and are suitable for the rockery.

Poppy Anemones.-Coronaria, the Crown, Poppy, or Garland Anemone, is the most valuable of all. The original species, introduced from the Levant in 1596 , had single striped flowers. It is not much grown, but its offspring, single, semi-double, and double, are cultivated in thousands of gardens. The flowers are large, brilliant, and varied. The foliage is attractively cut (laciniated). The Poppy Anemones make beautiful beds, and by judicious management can be had in bloom over a long period. They are tuberous-rooted, and can be planted in autumn to flower the following spring; but they are easily and quickly raised from seed, and a large stock of flowering plants can be raised in a year.

The double Poppy Anemones are particularly prized, and the following are fine varieties or strains :-

Alderborough, a mixed strain.

Chapeau de Cardinal, cerise.

Chrysanthemum-flowered, a mixed strain.

King of Scarlets, beautiful form and brilliant colour, no seed.

L'Ornement de la Nature, azure.

Queen of Roses, rosy-carmine, no seed. 
Rose de Nice, rose.

St. Brigid, a mixed strain.

Salmon King, salmon.

Sir Joseph Paxton, light violet.

The singles are not so keenly sought after as the doubles, but they are beautiful. Scarlet, white, and blue varieties can be procured.

All the Poppy Anemones grow about a foot high, and they thrive in most kinds of soil. If they are grown from tubers they should be planted in autumn for spring bloom, and in spring for summer flowering. If the tubers are examined, the incipient buds can be distinguished, and these should be uppermost. The tubers should be set two inches deep and six inches apart. Heavy clay soil is not supposed to suit the Anemones, but I have had excellent results from it when well drained, so that moisture had no chance of collecting and becoming stagnant. If I had undrained soil to deal with, I should either plant on a bed the level of which had been raised, or in spring. Given these provisions, clay soil is good, especially for summer blooming, as it supplies the moisture which these plants love so well. Poor soil should be well enriched with decayed manure. After the flowering the leaves will gradually die away, and when they have withered the roots of the springflowering plants may be lifted, dried, and stored in thin layers in a dry place.

On a cool, fertile clay soil in a mild district in Kent I found seedling Poppy Anemones a source of great pleasure and interest. Some of the plants flowered the same year, others the following spring. As the seed is fluffy, and given to close adherence, thin sowing is not easy until the seed has been rubbed up in sand or I fine soil. After this has been done it can be spread 


\section{ON ANEMONES}

readily. It should be covered with about half an inch of fine moist soil. If the plants come up thickly they should be thinned, and they may be subsequently transplanted if desired, but it is not indispensable. The seed bed should not be allowed to get quite dry. The seed may be sown in a frame or greenhouse if the grower has either.

By making special provision it is easy to have Poppy Anemones in bloom for several months. By sowing seed in spring and planting in frames in autumn, flowers can be had in January and February. In March, outdoor plants from tubers inserted in autumn will begin to bloom in sheltered places, and there should be bloom in April and May. Flowers can be had in June and July by planting tubers in February or March. Autumn and winter bloom should come from seed sown in spring. Thus it is possible to get Anemones from one class alone nearly every month in the year.

The specialist will grow all the varieties of the Poppy Anemone which he can get, but others will be content with the St. Brigid mixture and King of Scarlets. These will give some of the finest forms. The St. Brigids embrace a great diversity of beautiful colours, and the Iflowers are as large as breakfast-cups. Most of them I are semi-double. Considering their beauty and cheapness (the best strains only cost about five shillings per roo tubers) they should be grown by every flowerlover.

Fulgens, the next on our list of Anemones, is the well-known scarlet Windflower, and a most brilliant one it is. It grows about a foot high, and has several varieties, notably annulata, crimson with white base; flore-pleno, double scarlet; græca, scarlet, with black boss; oculata gigantea, scarlet, with pale yellow eye; 
and The Queen, salmon pink. The flowers of oculata gigantea are of great size.

The treatment of this class is very similar to that of the Poppy Anemone, and flowers can be had for several months by the same procedure. They like a sunny position. They are tuberous-rooted. In the ordinary way they will bloom in spring from seed sown the previous spring or tubers planted in autumn. If there is room to spare in a cold frame, it is always worth while to put in a few tubers of Anemone fulgens, as the brilliant scarlet flowers are very cheerful at mid-winter.

Hepaticas.-Our next species is Hepatica, that little plant which has received the popular award of a generic standing, and is grown, not as Anemone Hepatica, but as the Hepatica, in thousands of gardens. It is not a tuberous species, and this fact, coupled with its inclusion in the catalogues of most florists apart from the Anemones, deceives non-botanical flower-lovers, who do not look on it as an Anemone at all.

The common Hepatica, with its three-lobed leaves (triloba) has single lilac flowers, and is a very pretty plant. There are several varieties, such as single red and white, and double red, blue, and white. The last is very rare, and is too expensive to plant in quantity. Angulosa, blue, with its white and rose varieties, is also a Hepatica.

The Hepaticas have fibrous, not tuberous, roots, and grow about six inches high. With their low, dense growth, early period of blooming, and abundance of bright flowers, they would be valuable rockery plants but for the fact that they cannot endure a sunny position. They love a cool, moist soil and a shady I place, and thrive under trees. They should be planted in March, or as soon as the flowers have decayed and 


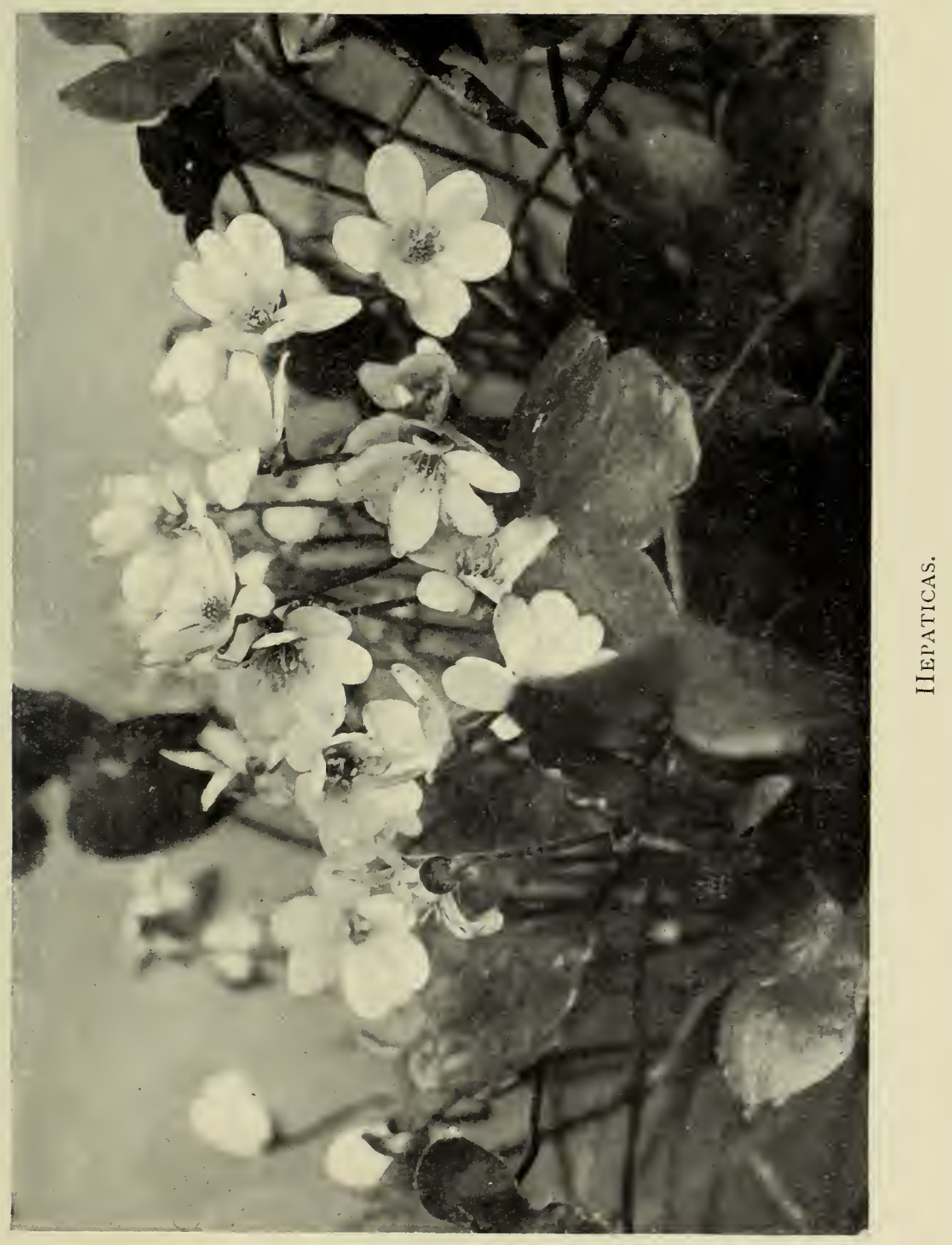



the young foliage shows. When established they should be left alone, as they do not relish frequent disturbance.

Hortensis (stellata). - With the star Windflower we get back to the tuberous-rooted class. The botanists make hortensis embrace fulgens as well as stellata; both, they tell us, are forms of the one species. Doubtless this is correct, but we have grown into a way of regarding hortensis and fulgens as distinct in gardens.

The species produces scarlet, purple (or blue), and white flowers. It has several varieties, notably White Gem, an exquisite silvery flower with dark anthers. Jewel, violet, with white centre, is also charming. All grow nine inches to a foot high, and bloom in spring. The culture is similar to that of coronaria and fulgensthat is, they may be raised from seed sown in spring or tubers planted in autumn; but they will not thrive so well as the Poppy Anemone in heavy soil. They like a light, warm, well-drained soil, in a sunny position, and are suitable for rockwork.

The Japanese Anemone, Japonica, which came from Japan in 1844 , is a glorious herbaceous plant, producing its beautiful flowers on long, arching stems in August, September, and October. A fibrous-rooted species, it will grow almost anywhere. I have seen it really good in a London suburban garden. It loves a deep, cool, rich soil; and in such a medium is a very different plant from the ones that are seen in thin, poor, sunbaked soil, often rising to four feet high.

The type has red flowers, and is less popular than the white variety Honorine Joubert, which first appeared in the garden of a French horticulturist named Joubert (or Jobert) at Verdun-sur-Meuse. The latter produces its large, white flowers in great abundance, and as the stems are long, the plant is valuable to cut from. 
Many fine varieties of the Japanese Anemone have been raised from seed, and the following may be named for the benefit of gardeners who want to specialise this beautiful plant :-

Alba (Honorine Joubert), white.

Beauté Parfaite, double white.

Collerette, white, yellow anthers, semi-double.

Coupe d'Argent, white, double.

Couronne Virginale, white, tinted.

Honorine Joubert, white.

Lady Ardilaun, white, larger than the preceding.

Mont Rose, rose, semi-double.

Vase d'Argent, silvery, double.

Whirlwind, white.

The Japanese Anemone and its varieties are delightful for herbaceous borders. They may be planted in spring. Propagation can be effected by division, or by taking cuttings of the roots in spring, placing them in pots, and putting them in a heated greenhouse or warm frame.

Narcissiflora is not a very important species, but it is a pretty one, with its umbels of white flowers in April and May. It grows about a foot high. It will thrive on the rockery if the position is partially shaded. It may be planted in spring, and divided, if propagation is necessary, at the same season.

Wood Anemones.-In nemorosa we have the Wood Anemone, so much admired in the shady glades of the forest in spring. It abounds on the chalk hills of Kent, the colour varying from white to pale rose. It is not much grown in gardens, but the large, beautiful, lavendercoloured variety Robinsoniana is, and few more charming dwarf spring-blooming plants exist for the rockery or for naturalising. Other pretty varieties of nemorosa are alba flore-pleno, double white; Alleni, blue; bracteata, 


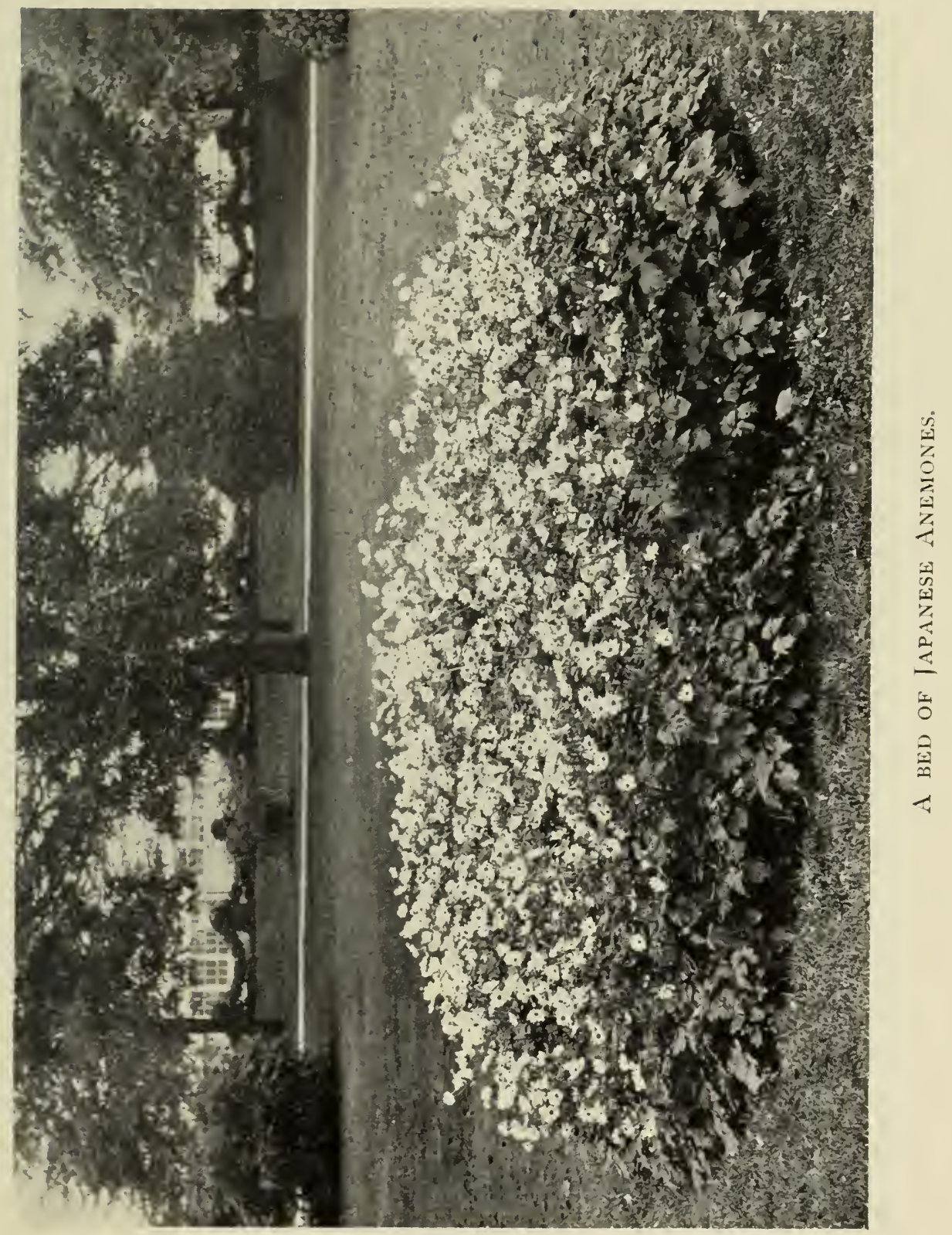



the flowers of which are surrounded by a green frill; and grandiflora (major), large single white.

All of the Wood Anemones are creeping-rooted, and flower in early spring if planted in autumn.

Pulsatilla, the Pasque Flower, is a popular mauveflowered herbaceous species, loving chalky soil. It blooms in spring from seed sown the previous March. Plants may be put in when growth starts in spring. It grows about a foot high. There is a charming white variety named alba, which is rare and rather expensive. Limestone chips should be placed round this plant in order to prevent moisture collecting at the ground level and causing decay.

Sylvestris, the Snowdrop Windflower, is a fragrant and beautiful species that opens in April. Before expansion the flowers resemble Snowdrops. There is a larger variety called grandiflora, and a double called flore-pleno, both lovely. All grow about a foot high. They are herbaceous plants, and are charming for mixed borders. They enjoy a position that is somewhat shady, and light, well-drained soil. Early spring is a good time to plant.

The foregoing are the principal Windflowers. Of the remaining species perhaps Alpina, which grows a foot high, produces white flowers in May, has fibrous roots, is best planted in early spring, has a pretty sulphurcoloured variety called sulphurea, and is useful either for borders or rockwork; Baikalensis, one foot high, with drooping white flowers in June, a fibrous-rooted species useful for the border and the rockery; palmata, which has yellow flowers in May, kidney-shaped leaves, and likes a damp site; and ranunculoides, a dwarf sort with small yellow flowers in spring, are the most desirable.

The list of species and varieties which I have given is much too long for owners of small gardens, but I have 
thought it well to describe all the principal sorts, in order that the reader may have the salient facts about the best Anemones before him. When it comes to a selection, there need be no difficulty in making a choice. The Poppy and Japanese Anemones-the former for spring, the latter for autumn-are the two most valuable classes. Both are easily grown. Both thrive in most soils. Both give large, brilliant flowers in abundance. As different from each other in bloom as in foliage, they are, nevertheless, sisters, and a more charming pair could not be found. 


\section{II \\ ON ASTERS, CHINA AND PERENNIAL}

IT comes as a shock to lovers of the China Aster, which has been a familiar object in every garden that they have known since childhood, to learn that it is an interloper in the Aster genus. The triumphant botanist will grant you that there is such a plant as an Aster, but he will produce irrefutable evidence that the "China" is not it. He will show you that the true Aster is a plant of respectable antiquity, with something of a history of its own, and, so to say, a family portrait gallery. And he will prove that the annual varieties are mere modern upstarts, practically without a history, and sadly lacking in family weight.

Those uncompromising botanists who object to "popular" names for plants will follow up the advantage that they have gained in showing that the "China Aster" is not an Aster by proceeding to demonstrate that the plant which really is an Aster is called generally by some other name. "Perceive your folly," they will thunder; "the name Aster is not simple enough for the plant which owns it, and so you must needs call it the Michaelmas Daisy or the Starwort ; but Aster is quite simple enough for another plant which has a name of its own." Truly, the botanist has us on the hip, and we can but hang our abashed heads in a becoming meekness.

Shall we, however, mend our ways? Shall we accept 
admonishment in a chastened spirit, and "do better next time"? That were too much to promise. It is one thing to acknowledge that the botanist has scored a point, but it is quite another to give him an undertaking to accept in future every name that he chooses to give us, and "use no other." We love our old garden names almost as much as we love the flowers themselves. They come "trippingly off the tongue." They revive old memories. Mignonette might smell as sweet if we had to grow it under the name of Reseda, but it would not seem the same to us. The Sweet Pea would sparkle as brightly in the sunshine with Lathyrus odoratus on the label as it does now, but we could not discuss it under that name as familiarly as we do at present.

The botanist, let us remind him, has his weak spot as well as we. $\mathrm{He}$ is much given tô growing dissatisfied with the names which he has given to the plants, and to changing them in consequence-or, to be more exact, to changing the names given by other botanists. If two botanists give different names to a plant, there is surely some excuse for ordinary folk giving it a third. By a remarkable coincidence, two botanical names have been given to the China Aster, one being Callistephus and the other Callistemma. Have we not now given the botanist a Roland for his Oliver? We have, and, being quits, we will part in good humour.

The Michaelmas Daisy is, then, the real Aster. Time was when it fell little short of weed-dom. It was a rampant grower, with a most aggressive root system, and its flowers were not so very striking. But the modern varieties are mostly compact growers, with large flowers of brilliant colours. So much improved has the plant been, indeed, that it is now extremely useful. Its intrinsic beauty is considerable, and is 
supported by late blooming. The Michaelmas Daisy now ranks with the Dahlia and the Chrysanthemum as an autumn flower of the first rank, and not a few gardeners prefer it to either.

Without making comparisons which might be painful to the feelings of Dahlia and Chrysanthemum specialists, we may throw into relief two of the merits of the perennial Aster.

In the first place, the genus is made up of a large number of species and varieties varying greatly in colour, height, and period of flowering. This means that it provides us with material for our beds and borders that we can utilise $(a)$ for particular colour effects, $(b)$ in different parts of the borders, $(c)$ for blooming over a long period. Instead of planting a dozen of one particular sort, and so having a block of one colour at one place at one particular period, we can plant several sorts, thus getting bloom in different places and at different times.

In the second place, they will grow in almost any soil and situation.

Students of hardy plants are fully alive to the importance of the modern Michaelmas Daisy, and have set up such a demand for it as to make it worth while for clever cross-fertilisers to specialise it. This means that a constant stream of new and improved varieties is flowing into the nurseries, just as there is of new Roses, new Chrysanthemums, new Carnations, new Dahlias, and new Sweet Peas. The old school of flower gardeners have no adequate conception of the modern Michaelmas Daisy. They neither know what it is, nor what it is capable of doing. Before me as I write is a clump of the violet-coloured variety Framfieldi (a variety, I ought to say, for the sake of botanical accuracy, of the old 


\section{I6 POPULAR GARDEN FLOWERS}

species amellus, which grows about two feet high, has blue flowers with yellow disc, and came to England from Italy as far back as I596.) It is mid-October, and the plant, which has been in flower several weeks, is still full of bloom. It is growing in thin, fibreless soil on a chalk bank, in spite of which it has spread to a yard across by two and a half feet high, and is bearing scores of flowers. (By the way, if the chalk bank does not conduce to vigour, it does, I think, to richness of colour; and I may be pardoned a brief digression, the object of which is to allude to the effects of chalky soil on blue flowers. The blue annual Love-in-a-mist (Nigella) luxuriates in chalk, bears huge flowers, and colours brilliantly. Certain wild flowers that may be white or pink on black lands become blue on chalk. Veronicas form one example, and the blue Wood Anemone, Robinsoniana, is found wild on the limestone.)

The beauty of my particular plant of Framfieldi is typical of many others. Some bloom in August, some in November. All are perfectly hardy. Many of the species come from North America, others from Siberia, and consequently no extremity of severe weather that we have in Britain injures the plants. What does sometimes happen is the tarnishing of the flowers by frost, but even this is not always fatal to the beauty of the plants. If the assault is not a heavy one, and if the sun does not strike direct on to the flowers early in the morning, the flowers freshen up again. They justify the figure of Dante in the Divina Commedia:

"As florets, by the frosty air of night

Bent down and closed, when day has blanched their leaves,

Rise all unfolded on their spiry stems ;

So was my fainting vigour new restored, And to my heart such kindly courage ran,

That I as one undaunted soon replied." 
The colours of some of the Michelmas Daisies are not to be matched by any other flowers of autumn. They are not vivid and dazzling, but in most cases they are rich, warm, and harmonious. Some of the tones are exquisitely refined. Others have a tawny, subdued glow which is both arresting and appealing. Invariably the plants bloom abundantly.

Flower-gardeners who like warm effects in their borders should draw largely on the perennial Asters. By selecting a few of the best varieties of each species, having in view differences in height, colour, and flowering season, beautiful effects can be had from mid-August to mid-November. The following table will give an idea of the material available. Except where otherwise stated, the height of the variety is approximately the same as that of the parent species :-

\begin{tabular}{|c|c|c|c|c|c|}
\hline \multicolumn{3}{|c|}{ Species. } & $\begin{array}{l}\text { Height } \\
\text { in Feet. }\end{array}$ & $\begin{array}{l}\text { Flowering } \\
\text { Season. }\end{array}$ & Varieties. \\
\hline Acris & . & & I & August & Nanus, lilac. \\
\hline Alpinus & . & . & I & June, July & Purple species. \\
\hline Amellus & - & . & 2 & $\begin{array}{l}\text { August, } \\
\text { September }\end{array}$ & $\begin{array}{l}\text { Bessarabicus, purplish- } \\
\text { lilac. }\end{array}$ \\
\hline$"$ & - & - & 2 & Sept. \& Oct. & $\begin{array}{l}\text { Distinction, rosy- } \\
\text { mauve. }\end{array}$ \\
\hline Cordifolius & & - & 2 & "August" & Framfieldi, violet. \\
\hline Coranonus & . & & 3 & & $\begin{array}{l}\text { Elegans, lilac, } 4 \cdot \\
\text { Ideal }\end{array}$ \\
\hline Diffusus & . & & 2 & October & White species. \\
\hline$"$ & - & & - & $"$ & $\begin{array}{l}\text { Coombe Fishacre, } \\
\text { bluish-rose. }\end{array}$ \\
\hline Dumosus: & : & & $\overline{I \frac{1}{2}}$ & $"$ & Horizontalis, lilac-rose. \\
\hline Ericoides & & & 3 & September & $\begin{array}{l}\text { Mauve species. } \\
\text { Golden Spray, white, } \\
\text { yellow disc, I I } \frac{1}{2} \text {. }\end{array}$ \\
\hline$"$ & & & - & $"$ & $\begin{array}{l}\text { Freedom, white, yellow } \\
\text { centre. }\end{array}$ \\
\hline$"$ & - & • & - & $"$ & Clio, white, I $\frac{1}{2}$. \\
\hline
\end{tabular}




\begin{tabular}{|c|c|c|c|}
\hline Species. & $\begin{array}{l}\text { Height } \\
\text { in Feet. }\end{array}$ & $\begin{array}{l}\text { Flowering } \\
\text { Season. }\end{array}$ & Varieties. \\
\hline Grandiflorus & & November & Blue species. \\
\hline Lævis & $2 \frac{1}{2}$ & September & $\begin{array}{l}\text { Hon. Vicary Gibbs, } \\
\text { reddish-blue. }\end{array}$ \\
\hline Novæ-Angliæ & $4-5$ & $"$ & $\begin{array}{l}\text { Mrs. J. F. Rayner, } \\
\text { rose, 4. } \\
\text { Mrs. S. T. Wright, rosy- } \\
\text { purple. }\end{array}$ \\
\hline Novi-Belgii & 4 & $"$ & $\begin{array}{l}\text { Lil Fardell, pink. } \\
\text { Arcturus, blue. } \\
\text { Captivation, pale pink, } 3 \text {. } \\
\text { RobertParker,lavender. } \\
\text { Top Sawyer, lilac. } \\
\text { White Spray, white, } 5 \text {. }\end{array}$ \\
\hline Shortii & 3 & October & Lavender species. \\
\hline $\begin{array}{l}\text { 1 radescantil } \\
\text { Turbinellus }\end{array}$ & $\begin{array}{l}4 \\
2 \frac{1}{2}\end{array}$ & $\begin{array}{l}\text { August } \\
\text { October }\end{array}$ & $\begin{array}{l}\text { White species. } \\
\text { Lilac species. }\end{array}$ \\
\hline Vimineus & - & Septëmber & $\begin{array}{l}\text { Albus, white. } \\
\text { Blue species. }\end{array}$ \\
\hline
\end{tabular}

The foregoing is really a small selection, and as many varieties as are named in it could be found in one popular section, such as Novi-Belgii, alone. Alpinus is suitable for rockwork. Amellus and its varieties, diffusus hori-

1 zontalis, and the ericoides varieties are suitable for positions from the middle to the front of the border. The Novæ-Angliæ and Novi-Belgii varieties are suitable for sites from the middle to the back. In order to have each variety well represented in characteristic form, it is advisable to put at least three plants in each clump about eighteen inches apart, wider or closer according as the soil is rich or poor.

Soil.-With reference to this question, while the Michaelmas Daisies will grow in almost any ground, they give the best effects in deep, rich, moist ground, attaining to noble proportions and flowering in great profusion over a long period. If there is any marked 
difference in the soil, the tall, strong growers may be given the poorest, but it is a bad principle to provide poor soil in a herbaceous border, which the Asters, after all, only share with other plants. The most that should be done is to abstain from manuring the ground for the strong growers.

Propagation.-They must be taken up every three years at the most, however, and the clumps split up, as the root system is very strong and impoverishes the soil rapidly. By this division a larger number of plants can be secured, but it is best to keep the outside portions for propagation, as they are stronger than the hearts.

Young shoots taken off in spring and struck as cuttings in sandy soil afford another means of propagation. The plants come readily from seed too.

The suburban gardener must be careful not to overlook the Michaelmas Daisies, as they are good near-town plants; and the fact that they will grow in borders under walls and fences where the soil is none too good is a great advantage from his point of view. We have seen that they are not at their best in such ground, but it is not clear that the suburbanist wants their best, if by this we understand the greatest vigour of growth. His circumstances are quite different from those of the country gardener who has plenty of room, and can afford to smile when his plants spread into broad masses. The suburbanist wants compactness; he wants neat, comparatively restricted growth, with as much bloom to the square inch as can be had. For him, such small but free-blooming varieties as Amellus and its varieties, diffusus and its varieties (particularly horizontalis), and the dwarf varieties of ericoides, are the most suitable. With them in good form he can very well do without 
the taller, looser sorts like the Novæ-Angliæ and NoviBelgii varieties.

China Asters.-Suburban and country gardeners alike will grow China Asters, which, being annuals, grow from seed in spring and die in autumn. Like the worker bees, they have a few months of bright, bustling life, and then depart into the shades. They are adorable little plants, and have a time-hallowed association with ten-week Stocks; indeed, one might speak of the two in commercial language as "Messrs. Stocks and Asters, specialists in garden decoration, established over one hundred years."

The original China Aster came over in I731. Botanists called it Callistephus chinensis. The first name means "beautiful crown," the second indicates the habitat. Whence the popular name of Aster? It is probably derived from aster, a star, in allusion to the somewhat stellate form of the flowers. (Remember that the original was single, not double.) Be this so or not, the name Aster was given, and it stuck. It is as Asters that we know the Callistephuses to-day, and it is as Asters that our descendants will grow them a thousand years hence.

The original Aster had mauve flowers, and the flowerlover who is sufficiently interested may get seed of it from a few of the larger seedsmen, under the name of Callistephus sinensis. It is a really pretty thing, worth growing for its own sake, as well as for the interest which springs out of a comparison between the earliest and the latest forms. Such a comparison pays a remarkable tribute to the skill of the florist, who has not only developed fresh colours, but also new forms. The unversed amateur who opens a seedsman's catalogue with the view of finding the cost of a packet of Aster 


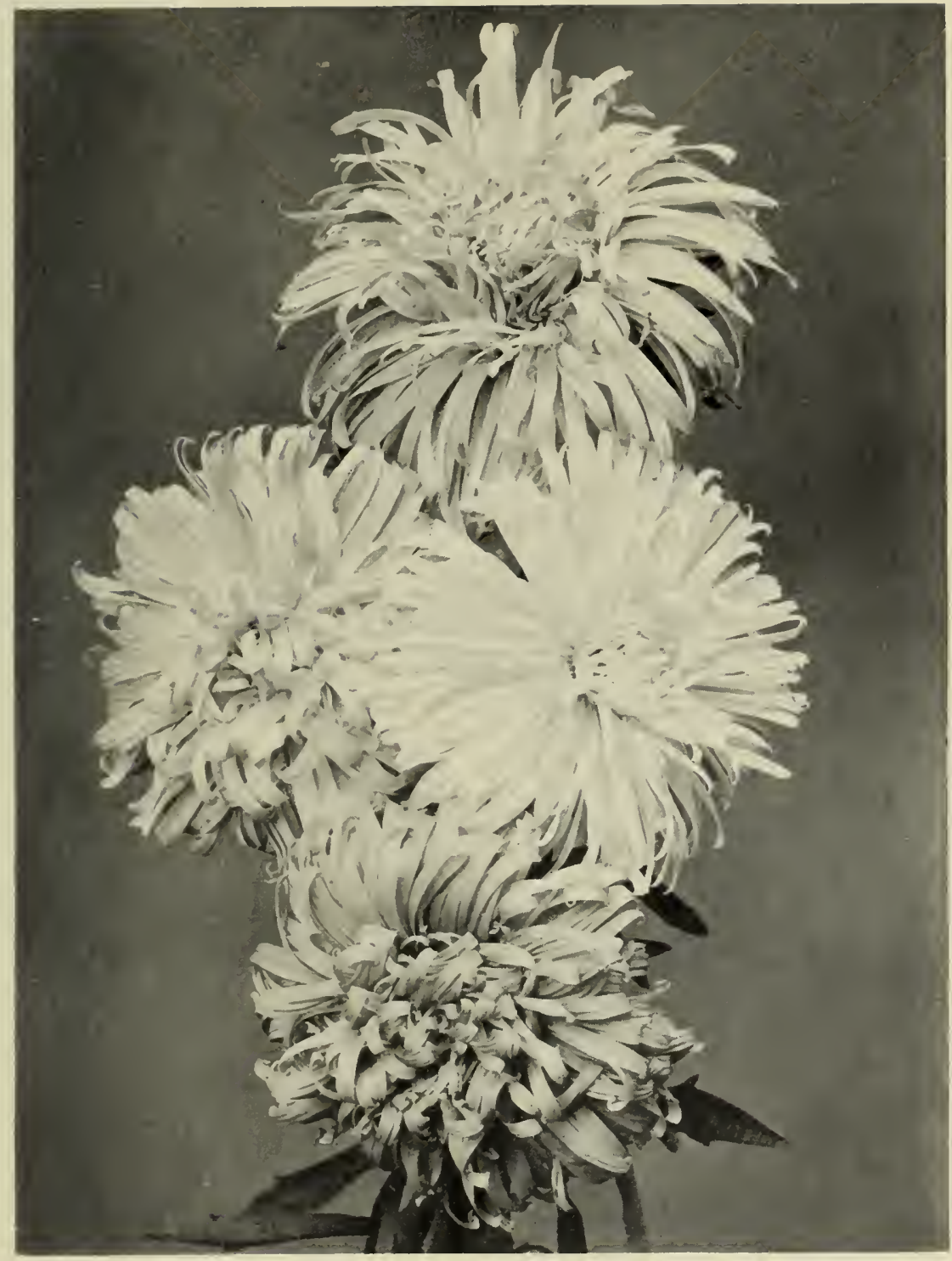

Axingal Asters. 

seed, is often astonished to find many different classes offered. He sees Quilled, Pæony-flowered, Ostrich Plume, and many others, and knows not the difference between them. The following table gives the principal types, with a brief description of them:-

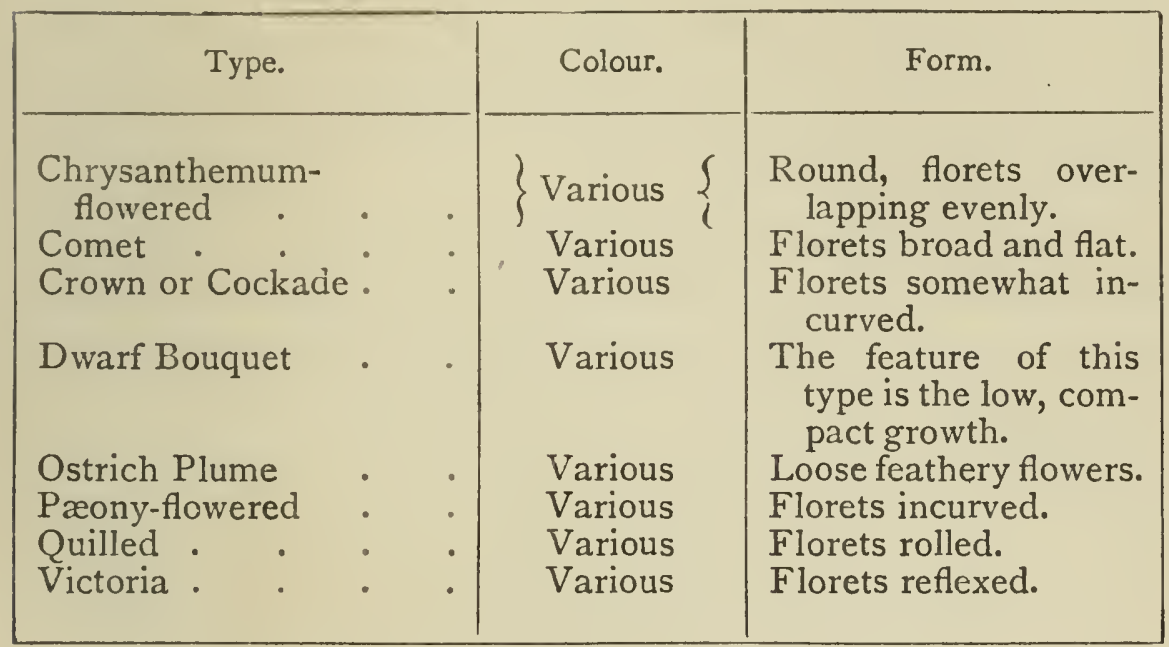

Up till comparatively recent times the Chrysanthemum-flowered and Victoria were the two most popular annual Asters for the garden, and the Quilled for exhibition. They are still grown extensively, but the newer types, Comet and Ostrich Plume, have increased so rapidly in popularity as to dispute the position of the old favourites. The Ostrich Plume is particularly beautiful, as the flowers, although large and rich in colour, have a light and feathery appearance. It grows eighteen inches to two feet high, very little more than either Comet or Victoria, but the habit is a little looser. Unless space is very precious, I should recommend the Ostrich Plume in preference to any other type. If a compact grower is wanted, the Dwarf Chrysanthemumflowered had better be chosen. The Dwarf Bouquet 
is smaller still, but it is more suitable for edgings than anything else in the garden.

The seedsmen offer the various types in separate colours as well as in mixture, so that gardeners can make special arrangements if they wish. As a large number of plants can be raised from a packet of seed, the cost of which need not exceed sixpence, and may be as little as a penny, the Aster is one of the cheapest of flowers to grow in quantity. Whole beds can be had for a few pence.

Culture.-Little skill is required to grow the plants, the principal points being to keep them uncrowded and free from black-fly while in the seedling stage. A simple way of getting a stock of plants is to fill some shallow boxes with fine soil in March, draw drills half an inch deep and three inches apart, sprinkle the seeds thinly, and place the boxes in a frame or greenhouse. In the absence of both, stand the boxes on a layer of ashes in the garden in April, and cover with squares of glass. Immerse the boxes in a tub of water as deep as the level of the soil when the latter becomes dry. Seedlings raised in a greenhouse should be kept on a shelf close to the glass, in order to prevent their getting drawn or weak; but Asters are best in an unheated frame. Abundance of air should be given in fine weather.

When the seedlings have developed sufficiently to begin crowding, they should be set three inches apart all ways in other boxes, or they will spoil each other. They can remain in the second boxes until the ground is ready for them in May or June. If they are attacked by black-fly (and a sharp lookout should always be kept for this injurious aphis), sprinkle them with water in which a handful of quassia chips, which chemists 
supply, has been soaked for several hours. Or dust some tobacco powder on them, and wash it off a few hours later.

No small part of the value of China Asters lies in their adaptability for bedding. Those who fill their flower-beds with bulbs, Wallflowers, and Forget-me-nots in autumn, should always raise or buy a supply of Asters in spring, so that when the spring flowers are over they can be cleared off at once, and the beds, after being dug, replanted at once. The beds can either be filled with Asters alone, or with Asters associated with graceful Salpiglossis, Tobacco (Nicotiana), and Snapdragons, which can also be raised from seed in spring.

The soil need not be manured heavily for any of the plants which I have named, and particularly for the Asters. If very poor, a light dressing of decayed manure can be worked in, otherwise it will suffice to dig in some burnt refuse, saved from the last garden fire.

I need hardly say that the use of China Asters is not limited to bedding. Groups of them look charming in herbaceous borders, if the colour blends with those of the permanent plants. Wherever there is a gap in the garden, be it in bed or border, Asters may be pressed into service; and the sensible flower-gardener will always have a box or two of sturdy seedlings by him in May, ready for strengthening any weak spot. 


\section{III}

ON BEGONIAS, MOST BRILLIANT OF BEDDING PLANTS

THE tuberous Begonia, as we grow it in our gardens to-day, is an entirely modern production. Begonias, and Begonias with tubers, were known a good many years ago, but flower gardeners took very little notice of them, because they were either straggly and ungainly in habit, or had drooping, ineffectual flowers.

"Begonia" is derived from Begon, the name of a French floriculturist.

There is little of the interest of folk-lore or literary association in the Begonia. When the reader who is interested in the beginnings of popular plants looks up a botanical dictionary, he finds the names of an enormous number of species, but nearly all were introduced in the nineteenth century. Nitida is one of the oldest, and that came from Jamaica in I777; it has not played any part in the development of garden Begonias, and we can pass it over. Modern garden Begonias have come in the main from six species, the salient facts about which are set out in the following table:-

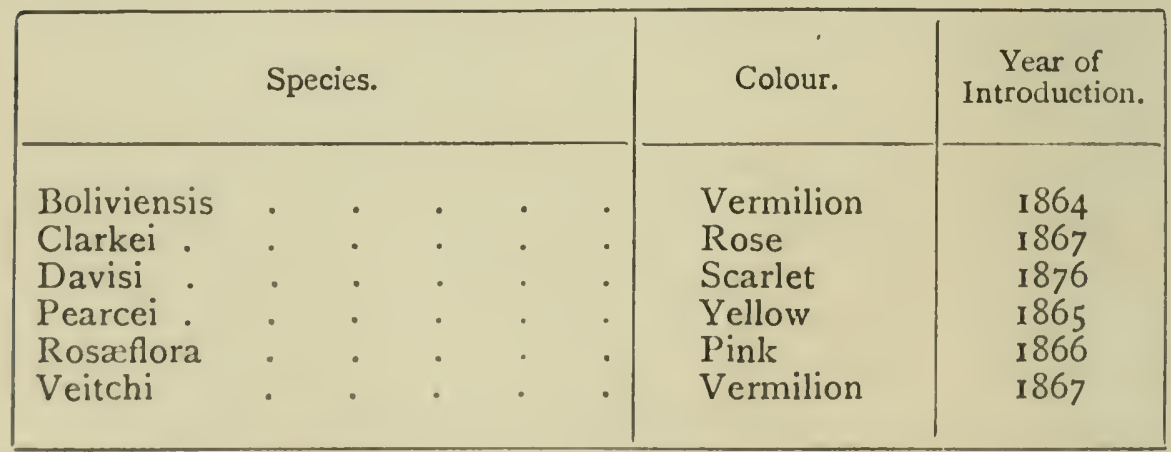


All of these came from South America, and their offspring are not hardy. The earliest to arrive came, we see, as recently as 1864 , so that it is vain to ransack libraries in search of ancient rites and ceremonies, or old beliefs, or literary references, in connection with this now popular flower. It is as modern as torpedo-boats, and society newspapers, and electric tramcars. It can hardly be said to have a history at all. Florists have rushed it into being just as engineers have rushed ironclads and type-setting machines.

The history of the development of a popular flower is briefly as follows :-

(I) The introduction of certain species.

(2) The crossing of these species, resulting in the production of hybrids.

(3) The intercrossing of hybrids, resulting in the production of varieties.

(4) The intercrossing of varieties ad infinitum.

Botanists generally keep records of the crossing of species, and often of the intercrossing of hybrids, but when florists take to crossing varieties the herbarium authorities give up in despair. In case the reader is interested in the derivation of garden Begonias, I may give a table showing a few of the early crosses :-

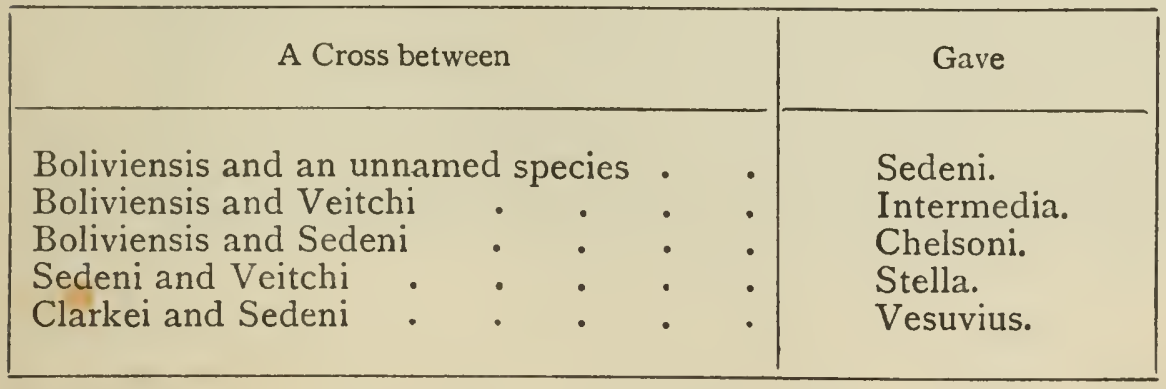

But this has no practical value, because none of the offspring, or the offspring of the crosses which immediately 
followed these, are grown now, with the possible exception of Vesuvius. We see that the hybrid Sedeni was produced by crossing two species, and that this hybrid was almost immediately used as a parent itself, resulting in the sub-hybrids Chelsoni and Vesuvius. Thenceforward the work of crossing was no longer botanical. Trade florists, both in this country and abroad, crossed and re-crossed; and they kept the records of the various crosses to themselves. One of the first of the nurserymen to become famous as a raiser of Begonias was the late John Laing, and he was followed by Pope, Cannell, Lascelles, Blackmore, and Langdon. They all did good work, but none of them published details of his crosses, and it may be said truly that it is a wise Begonia child which knows its own father.

Laing did not begin till 1875 or 1876 , but things moved so fast that by 1906 we had a magnificent array of varieties, including many shapes and colours. At the present time they could be classified by form if desired. Some are single and others double. The former could be classified as plain and frilled, the latter as Camelliashape, Hollyhock-shape, Rose-shape, and Water-lily shape. All the doubles are beautiful, whatever their form, as long as they have only one centre, and that symmetrical.

It is an interesting fact about single Begonias that the flowers are generally borne in clusters of three, the central one being a male, and the other two females. Double Begonias are sexless, as the organs of fertilisation are transformed into petals.

Single and double alike are now distinguished by good habit. The flowers do not hang nerveless on slender stems, but are borne erect on strong stems, and show up in handsome clusters above the leaves. This is 


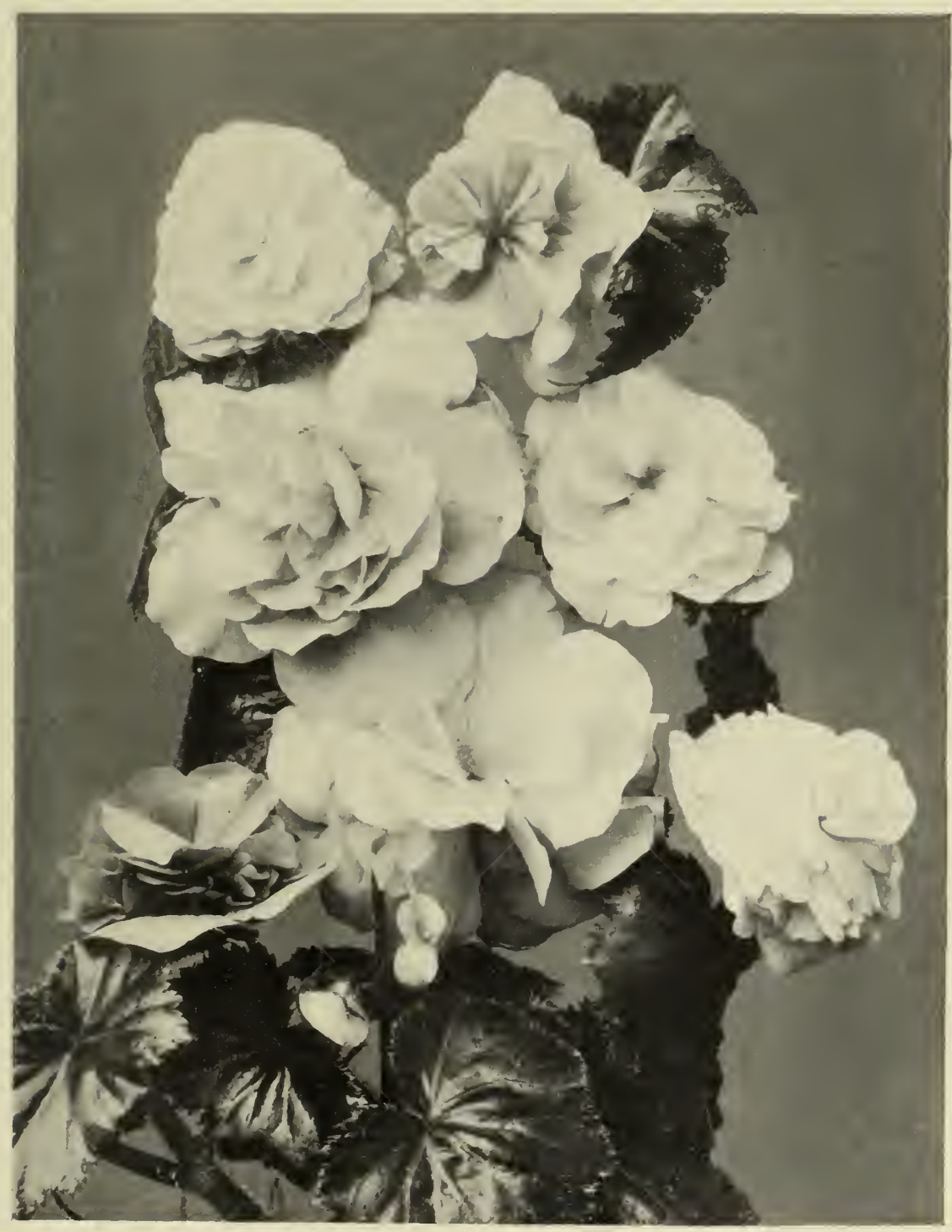

IOCBIE BEGONIAS. 

a great advantage when the plants are bedded out. The leaves are thick and handsome, borne on fat, reddish or brown stems.

The florists have not given us a blue Begonia yet. This colour baffles them almost as effectually in Begonias as it does in Zonal Geraniums and Chrysanthemums. We should be glad to have it, if it was a real blue, and not a wishy-washy, lilac-cum-lavender-cum-purple, the exact shade of which could not be found even in the colour chart; but we can do very well without it.

The fact that the parentage of our best modern Begonias is unknown will not worry the majority of flower-gardeners; it will be enough for them that we have the varieties. Here is a table of good bedding sorts :-

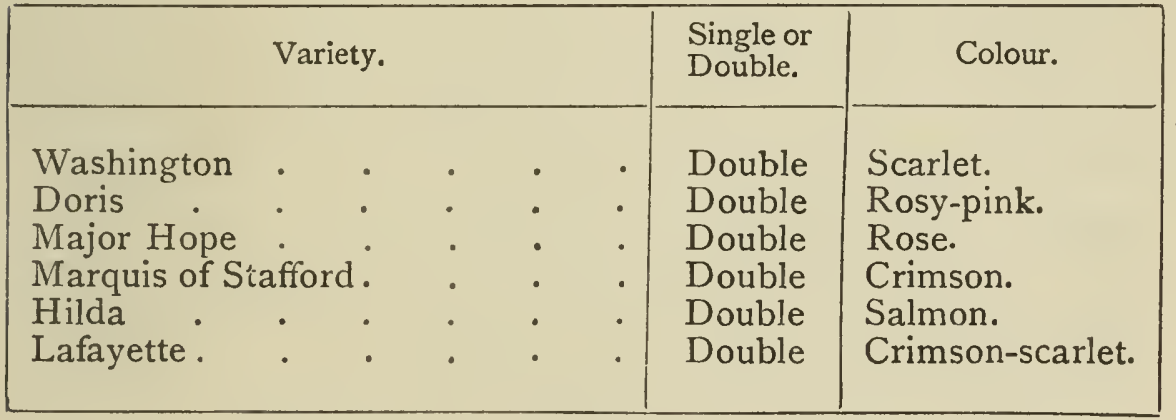

Singles are generally labelled to colour, and sold as such for bedding without names. The best colours are white, crimson, rose, scarlet, pink, and salmon.

If the grower buys varieties under name he will have to pay more for them than for unnamed sorts, and further, he will feel himself under the obligation of labelling them, propagating them, and storing them separately. As a set-off to the extra work he will have the advantage of being able to arrange his colours exactly to his taste, and the interest of comparing his varieties with those of 
other growers. He will have to propagate by cuttings or dividing the tubers to keep them true. He could save seed of the singles perhaps, but it would not give the form and colour of the parent plant.

Cheap Begonias.-Most gardeners do very well with unnamed Begonias. The florist can sell these cheaper than named sorts, because he has not the expense of growing them separately. I open the catalogue of a good florist, and I find the following:- "Begonias for bedding, singles, specially selected, free bloomers with erect flower stalks, colours mixed, large tubers, 2s. $6 \mathrm{~d}$. per dozen; doubles, mixed, 4s. per dozen." This is quite a genuine offer, and a dozen other reliable dealers would make it in slightly different words. It is perfectly safe to buy these cheap mixtures so long as the florist is a man of repute.

How to Start.-It is a good plan to buy the tubers in March, embed them six inches apart in soil in shallow boxes, and put them in a greenhouse or frame. The compost may consist of two parts loam, one leaf mould, and half part sand. When growth starts the boxes should be placed close to the glass, and water should be given when the soil becomes dry. The grower will first see a thick, reddish stem push up; the leaves will form at the top of it. Growth will be slow in April, but fast in May, and by the end of the merry month the boxes will be full of foliage. By this time the spring flowers will be over, and the beds can be cleared of them. The ground should be dug deeply and dressed with decayed manure if poor; but if it is in good condition, a couple of handfuls of superphosphate to the square yard will do. A hot, dry position should be avoided, as Begonias love partial shade and abundance of moisture. The plants 


\section{ON BEGONIAS}

should be put in a foot apart. If the soil is shallow it will be wise to spread on a coating of manure or cocoanut fibre refuse after planting. Soakings of water in dry weather, with a liberal drenching of liquid manure once a week, will go a long way towards producing good results.

Raising from Seed.-A stock can be secured by sowing seed, and this certainly gives a large quantity of plants cheaply. The habit of the plants and the quality of the flowers will be all that can be desired if the seed is bought from one of the large firms who specialise the principal florists' flowers. But full beds must not be relied on the first year. If the seed is sown early, if the treatment is good, if the soil is fertile, and if the season is a damp one-if, in a word, all the circumstances are favourable-there may be a nice bed the same year as the seed is sown. But the circumstances must be favourable.

The seed, which is very fine and needs careful handling, ought to be sown on the surface of very fine moist soil in January, and merely settled down with a film of silver sand. The pan should be covered with glass shaded with paper until germination has taken place, when the seedlings should be inured to the light by degrees. When the soil gets dry it should be moistened by lowering the pan into a vessel of water. Pouring water on to the surface, even through a fine-rosed can, is dangerous, as it is liable to displace the seed or seedlings. The pan should be put near the glass, and air given in fine weather.

Planting.-The seedlings can be removed on the end of a label when they begin to crowd each other, and set three inches apart in a shallow box. As they have to form tubers, they must not be expected to move as fast 
as young Cinerarias or Primulas, which only have to form a few fibres; Begonias develop very slowly. When they have grown sufficiently to crowd in the boxes each may be given a small pot, and on their progress after this shift, and the weather, turns their future for the current year. If they grow to six inches high and through by mid-July, and the weather is moist, they may be planted out, as, in the absence of early frost, they will have three months in which to develop, and that should be sufficient-given good soil and plenty of moisture-to bring them into beauty.

Begonias are often at their very best in October, as they love the cool nights and heavy dews. And their best is something that no other "bedding plant" can equal. The colours are not more brilliant than those of Zonal Geraniums, but the flowers are finer, and the foliage is more handsome. Some of the shades are exquisite, notably the soft pinks, yellows, and blushes. The whites are as pure as snow.

The tubers should be taken up when the plants wither or are blackened by frost, dried, and stored in a dry, frost-proof place to which mice cannot gain access.

Fibrous Begonias.-Several varieties of a fibrous-rooted Begonia named semperflorens exist. The species, a Brazilian plant with pink flowers, is generally used for pot culture; but the varieties are planted out in the garden. Being of neat, shrubby habit, and flowering profusely for many weeks, they are very attractive. In addition to pretty flowers some of them have tinted leaves. When cold weather comes on they may be lifted, put into pots, and placed in a warm greenhouse, where they will give winter bloom. The following are charming varieties :- 
Coral Pink.-Coral, large flowers.

Crimson Gem.--Red flowers and bronzy red leaves (sometimes grown under the name of Vernon).

Crimson Bedder.-Crimson flowers and dark red foliage.

Fairy Queen.-Pink (there is also a white variety).

These pretty fibrous-rooted Begonias come readily from seed, which may be sown in a similar way to that of the tuberous varieties. As the seedlings have no tubers to form they grow faster than the latter, and soon make nice plants for the beds. They only grow eight to ten inches high, and should be put at the front of beds which contain large plants. 
ON BELL-FLOWERS (CAMPANULAS) AND CANTERBURY BELLS AS BEAUTIFUL BORDER PLANTS

THERE is better ground for the popular name of the Campanulas than there is for many of the English names which are given to plants. Here, the popular and the botanical names are associated. Campanula comes from campana, a bell, and is, indeed, one of those endearing diminutives which the Latin races love, meaning "little bell." It flows softly from the tongue however it is accented, and lingers on the ear with a memory of the tinkle of sheep bells on Alpine slopes. The pronunciation is Cam-pan'-u-la. Repeat it, lingeringly-Cam-panu-la-a-a-a. How sweetly it falls, suggesting song !

But the poets have not dealt kindly with the Campanulas. Shakespeare does not mention them. Does some alert and swift-moving reader bound to his shelves and, first shaking a protesting finger at me, then point it to Act iv. scene 2 of Cymbeline, where Arviragus cries:

"With fairest flowers

While summer lasts and I live here, Fidele, I'll sweeten thy sad grave; thou shalt not lack The flower that's like thy face, pale Primrose, nor The azured Harebell, like thy veins, no, nor The leaf of Eglantine. ..."

I reply that the Harebell of Shakespeare was not our Harebell, Campanula rotundifolia, but the Wild Hyacinth, Scilla nutans, which is often called Bluebell. 


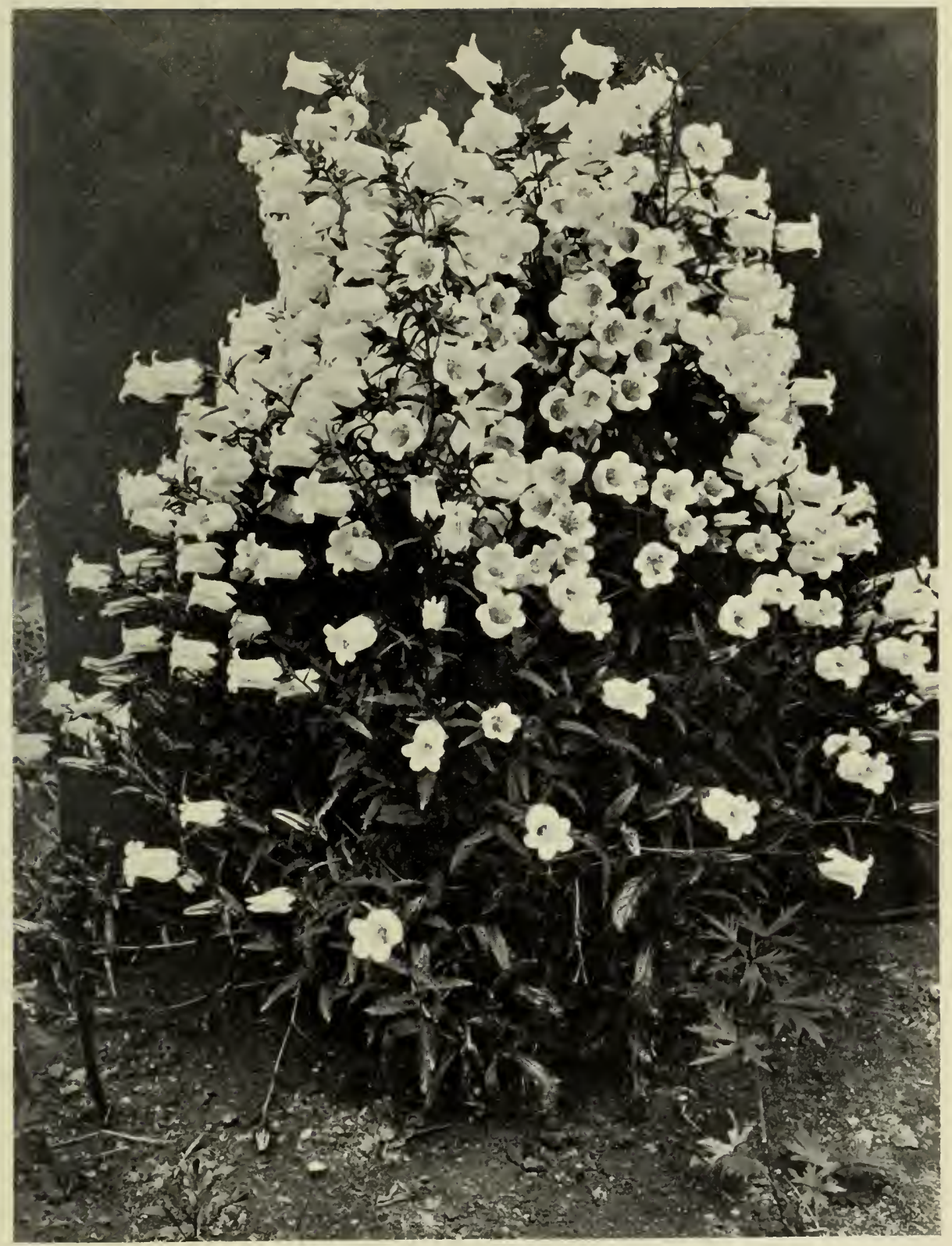

Canterbury Bellas. 

"At least the Canterbury Bell has been immortalised," some one will say, "and it, too, is a Campanula." Oddly enough, the Canterbury Bell, popular flower though it is, seems to have received scant attention. You turn up reference book after reference book, and "See Campanula" meets the eye with exasperating iteration. And when you get to Campanula you merely find "Medium, the Canterbury Bell." Writers seem to have troubled about it very little; in fact, they have not even asked themselves how it got its popular name. If the SouthEastern Railway had existed when it was christened I might have suggested that some traveller had called it the Canterbury Bell because of its abundance on the sides of the chalk cuttings on the Elham Valley line near the old cathedral city. The Canterbury Bells are very happy there, and nowhere is their blue more sparkling than on chalk, though to be sure the plants do not grow with anything like the vigour that they display on the deep clay. These wildlings have doubtless strayed out of gardens, and we may assume that the Canterbury Bell has long been a popular flower in East Kent.

It is one of the oldest Campanulas that we have, having been introduced from Germany in 1597, one year later than the Peach-leaved Campanula, persicifolia. Stevens and Leebault included Canterburie bels in the garden of the Maison Rustique, published in 1600. Those grand old botanists, Gerard and Parkinson, both gave illustrations of the Canterbury Bell, but the drawings are almost as quaint as the descriptions. Philip Miller referred to it in his Gardener's Dictionary, telling us that it grew wild in Austrian and Italian woodlands, but was appreciated by English gardeners for the beauty of its flowers. His description is minute :-

"There are the following varieties: the blue, the 
purple, the white, the striped, and the double flowering. This hath oblong, rough, hairy leaves, which are serrated on their edges; from the centre of these a stiff, hairy, furrowed stalk arises, about two feet long, sending out several lateral branches, which are garnished with long, narrow, hairy leaves, sawed on their edges; from the setting on of these leaves come out the footstalks of the flowers, those which are on the lower part of the stalk and the branches being four or five inches long, diminishing gradually in their length upward, and thereby form a sort of pyramid."

New forms and colours have been added to the Canterbury Bells since Miller's day. We have rose and mauve as well as blue and white, and we have the cupand-saucer Canterbury Bell (Campanula medium calycanthema) in various colours. The calyx of this is coloured like the corolla. Many people prefer it to the plain type, but the latter is quite good enough for the majority of flower-gardeners when it is well grown.

All the Canterbury Bells belong to the class known as hardy biennials, which are sown in late spring in the open ground, flower the following year, then seed and die. They often come up year after year in the same place, but it is not a case of fresh growths from the same rootstock; the new plants are self-sown seedlings.

Having grown Canterbury Bells on heavy soil and on light, I have to confess a preference for the former. Given strong, moist ground, they branch freely. On thin, dry ground they make very little lateral growth. Plants with strong side shoots are much more handsome than those with only one stem. Those who want to get the best out of these fine old flowers (and their best is really well worth having) should enrich the soil, 
if poor, with well-decayed manure, taking care to dig deeply.

Sozving.-There is no difficulty in getting strong plants by autumn if seed is sown thinly at mid-May, and the plants are put out nine inches apart in a spare plot a month or so later. They will not grow very fast through the summer, as they move slowly while quite young, but they will have filled their allotted space nicely by October, when they can be planted out in their permanent positions if convenient, otherwise being left till spring. If the soil is good they should be put a yard apart.

The plants will bloom early in summer, and will last a long time in beauty, especially if the first flowers are picked off as soon as they fade.

There are many biennial Bell-flowers beside the Canterbury Bell, but the majority are not of much value, and we have to look for the best of the other Campanulas among the perennial species, which (in the case of the hardy ones at least) come up from the same rootstock in the border year after year. There are one or two good annual species, notably Loreyi, purplish-blue, and macrostyla, light violet with purple spots. The name of the latter comes from the large, brown, spindle-shaped style (the "style" of a flower is that portion of the pistil between the ovary and the stigma). These annual kinds flower in summer from seed sown out of doors the same spring.

The perennial Bell-flowers vary enormously in habit. One, Raineri, a charming little lilac-flowered Italian species, only grows three or four inches high. On the other hand, we have the Chimney Campanula, pyramidalis, which grows six or seven feet high under good culture. The latter, by the way, is not considered to be 
hardy, but it is far from being tender, and often passes severe winters unharmed.

The following is a representative table of perennial Bell-flowers :-

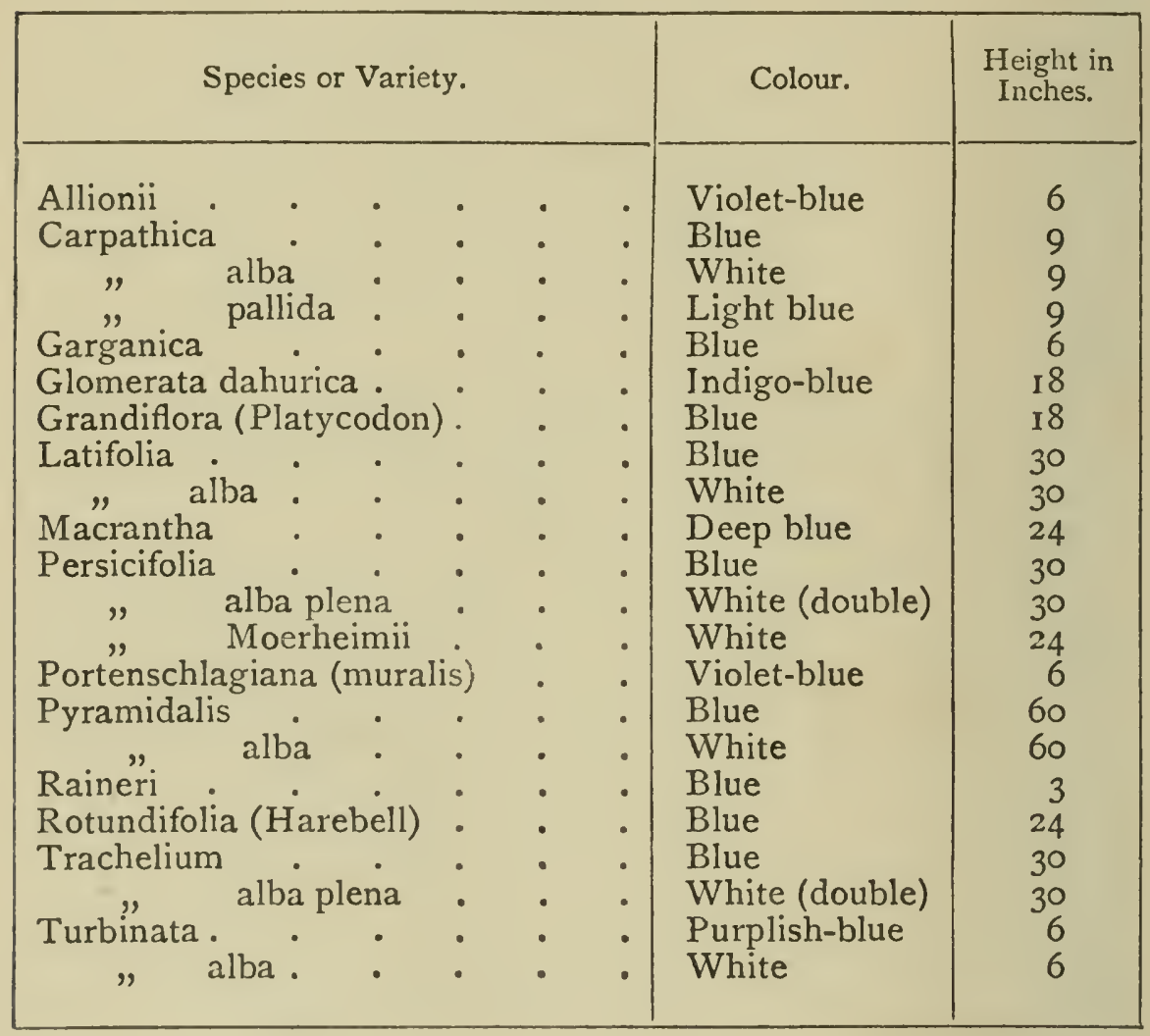

Seed of nearly all of these is procurable at a cheap rate, i) and if it is sown out of doors in early summer, and the plants thinned, they will bloom the following year, and propagation can be effected afterwards by division in spring. They are beautiful border plants, and the dwarf sorts are good for the rockery.

It will be observed that in all cases the species is blue, and if it be true that this is Nature's most difficult colour, which she has been longer elaborating than the 


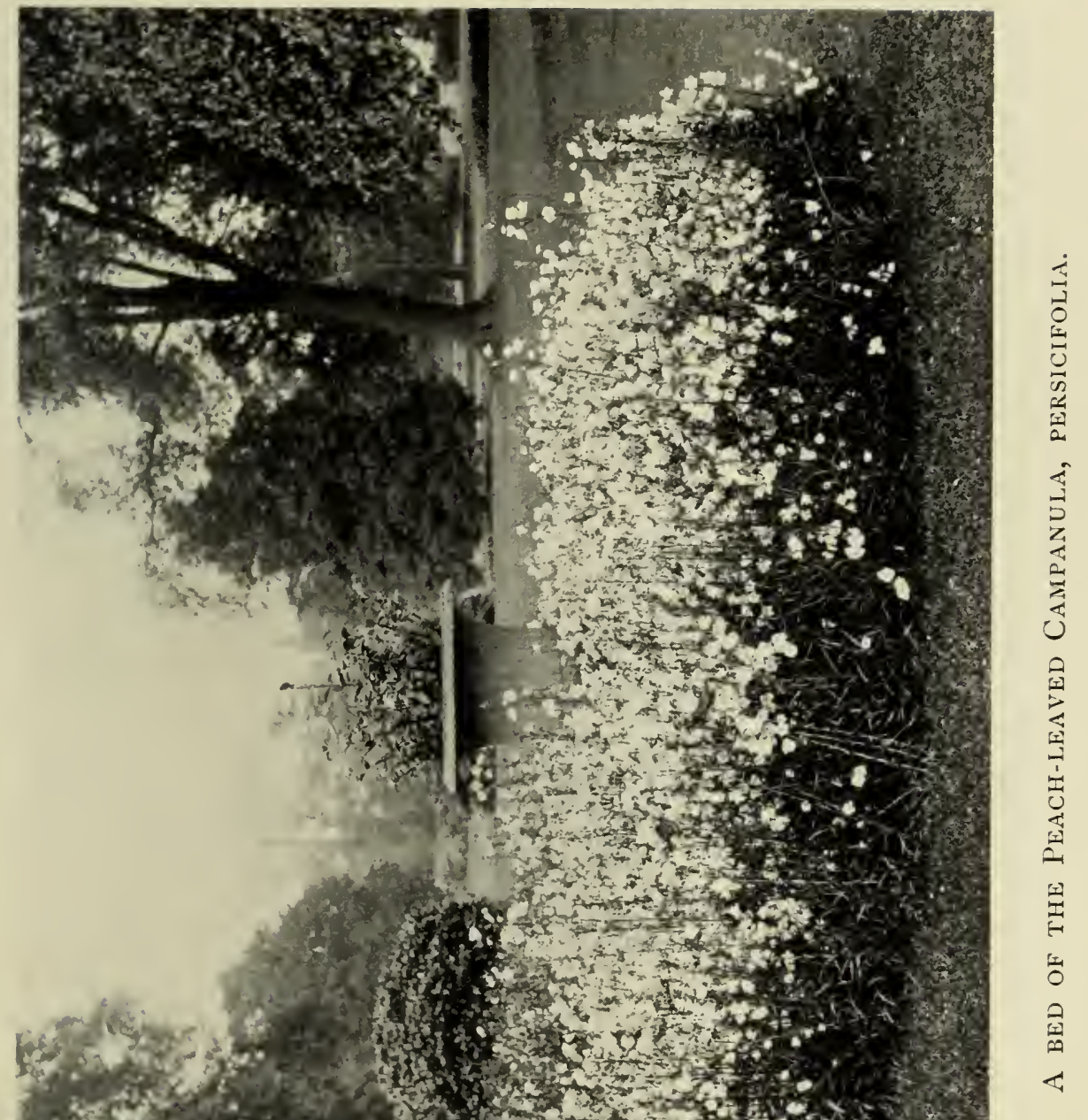





\section{ON BELL-FLOWERS}

rest, the Bell-flowers must have come late in the stages of evolution.

If I had to pick out what I regarded as the most precious of the foregoing Campanulas, I should be disposed to take the double white form of the Peach-leaved (persicifolia alba plena). It is a graceful, lasting, and beautiful plant, which in my experience is not fastidious as to soil, and is well suited for a suburban garden. It is stocked by all the hardy plant dealers, and costs but a small sum. Grandiflora and glomerata dahurica are two valuable species.

All the Campanula like cool conditions in the summer; they enjoy a semi-shady position and a friable soil. Little summer attention is needed except staking. 


\section{V \\ ON SHRUBBY BORDER AND BEDDING CALCEOLARIAS}

THE garden Slipperworts have lost some of the importance which they possessed in the days when "beddingout" was popular. Inasmuch as flower-gardening has spread so much during these latter years it is probable that if a Calceolaria census were taken it would be found that the plants are grown in greater quantities than they ever were; but florists pay little attention to them, and it is rare for a new variety to come out. If one did, very little notice would be taken of it. It would certainly not be surrounded by a thick crowd of admirers at a show like a new Rose or Sweet Pea.

The Slipperworts were misused in days gone by. They were associated with red Zonal Geraniums and blue Lobelias in the famous "ribbon border," of which cultured people grew so weary that they could not see, read, or hear of it without an impatience that almost amounted to anger. And as if the ribbon border were not enough, it was common to fill the principal beds with Geraniums and border them with yellow Calceolarias and blue Lobelias. In fact, flower-lovers became so surfeited with this eternal red, yellow, and blue (and all on plants that required glass protection in winter), that they could hardly look on the triumvirate without loathing.

There is nothing inherently repulsive in a Calceo- 
laria: on the contrary, it is a pretty and pleasing little plant, neat in its growth, very free blooming, and so bright in colour as to be as cheering as a sunny morning. It is the gardeners who over-used it, and not the plant itself, that we ought to condemn. Now that it has settled down to the modest position to which its merits entitle it, we can well afford to regard it with favour.

The shape of the flower gave it its name. The resemblance to a slipper (calceolus) is not very close in modern flowers, which come nearer to the form of a tobacco-pouch than that of a slipper, but doubtless the flowers have become rounder with cultivation. Florists always try to take angles out of flowers, and make them smooth and round.

Although Calceolaria is a botanical name the public has taken kindly to it-so kindly, in fact, that it is often affectionately reduced to the diminutive "Calcie," which might almost be the name of a favourite daughter. The pronunciation is Cal-se-o-lair'-i-a. The fancies of the people with respect to plant names are past comprehension. Calceolaria would prove a troublesome mouthful, one might have thought, to the class of gardener that gives plants popular names; but apparently it did not discommode them. To be sure, the bedding Calceolarias are comparatively modern plants, most of the species from which the bedding varieties have sprung having been introduced during the nineteenth century, so that the plant plays no part in folk-lore or tradition. Integrifolia (rugosa) came over in 1822 , and we know that this was used as a parent by hybridists. Perhaps floribunda (petiolaris) and violacea were also used as parents. These were introduced in 1843 and 1853 respectively. All three species came from South America, and this being so, we should not expect them to be hardy. 


\section{0 POPULAR GARDEN FLOWERS}

Good Varieties.-Very few people who grow Calceolarias in the garden trouble about names; nay, the nurseryman who grows a particular variety by the thousand to sell in spring may not know its name. There are, nevertheless, several distinct varieties, and they can be had under name if desired. Gaines' Yellow is a famous variety, and it is probably used more largely than any other; it grows about a foot high and blooms abundantly, so that it makes a good bedder. A newer variety called Golden Glory is larger both in growth and bloom than Gaines' Yellow; it is a splendid sort, but more expensive than the older one. The red, orange, and purple varieties are not much used, but can be bought if wanted under the respective names of Bijou, Prince of Orange, and Sultan. All grow about a foot high.

Propagation.-The bedding Calceolarias differ from

1 the greenhouse sorts, being evergreen shrubs. The greenhouse Calceolarias lose their stems after flowering, and are generally raised from seed annually, although occasionally cuttings are taken when young shoots push up from the rootstock. Propagation by cuttings is general with the bedders, and the shoots, which are taken off and inserted in sandy soil in a cold frame in autumn, retain their leaves all the winter. They are so nearly hardy that they do not require any protection in mild winters, but it is well to put a mat over the frame when severe frost threatens. If the cuttings are taken early - say with those of Zonal Geraniums in Augustthey start growing before autumn, and the new wood is

I likely to be injured by frost. October is early enough.

The young plants begin to grow in March if the weather is mild, and by mid-April they are bushy little fellows. They ought to be planted then, as if they get well established before the hot weather comes on they 


\section{ON SHRUBBY BORDER}

will not be likely to fall a prey to the fungus which kills so many yellow Calceolarias every year. The soil should be deep and fertile, to encourage healthy growth.

Well-grown "Calcies" are worth dropping into borders in clumps of six or so, and they also make a cheerful border, but I must guard against saying anything that might arouse painful memories in the minds of my middle-aged and elderly readers.

Suburbanists will find the yellow Slipperwort a useful plant, alike for their gardens and window-boxes, if they will avoid the error of planting it late in poor, shallow, sun-scorched soil; and remember that it shares with most other plants the weakness of enjoying a few gallons of water (with an occasional dose of liquid manure) in dry weather. 


\section{VI}

ON THE CANARY CREEPER AND OTHER "NASTUR. TIUMS" AND TROPEOLUMS

THE Canary Creeper is one of the most familiar of summer ramblers, and at the first glance there is little to connect it with the "Tom Thumbs" of our garden borders, which have round leaves and large, openthroated flowers. Its blossoms are small and crinkled, and its leaves are much cut on the edges (five-lobed). But it is closely related to the so-called "Nasturtiums" in spite of this, for all are Tropœolums.

The Canary Creeper probably got its popular name from the colour of its flowers, which resembles that of the feathered songsters so often to be found in the parlours of elderly maiden ladies. True, it is sometimes given the name of Canariense, and this would indicate the Canary Islands as its home if it were accurate, but it is not. Canariense or Canariensis is a seedsman's name, and has no support from the botanists. The plant did not come to Britain from the Canaries, but from New Grenada, the year of its advent being I8Io. By some odd happening "Canariensis" has become adopted as a popular name, and it is not at all uncommon to hear it used by amateurs in place of Canary Creeper.

In case the reader is not content to leave the plant without a specific name, and demands that, since he is told that Canariense is not correct, he should be in- 
formed what is, I tell him that the botanists have made two attempts, the one being aduncum (reference to the basal hook) and the other peregrinum, or wandering. I The former is now the accepted botanical name.

The Canary Creeper is certainly a peregrinating plant. It loves to ramble, peering here and there. It enjoys sprawling along a rustic fence, climbing a trellis, and creeping up an old bole. The one thing that it does not like is tiresome restriction, and it looks least happy when it is led on a piece of string, like a slum urchin's flea-bitten and doleful-looking dog. One may plant it at the front of window-boxes and large tubs, allowing it to droop over; it is not so vigorous as usual when so treated, much preferring to climb, but it looks bright. A more humane way of using it in a window-box is to press the ends of a bamboo rod in the ends of the box, thus forming a bow or arch over it, and let the plant ramble over that.

Sowing.-It is a charming plant for one of the pillars of a pergola, or the rustic work often employed in summerhouses. If the basal position is shaded part of the day, all the better, because it likes to have its roots in cool, moist soil. But so far as the shoots are concerned, the more sunshine that falls on the long gay streamers the more cheerful the plant looks. It is classed as a half hardy annual, and the plants in this section are generally raised under glass in March or April, and planted out in May or June. The angular, purplish seeds may be put three inches apart and an inch deep in a shallow box of soil, and placed in an unheated frame. Some twigs should be put among the plants if they cannot be planted out by the time they are four inches high, otherwise they may cling round each other and be difficult to separate. 


\section{4 \\ POPULAR GARDEN FLOWERS}

I have known the Canary Creeper seed itself in a place that it liked, and come up year after year. One such colony, however, was invaded by a Dorothy Perkins Rose, and even the Canary Creeper had to knuckle under to that robustious plant.

There are, of course, many beautiful Tropœolums besides the Canary Creeper, albeit we call some of them Nasturtiums. This name has stuck so tightly, in spite of the fact that it is Latin, that we have never been able to get rid of it, and never shall. There actually is a genus Nasturtium, so that the case presents a parallel to Geranium and Pelargonium, the Zonal Pelargonium being almost always called Geranium, in spite of the fact that a totally different class of plants owns the name. Nasturtium and Tropœolum are really further away from each other than Geranium and Pelargonium; and it is curious to find the reason of the application of the name "Nasturtium" to the Tropœolums. The true Nasturtiums are Cresses, $N$. officinale being the wellknown Water Cress. "Nasturtium" comes from nasus, nose, and tortus, tormented, in allusion to the acrid smell of the Cress. The leaf of the Tropœolum has much of the pungency of Cress, and was consequently called the Indian Cress. (Why Indian is not clear, as the Tropœolums are natives of South America.) From this stage it was easy to reach the next, and decide that if the Water Cress was a Nasturtium the Indian Cress must be one also. Country folk often corrupt Nasturtium to "Sturshon," and when we hear this we realise how far the Tropoeolum has gone. The cottagers do more-they use the green seeds as a substitute for capers.

Nasturtiums. - It is generally the hardy Tropœolums which are called Nasturtiums, only the tender varieties being given their proper name. Readers are familiar with 
both the dwarf (Tom Thumb) and tall hardy annual Nasturtiums, which bloom so brightly in summer and far into the autumn, flowering when almost every other annual has gone. They certainly bloom more profusely on chalk than on rich, strong soil; and the colours are exceptionally brilliant. The explanation of the more abundant bloom is the less vigorous and succulent growth. Leaving out Sweet Peas, they are my best late annuals on chalk, only the Candytufts and Love-in-a-mist making a real effort to vie with them. The suburban gardener soon proves their worth on his often poor and baked soil. The Lilliput strain of dwarfs is almost better than the Tom Thumb, as the flowers are thrown up more boldly above the leaves. This habit is particularly valuable in rich soil. The strain can be had in separate colours, like the Tom Thumb, or in mixture.

In the Queen of Tom Thumbs, in Variegated-leaved, and in Cloth of Gold, we get coloured foliage. These are attractive before any flowers appear.

Colour of flower and marking of leaf are both repeated in the tall (majus) section, the members of which are excellent for training over rough ground, as well as over trellises, arbours, and railings. There is an Ivy-leaved variety with yellow flowers that is very pretty.

The reader who has never tried orange, salmon, and yellow Nasturtiums for table decorations should do so. If cut with long trails of stem and bloom, they will give beautiful and uncommon effects.

Two or three of the species of Tropœolum are grown in the garden, notably polyphyllum, a prostrate perennial with yellow flowers, thriving in dry, warm spots if left alone; and speciosum, the Flame Nasturtium. The latter is a glorious rambler in Scotland, and one 


\section{POPULAR GARDEN FLOWERS}

occasionally sees it succeeding in southern England, but only when the roots are in a cool, shady place. It likes association with some other plant, which gives it protection and partial shade. Tuberosum, which has red and yellow flowers, will pass the winter safely in sandy soil and a sheltered place, but it is not really hardy, and, as a rule, the tubers are taken up and stored for the winter. The Lobbianum section, such as Ball of Fire, are charming trailers, and although often grown under glass, are quite suitable for window-boxes and balconies in summer.

Erasmus Darwin wrote of the Tropœolum in "The Loves of the Plants":

"Ere the bright star which tends the morning sky

Hangs o'er the flushing east his diamond eye,

The chaste Tropeo leaves her secret bed;

A saintlike glory trembles round her head;

Eight watchful swains along the lawns of night

With amorous steps pursue the virgin light."

The "watchful swains" are doubtless the stamens of the flower.

The poets, therefore, have not neglected this old garden flower. 


\section{VII}

\section{ON CANDYTUFTS AND CERTAIN OTHER ANNUALS}

THERE are a few kinds of annuals which possess such outstanding qualities-whether of colour, perfume, or habit-that every flower-gardener feels that he must grow them. The most remarkable example is, of course, the Sweet Pea, which combines every merit, and is of such importance as to claim a chapter to itself. Falling below it in beauty and utility, yet still valuable, are a few particular kinds that stand out from the bulk of their class. Of such are Asters, Candytufts, Chrysanthemums, Clarkias, Godetias, Larkspurs, Mignonette, Petunias, Phloxes, Poppies, Stocks, and Sunflowers, while Sweet Alyssum, Convolvuluses, Coreopsis, Cornflowers, Eschscholtzias, Lavateras, Leptosiphons, Linarias, Linum, Lupins, Love-in-a-mist, Marigolds, Nemophilas, Saponarias, Sweet Scabious, Silene, Salpiglossis, Sweet Sultans, Virginian Stocks, and Zinnias, follow them closely.

It is only when the flower-lover sees a large collection of annuals on the trial grounds of one of the great seed firms that he fully realises the beauty of the class. $\mathrm{He}$ is astonished alike at the range of colours, the splendid habit, and the duration. And when he realises that seed of all can be bought for a few pence a packet, he fully appreciates the strength of their claims.

Town and suburban amateurs are great people for annuals. Many a small back-garden would go bare 
but for these beautiful flowers. The suburbanist's borders are comparatively narrow and restricted, as a rule, and he cannot get the pleasure and satisfaction out of hardy herbaceous perennials which people more fortunately situated can. For a modest half-crown he can buy a collection of several kinds of annuals, each packet containing enough seed to yield a considerable number of plants-sufficient in the aggregate, indeed, to fill his garden with beautiful and fragrant flowers through the summer and into mid-autumn. If the amateur supports a penny-packet firm, he could get a packet of each of the kinds which I have named for two shillings and eightpence. It is good indeed to think that so much beauty is available for so modest an outlay.

Let me take the Candytuft (Asters have been dealt with in Chapter II) as typical of the annuals. On April 7 I sowed a packet of Giant White Hyacinth-flowered (the seedsman said the spikes would be nearly as large as Hyacinths when at their best, and so they were) in front of a Rose-bed, and to-day (October II) the clumps are still full of bloom after several weeks of incessant flowering. The packet cost threepence, and by dint of careful sowing, the seed being sprinkled very thinly over an area of half a square yard in each case, I was able to make it provide me with several clumps. This Candytuft, with its great white spikes reminiscent of Hyacinths, has been as much a feature of the garden as any of the herbaceous plants. The spikes are very reluctant to part with their flowers. At their best they are, of course, all bloom; as the seeding instinct asserts itself the lower flowers wither, leaving seed-pods; and this process repeats itself, but very slowly if the plants are growing unrestricted, and many weeks elapse before 
the clumps show serious signs of decay. It is, however, only fair to say that culture has much to do with duration of bloom. Plants with plenty of room, growing in fertile and moist soil, flower much longer than others that are crowded together in poor dry soil. The latter go to seed prematurely in sheer self-defence, anxious to perpetuate their kind before they seek an early grave.

Other Candytufts besides the Giant White Hyacinthflowered, and other annuals besides the Candytuft, respond with equal generosity to such little labour and care as are involved in digging soil deeply, manuring it if poor (but not heavily, especially for Nasturtiums), preparing a fine surface tilth, sowing thinly, thinning out, and watering in dry weather. The double pink Clarkia and the double pink Godetia will rival the Candytuft in length of blooming; and both will come in admirably for vase decoration. The touch of orange at the base of some of the Godetias makes them associate very well with salmon-coloured Sweet Peas, like Henry Eckford, in wide bowls. Larkspurs are long lasters, but it is important to get a dwarf strain, as the tall are very straggly, and apt to look gawky and untidy. Poppies are not, in the main, lasting flowers; their value lies in the brilliant biaze of colour which they make at midsummer; but the doubles are not nearly so transient as the singles, and the flowers are nearly as large and rich as Pæonies. The Eschscholtzias, with their orange flowers and finely cut leaves, are long lasters. So are the Rose Mallows (Lavateras), and the blue Love-in-amist (Nigella). Not so clurable, but free growers, free bloomers, and bright in colour, are the Coreopsis, Leptosiphons, Linarias, Linums, Lupins, Nemophilas, Silenes, and Virginian Stocks. 
The principal half-hardy kinds (which respond to the treatment indicated for annual Asters in Chapter II) also last well. Petunias, Phloxes, Salpiglossis, and Stocks blow well into the autumn if the plants are roomily grown and watered in dry weather.

Mignonette, Night-scented Stock (Matthiola), Sweet Alyssum, Sweet Scabious, and Sweet Sultan give us perfumed flowers. The two first are long lasters, especially, I think, on limestone soils. Certainly Mignonette gives me far more bloom on chalk than on clay, although, oddly enough (yet perhaps not so odd, since the position is bleak) it is later to open on the former.

While I am a strong believer in giving annuals good culture, on the lines indicated above, I find that it is well worth while to broadcast a few kinds on any rough bank or chalky slope, and leave them to Nature. Such scatterings of seed may appear to be useless, since the conditions afford no sort of hope of success; and perhaps half the summer passes without any result being observed, then suddenly some evening a whiff of perfume reaches your nostrils, and search reveals a lusty colony of Mignonette that had been overlooked. Clarkias, Eschscholtzias, Godetias, Linarias, Love-ina-mist, Mignonette, Night-scented Stock, and Poppies are all particularly likely to succeed on this rough-andready system. 


\section{VIII}

ON CARNATIONS, PICOTEES, AND PINKS

From the earliest times the Carnation has interested flower-lovers deeply, and it interests them deeply to-day. The old writers loved it, the people loved it. With the possible exception of the Rose, it has figured more prominently in literature than any other flower, and it has loomed large in the customs of the proletariat. Monarchs have chosen it as one of their favourite flowers. Florists have specialised it, and formed societies to guard its interests.

It is easy to find an explanation for the popular name Carnation; it can be attributed to the colour-flesh colour. Note Shakespeare's-

"A could never abide carnation; 'twas a colour he never liked." -Henry $V$.

Even so good a scholar as Dr. Johnson was satisfied with this. But the obvious is not always the correct, and this appears to be a case in point. In Lyte's Herbal the name is spelled Coronations, and now, when we read Spenser's "Shepherd's Calendar"-

"Bring Coronations and Sops-in-wine Worn of paramours,"

and recall the old custom of wearing flower-crowns (coronce) by the Romans and Greeks, we arrive at the true derivation. The Carnation held a high place among 
these garland flowers. Our flower being a popular one for head wreaths, it was called the coronation flower, and coronation became Carnation.

The old writers called several plants Gillyflowers (this name was sometimes spelled Gilliflower or Gilloflower), amongst them being the Stock and the Wallflower; but when they wrote of the two latter as Gillyflowers it was with the prefixes "Stock" and "Wall." When they referred to Gillyflowers without any such distinctions it may be assumed that they referred to Carnations. It is true that Shakespeare alluded to them in such a way as to lead to the supposition that they were different plants. Note-

\section{"The fairest flowers o' the season Are our Carnations and streaked Gillyvors, Which some call Nature's bastards."}

-Winter's Tale.

But it is probably safe to assume that the "streaked Gillyvor" (Gillyflower) was merely another sort of Carnation.

We may carry the interest of derivations a little farther. The botanist's name for the Carnation is Dianthus caryophyllus. Dianthus comes from dios, divine, and anthos, a flower-Jove's flower. Caryophyllus means nutleaved (see Corylus, the Nut; Carya, the Hickory ; Caryocar, the Butter Nut, \&c., all deriving from the Greek karyon, a nut). As the Carnation has grassy leaves, differing entirely from those of the Nuts, the specific name

1 caryophyllus seems at first inappropriate and difficult to explain, but it was first applied generically to the Indian Clove tree, Caryophyllus aromaticus, and the name became attached to the Carnation through the latter having a smell of Cloves. Having got so far, the rest is easy, because Gillyflower is certainly a corruption of 
caryophyllus. (Some authorities have suggested that Carnation itself is a corruption of caryophyllus, but this cannot be accepted). If the objection is raised that Gillyflower is very different from caryopliyllus, it may be replied that Gillyflower is a comparatively modern form of the word; older forms are gillyvor and gilofre. Chaucer speaks of the "clow gilofre" with

\footnotetext{
"Notemuge to put in ale

Whether it be moist or stale."
}

Some writers think that he had the dried flower-buds (commercial cloves) of the Clove Tree in view here, since he speaks of nutmeg and other spices. Carnation flowers were, however, used to flavour wine and beer, and hence the name Sops-in-wine. In Blount's Antient Tenures "July-flower wine" is referred to, and writers are not wanting who declare that Gillyflower is simply a corruption of July flower. The correct explanation is probably as above.

The name Picotee comes from the French picoté, "pricked" or "marked," and was applied to flowers with colour marks on the edge. Our modern Picotees are really Carnations in which the colour runs round the edge of the flower, sometimes in a thin line, sometimes in a broad band. Picotees are classified by the depth of the edging.

Pinks.-The origin of the name "Pink" would be sought naturally in the colour; it would be assumed that the first flower which bore this name was pink in hue, and that the flower would be called, therefore, the Pink, i.e. the pink Gillyflower. The reverse is the case; it is the colour that comes from the flower.

According to that careful authority, Dr. Prior, Pink comes from Pentecost through the German word Pink- 


\section{4 \\ POPULAR GARDEN FLOWERS}

sten. It was the Whitsun-blooming Gillyflower. The Pink does, in fact, bloom much earlier than the Carnation and Picotee, and is generally at its best in June. I The early forms were, of course, single.

The flower was highly esteemed, as we may judge from the expression "the pink of courtesy." Note Romeo and Juliet, Act ii. scene 4.-

Mercutio. Nay, I am the very Pink of courtesy. Romeo. Pink for flower.

Mercutio. Right.

See also Spenser's-

"Her lovely eyes like Pincks but newly spread."

Pinks are of two classes, the Laced and the Garden or Feathered. The former are probably varieties of Dianthus caryophyllus like our Carnations, and the latter (Pheasants' Eyes) of the feathered Pink (Dianthus plumarius). The Laced Pink has a coloured centre, which distinguishes it from the Carnation and Picotee; and also a coloured band near the edge of the petal, but not on the margin, as in the Picotee; there is a band of white on the outside. Like the florists' Carnation and Picotee, it is a smooth-edged flower. The Garden Pinks have cut-edged or serrated petals.

The multiplicity of names may be taken as evidence of the popularity of the Carnation. Cultured and illiterate people alike loved and grew it.

The clove-scented Carnation is a very old plant-certainly one of the oldest of which botanical historians have any record. The old Roman writer Pliny describes it, and tells us that it was discovered in Spain. Plant dictionaries make no attempt to fix the period of its introduction to Great Britain, and boldly class it as a 


\section{CARNATIONS, PICOTEES, AND PINKS 55}

native, which, in a sense, it is, inasmuch as it has grown as a wilding for centuries in some places. It is naturalised on some of the old castles of Norman construction, such as Dover and Rochester; and this raises an interesting point: Was it introduced advisedly by the Norman builders, or accidentally with the stone which they quarried and shipped? It was certainly a popular plant in Normandy, and it is probable that the barons brought it over to please their ladies, who doubtless looked with scant favour on their new homes, and needed placating.

It is not easy, either, to fix the period when flowerlovers in England began to specialise the Carnation. When we find so old a writer as Gerard (I545-I6I2) saying that it would require a large volume to describe all the varieties of Carnations, Picotees, and Pinks, we may infer that it was a highly specialised flower as far back as I597, when his Herball appeared. Shakespeare's reference to "streaked Gillyvors" in The Winter's Tale showed that Carnations differing from the old fleshcoloured Self (which he referred to in the same line) existed in I60I ; and Gerard credits Lete with the introduction of yellow varieties in or about the year $\mathrm{I} 580$. John Parkinson (1567-1650) appears to have had a large collection of aifferent kinds, but not Picotees.

These historical facts about Carnations increase our interest in the flower. They show us that it has long been rooted deeply in the national life. It is not an ephemeral plant, the interest of which passes within a few hours of its introduction, but a flower of abidingone might almost say constitutional-interest. It is woven into the national fibre. As we move about among our collections to-day, propagating, potting; planting, so we may imagine Lete, Gerard, Stow, 
Parkinson, and other old florists doing in the spacious Elizabethan epoch. These men were as eminent in floriculture as their contemporaries Spenser, Marlowe, and Shakespeare were in literature. But what different lives they led-John Gerard pursuing the peaceful art of gardening at Burghley and compiling his Herball in placid seclusion (cribbing freely from Dodoens' Pemptades, however, according to some unkind biographers), Kit Marlowe carousing in the taverns, and getting killed in a vulgar brawl!

The Carnation presently began to develop on certain well-defined lines. The "streaked Gillyvors" became the "Bizarres" and "Flakes" of modern florists. The different character of the markings led to the flowers being separated into classes. When we open a Carnation catalogue to-day we find such sections as Bizarres, Flakes, Selfs, Malmaisons, Trees (or Perpetuals), Americans, and Fancies; and all of these are subdivided by colour. Among Picotees we have Yellow Grounds and White Grounds, with sub-divisions according to the breadth of the marking on the edge of the petals and the colour.

When the old florists had secured their sections they kept them distinct and good by formulating rules and standards. They fixed on an ideal flower, and worked up to it with their new seedlings, retaining only those that conformed to the standard, and keeping them true to form and colour by propagating from layers and cuttings. They gave us a round, smooth-edged flower, full in the centre, and with the petals overlapping each other evenly. They did their work so well that we have not been able to make improvements in form during the past I 50 years (some of the old school declare mournfully that we are receding, since we have admitted the 
cut-edged "American" section to favour), but we have secured increased size and a larger range of colours.

A brief description of the various sections may be of interest.

A Bizarre is a flower the clear ground colour of which is marked radially with two or three other colours. According to the predominant colour in the flaking, it is a Scarlet, Crimson, or Pink and Purple Bizarre.

A Filake is a flower the clear ground colour of which is marked radially with one other colour ; the shade of the mark decides whether it is a Purple, Rose, or Scarlet Flake.

A Self is a flower with one colour only.

A Malmaison is a large-flowered sub-section of the Tree or Perpetual Carnation, flowering in spring and early summer. The original variety was blush-coloured, and was raised in France. Its full name was Souvenir de la Malmaison. The reader hardly needs to be reminded that La Malmaison was the chateau occupied by Napoleon and Josephine, and he may suppose, if he pleases, that the Malmaison Carnation was grown and admired by these remarkable beings, but its origin cannot be traced. Josephine certainly loved Carnations, and grew the best varieties of her day. The Malmaison Carnations are self-coloured, and distinguished by their powerful clove fragrance. The stems and leaves are more vigorous than those of other Carnations, and the plants can be distinguished readily, even when not in bloom.

Tree or Perpetual Carnations have a tall, upright habit of growth. They are winter and spring bloomers, and self-coloured.

American Carnations are large-flowered Perpetuals 
with cut-edged petals. They are winter-and spring bloomers, self-coloured, long-stemmed, and very sweet. (What might be termed an Anglo-American class has been evolved, the members of which have the large flowers, long stems, rich colours and full perfume of the Americans, but smooth-edged instead of cut-edged petals. A cut-edged petal has always been an abomination to British florists.)

Fancies are flowers with irregular markings on coloured or white grounds. The Yellow Ground Fancies are a beautiful class, which has been greatly increased and improved in recent years. The body colour is marked with plum, pink, rose, or some other colour in stripes and flakes.

Picotees may be first classified as Yellow or White Grounds; secondly, as light, medium, or heavy-edged; and thirdly, as red, rose, scarlet, or purple-edged. If the colour is a thin line on the very edge of the petal, the flower is a light-edge; if it is a belt a sixteenth of an inch wide, or thereabouts, the flower is a mediumedge; if it is a broader belt of something like an eighth of an inch, the variety is a heavy-edge. Thus a flower will be a "White Ground, heavy rose-edge," if the body colour is white and the marginal colour a broad belt of rose.

The Malmaison, Tree, American, and Anglo-American Carnations are grown under glass most of the year, although it is not unusual to stand them out of doors on a bed of ashes in the summer. The Malmaisons are usually propagated by layering in a frame in spring, the method being the same as that which is to be described presently for garden Carnations; but also by cuttings. They need great care in watering and ventilating. They are not plants for the one-house amateur, 
and are principally used by wealthy flower-lovers, who grow them in a house to themselves. The Tree, American, and Anglo-American Carnations are propagated by cuttings of young wood inserted in sandy soil in small pots in winter or spring.

Pot culture.-Exhibitors of Carnations grow the Bizarres, Flakes, Selfs, Picotees, and Fancies in pots. They generally put two plants in a 7 -inch or 8 -inch pot, using a compost of fibrous loam, with a fourth of leaf mould, dried cow manure, and mortar rubbish (or road grit) in equal parts. They grow the plants, while quite young, in frames, and later in light, airy houses. It is only when the plants are thus grown that the exhibitor can rely on flowers of the standard which judges look for.

Flower gardeners need not regard so old a garden favourite as the Carnation as an indoor plant, however. It is delightful to see flowers in perfect form and texture, but the flower-gardener need not deny himself a Carnation-bed in order to secure perfection of outline and colour in a limited number of flowers on a show-board. He will the more particularly refrain from making this mistake when he sees that the exhibitor is never satisfied with the native beauty of the flowers which he has produced at so much cost, but embellishes them by "dressing" with tweezers, and staging in "collars" of white papers.

Flower-gardeners will sympathise with the main work of the exhibitor, because they will recognise that it makes for quality of bloom. They will gladly take the beautiful varieties which his operations bring into being, but they will judge the sorts by a different standard-a standard of vigorous growth, free blooming, and clear, decided colours.

The Selfs are undeniably the best garden Carnations. 
The Bizarres and Flakes, particularly the former, fail to strike a sufficiently bold and clear note. The Fancies are fairly good. The Picotees are pleasing at a close view, but ineffective at a distance; they are, however, exquisite in pots.

Every Carnation-lover who grows his favourite as a garden plant pure and simple should make a special study of the Selfs. He should note the bearing of the different varieties when he has opportunities of seeing them out of doors-in parks, in nurseries, in private gardens. He should look out for a good white, a good pink, a good rose, a good scarlet, a good yellow, and a good crimson. He should note which sorts grow strongly and which weakly, which bloom freely and which sparsely, which are decided in colour and which washy, which keep their shape, and which become deformed through the bursting of the calyx; for all these points have a bearing on flower-garden results.

The following are good Self garden Carnations in the various colours:-

Scarlet.

Banner.-A large bloom of rich colour.

Barras.-Bright and strong.

Hayes Scarlet.-A free bloomer, fine in form, habit, and colour.

* Herbert J. Cutbush.-A splendid flower of brilliant colour.

\section{Crimson and Maroon.}

Agnes Sorrel.-Very dark crimson.

* Gil Polo.-Magnificent flower, crimson.

Lady Hindlip.-Fine flower, a light rather than a rich crimson.

*Uriah Pike.-An improved Old Clove, very sweet. 


\section{CARNATIONS, PICOTEES, AND PINKS 6I}

\section{Yellow.}

* Daffodil.-A modern sort, with a much larger flower than Germania, and very rich in colour.

Germania.-A very old variety, a strong grower, and clear in hue.

Miss Audrey Campbell.-A well-proved sort, primrose in colour.

\section{White.}

Hildegarde.-Lovely flower, and a free bloomer.

* Mrs. Eric Hambro.-A strong grower, and with large, pure flowers.

Trojan.-A large and beautiful flower.

Vesta.--Good habit and a free bloomer.

\section{Blush, Pale Pink, or Peach.}

Lady Nina Balfour.--Peach-colour, very strong grower, a great favourite in Scotland.

Lady Ridley.-Cream, very vigorous, with long stalks.

Mrs. Weguelin.-Blush, long stalk, very sweet.

Seagull.-Blush, strong, a fine garden sort.

\section{Pink and Rose.}

Endymion.-Salmon-pink, splendid flower.

*Exile.-Rose, very vigorous and free.

Raby Castle.-The old salmon pink.

\section{Heliotrope and Lavender.}

Capuchin.-Large, handsome flower.

* Garville Gem.-A fine, strong, free border sort.

$$
\text { Orange, Terra-cotta, and Apricot. }
$$

$N a b o b$.-Orange-buff, strong and free.

* Sir R. Waldie Griffith.-Apricot, very vigorous and floriferous, a great favourite in Scotland.

\section{Yellow Ground Fancy.}

Clio.

Hudibras.
Mrs. F. Wellesley.

Zingara. 
All the foregoing are varieties of proved merit, not untried novelties. They are inexpensive. They represent the best type of garden Carnation, growing strongly and healthily, and giving abundance of bloom of good quality. Those marked with an asterisk (*) might be chosen for a smaller collection. While, however, the varieties are good for the garden, most of them are capable of being grown into exhibition form.

The following are selections of the other sections :-

Scarlet Bizarres.

Admiral Curzon.

Robert Houlgrave.

Robert Lord.

Purple Flakes.

George Melville.

Gordon Lewis.

James Douglas.

Crimson Bizarres.

Harrison Weir.

Master Fred.

Rifleman.

Pink and Purple Bizarres.

Mrs. Barlow.

Sarah Payne.

Wm. Skirving.

Scarlet Flakes.

Alisemond.

Matador.

Sportsman.

Rose Flakes.

Rob Roy.

Sybil.

Thalia.
Heavy Red-edged Picotees.

Brunette.

J. B. Bryant.

John Smith.

Medium Red-edged.

Charlotte Brontë.

Euripides.

Lena.

Mrs. Gorton.

Thomas William.

Violet Douglas.

Heavy Rose or Scarlet-edged. Edith D'Ombrain.

Mrs. Payne.

Mrs. Sharpe.

Medium Rose or Scarlet-edged. Clio.

Daisy.

Duchess of York.

Light Rose or Scarlet-edged. Ethel.

Favourite.

Nellie. 


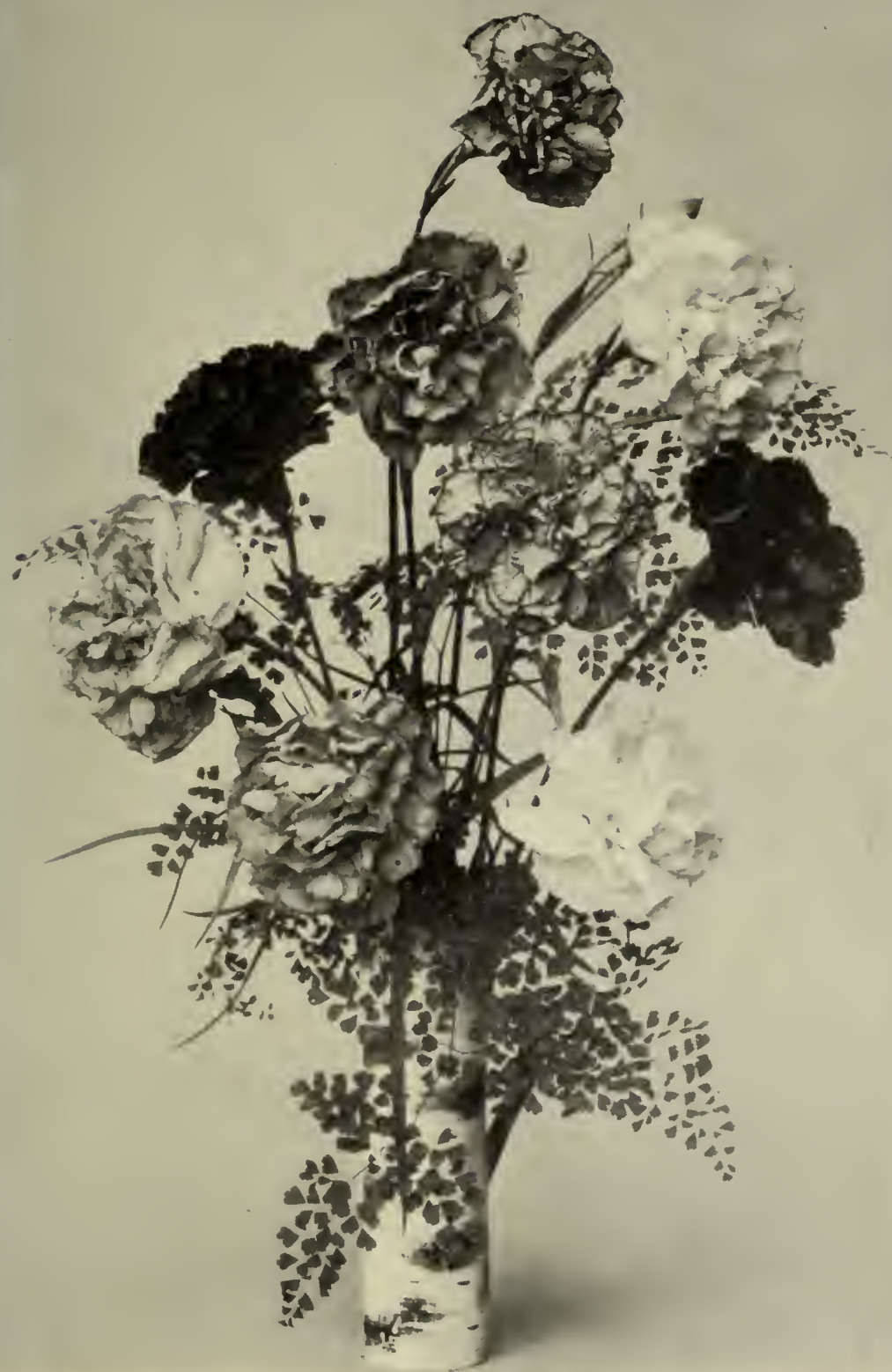

Carnations in a VASE. 



\section{CARNATIONS, PICOTEES, AND PINKS $\sigma_{3}$}

Heavy Purple-edged.

Mrs. Chancellor.

Muriel.

Zerlina.

Medium Purple-edged.

Amy Robsart.

Jessie.

Mrs. Kingston.

Light Purple-edged.

Ann Lord.

Clara Penson.

Mary.

Yellow Ground Picotees.

Gronow.

Hy. Falkland.

Lucy Glitters.

Pilgrim.

Malmaisons.

Blush (original type).

Lord Welby, crimson.

Mrs. Trelawny, salmon.

Nell Gwynn, white.

Pink (original type).

Princess of Wales.
Tree or Perpetual.

Deutsche Brant, white.

Lady Carlisle, pink.

Lord Roberts, yellow.

Mdlle. T. Franco, light pink.

Uriah Pike, crimson.

Wm. Robinson, scarlet.

\section{Americans.}

Alpine Glow, salmon-rose.

Beacon, scarlet.

Enchantress, light pink.

Harlowarden, crimson.

Helen Gould, rose.

Jessica, white, pencilled scarlet.

Lady C. Waring, yellow.

Robert Craig, scarlet.

Winsor, silvery-pink.

\section{Anglo-American.}

Britannia, scarlet.

Carola, crimson.

C. W. Cowan, claret.

Lady Ridley, cream.

St. Louis, scarlet.

White Perfection, white.

The laced Pinks are, as we have seen, as closely related to the Carnation as Picotees are. The principal difference is in the arrangement of the colour bands. These beautiful Pinks have not kept pace with the Carnation and Picotee. There was a time when they ranked almost as high with florists, but that is long past. The grower who wants a small collection might choose the following varieties :-

Amy.

Arthur Brown.

Empress of India.
Harry Hooper.

Morna.

Old Chelsea. 


\section{The following are beautiful garden Pinks :-}

Anne Boleyn, purple.

Ascot, pink.

Brackleen, rose, white ground.
Ernest Ladhams, blush.

Mrs. Lakin, white, pink centre. Mrs. Sinkins, white.

If we are to get beautiful Self Carnations in the garden, we must attend to a few important practical points. We aim at border clumps or beds in which the plants are strong, healthy, and bearing a number of large, brilliant, fragrant flowers. We cannot very well get such plants if the soil is bad or infested with wireworms. We can get plants of a kind, but they will be small, weak, and incapable of producing flowers of the quality we desire.

Soil. - There should be at least a foot in depth of soil, and if it is loam all the better, but clay will do if it is well drained and rendered friable by deep digging towards the end of winter. A light dressing of thoroughly decayed manure will improve it, and mortar rubbish, road grit, and wood ashes from a garden fire may be added with advantage. Light soil should be dressed with decayed turves that have stood in a heap for several months if possible, as this adds fibre, and Carnations like a soil with body in it.

Wireworm and leather-jackets are not common, as a rule, in ground which has been cultivated for several years, but they are often abundant in new gardens, especially those that have been made out of meadowland. Now, wireworms are particularly fond of Carnations, and will troop ravenously to them, feeding on the roots, and so worrying the plants that they have no chance of growing well. Small plants never "get away," as gardeners say; they remain stunted and sickly. If the Carnation-lover is going to plant on freshly-broken 


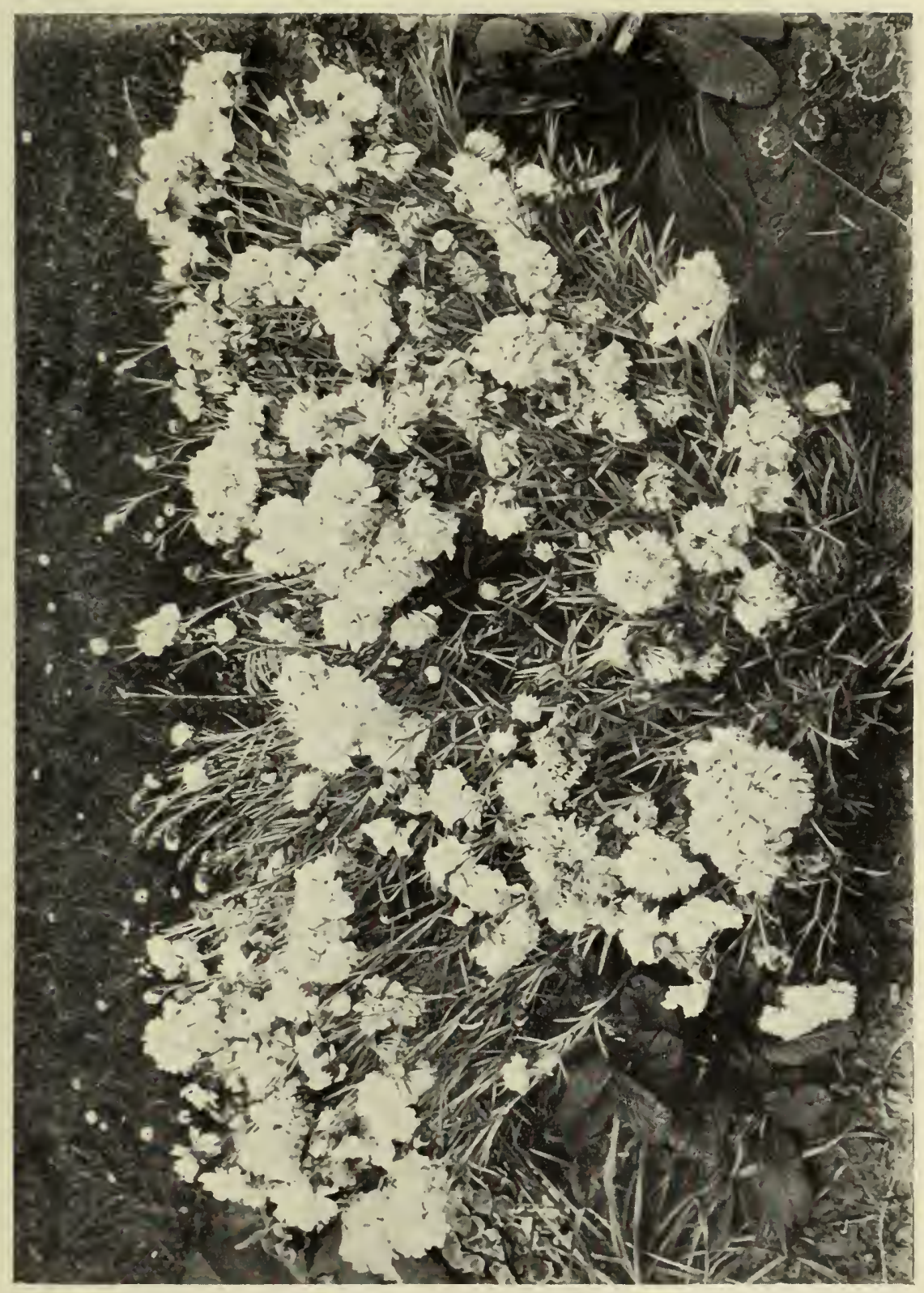

2.1 



\section{CARNATIONS, PICOTEES, AND PINKS 65}

pasture, he had better dress the soil with vaporite or apterite, which seedsmen sell, a few weeks before planting. These compounds are not expensive, and they certainly tend to reduce wireworm. Another plan is to work in kainit, a cheap chemical manure, at the rate of half a pound to the square yard, when the ground is being dug. It worries wireworm, and acts as a fertiliser to the soil at the same time. If the plants still refuse to grow, and, on one being taken up, hard yellow worms about an inch long are found at the roots, pieces of potato and carrot may be impaled on sticks and thrust in near the plants. It is better to keep taking up these than to take up the Carnations themselves; and they form good baits.

Planting.-When the grower is making a start with bought plants, he should buy in October or March. He can get nice young plants growing in small pots at a low rate, except in the case of novelties, which are dear. He should make the surface soil level and fine, and plant at once fifteen inches apart, making large holes for the plants with a trowel, sinking them to the lower leaves, and pressing the soil firmly round them. If making a bed, he should plant in diagonal lines thus-

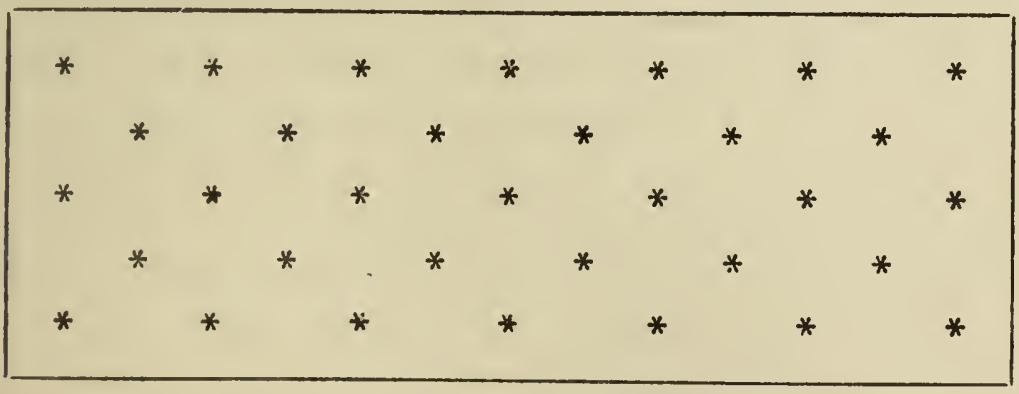

After planting, the soil should be raked over and the bed left neat.

If the plants are being grown in the borders, they 
should be set near the front, in clumps of not less than three, the soil being prepared and the plants put in fifteen inches apart as before.

If there is wireworm about, it would be well to put as many of the plants as pots can be spared for into five-inch pots, and stand them in a sheltered place on a bed of ashes, in order to grow them stronger before putting them out. Carnations do quite well if planted in May, provided they are put out with good balls of earth round them in showery weather, and watered if dry. While they are making root, and generally strengthening in preparation for their fight with the wireworm, the latter is being harassed and reduced by the vaporite, kainit, and baits.

Disease.-While they are in pots (and, for the matter of that, when they are planted out also) they should be looked over regularly to make sure that no fungoid disease is beginning to attack the leaves. If any blotches show, pick off the leaves which are affected, and then spray the plants over with water in which liver of sulphur (sulphide of potassium) has been dissolved at the rate of half an ounce per gallon.

Directly Carnations begin to grow in the beds and borders they become attractive. The flowering season may be a long way off, but the glaucous grey foliage is pleasing in itself; and herein lies one of the great advantages of the Carnation as a garden plant; as long as it is healthy, it is always handsome, whether in or out or flower. Old plants, it is true, are apt to be unsightly, because they show a considerable amount of bare stem at the base; but no one need keep plants until they become ugly, because new ones can be raised easily.

A bed of Carnations in free, healthy growth is beautiful and interesting all the summer. The plants throw out 
CARNATIONS, PICOTEES, AND PINKS 67

tufts of grassy grey leaves, and presently push flower stems. They will not need much cultural treatment until the stems are long, but the bed may be hoed to keep weeds down, and water may be given in dry weather. When the flower stems begin to bend over, stakes should be put to them. The loops made in tying should be loose, in order to avoid checking extension. Carnation experts use special supports which florists sell. Porter's and Sydenham's are both very good:

When flower-buds show, the number on each stem may be reduced to three, if very nice flowers are wanted. If no disbudding is practised, there will be a larger number of smaller flowers. Exhibitors permit only one flower stem, and disbud, but many flower gardeners do not, preferring to let the plants bloom naturally.

For towns. - The plants will come into flower in July, and will probably be at their best towards the end of that month. If they are healthy, and the flower stems strong, the beds or clumps will be objects of great beauty. And they can be had in town or suburban as well as in country gardens, for the Carnation is one of the best of town flowers. Several of the most successful exhibitors grow their plants in or near large towns. It may be said that of all the great popular flowers Carnations and Chrysanthemums are the two best for town and suburban gardeners to specialise.

The propagation of garden Carnations is conducted by means of seeds and layers. Seeds give large, healthy, free-blooming plants if the strain and culture are good; from a poor strain the flowers are small and of no special quality. They look charming in the garden, however, and are good for cutting. Seed should be sown thinly in June, in well-pulverised soil, and covered half an inch deep. If the seedlings come through in a mass, they 
should be thinned. They can be planted out where they are to bloom in autumn or spring. Or seed may be sown under glass in March, to give bloom the same year.

The propagation of all varieties grown under names, and, indeed, of any sorts that the grower wishes to keep true to form and colour, is by layering. All the grassy side-shoots previously alluded to can be layered in August, and the process is simple. The grower slices the small leaflets from a short length of stem about three inches from the parent plant, cuts half-way through the shoot as though he were going to sever it, then changes the direction of the knife and runs the blade through the centre of the stem in the direction of the tip of the shoot to the length of an inch; he then withdraws the knife. By this act he makes a slit in the shoot without separating it from the plant. A small pebble may be slipped in to keep it open. Each shoot is then depressed and the slit portion of the stem pegged down in a small mound of sandy soil put there for the purpose of receiving it. Such is layering, and any amateur gardener may succeed in it with very little practice.

Roots will form in and around the slit, and by miclOctober they will be so numerous as to form a small mat of fibres. The shoots will no longer need support from the old plant, and may be cut away from it.

The young plants procured by layering will be better than their parents a year later if all has gone well with them. Specialists often put them in small pots, and winter them in unheated frames on a bed of ashes. They then get larger plants, but a sharp watch must be kept for leaf spot. Amateurs would be well advised to plant them out, as the plants will probably remain cleaner than in frames, and there is not likely to be any 


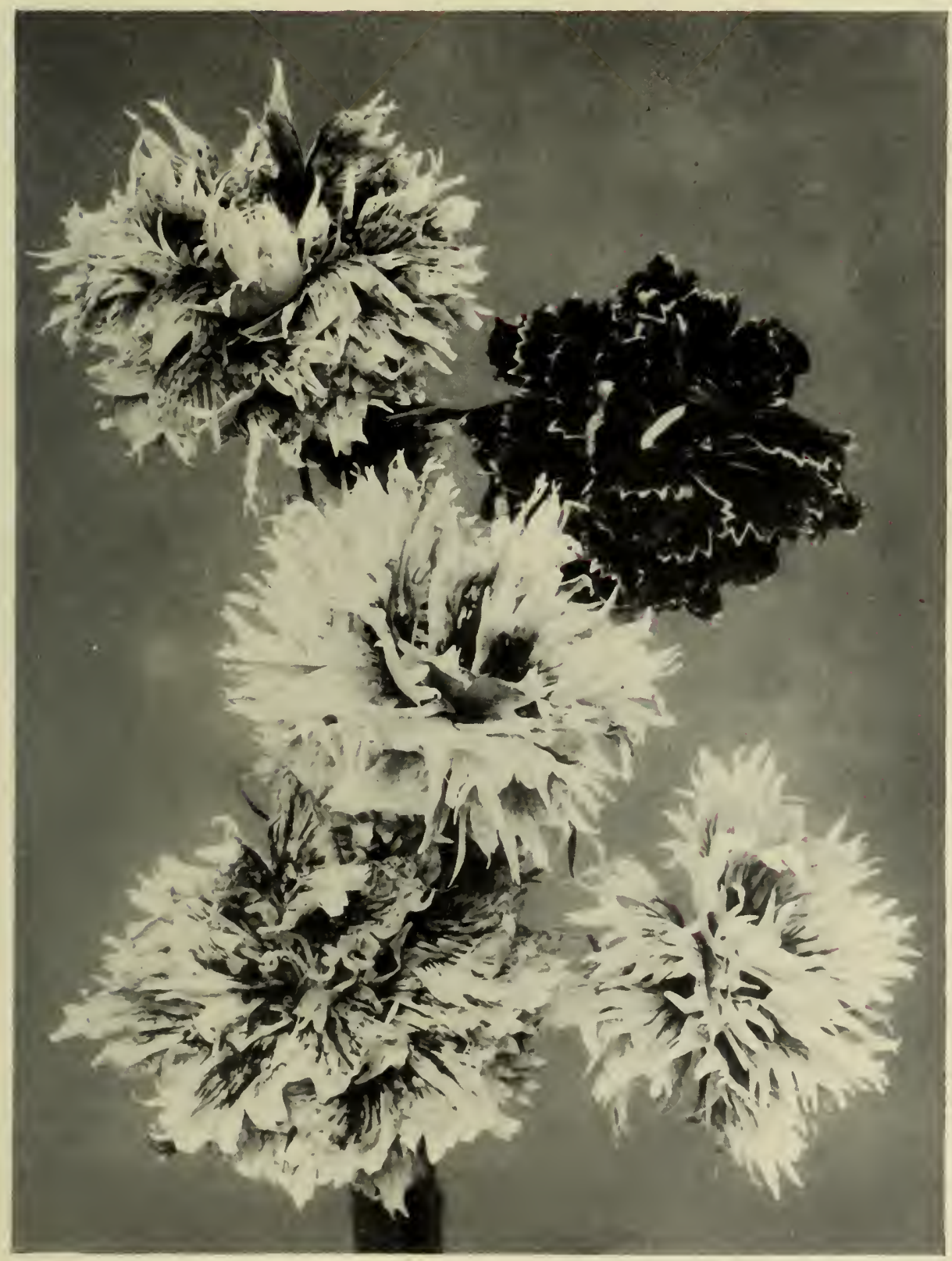

Double INIMAN PINks. 

serious loss from frost if the soil is well drained. In wet soil some sharp road or other grit may be sprinkled round the plants to prevent damp affecting the collar. Dry cold will not kill the plants.

Pinks do not produce tufted side-growths so freely as Carnations, and are often propagated by division, or by pulling young shoots out of their sockets early in summer and inserting them as cuttings in sandy soil. These shoots are called pipings. The strong-growing. Pinks which produce vigorous side-shoots may be layered like Carnations. They are often used as marginal plants for beds and borders. As they will grow in almost any soil if rabbits are wired out of the garden, and bloom most profusely, they are invaluable plants to the amateur. A line of Pinks makes a neat and pleasing margin to a bed or border, besides yielding a large quantity of sweet and pretty flowers.

Maggot.-Sometimes a blistered spot, with a brownish track running from it, is seen on a leaf. If so, the leaf should be sliced down at once with the point of a knife and a pair of small maggots searched for with the aid of a lens. If the attack is not observed, the maggots, unchecked by the grower, will work their way down to the stems, and whole shoots may become sickly and drop out.

There are several beautiful plants grown in gardens as Pinks of different kinds, such as the Indian Pink (Dianthus chinensis), the Japanese Pink (Dianthus Heddewigii), the Cheddar Pink (Dianthus casius), the Maiden Pink (Dianthus deltoides), and the Mule Pink, of which there are several hybrids, Napoleon III. being one of the best.

The Indian and Japanese Pinks are generally treated as annuals. With the seed sown in winter or spring 
under glass similarly to that of China Asters (Chapter II), the plants flower in July, and remain in beauty a long time. They are dwarf, free-blooming plants, bright and varied in colour, but have not the perfumed charm of the old garden Pinks and Carnations.

The other species are suitable for the rockery. They may be planted in spring or raised from seed in summer.

\section{The Carnation-Grower's Year-a Summary}

Jamuary and February.-Border Carnations will be almost, if not entirely, quiescent during these months. It is only in mild spells that outdoor plants will make any visible movement. There will be little to do among them. If the grower lives in the country he must keep a sharp lookout for hares and rabbits, especially in severe weather. In districts where rabbits abound, the best plan is to go to the expense (not very serious) of fastening two feet of wire netting, one and a half inch mesh, to all the fences. The lower portion should be embedded in the ground a few inches, to prevent the rabbits scratching away soil at the ground level and getting under. If any leaves become blotched with disease, they should be picked off and burned. Pot plants in frames should be ventilated regularly, except in very bad weather. Diseased leaves should be picked off. Very little water will be needed. It is only in periods of severe frost that any protective covering need be placed on the lights. Tree and American varieties will be in bloom in warm greenhouses, and will need attention in respect to staking and watering. Young shoots may be struck as cuttings in small pots of sandy soil. If possible, give bottom heat till rooted, then place on a shelf near the glass, 


\section{CARNATIONS, PICOTEES, AND PINKS 7 I}

March.-Planting in beds and borders may be done in favourable weather. If any of the plants put out in autumn have done badly, they may be removed and fresh plants put in their places. Prepare the soil thoroughly. Young plants in frames should be planted out. Carnation seed may be sown in boxes and placed on a hotbed or shelf in a warm greenhouse. Continue the propagation of winter bloomers. If green-fly should appear on the cuttings, dip them in water at a temperature of $100^{\circ}$. If the cuttings show a tendency to damping off, put a tumbler or bellglass over them to check evaporation from the leaves till roots have formed. When the roots of struck cuttings have reached the bottom of the pots, repot them in a compost of three parts loam, one leaf mould, one decayed manure, and some coarse washed sand.

April.-Plants in the garden will now be in active growth. The soil should be hoed regularly. Fresh plants may still be put in. Seedlings raised in March may be picked off three inches apart and put on a shelf in a greenhouse. Young winter bloomers may be repotted as required, and kept in a light, airy greenhouse. From now onwards vaporising the house once a fortnight with a vaporising cone (which seedsmen supply) will keep down green-fly and other insects. Malmaisons will perhaps be in bloom. Meet their requirements for water judiciously, never letting the soil become parched, but at the same time guarding against keeping it sodden.

May.-Bed and border plants which were planted in autumn or March will now be growing rapidly. By the middle of the month it is quite likely that the flower stem will begin to spindle up; anyway, stakes should be procured and kept in readiness. Tying cannot be com- 
pleted in one operation, but must be done at intervals as the stem extends. Continue hoeing. If the soil is shallow and dry, a mulching of cocoanut fibre refuse or short manure may be spread round the plants. Seedlings may be planted out from the boxes about the end of the month. Winter bloomers should have free ventilation in fine weather, and freshly struck plants may be put into frames about the middle of the month if the weather is mild. Give full exposure to air except in bad weather. Old plants may be stood on a bed of ashes in a sunny, sheltered place outdoors, and will flower again in autumn.

- June.-Continue the hoeing and staking of outdoor plants. Green-fly, the cuclioo spittle, and earwigs may now become troublesome. Vigorous syringing once or twice a week will harry the two first, and prevent them from doing serious damage; it will also benefit the plants. If earwigs do damage, place hay in some small flower-pots, invert them on sticks among the plants, and examine them daily. Tying the flower stems will need regular attention. If the grower intends to exhibit, he should restrict each plant to one stem, and the buds may be thinned to three at the most when they appear. Some varieties are thinned more severely than others, only two, or in some cases even one, bud being left; experience of the peculiarities of each sort will guide him. He should guard against severe disbudding at first; to restrict a plant to one bud might mean a coarse bloom. The exhibitor will also prepare his show boxes. A stand for six blooms may be $13 \frac{1}{2}$ inches long (from back to front), $8 \frac{1}{4}$ inches wide, $4 \frac{3}{4}$ inches high at the back, and $2 \frac{1}{2}$ inches high at the front. It should be perforated with holes large enough to contain the metal tubes which hold the stems of the flowers, and should be 
painted green. The flowers will stand in two rows of three each from back to front. A stand of this size will accommodate the largest flowers. Two such stands may be placed side by side to show twelve flowers. If several stands are to be taken to a show, a case fitted with ledges ought to be made for them. Cases, stands, and tubes can all be bought ready made from Carnation specialists. Round pieces of Bristol cardboard, about four inches across (rather more for large fancy flowers) may be procured, and a circle cut in the centre large enough to envelop the calyx loosely (the calyx is the circle of green segments just beneath the flower). A slit can be cut from the circumference of the card to the central hole, and by depressing one edge of this the stem can be slipped through. The preparation of exhibiting necessaries betimes prevents any confusion when show day arrives. Repot winter-blooming plants as required, and stand them on ashes in a sunny, sheltered place. Attend to watering and the suppression of insects.

July.-This is the flowering month, but the plants will not be in full bloom until the latter part, in most seasons. Continue tying, disbudding, and watering, as needed. If some of the opening flowers threaten to burst the calyx, slip an indiarubber band over it. Note hints under June as to exhibiting stands and collars. Before show flowers are finally put in the stands, in readiness for the judges, exhibitors make a practice of looking over them, and remedying any defects with tweezers. Thus, narrow, curled, or deformed florets in the centre of the flower are removed with a pair of ivory tweezers, together with "run" petalsthat is, petals in Bizarres or Flakes coloured all over instead of barred on white, and Picotees with the colour leaving the edge for the body of the petal. The flower 


\section{POPULAR GARDEN FLOWERS}

is finally mounted and dressed in the following way: a small circular card-preferably of Bristol cardboardis cut, with a star pattern in the centre, two-thirds the diameter of the pod, and the stem of the flower is then drawn through it. The points of the stars yield and bind round the pod. This small card serves as a "platform," as it were, for the display card referred to under June. The small card does not, in clasping the calyx, interfere in any way with the movement of the petals, which must be quite free. The large card, with its central hole (which is large enough to allow the petals to move freely), is then fixed above the smaller one by drawing the stem through the slit edge. The top of the calyx is turned outward with a pair of steel tweezers, to allow the petals to move freely, and then the flower is dealt with. First the large outer petals ("guard" petals) are drawn towards the edge of the large card and arranged in a ring, then the second row of petals is arranged over the edge of the first; other rows are treated likewise; and, finally, the central petals are lightly curved over the centre. With practice this can be done without giving the flower an unnatural and artificial appearance. If made to look very stiff, it would be regarded as "over-dressed." Seedlings in the beds should be examined as they come into bloom, and any very good ones marked for preservation and propagation by layering. Pot plants should be watered and syringed regularly.

August. - Layer young shoots out of doors in mounds of soil in the manner previously described, beginning early in the month. Should the weather be very hot and dry, the layers ought to be watered daily to encourage rooting. Pot plants should be watered and syringed as in July. 
September.-The layers in the garden should be forming roots freely, and the process will be hastened by watering in dry weather. By the end of the month the layers made early in August ought to be well rooted, and, if so, they may be cut away and the young plants (for such they will now be) planted out where they are to bloom the following year. The soil should be prepared as previously advised, and pressed firmly round the plants. A few plants of special varieties may be potted and put on a layer of ashes in a frame as a reserve. Early pot plants will now be forming flower-buds, although the later-struck ones may not yet be doing so. All ought to be put in the greenhouse towards the end of the month.

October.-Complete the planting-out of rooted layers and the potting of a few reserves. The latter, which may be potted firmly in three-inch pots, should be kept close for a few days after potting, but subsequently given abundance of air in fine weather. They will need very little water, and none should be sprinkled over the leaves, or mould may follow. Pot plants in the warm greenhouse will now be giving flowers, and if the batch is in different stages, some being from early and others from late cuttings, the display will be a prolonged one. A high temperature is not necessary $-50^{\circ}$ to $60^{\circ}$ being ample. The house should be a light, well-ventilated one, and abundance of air admitted in fine weather.

November and December.-If any plants out of doors are upheaved by frost, press them back again. Ventilate frame plants at every opportunity, and water very sparingly. Keep a sharp lookout for rabbits. Pick off any diseased leaves directly they are seen and burn them. Maintain a fresh, buoyant atmosphere in the 
76 POPULAR GARDEN FLOWERS

greenhouse. Give water when the soil is actually dry, but be careful not to overwater, and avoid spilling water about, thereby creating a damp atmosphere. Ventilate regularly, except in foggy weather. This treatment, combined with the above temperature, will insure abundance of flowers for a long period. 


\section{IX}

ON CHRISTMAS AND LENTEN ROSES (HELLEBORES)

GREAT as is the skill of the modern flower-gardener, and vast as is the number of plants at his service, he has not yet arrived at the point of being able to fill his beds and borders with bloom at mid-winter. He has flowers in abundance in spring, summer, and autumn, but the hard weeks from the end of November to mid-February are practically bare, the few unimportant and comparatively ineffective plants which give odd flowers in sheltered places during that period hardly counting seriously.

There is, however, one flower which does count, and that is the Christmas Rose (Helleborus niger). It counts as the best summer flowers count-with amplitude of growth, abundance of bloom, and real beauty of flower. It is not one of those little plants that we speak of as merely "pretty" or "interesting," and which we fondle in some corner of the rockery. It is a strong grower, capable of forming a bold break of bloom. When we have learned to give it the best of treatment, and to utilise it in the best way, we shall appreciate it more and more.

We always think of the Christmas Rose as a white flower, and yet the dictionaries tell us that the original species was pink. Naturally we resent this. We have grown used to employing such terms as "snow-white" 
and "pure as the driven snow" in relation to it, and we do not relish the idea of parting with our choicest figures of speech. The truth is that the Helleborus, which came to us from Austria in I596, is pink externally, but it is white within, and that is enough for us.

It is a poisonous plant, yet not a dangerous one. The very name Helleborus points to poisonous qualities, as it comes from heleim, to kill, and bora, food. Both the leaves and roots are poisonous, and half a drachm of an infusion of the leaves has been known to kill an elderly man; but no one is likely to prepare and drink an infusion, or to make a supper off the roots. There is no berry for children to pick and eat. The only circumstances in which the Christmas Rose is at all likely to do injury are when flower stems are put in the mouth, and when the plant is used as a drug by incompetent practitioners. Growers may be warned against the former, and, as to the latter, the plant has been discarded from the Pharmacopœia.

Some confusion arises at times owing to another poisonous plant, Veratum album, being called the White Hellebore. The Hellebore powder used for destroying Gooseberry caterpillars is prepared from this plant.

The case is an illustration of the muddle which may easily arise from a careless use of popular names. We hear of the White Hellebore, and we have a plant that we know to be a white Helleborus; what more natural than that we should conclude them to be the same? They are really quite different.

The coiner of popular names who minted "Christmas Rose" deserves more approbation than coiners in general. It is true that the flower is not in the least like most of the Roses which we grow in our bedsour Mrs. John Laings, our Frau Karl Druschkis, our 
Crimson Ramblers. It is single. But, after all, there are single Roses as well as doubles, and I have a single white Rose that is absurdly like the white Helleborus. The "coiner" had not that particular variety in his mind, because it is a modern variety, but he had another something like it.

The word "Christmas" completes the charm. It wins our hearts and interest at once. The veriest Scrooge must admit its power when allied with a beautiful flower. There are two things inseparable from the popular conception of a cheerful Christmasa roaring fire and a well-laid table. In the old days, according to every popular writer, the table "groaned" under its burden of turkey, roast beef, pudding, and other comestibles. Now, a groan is a sound of distress, and if a table of a normally cheerful disposition really did emit a note of agony (which I for one take leave to doubt), it was not because it had to bear an extra burden once a year-it would have done that cheerfully enough -but because it deplored the absence of delicate and refined touches. Anyway, no self-respecting Christmas table will be satisfied with a sprig or two of holly nowadays. There must be a plentiful supply of bowls and vases of flowers. Rather than leave these out, either the beef or the turkey must go.

Situation.-The person who buys plants of Christmas Roses naturally does so with the object of having flowers at Christmas, but he does not always get them. The weather and the site have their say in the matter. If the plants are put in an exposed place, and the Clerk of the Weather should develop a cantankerous attitude, there will be no flowers on the poor Hellebores. They will be too pinched and miserable to think of blooming. The plant does not like being beaten and bullied by 
blusterous winds. It likes peace and quietude. Of course, it is hardy. It will not be killed by cold. But there is a difference between merely living and passing a happy, healthy, joyous existence.

Lovers of the Christmas Rose who really want it as a Christmas flower should give it a sheltered position. There ought to be sheltered places in every border of any size, because the owner will have worked in a few evergreen shrubs or conifers. These divide the border into "bays," and prevent the winter winds from sweeping in a savage, mad-dog rush from end to end, and tearing off every green leaf or blossom that ventures to show itself.

Another plan of providing shelter is to leave the old stems of herbaceous plants on until spring; but this is abhorrent to any mind with a sense of neatness and order.

Christmas Roses will do perfectly well under trees if they have shelter of some kind, such as a windscreen in the form of a neighbouring belt of shrubs, or the fronds of hardy ferns around them. The latter have not the ugliness and disorder of decaying herbaceous plants when they are turning brown. Some pretty, dwarf, winter-flowering bulbs, such as Snowdrops, Scillas, and Glory of the Snow, may be dotted among the Christmas Roses. The last-named (Chiondoxa) is a beautiful little blue bulb that one can buy for about three shillings per hundred in autumn.

With a reasonable allowance of mild weather in autumn, and shelter, there certainly ought to be flowers on the Christmas Roses at Yuletide; in fact, if several different varieties are grown, there will be flowers before, at, and after Christmas. There are Christmas Roses that bloom early and Christmas Roses that bloom late. 
Sticklers would contend that a Hellebore which flowered in November could not be a Christmas Rose, but there are no sticklers in gardening.

Planting.-The time to plant Christmas Roses is undoubtedly September. During that pleasant month they begin to make roots, and it is desirable to shift them when the process is starting. To move them afterwards means the destruction of new roots, which is a slap in the face for Nature that she is quite likely to return with interest.

The character of the soil is not of great importance as long as it is drained. Heavy soil and light will alike grow the plants well. But there should be no damp, no stodginess. Light soil may be improved by digging in a dressing of well-decayed manure, and the ground should be moved to a depth of at least a foot-preferably eighteen inches.

Some growers, unable to find the ideal sheltered spot for their Christmas Roses, yet very desirous of having early flowers, place the plants in groups and put frames around and over them. Or they cover small clumps with separate handlights. The French gardener's frames and cloches would serve this purpose admirably. But it is not every amateur who has frames and handlights to spare. At a pinch artificial shelter could be provided, in the form of a few armfuls of fern fronds thrown among the plants. These also form a soil-covering which prevents particles of grit being splashed up by rain on to the flowers. Should the flowers be caught by frost, it is a good plan to sprinkle them with cold water before the sun rises.

The Christmas Roses begin to grow (in the ordinary sense) in spring, for it is then that the new leaves appear. When they are furnished with fresh foliage 
the old leaves can be dressed off. The season for propagation is autumn, when the clumps may be divided.

The Lenten Rose is a Hellebore, but not the same species as the Christmas Rose; it is $H$. Orientalis, or the Eastern Hellebore, its native country being Greece. It is a handsome plant, with deep rose flowers and abundance of leafage. Blooming later than the Christmas Rose, it gives successional flowers, and the colours of the varieties are richer. It and its hybrids are plants to study for late winter and early spring blooming.

A description of the best varieties and hybrids may bring our chat about Christmas and Lenten Roses to a close.

Varieties.-Of the Christmas Rose there are two large varieties, one called major and the other altifolius or maximus. Both have flowers which are rose outside and white within. The latter is the earlier bloomer, often flowering in October and November. Madame Fourcade is a pure white form. Angustifolius (meaning narrowleaved), St. Brigid's Christmas Rose, is a beautiful pure white variety. It is a strong grower, and altogether desirable. These are a few of the best varieties of Helleborus niger, but the reader need not allow himself to become perplexed by the difficulty of choosing among them. The old Christmas Rose is good enough for anybody when it is well grown, and it is the cheapest.

The following are pretty varieties and hybrids of Helleborus orientalis: the Lenten Rose; Apotheker Bogren, purple, spotted; Frau Irene Heinemann, purple, spotted; Gretchen Heinemann, purple, red streaks; and Persimmon, white, with red spots.

There are several green Hellebores, notably abchasicus, viridis, and odorus, the last of which has sweet flowers. H. fotidus has greenish flowers also. But 


\section{CHRISTMAS AND LENTEN ROSES 83}

while they are not without charm and interest, they lack the beauty of the Christmas and Lenten Roses. These are the real indispensables. Would that I could conclude by saying that they are good plants for the suburban gardener, but the truth is that the average garden near towns, with its poor soil and hot aspect, is not suited to them. Hellebores are plants for shady spots, for ferny glades, for woodlands, for cool banks; and it is the exception to find such sites in the suburbs. But if they exist, Christmas Roses may be grown. 


\section{$\mathrm{X}$ \\ ON THE CHRYSANTHEMUM FOR TOWN AND COUNTRY}

To mention the Chrysanthemum is to arouse the interest of every lover of flowers. The professional gardener in large places thinks of his conservatories and corridors, the amateur of his general greenhouse, that threatens to be so bare of bloom in autumn, the flower-gardener of his borders, the townsman of the feasts of bloom provided in the public parks during the gloomy days of November, the suburbanist of the small number of highclass plants on which he can draw, the lady of the house of her bowls and vases. All fall under the spell of the flower, for all have had ample proof of its beauty and value.

The Chrysanthemum is one of the most remarkable of plants, alike for its season of flowering, the number of forms in which it can be grown, its adaptability for different conditions of growth, its indifference to impure air, and the extraordinary size, diversity of shape, and colour of its flowers. There are almost as many types of Chrysanthemum as there are of breakfast foods, and all are distinguished by a wide range of bright and cheerful colours; moreover, they can be grown in many ways and places.

History.-Our interest in Chrysanthemums, and our knowledge of the degree to which they have been de- 


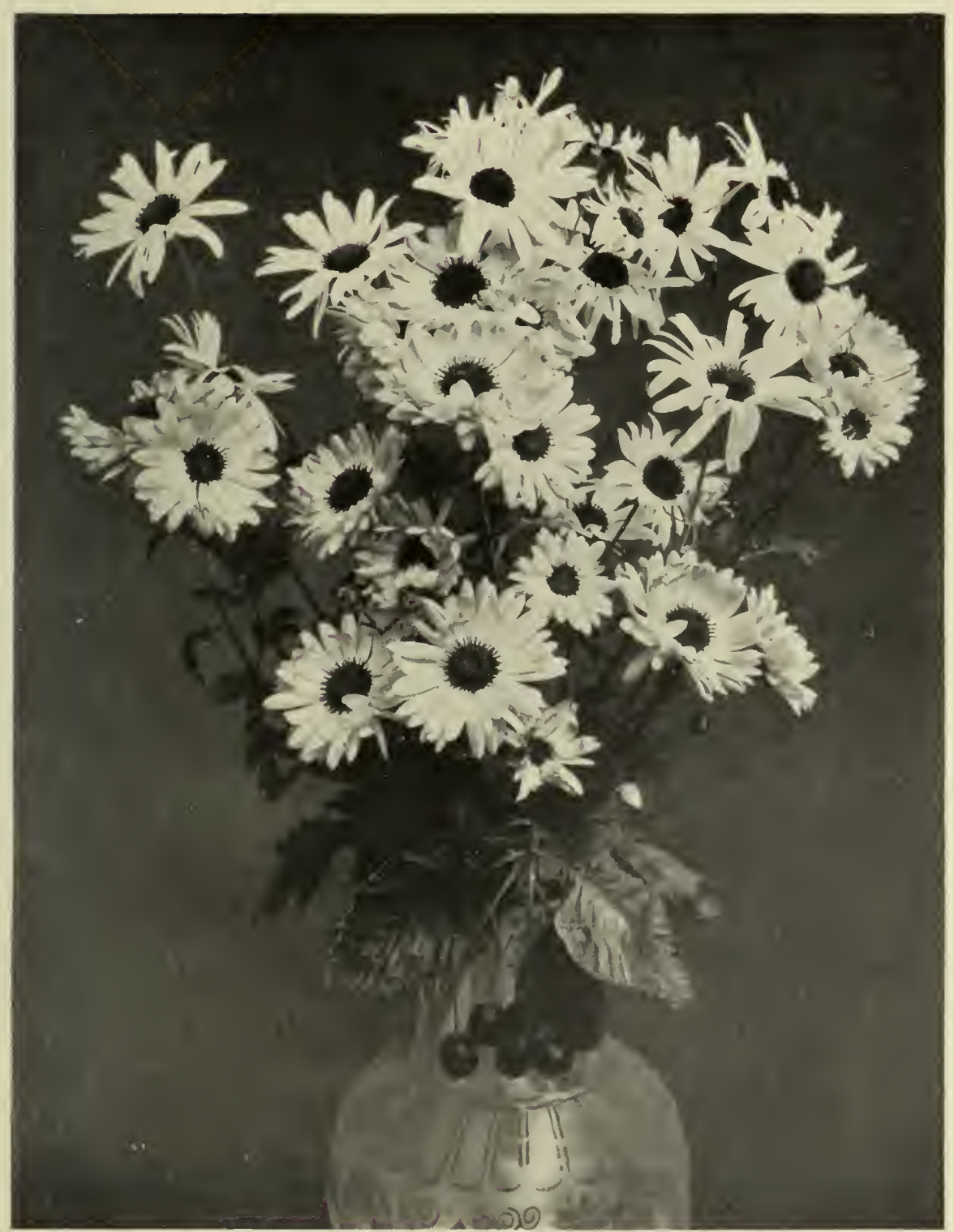

Single Chrysanthemuns as Cut flowers. 

veloped even in our own time, prompts us to speculate on their origin. We feel that the history of so great a flower must have much that is remarkable about it. But when we begin to probe into the heart of Chrysanthemum history we run against the stony obstacles of Oriental secrecy and passivity. The trail meanders away into the dust-tracks of past centuries-tracks sprinkled plentifully with boulders. We even read of references to the plant in the pages of Confucius, the immortal sage of China, whose memory still receives the homage of the Manchu emperors; and Confucius was born as far back as 551 B.C. Who can follow the progress of a plant which was grown for hundreds of years before it reached Europe-grown, too, in the Far East? The task is clearly impossible. We know that our modern Chrysanthemums ("florists" Chrysanthemums, not the comparatively unimportant annual varieties of the summer garden) are the offspring of two species, indicum and sinense, both of which came from China, and had single flowers, the former yellow in colour, the latter variable. Those who are sufficiently interested to want to know what the early blooms were like may turn to the Botanical Magazine, that great picture gallery of plants, where t.t. 327,2042 , and $255^{6}$ portray the two parent species.

It is common to indulge in playful badinage at the expense of the Celestial, but it would be somewhat dangerous in the case of the Chrysanthemums, for our own botanists seem to be undecided about the respective parts played by Chrysanthemums indicum and sinense in fathering modern varieties. One boldly attributes all of them to $C$. indicum. Another as roundly declares that $C$. sinense is the parent. In these circumstances it behoves us to preserve a prudent silence, and reserve our gibes for a subject on which repartee would 
be less embarrassing. That $C$. indicum and $C$. sinense have been confounded is probable, for one authority is silent as to the period of introduction of the former, but gives the year for the latter as 1764 . Now, other records state that the first specimen of Chinese Chrysanthemum that flowered in this country was a small yellow species which bloomed in the Botanic Garclen, Chelsea, in 1764. Surely this was $C$. indicum. The name was given to it by Linnæus in his Species Plantarum, first published eleven years before the plant bloomed at Chelsea. It had been described previously by Breynius in his Podromus in 1689, but was referred to by him under the name of Matricaria Japonica maxima, or the large Japanese Matricaria. (Matricaria is closely allied to Anthemis, and, as we shall see presently, the unfortunate Chrysanthemum was given yet another name by botanistsAnthemis artemisicefolia). Breynius stated that there were several varieties under cultivation in Holland in 1689 , and it seems peculiar that the plant should not have flowered in England until seventy-five years later. This fact lends colour to the supposition that there was confusion between two different species.

As I764 seems to be the first year that we can fasten on safely with respect to the appearance of the Chrysanthemum, we will accept it, and see what happened afterwards. The plant which flowered at Chelsea aroused considerable interest, and a dried specimen was presented to the Royal Society by the Chelsea gardener, the famous Philip Miller. It is now in the British Museum. The plant soon died, and we have no further definite record of Chrysanthemum culture until s790, when a large-flowered double variety was grown at Kew. It was said to have been procured from a French merchant named Blanchard or Blancard, who imported 
it, with two other varieties, the previous year. It was called the Old Purple, and considered to be a double form of indicum. It forms the subject of Plate 327 of the Botanical Magazine. Six years later a collection of plants was grown in Colville's nursery at Chelsea, and these, well cultivated and flowering freely, first taught the general public that an important new plant had arisen.

That greatest of horticultural writers, John Claudius Loudon, called the Chrysanthemum Anthemis artemisiafolia. Anthemis nobilis is the common Camomile, and the characteristic odour of the Chrysanthemum can now be located by the amateur.

Loudon wrote of the varieties in 1822 : "The Chinese are supposed, on good authority, to have fifty varieties or upwards; there are fourteen described by J. Sabine as having flowered in this country, and as many more of recent introduction, which have not yet flowered.... J. Sabine describes as having flowered in the garden of the Horticultural Society the following :-

The Purple.

Changeable White.

Quilled White.

Superb White.

Tasselled White.

Quilled Yellow.

Sulphur Yellow.
Golden Yellow.

Large Lilac.

Rose or Pink.

Buff or Orange.

Spanish Brown.

Quilled Flamed Yellow.

Quilled Pink.

From 1822 , therefore, British florists had at least fourteen varieties to work on, differing both in form and colour. We see that there were white, yellow, lilac, purple, orange, and brown sorts. The terms "quilled" and "tasselled" are not used in reference to Chrysanthemums at the present day, although we have quilled 
Asters. A flower is spoken of as quilled when the petals or florets are rolled or tubular, like the stem of a quill pen. The petals of many of our modern incurved and Japanese Chrysanthemums are quilled. Loudon might have had the former in mind, although there is no record of it till 1836 . The term "tasselled" would fit the early forms of what we now call Japanese flowers, but this section was not introduced till I 860-1862.

Whatever the shapes, British raisers made haste to cross them, and so get a large number of new and improved varieties. They perceived immense possibilities in a plant which grew strongly and bloomed freely in autumn, when flowers were scarce. It is quite likely, however, that even the most far-seeing of them never foresaw the marvellous results of their work. They did not see huge halls full of brilliant flowers, nor conservatories in the public parks through which thousands of people passed daily to admire the beautiful forms and glowing colours. They did not picture groups of Chrysanthemums in almost every garden, a great market industry in the flower, and scores of societies specially devoted to the plant.

By 1826 the Horticultural Society had forty-eight varieties, and three years later (although, according to some writers, it was seventeen years later) the first show was held in that grand old city, Norwich, whose gardeners are to this day as active, enterprising, and skilful a body as their craft can show anywhere. London claims to have followed. A Chrysanthemum Society was founded in Stoke Newington, and a show was held in 1847 , which was not only to become an annual fixture, but was fated to start a host of others; for the Stoke Newington Chrysanthemum Society became, in course of time, the National Chrysanthemum Society, and the flower which 
it had taken under its wing became one of the great flowers of the country, second only to the Rose in the number of its admirers. But the claim of London cannot be admitted, as a Chrysanthemum show was held at Birmingham in 1836 .

Famous Growers.-Let us put on record a few of the names most closely identified with the development of Chrysanthemums in Great Britain. One of the earliest raisers of seedlings was Isaac Wheeler of Oxford, who exhibited a batch before the Horticultural Society in 1832 ; and a Norfolk gardener, Freestone, followed him closely. In 1836 Chandler of Vauxhall exhibited improved varieties, and the incurved Chrysanthemum is said to have come into being about this time. Greater than any of these raisers, however, was John Salter, who, although gardening at Versalles when he first seriously set himself the task of improving Chrysanthemums, was an Englishman, and, returning to England in 1848 , became a trade florist at Hammersmith. He began about 1838 , and made enormous improvements in the flower.

In 1846 the "Chusan Daisy" was introduced by Robert Fortune from China, and it developed into the Pompon Chrysanthemum. In the course of a second visit to the Far East (1860-1862) he sent to England the first Japanese varieties, which constitute the most important section of modern Chrysanthemums.

Thomas Pethers, a Channel Islands grower; Samuel Br oome, gardener at the Inner Temple, London; Adam Forsyth, of Stoke Newington; J. Dale, gardener at the Middle Temple; Edwin Molyneux of Bishops Waltham; George Mileham of Leatherhead; W. Wells of Earlswood; H. J. Jones of Lewisham; and Norman Davis of Framfield, may be named among the eminent raisers and 
growers of Chrysanthemums who bring its development up to the present day. It would be impossible to give a complete chronology of the varieties, as the number probably exceeds three thousand, and records of the parentage of the great majority of these have never been published.

The Blue Chrysanthemum.-The various raisers have given us a great range of colours in Chrysanthemums, but not a blue. It is interesting to hear that blue Chrysanthemums appear on the splendid pottery of the Japanese; and, in view of their usual fidelity, it is claimed that a blue Chrysanthemum must have existed at the time.

The Japanese cultivated the Chrysanthemum with great ardour. They went, indeed, farther than the Chinese, exhibiting in this, as in so many other things, a more progressive and energetic spirit. They made it their national flower, and in 1876 the Mikado instituted the Order of the Chrysanthemum, consisting of a star in the form of a cross with thirty-two rays. A Chrysanthemum is placed in each of the angles tormed by the principal arms. The star is attached to a red ribbon by a gold Chrysanthemum, and this is entirely appropriate, for the Chrysanthemum is the Golden Flower, the name deriving from chrysos, gold; and anthos, a flower. The decoration is not for florists; it is an honour reserved for crowned heads and the highest dignitaries of states; but the man who introduces a good blue Chrysanthemum will need no order to commend him to posterity. His name will be famous for all time.

Classification.-We may begin our survey of presentday Chrysanthemums by a brief consideration of the various classes. To many growers a Chrysanthemum is a Chrysanthemum, neither more nor less; but to 
the cognoscenti it is either an Incurved, a Japanese, a Japanese Incurved, a Japanese Reflexed, a Reflexed, a Large Anemone, a Japanese Anemone, a Pompon, a Pompon Anemone, or a Single. A system of classification for a popular flower is apt to alarm and irritate the amateur at the outset, but the more he learns about the plant, the more clearly he sees that it is desirable. He goes farther if he becomes an exhibitor-he sees that it is absolutely necessary. Varieties of totally different types could not be shown against each other in one class with satisfactory results. Picture Japanese flowers as large as footballs competing with Singles of the size of border Pyrethrums!

While describing the different sections, I may indicate a good type of flower for the guidance of would-be exhibitors.

An Incurved Chrysanthemum has quilled florets turned in towards the centre. A good flower is globular, not flat, with a smooth, even outline; the florets are broad, gracefully curved, and fill up the centre so thoroughly that no hollow is discernible. A flat flower, with thin, pointed florets, and showing an "eye" or hollow centre, is defective.

$A$ Japanese Chrysanthemum may have flat, quilled, fluted, or thread-like florets. The class is a large and varied one, and consequently it is difficult to describe it in a few words. In most varieties the florets droop, but in some they are erect, while others, again, have erect central and drooping outer florets. A good show Japanese Chrysanthemum is from six to ten inches across, according to the variety, and the same in depth, measuring from the crown to the tip of the drooping florets. The colours are fresh and clear. A lop-sided, thin, dull flower is defective. 
The Japanese Incurved Chrysanthemum has broad florets, but they are arched, so as to give the flower an incurved, globular form. Many societies do not make this a separate class, and when this is the case, exhibitors may exhibit them with ordinary Japanese.

The Japanese Reflexed Chrysanthemum has broad, flat florets, which are reflexed instead of being incurved or merely drooping. It is not kept separate from the ordinary Japanese by some societies.

The Reflexed Chrysanthemum is much smaller than the Japanese, and has broad, reflexed florets. A good flower is circular, with broad, overlapping florets.

The Large Anemone Chrysanthemum has two sets of florets of different shapes, the one being quilled, and forming a raised disc or cushion in the centre; the other flat, nearly or quite horizontal, and forming a ring round the disc; the latter are called the ray florets. A good flower has a smooth, even disc, and broad ray florets evenly disposed.

The Japanese Anemone Chrysanthemum has the central disc of the large Anemone, but the ray florets vary in shape and arrangement, being twisted, curled, or drooping.

The Pompon Chrysanthemum is a small-flowered type, with globular double blooms, the florets of which may be flat, fluted, or quilled, in different varieties, but not differing in the same flower. The blooms do not exceed two inches across.

The Pompon Anemone Chrysanthemum has a raised disc of quilled florets like the Large Anemone, and a ring of flat ray florets, but the flowers are a great deal smaller than those of the Large Anemone.

The Single Chrysanthemum has a flat disc, and not more than two rows of ray florets. 
The foregoing ten sections contain types varied enough to please the greatest enthusiasts in Chrysanthemums. The Japanese is far the most important for indoor culture. The Incurved, though still prized for exhibitions, tends rather to recede than advance. Of the remainder, the Single and Pompon types are perhaps the most popular at the present day. The latter is even more useful than the Japanese for garden culture, owing to the dwarfer growth and neater habit. I may sum up by saying that the average amateur could get along very well with no other section than the Pompon for his garden.

Varieties.-In view of the fact that the Chrysanthemum is still under development, varieties are superseded somewhat frequently, and selections tend to become out of date within a few years of being made. The following sorts (page 94) have, however, sufficient merit to justify the belief that they will hold their places for a considerable time.

The object of giving two selections of Japanese is to emphasise the fact that exhibition varieties are not necessarily, or even probably, good garden and greenhouse sorts. The amateur grower who goes to a show, and sees huge flowers of beautiful shape and colour, is apt to conclude that the condition in which he sees them is their normal one, and that it would be repeated if they were grown in his own little conservatory or back garden. The truth is that the condition is entirely abnormal, and is only brought about through treatment of a highly skilled and specialised character. Most of the show sorts do not shine under a simple system of culture: the habit is not good, and the flowering is sparse. There are, however, varieties which grow naturallyor with very little training-into a suitable shape for 
Large Japanese for Show.

\begin{tabular}{|c|c|c|c|c|c|}
\hline \multicolumn{5}{|c|}{ Name of Variety. } & Colour. \\
\hline Bessie Godfrey & - & $\bullet^{\circ}$ & & & Yellow. \\
\hline Brilliant $\quad$. & - & . & • & & Amaranth. \\
\hline Florence Penford & - & • & - & & Lemon, chrome reverse. \\
\hline F. W. Lever . • & - & & & & Cream. \\
\hline F. W. Vallis. & - & & & & Crimson. \\
\hline Henry Perkins & - & & & & Yellow, flaked chestnut. \\
\hline J. H. Silsbury & - & & & & Crimson, yellow reverse. \\
\hline Lady Conyers & - & & & & Pink, silvery reverse. \\
\hline Lady Hopetoun . & - & & & & Silver. \\
\hline Leigh Park Wonder & - & & & & Dark crimson. \\
\hline Madame R. Cadbury & & & & & Ivory. \\
\hline Madame Paolo Radael & & & & & Blush or ivory. \\
\hline Madame G. Rivol & - & & & & Yellow, shaded rose. \\
\hline Magnificent . . & . & & & & Crimson. \\
\hline Marquise V. Venosta & . & & & & White. \\
\hline Melchett Beauty. & . & & & & Yellow, flaked rose. \\
\hline Miss Elsie Fulton & & & & & White. \\
\hline Mr. F. S. Vallis. & & & & & Yellow. \\
\hline Mrs. Barkley & & & & & Rosy mauve. \\
\hline Mrs. A. H. Lee & & & & & Crimson. \\
\hline Mrs. A. T. Miller & • & & & & White. \\
\hline Mrs. G. Mileham. & - & & & & Rose, silvery reverse. \\
\hline Norman Davis . & - & & & & Brown, yellow veins. \\
\hline President Viger & & • & • & - & Lilac. \\
\hline
\end{tabular}

Smaller Free-Flowering Iapanese.

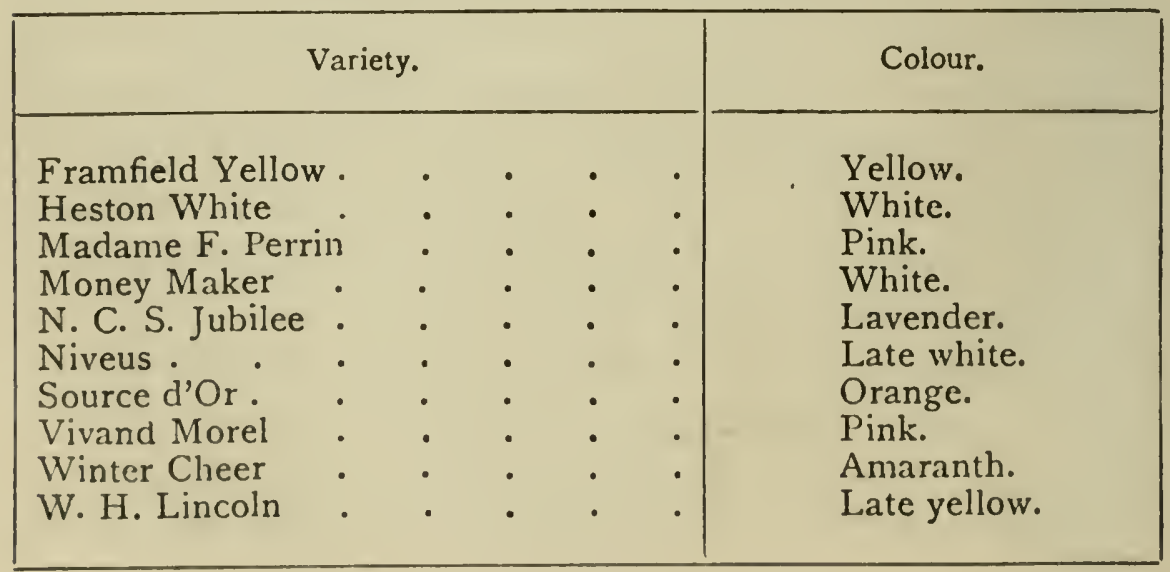




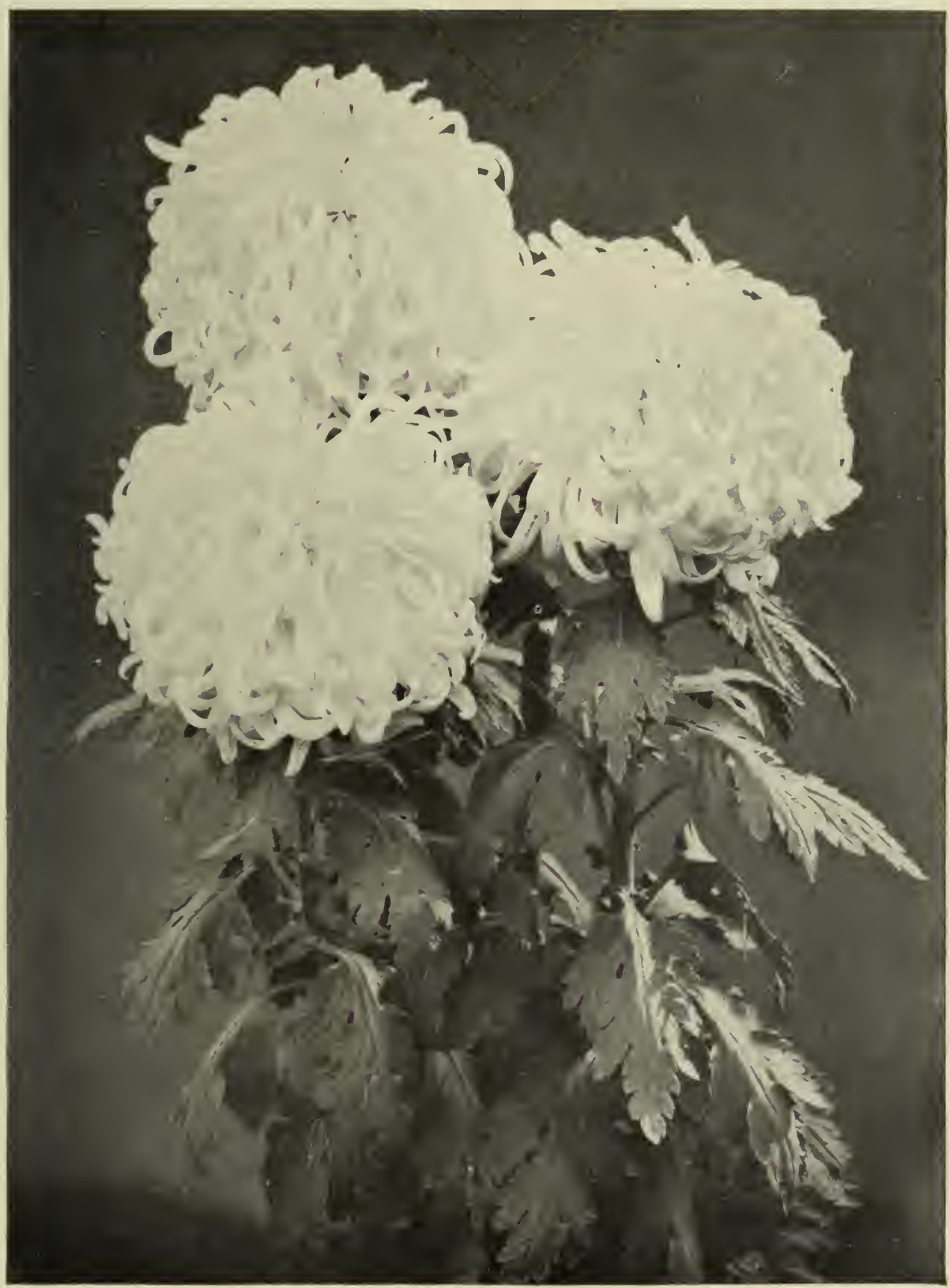

P'RIZE JAPANese ChRYSanthemeMs. 

small houses and for garden use. The flowers are not nearly so large under any system of culture as those of the show sorts, yet they are beautiful.

By making a prudent selection of varieties these free-flowering Chrysanthemums will give blossoms for many weeks, because some are naturally later bloomers than others. This is a great advantage, and the point has been borne in mind in making the selection. Framfield Yellow and Heston White will bloom in the ordinary way much earlier than W. H. Lincoln and Niveus, which are of similar colour. The two first are of particularly good habit, and produce their flowers in abundance. They are beautiful sorts for growing in a small greenhouse or conservatory, for standing in porches, and for cut bloom.

\section{Large Incurved for Show.}

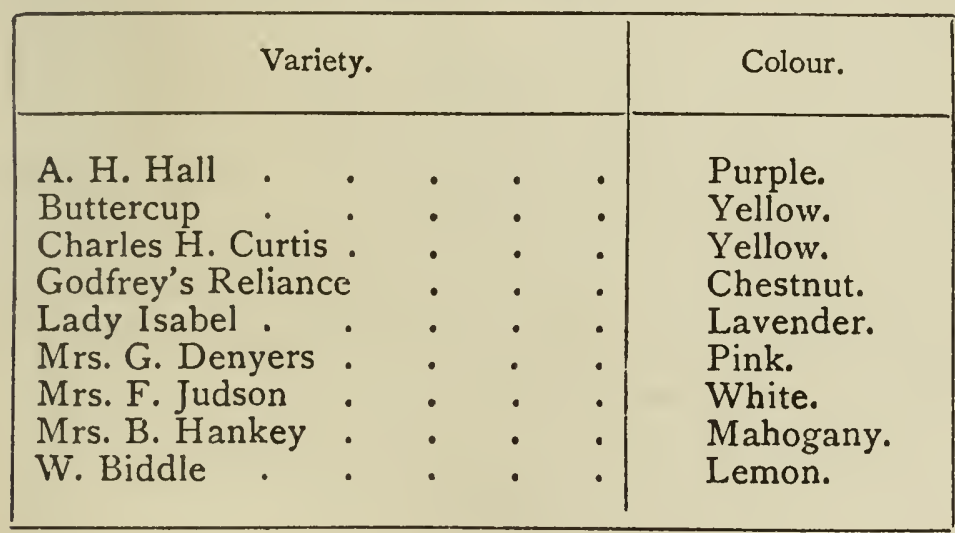

I do not recommend this class for amateurs who want a profusion of bloom in the garden, or in a small house, because the selected Japanese already named will serve the purpose much better. The Incurved varieties have not the freedom and grace of the Japanese, they do not bloom so abundantly, and the habit of growth is less compact. The Incurved are really only quite at 
home on the show-board, where well-finished flowers have the attraction which perfect form, smoothness, and richness of colour can impart to a flower. Experts gloat over them as highly finished examples of horticultural skill; and to experts they may be left.

\section{Reflexed.}

This class gives effective pot plants. The most popular variety is Dr. Sharpe, magenta. King of Crimsons is also grown a good deal. One of the Reflexed varieties, Progne, has agreeably scented flowers.

\section{Large Anemone.}

Descartes, crimson; Gluck, yellow; and Lady Margaret, white, are three of the most popular varieties of this not very important class.

\section{Pompon.}

Several of this class are included in the selection of garden varieties below. Of those grown in pots for greenhouse or show, Bob, brownish-red; Mdlle. Marthe, white; Mdlle. Elise Dordan, blush ; and Wm. Westlake, yellow, are the most popular.

\section{Single.}

This class tends to grow in favour now that varieties of good habit, free bloom, and beautiful colours, some flowering early and some late, have been raised. They are charming for pots, and the early varieties are suitable for the garden. The later sorts may be tried out of doors if desired, but there is always the risk of early frost injuring the flowers. 


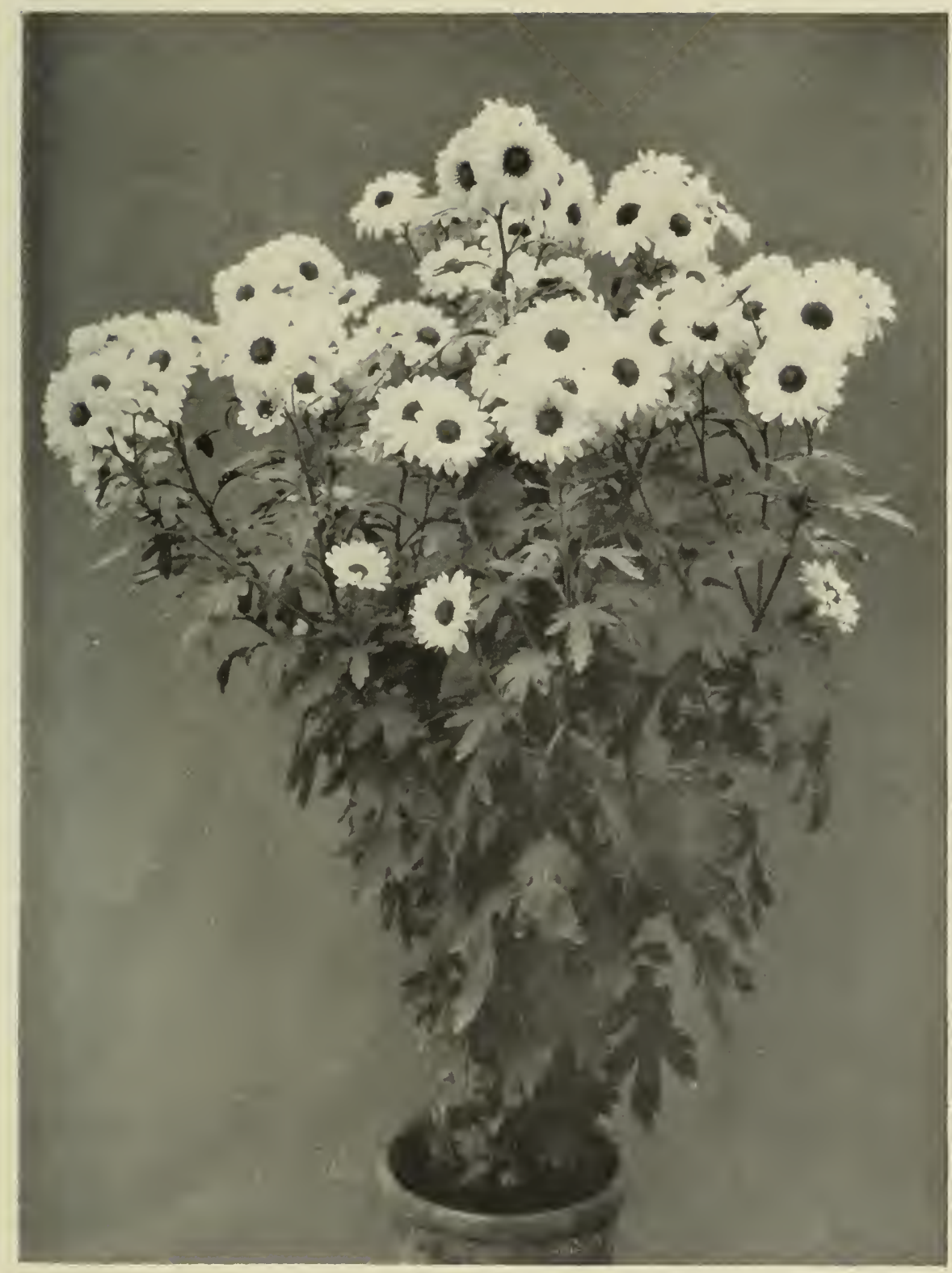

Single Chrysanthemum A. Ferguson. 



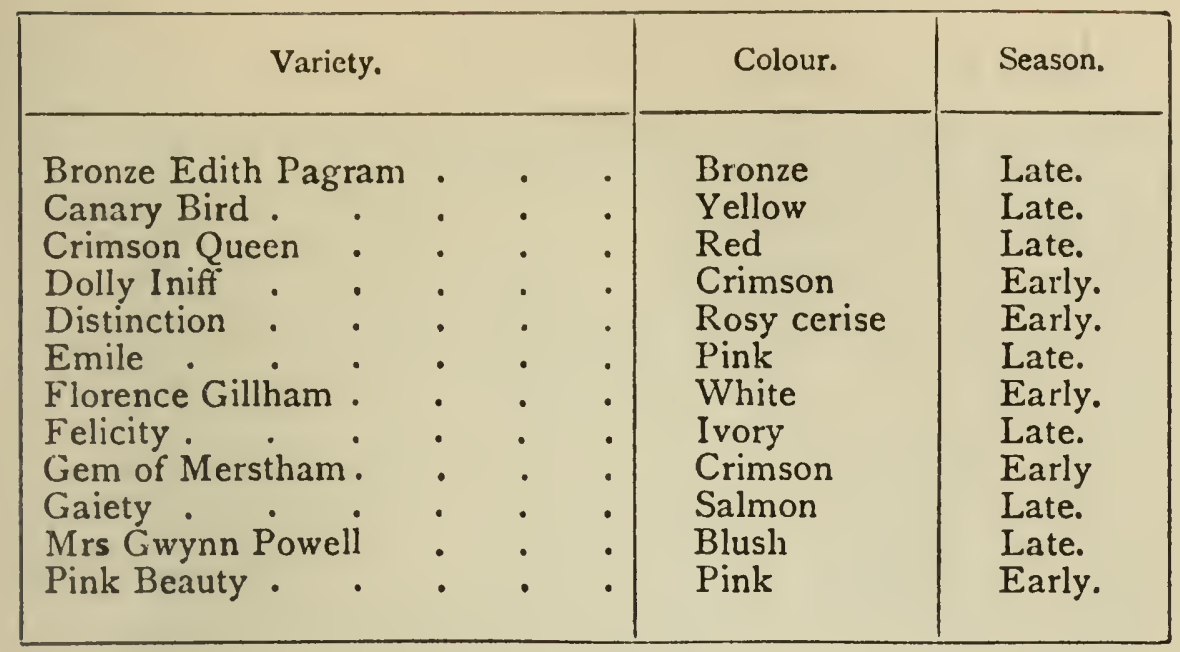

\section{Double Garden Varieties.}

In August, September, and October the flowergarden may be gay with beautiful Chrysanthemums, which will give brightness to the beds and borders when most other flowers are fading. Those who are planting borders have one great point to bear in mindthat the material which they employ must be capable of giving successional bloom. In many cases the gardener chooses a certain number of things that he particularly likes, and plants them, overlooking the fact that they are all summer bloomers, and that both spring and autumn are left unprovided for. The proper course when planting a large bed or a border is to begin by choosing a few particularly good things for the various seasonsDaffodils, Tulips, and Pyrethrums for spring; Irises, Lupins, Rockets, Pæonies, Delphiniums, Carnations, and Columbines for early summer; Pentstemons, Phloxes, Snapdragons, Ox-eye Daisies, and Chrysanthemums for late summer and autumn. This insures bloom from March to November. There is no need, of course, for the gardener to restrict himself to these 
kinds; he may introduce such others as he likes; but at the same time he may rest assured that if he made good selections of the kinds named, and grew them well (and both good selections and good culture are described in the present work), he would have a beautiful and interesting garden, whatever else he left out.

Chrysanthemums are not the least important feature of the late-flowering section. Beginning in August, they go on to November. Given a mild autumn, there is bloom when schoolboys are celebrating Guy Fawkes' Day, and crowds are cheering the newly elected Lord Mayor through the streets of London.

In Town Gardens.-They are nearly as happy in town gardens as the crowd itself. Who has not seen Chrysanthemums on which a rain of smuts from an adjoining factory or railway is falling most of the year blooming cheerfully? Fumes which shrivel up Roses like a blast of flame, and make Sweet Peas uncomfortable, have very little effect on Chrysanthemums.

They will thrive, too, in most kinds of soil; but no one should take advantage of this and leave them to make the best of poor, hot, shallow ground, especially if the site is one that is much swept by strong, cold winds late in spring. The grower should help his plants with deep spade work and liberal manuring.

When the amateur reflects that, in addition to making charming garden pictures, by choosing good Chrysanthemums and growing them. well, he can also provide his wife with abundance of light and pretty sprays for decorating the house, his arm will be strengthened.

If his borders are so small that he can hardly find room for all the plants that he wants to grow in it, he can perhaps grow his collection of Chrysanthemums in 


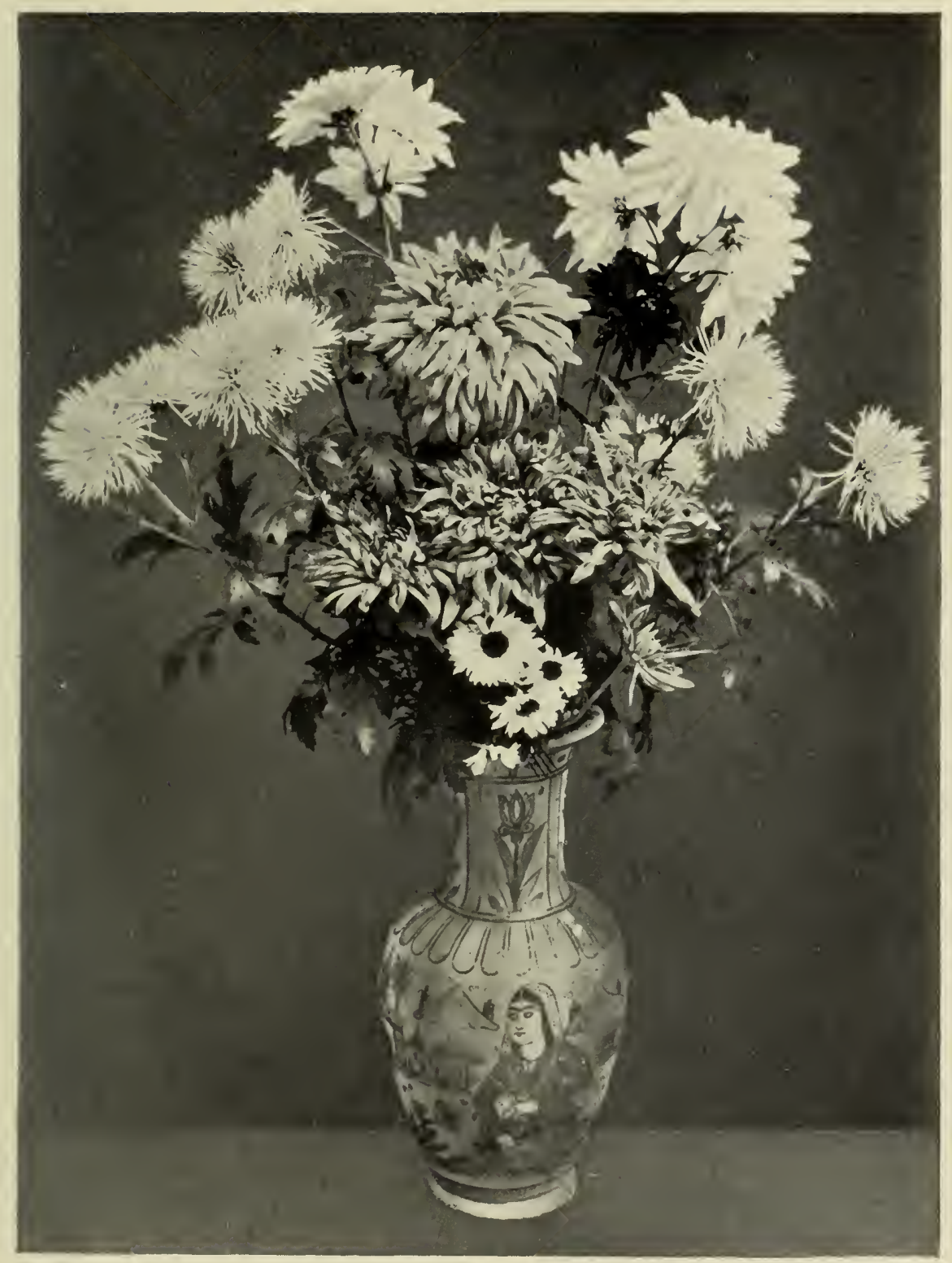

Decokative Chrysanthemuns. 

a spare bed somewhere, and, cutting back the early blooming plants when their beauty is past, plant the Chrysanthemums near the clumps. The Chrysanthemums will "shift" quite safely in showery weather in August and September.

Let us now make a selection of double garden Chrysanthemums, with their colours and usual month of flowering :-

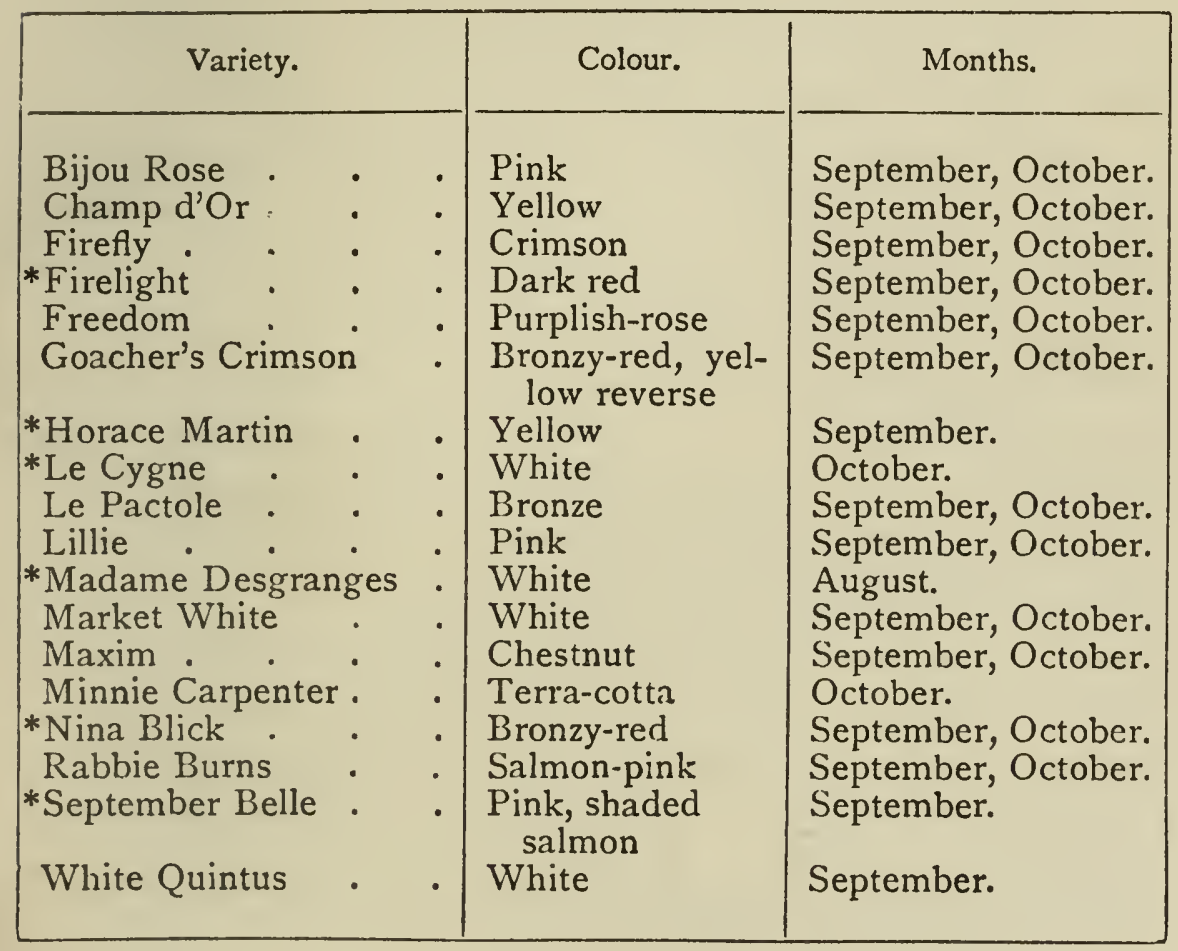

The six marked with an asterisk would form a good half-dozen, giving, as they do, different colours and seasons of blooming.

Truly, when one thinks of the beauty of Chrysanthemums, of their tough constitution, and of their obliging disposition, one's heart warms to them. They have nothing in common with plants which demand that 


\section{IOO POPULAR GARDEN FLOWERS}

everything shall be just right before they will consent to grow and bloom. They do not pule and whine because their bread is not buttered on both sides. The wisest of plants, they take the good things of life with wholehearted enjoyment when they are available, and do without them when they are not. There is one sin that they never commit-they do not cold-shoulder any earnest grower. They befriend him constantly, faithful to the end. Whether he be townsman, suburbanist, or countryman, he can rely on their fidelity if he give the smallest proof that he deserves it.

Large Daisies.-The florists' Chrysanthemum, in the various forms which we have just been considering, dominates the genus so strongly that other species and varieties hold but a small place. Yet the perennial $\mathrm{Ox}$ eye, Shasta, and Pyrenean Daisies are Chrysanthemums, and very useful ones too, as they grow vigorously and bloom for a long period in summer and autumn. They are hardy perennials, will grow in almost any soil, and are easily propagated by division. The Ox-eye Daisy is Chrysanthemum Leucanthemum, which blooms in early summer; and the Pyrenean Daisy is Chrysanthemum maximum. There are now several fine varieties of the latter available, such as King Edward, the Munstead variety, and Wm. Robinson. Another good hardy perennial Chrysanthemum is the tali, white-flowered, late-flowering plant commonly grown under the name of Pyrethrum uliginosum.

Golden Feather.-The reader may be surprised to hear that yet another popular plant in the yellow

( Feverfew, or Golden Feather, is a Chrysanthemum (Parthenium) according to modern botanical classification, although it used to be called a Pyrethrum. This plant was in great demand in bygone days, when carpet 


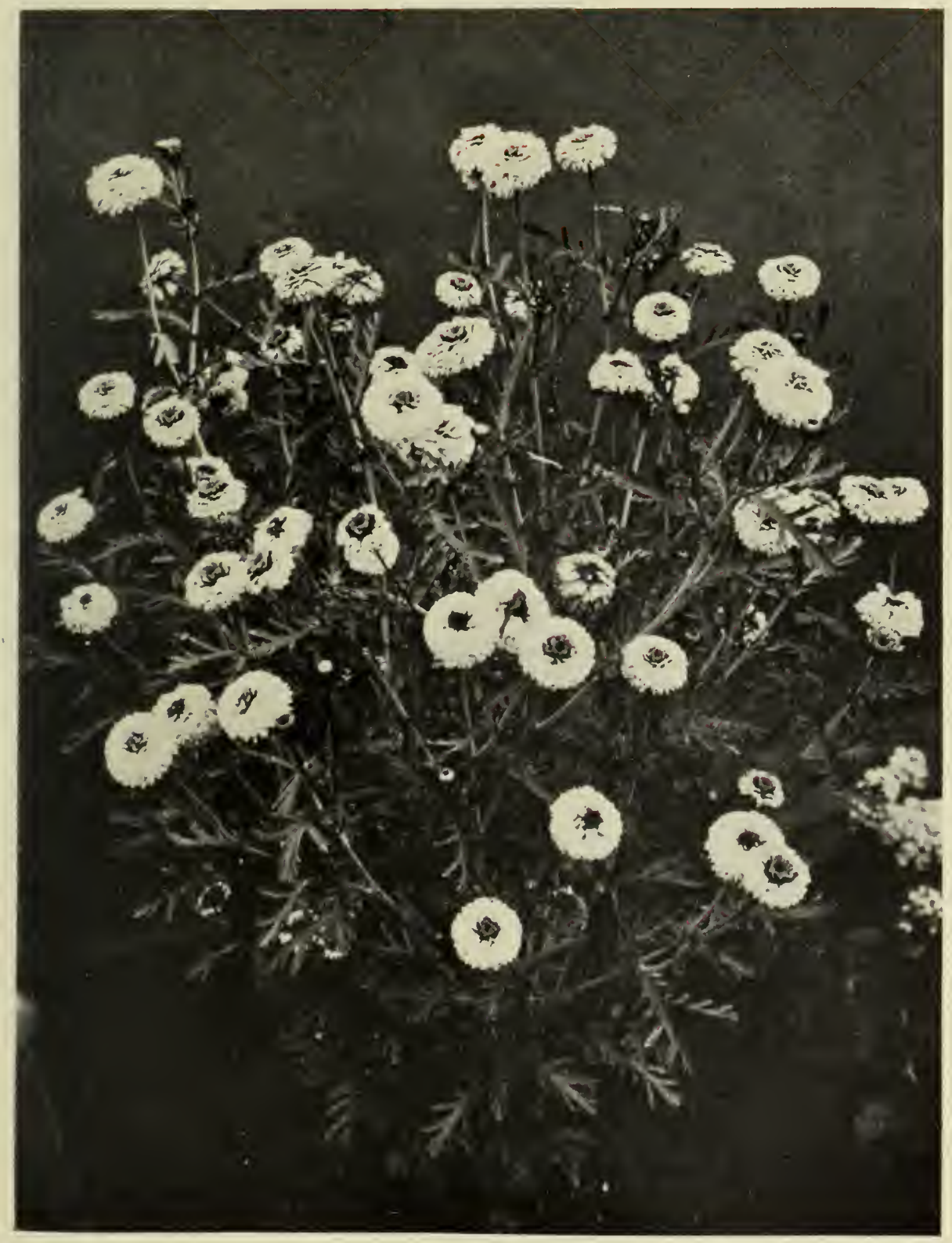

Double white, anNual, Chrysanthenum. 

bedding was in vogue, but it is not much used now. It was raised from seed sown in heat in spring, and when planted out was kept low and compact by being cropped with finger and thumb every few days.

The Marguerites of our flower-gardens and windowboxes are Chrysanthemums, and their free blooming, duration, and neat habit render them extremely serviceable. They are propagated by cuttings in spring or autumn, and thrive in ordinary potting soil.

The hardy annual Chrysanthemums, double and single, are desirable, as they flower in a few weeks from seed sown outdoors in spring, and are suitable for cutting. They have come from the two old species carinatum (tricolor) and coronarium, the former of which had purple and white flowers, the latter yellow. Burridgeanum, Lord Beaconsfield, Morning Star, and W. E. Gladstone are popular varieties of carinatum. Segetum, the Corn Marigold, is also a hardy annual, and improved forms are grown in gardens, notably grandiflorum.

The genus Chrysanthemum is not a large one, but when we survey the florists' varieties, the summer annuals and perennials, and the Marguerites, we recognise that it is in every way a remarkable one. It would go ill with flower-lovers now if they had to do without it.

Having considered the scope of the genus, and picked out some of the best of the good things which it gives us, we nay deal with the culture of the florists' section.

Hardiness.-From time to time questions are asked, and discussions arise, as to the hardiness of Chrysanthemums. This is hardly worthy of argument except on an academic basis, because it is a simple matter to procure a few fresh cuttings, rooted or unrooted, every spring; and when new plaits can be bought for a penny or twopence each, it is hardly worth while to keep old 


\section{O2 POPULAR GARDEN FLOWERS}

ones. Personally, I have tried leaving Chrysanthemums in the open ground throughout the winter as the cottager does; some have died, some have lived. But the type of plant that one gets by treating the Chrysanthemum as

I a hardy herbaceous perennial is not pleasing to me, and I will not assume that it is any more gratifying to my readers. If the plants are cut back in autumn, the rootstock generally survives the winter and throws up fresh growth in spring if the soil is light and well drained. In damp soil the rootstocks often die in winter.

Propagation.-A person who particularly wanted to propagate from his own stock, and had stiff soil, could, if he liked, lift a few roots in autumn, pack them in soil in boxes, and keep them in a sheltered place till spring. They would probably live, and if put in a frame or in a warm place in spring would throw up shoots, which could be taken off and struck as cuttings in a greenhouse or frame. New plants could be raised thus, and they would probably give better results than old ones which had passed the winter out of doors.

Many florists make a speciality of collections of rooted cuttings in spring, and sell excellent varieties at prices averaging twopence a plant or thereabouts. By buying fifty or upwards the cuttings can be procured cheaper still.

If the cuttings are not rooted when they arrive they should be put into small pots or shallow boxes filled with a compost containing a considerable proportion of leaf mould and sand. It is wise to cover them with a bellglass or small handlight if convenient, but as a rule they will root without provided they are not exposed to hot sun and dry air, but are sprinkled if they flag. The soil should be kept just moist, but not saturated. Homemade cuttings may be treated in the same way. 
When growth starts it may be assumed the roots have formed and a little more water may be given, but still care should be taken to avoid keeping the soil sodden. Air may be admitted to the plants, and they should be put close to the glass. The best place for them is an unheated frame. When they have filled the pots with roots they may be planted out.

Soil.-The ordinary soil of most gardens suits Chrysanthemums very well, as they are not fastidious plants; but that is no reason why special provision should not be made to get them at their best. If the soil is very stiff it may be improved by the addition of leaf mould, road sweepings, or lime rubbish. These materials will lighten and enrich the ground simultaneously. In adding them, take the opportunity of digging deeply, breaking up the subsoil in the process. This will lead to increased vigour of plant and finer quality of bloom. If the soil is light, a liberal dressing of decayed manure will be the best addition to it.

There is not a great difference in the height of the varieties of early garden Chrysanthemums. They grow from two to three feet high in most cases, and the habit is compact; consequently they are plants for the front and middle of borders rather than the back. Groups of three can be set here and there in large borders, so placing them in association with earlier-blooming plants that they carry on the display of flowers, not putting them with late Phloxes, Michaelmas Daisies, and Sunflowers, and so having a part of the border full and a part bare. In small borders the plants can be put singly.

They will not call for a great deal of attention through the summer. If the soil is hoed regularly, and a pail of water is given occasionally in dry weather, they will 


\section{IO4 POPULAR GARDEN FLOWERS}

grow steadily. Should any plants show a tendency to straggle, the tips of the shoots may be pinched off, in order to make them break from below and form a bush ; otherwise no stopping will be required. It is hardly likely that staking will be needed, but it should be done if the plants are badly blown about. If green-fly should attack the plants, they might be dusted with tobacco powder and syringed vigorously an hour afterwards. The course of treatment indicated ought to lead to great success with garden Chrysanthemums.

As the present work is devoted to garden flowers, the cultivation of the Chrysanthemum as a pot plant for conservatories and exhibition hardly comes within its scope; however, the principal items in pot culture may be included in the following calendar :-

The Chrysanthemum-Grower's Year-A Summary.

January.-Outdoor plants will be quite dormant. If there is much rain, mortar rubbish or dry litter may be put round the clumps. Keep an eye on any roots which are wintered in boxes, and moisten the soil only to prevent its getting dust dry; do not let it get sodden. Strike cuttings of pot plants, choosing the suckers which spring up from the root when they are about three inches long. They root best in sandy soil under a handlight. Put young plants from early cuttings on a shelf near the glass to keep them sturdy. They ought to be grown in a cool but frost-proof house to prevent their growing fast. Rapid growth is not desirable at this season.

February.-If boxed stools of outdoor plants have begun to throw up shoots owing to mild weather, put them in a frame and give them a little water. Take the 


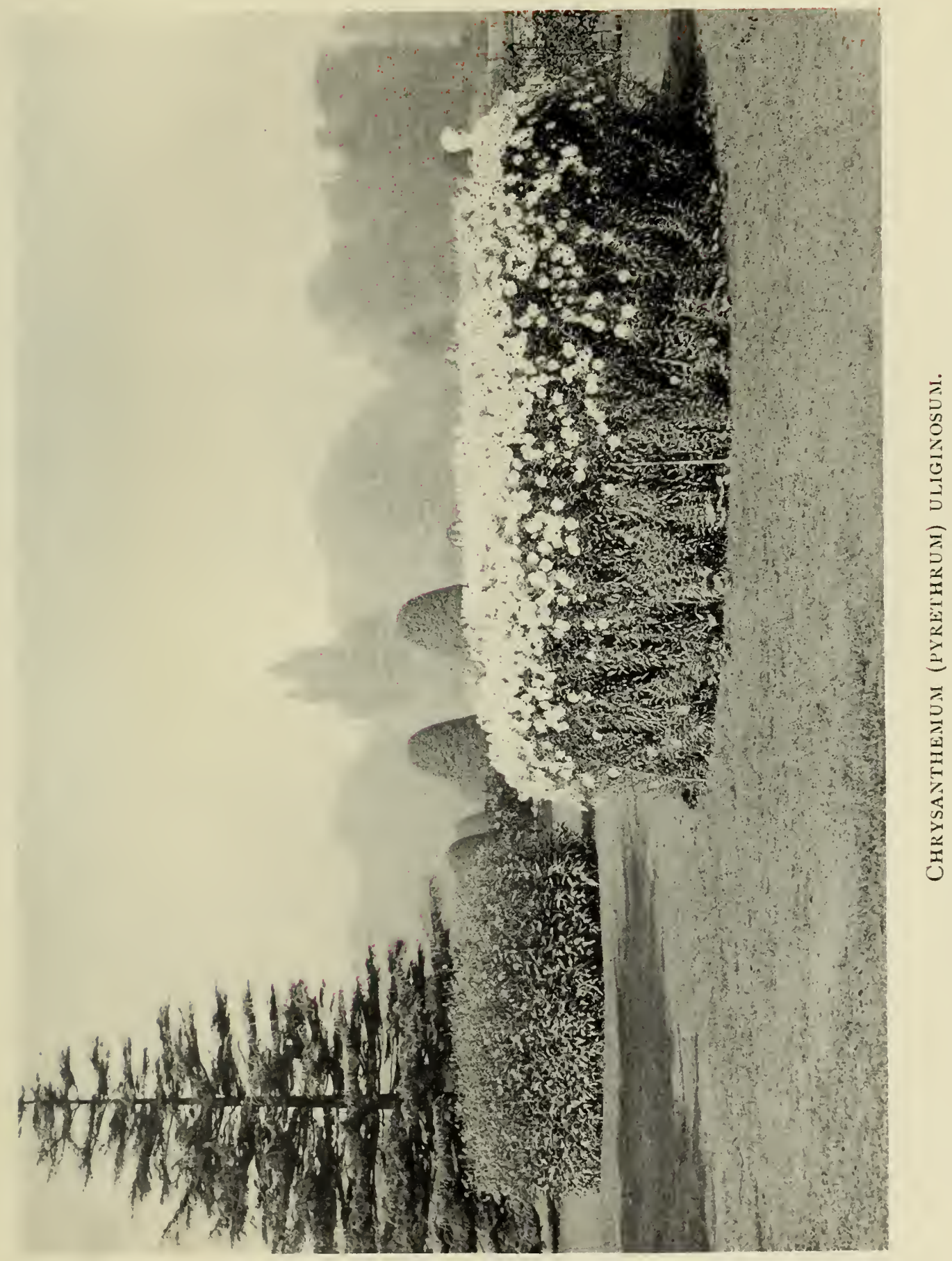



shoots off when three inches long, and put them in small pots containing sandy soil. Early struck plants for pot culture should be kept as cool as possible, and not be repotted until the roots show freely at the drainage hole. Directly they are repotted they call for nearly double the space which they required before, and that is a serious matter for amateurs with very little glass. The plants may be shifted from a three-inch to a five-inch pot. Use more loam and less leaf mould than for cuttings. Give plenty of air to young rooted plants in fine weather, and water only to prevent flagging.

March.-Cuttings of outdoor plants may be struck in any desired quantity this month. If cuttings are being bought, they may be procured about the middle of the month. Young pot plants which have not been repotted are certain to need a shift. They may go on to a bed of ashes in a frame at the end of the month, but a mat should be kept handy to throw over the light in case of severe frost. Ventilate freely in fine weather. More water will be needed as growth becomes more active.

April.-Complete the propagation of garden varieties. Prepare the beds and borders, and plant strong rooted plants from earlier cuttings out. If they have been grown in an unheated frame they will be hardy enough to withstand any frost which is likely to come now. If the position is exposed to cold winds, some temporary shelter can be devised in stormy spells. Pot plants in frames will be growing fast, and must have water when the soil is dry. Take the lights right off the frames in fine weather. Late-struck plants may be put into five-inch pots. The tips may be pinched off if bushy plants are wanted.

May.-Complete the planting out. As the weather may be hot and dry, take care to give a good soaking of 


\section{I06 POPULAR GARDEN FLOWERS}

water if the plants flag. Pot plants will require regular daily attention. Many of them will have filled their fiveinch pots with roots, and directly the latter begin to creep out of the soil into the ashes on which the pots stand they should be shifted into seven-inch. As the available frame space may not suffice now, a sheltered place out of doors may be chosen, a coat of ashes spread on, and the plants stood out; but a light framework of laths capable of supporting a cloth or mat should be kept handy, so that a protector can be speedily put over them if hard weather should come on. Some of the varieties form a flower-bud this month, with three incipient shoots below it. The bud should be picked off, and the three shoots grown on and tied to stakes in due course. To get flowers of exhibition quality, it is important that the break of the shoots referred to should take place at the right time, and if it does not come naturally the tips should be pinched off. As the sorts vary a great deal, the beginner should send a list of those which he is growing to the trade expert from whom he buys his plants, or to a gardening paper, and ask for the varieties to be marked according as they break naturally or have to be stopped. Stem cuttings may be struck for yielding small plants in pots.

June.-Outdoor plants ought to be in full growth now. Hoe the soil once a week, and give a soaking of water occasionally in dry weather. Pot plants grown for prize blooms ought to have their final shift, and if they are in seven-inch pots, they may go into nine-inch or ten-inch; if in six-inch they may go into eight-inch or nine-inch. The pots should be drained with crocks surfaced with moss or leaf mould. The compost may consist of three parts fibrous loam, one part of leaf mould, one part of decayed manure, with half a peck of 
sand to each bushel. The whole of the components should be well mixed and used in a moist state. Ram the soil in quite hard, and leave two inches at the top for water. Only give just enough water to prevent the plants from flagging until they have started growing again, then water regularly. Stand the pots on a bed of ashes in a sunny but sheltered place in the garden. The labour of watering, which is considerable, may be reduced by partially or wholly embedding the pots in ashes; but still, water is sure to be required at least once a day in dry weather. Remove side-shoots from the three stems.

July.-Many of the garden varieties will form flowerbuds this month, and a few of the earliest, such as Madame Desgranges, may come into bloom. Pot plants will need daily attention. They must be watered liberally, and should never be allowed to get so dry that the soil cracks away from the side of the pot. Should such a thing happen, prompt and drastic measures must be taken. A tub of water must be procured, and the pot sunk nearly to the brim in it. The water will rise through the soil, driving air before it, and causing a rush of bubbles to the surface. Only when these have ceased should the pot be raised. It may rest on the edge of the tub for a few seconds to permit the surplus water to escape, and then be replaced in its permanent position. If flower-buds should form at the tip of the three shoots, with incipient shoots just below them, they (the flower-buds) should be removed, together with two of the three incipient shoots on each stem, the third being left to grow on and form another bud in August. An exception to this rule should be made in case of any variety which an expert adviser says gives its best blooms from "crown" buds that form at the end of July. The 
number of such cases will not be great, as most do best from later buds. Look out for green- and black-fly. If either should attack the plants, dust with tobacco powder and syringe vigorously an hour or two later. Should it be observed that any leaves are getting covered with white streaks, squeeze them to kill the maggots within. If small warts should appear on the leaves, touch them very carefully with methylated spirit, and then spray the plants with water in which half an ounce of sulphide of potassium per gallon has been dissolved. If the warts are allowed to develop, the plants may be destroyed by the fungoid disease called "rust."

August.-If any garden plants are being grown as a reserve in a spare bed they should be planted out after the first showery spell. Should the weather remain hot and dry, they may still be planted, but it would be wise to chop round the plants with a spade the day before they were shifted, to check root action, and then give a soaking with water. Moreover, they should be moved towards evening, and afterwards well syringed. Plants already established in beds and borders will be coming into bloom. A soaking of liquid manure will do them good. The majority of the varieties grown in pots for large blooms will show their crown buds the second or third week in August. The new growth shoots just below them should be pinched out at once, leaving the flower-bud standing alone. Continue the watering and treatment for insects advised under July. Bush plants in pots may be showing buds in clusters. Do not thin if plenty of small flowers are wanted, but disbud if a few larger flowers are required.

September.-Garden plants will be in full beauty this month. The flowers may be gathered freely, as with moisture and liquid manure fresh growth and flowers 
will be made. Pot plants ought to be put under glass towards the end of the month-earlier if the buds are showing colour. The heavy night dews of September are enjoyed by the plants, but they are not good for the flowers. Should mildew appear, dust with flowers of sulphur. Keep the plants on the dry side for a few days after the housing, but as soon as they freshen up resume full watering. The plants should be arranged in a group according to height and colour. Ventilate in fine weather.

October.-Outdoor plants ought to be yielding flowers still, but the earliest varieties will be over, and may be cut down when the growth begins to wither. Flowers will be developing rapidly under glass. Less water will be needed, but the soil should not be allowed to get quite dry. The hot-water apparatus ought to be started in damp, foggy weather to help dry the air, but the house must not be hot; $55^{\circ}$ should be the maximum temperature. Ventilate every fine day. As most of the shows are held towards the end of October and in the early part of November, the exhibitor should procure the necessary appliances early in October. Large stands are required for Japanese blooms, owing to the great size of the flowers. 'They should be painted green. A showboard for twelve Japanese should be twenty-eight inches long (left to right), twenty-one inches from back to front, seven inches high at the back, and four at the front. The holes for the tubes should be seven inches apart. For six blooms the stands should be fourteen inches long, and the other dimensions the same. For twelve Incurved the size should be twenty-four inches by eighteen, back six inches high, and front three inches, holes six inches apart; for six Incurved, twelve by eighteen. If several stands are to be taken about, a large travelling case fitted 


\section{IO

with side strips should be ordered for them. Zinc cups and tubes are required to fit into the show stands. They consist, as a rule, of three parts: (I) a socket an inch wide, provided with a perforated flange to screw on to the board; (2) a cup four inches long, fitted with an external strip of brass which serves as a wedge, so that when the cup is put into the socket it can be raised or lowered, and fits firmly in any position; (3) a cup four and a half inches long, fitted with a brass strip and a top flange two and a half inches wide, which supports the bloom, and can be slid up and down in the cup just as the cup can in the socket. The object of the whole arrangement is to facilitate fixing the various flowers at the heights which show them to the greatest advantage. Only No. 2 has a bottom; it has to hold water. Steel tweezers in two or three sizes are required for dressing the blooms. Most large Chrysanthemum dealers supply stands, tubes, and tweezers; and if they do not, they are always able to tell an inquirer of some one who does.

November.-The last of the outdoor plants will now go out of bloom, and may be cut down. The roots of special varieties may be packed in boxes of soil, kept just moist, and wintered in a cool, dry, frost-proof place. Pot plants will be in full beauty. When they go out of bloom cut them right back and lift the pots to a position near the glass; the root suckers will then become sturdy, and make good cuttings. Watering should be continued. Treat the cuttings as previously advised.

December. - The remarks made under November apply to the closing month of the year. It is important to get good cuttings of pot plants and strike them early if prize flowers are wanted the following year. See remarks under January. 


\section{$\mathrm{XI}$}

\section{ON CLEMATISES}

DEAR old ramblers, these. We love them when we see them tumbling about the hedgerows almost as much as when they are covering our own summerhouses and pergolas.

It is curious to learn that the name comes from the word klema, a vine growth, in reference to their habit. The purists complain that the popular pronunciation of Clematis is wrong; but what is the popular pronunciation? As many people say Klem'-a-tis as Kleemay'-tis, but perhaps no more. The former is the better of the two, and I do not think that any flowerlover need be diffident about using it. The purists themselves oscillate between Klee'-ma-tis and Kleemat'-is, and we must leave them to enjoy playing pendulum. Klem'-a-tis is good enough for us, and Klem'-a-tis, therefore, it shall be.

Lovers of old English folk-names may say: "Why Clematis at all? Why not Traveller's Joy? Why not Virgin's Bower? They are charming names, and simple." True, but they belong to certain old species, and do not fit the new hybrids with their great brilliant flowers. You could not very well call Clematis Jackmanii blue Traveller's Joy or blue Virgin's Bower, though it may be assumed that travellers and virgins alike have fits of the blues. We may continue to call 
our old plants by the old names; but since the florists have given us such beautiful varieties we must, in ordinary courtesy, accept their names for these sorts.

The wild Clematis, known as Traveller's Joy, Virgin's Bower, and Old Man's Beard, is the botanist's species vitalba. The French have one beautiful name for it, les cheveux de Jésus, and also another that is not so pleasing. They sometimes call it l'herbe a gueux, or Beggar's Weed, because unscrupulous mendicants blister their legs with a plaster of the leaves in order to assist their appeals for alms; or rub the juice into sores on their hands and arms.

The reader may be surprised to hear of such uses of a plant that is not generally regarded as poisonous; but, in point of fact, the plant belongs to the Buttercup family (Ranunculacex), and all parts of it are poisonous. If fresh leaves were chewed, ulcers would form in the mouth; and if the juices were swallowed, they would probably produce severe dysentery.

The name Traveller's Joy appears to have been first given to Clematis Vitalba by Gerard, tor we read in his "Herball" : "It is commonly called Viorna quasi vias ornans, of decking and adorning ways and hedges where people travel, and thereupon I haue named it the Trauveiler's Ioie." The specific name vitalba is in allusion to the white fluffy masses of achenes (an achene is a dry single carpel containing a seed, and it does not open when ripe) which give the plant its distinctive beauty in late summer. It grows luxuriantly in the tall thorn and hazel hedgerows on the chalk lands in East Kent, and also on the great blackthorn hedges which skirt the road from Hythe to Romney Marsh, covering both with a fleecy white mantle in August and September. Large hedges, with their tangle of 
Traveller's Joy, Brier, and Wayfaring Tree, are open to the criticism that they indicate slothful farming, and be sure that students at agricultural colleges have various instructive data tending to the discredit of the spreading masses; but we cannot but rejoice in their free, untrammelled beauty. We remember, too, that it is to the English hedgerow that we owe our abundance of songbirds. Without the shelter and protection of the hedges, feathered life must necessarily diminish.

Pretty Species.-The Traveller's Joy is not much used as a garden plant nowadays, for there are many kinds far more suitable. The old species flammula, which came from France as far back as 1596, is one; the growth is much neater, and the flowers are fragrant. It is not entirely hardy, but in sheltered gardens it often lives for many years, gracing a gable or old roof with a foam of white blossom. But this good old plant has receded, in spite of its perfume, giving place to the earlier-blooming mountain Clematis (montana), which has forged ahead in popular esteem with such rapidity that it is now grown in hundreds of thousands of gardens. Its popularity is easily explained. In the first place, it blooms as early as May, and there are few wall, arch, or porch plants that flower so early. In the second place, it is a very rapid grower and profuse bloomer. In the third place, it will thrive in almost any soil or position, not objecting to stiff land, or an eastern aspect, or a town atmosphere. The flowers are white, and of about the size of a half-crown. They are scented, although not so strongly as those of flammula. The perfume of $C$. montana led to its being also called $C$. odorus.

The mountain Clematis is a native of the Himalaya, 


\section{4 POPULAR GARDEN FLOWERS}

whence it was introduced in I83I. It may be planted to cover a house wall or a rustic summer-house. Have you an unsightly object in or near the garden? Fix up a framework of rustic timber or wooden trellis-work, plant the mountain Clematis, and it is hidden speedily.

In most cases it goes away freely when planted; but I have known it "hang fire" when planted on chalky ground in a position where it catches drip from a roof. The soil gets splashed away, and nothing but chalk is left. In such circumstances some of the chalk should be dug out to form a pocket, and with this filled with fibrous loam the plant has a much better chance of getting established. Another source of failure is to put in a plant which has stood a good while in a nursery pot-bound, and has a long, tough, vine-like stem, and leave it unpruned. Such a plant ought to be cut back. It is better to begin with a young one, and prune it back to a good bud a few inches from the ground. There will be a strong growth from the bud, and in two or three years a large area will be covered with flowering shoots. It is not wise to prune established plants severely. The plant bears the finest flowers on the wood made the previous year, consequently the bloom would be cut away if severe spring pruning were practised. The wood which has bloomed may be pruned out in autumn if there are fresh shoots to take its place.

The mountain Clematis may be propagated by cuttings.

There are not many hardy species grown in gardens now, as the hybrids and varieties are so much finer. Cirrhosa, a spring bloomer, with green and white flowers; Erecta, a very old white species, blooming in July; Fortunei, white, brought from Japan in 1863 ; 


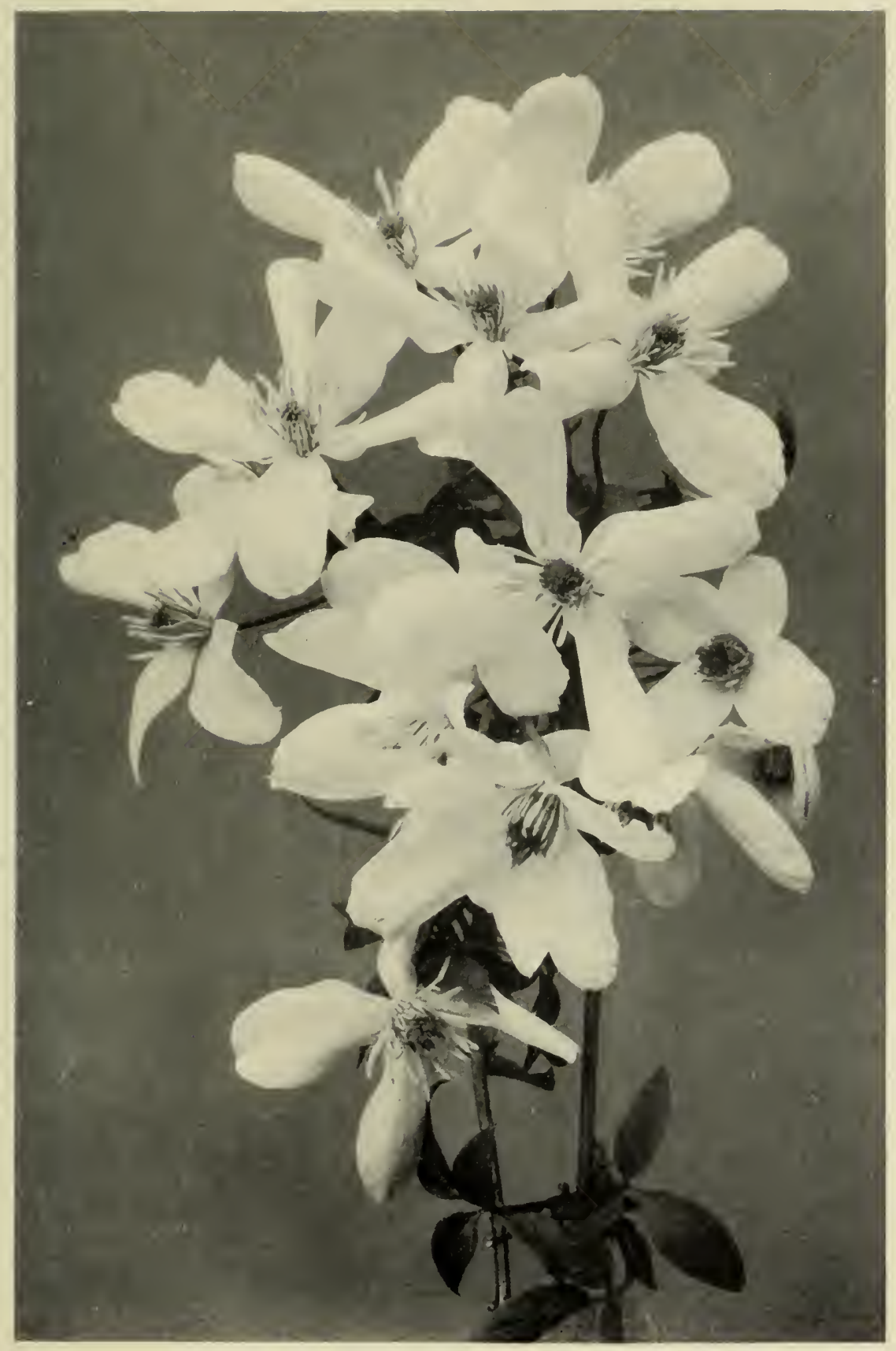

CIEMATS MONTANA. 

Florida, a white species introduced from Japan, blossoming in June; Lanuginosa, a blue June bloomer from China; Patens, white, a Japanese plant blooming in June; and Viticella, purple, an August bloomer, are well-known hardy species; but they are better represented by their varieties than in themselves. The last four have all given their names to sections.

Jackmanii has also done so, but it is a hybrid. This remarkable Clematis is certainly the most popular of all the large flowered, rich-coloured class, and is familiar to almost every lover of climbing plants. It is beautiful on porches, roofs, trellis-work, pillars, and verandahs, bearing its large violet-blue flowers in great abundance in July and August. It was raised in 1858 by a Woking florist, George Jackman, who obtained it by crossing the old blue Japanese species lanuginosa with a hybrid called Hendersoni. The latter was raised in 1835 by crossing the species integrifolia and viticella, and bore purplish-blue flowers. A hybrid called rubro-violacea, with purplish-maroon flowers, came from the same cross; but although it is a good Clematis, it was overshadowed from the first by Jackmanii.

Clematis Jackmanii is one of the most profuse-blooming plants ever grown in a garden. It becomes a mass of bloom in late summer, quite hiding whatever object it may be grown upon. Such a plant, if also hardy and a fast grower-and Clematis Jackmanii is both-is bound to become a great favourite, because it meets the wants of innumerable gardeners. Suburban as well as country amateurs love Clematis Jackmanii, and town gardeners might succeed with it nearly as well as their rural brethren if they would provide better soil than they generally do, and use the knife with a little more courage. It is very rarely that the natural soil of a suburban 
gardener is really fertile, and in nine cases out of ten it is advisable to take out some of it, and make a hole big enough to hold a bushel of fibrous loam and leaf mould, which the local florist will provide for a shilling. The plant is worth that.

Pruning.-The use of the knife should begin directly the plant is put in, and that should be either in November or March. Many plant late in April or in May, on a hot site, with the result that the plant is scorched up before the roots have time to get to work and feed it. With autumn or early spring planting the plant has a chance to make new roots before the hot weather comes on, and as these fibres begin to send up food at once, the plant is strengthened and can endure the sun. But a gardener who has once summoned up enough courage to cut back a Clematis Jackmanii after planting it will always be ready to repeat the operation in future plantings.

If shortened to a bud near the ground all the energies of the plant are concentrated on that bud, and it pushes a fine, vigorous shoot, which is soon several feet long, and produces flowers the same year. The second year it will do better still, and in the third the plant will be at its best, covering an immense area, and producing hundreds of flowers.

It may sound strange to the non-professional reader, but Clematis Jackmanii produces the finest flowers when all the flowering shoots of the previous year are cut back in spring. The reason of this is that the plant blooms on new wood. We cannot lump all the Clematises together and say that they should be pruned in such-and-such a way. Jackmanii, we see, differs from montana; and others differ from both. The amateur may protest that his Clematis Jackmanii blooms without any pruning at all. So it does-kindly, generous-hearted 
plant that it is; but it often gets into a terrible tangle, and is not far short of being positively unsightly when the leaves have fallen. Moreover, as the soil becomes exhausted, the flowering falls off. The pruned, trained plant is never ugly, leaves or no leaves; and it produces the finest of flowers-large and full of glorious colour. About every third year, some of the old soil should be forked away from the roots and a fresh coat of loam, leaf mould, and manure put on. A few pailfuls of liquid manure will do good.

The white variety of Jackmanii is worth making a note of, but it is not so valuable as the blue. Some Clematis lovers like to mix the latter and fammula, for the sake of the perfume which the latter possesses. There was a movement to grow them as dwarf bedding plants trained over hoops a few years ago, but it has nearly died out. More convincing is the idea of growing them on groups of tall pillars in a large bed. The bigger the boles used the better. If they are moderatesized tree trunks twelve feet out of the ground, no matter, the Clematis will reach the top in one season if the soil is rich, and in the second will be sprawling over them, and dangling flower-laden shoots over the top as a kind of flag of victory.

Beautiful Varieties.-Some of the large varieties of the other sections may be used to support Jackmanii for this purpose. Their flowers are even larger than those of the famous blue, and they give variety of colour. For instance, there are The Queen, a beautiful lavender variety, and Lord Londesborough, mauve, both of the patens type. These bloom in early summer, and need no pruning except when they get very crowded. There are Beauty of Worcester, violet, and Venus Victrix, lavender, double, of the Lanuginosa section, which also 


\section{8 POPULAR GARDEN FLOWERS}

need no pruning beyond thinning. There is Lady Bovill, light blue, of the Viticella type, which does best when cut back hard every autumn. And there is Madame Edouard André, red, of the Jackmanii class, which, as already mentioned, should be pruned back to the old wood in spring.

We see that there is great variety of habit and colour in the Clematises, and although this may, at the outset, tend to cause the amateur a little perturbation, he soon gets over it, and finds a deeper interest in the flowers from the demands that they make on his knowledge and skill. 


\section{XII \\ ON COLUMBINES (AQUILEGIAS)}

As the sweetheart of Harlequin, Columbine was a prime favourite in the days when we were young enough to love the pantomime; and in the form of a distinct and graceful flower we give her a high place among our garden favourites.

Her charming name comes, of course, from the Latin columba, a dove, but we are not quite sure whether it is Lady Wilkinson or Dr. Prior who may be accepted as the true guide to the derivation. The former tells us that it arises from the fact that if we pull off a. petal with its attached sepals we see a semblance of the figure of a dove with expanded wings; the latter, that it is due to the nectaries resembling the heads of pigeons arranged in a ring round a dish. There is a third view-that the dove association arises merely from the colour, and its supporters quote Chaucer-

"Come forth now with thin eyghen Columbine."

But this is a little strained.

\section{-The Marchaundes Tale.}

It is a coincidence that the botanical name, Aquilegia, is also supposed by many to arise from a bird, but a very different one from the dove. The derivation ascribed is that of aquila, the eagle, in reference to the form of the petals; but this does not satisfy some scholars, who prefer to trace Aquilegia to aquilegus, a 
water-collector, in allusion to the capacity of the flower for holding water.

We see that in the case of both scientific and popular names there is fine scope for learned controversy, but it is probable that modern flower-lovers will be disposed to confine their discussions to the relative merits of the varieties.

The poets have dealt richly with the Columbine. John Clare, the peasant rhymer, who was for a short period an under-gardener at Burghley, and who died in the Northampton lunatic asylum in 1864 , included it in some charming verse on old-fashioned flowers :

"The Columbines, stone blue, or deep night brown,

Their honeycomb-like blossoms hanging down;

Each cottage garden's fond adopted child,

Though heaths still claim them, where they yet grow wild."

Let us recall, too, John Skelton, the satirical poet, once Rector of Diss, in Norfolk, who was bold enough to make a fierce attack on the all-powerful Cardinal Wolsey in "Why come ye not to Courte?" In "Phyllyp Sparowe" he cries:

"She is the Vyolet,

The Daysy delectable,

The Columbine commendable

The Ielofer amyable."

Spenser uses the delightful comparison :

"Her nekke lyke to a bounch of Cullambynes."

Shakespeare refers to the Columbine in "Love's Labour's Lost" :

Armado. Peace!

The armipotent Mars, of lances the almighty,

Gave Hector a gift, the heir of Ilion;

A man so breathed that certain he would fight; yea,

From morn till night, out of his pavilion. 


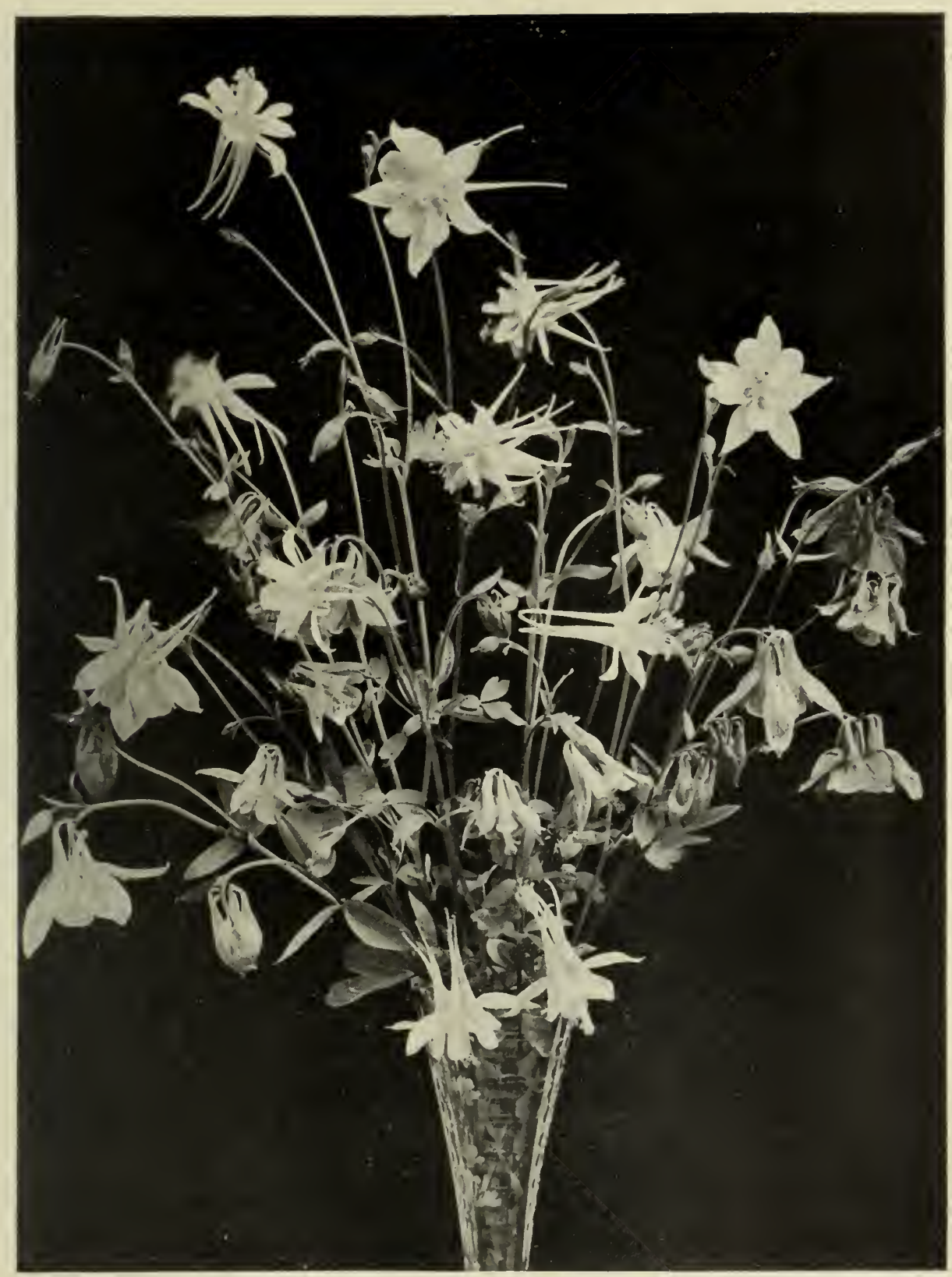

Columbines. 



\section{ON COLUMBINES}

I am that flower;-

Dumaine.

Longaville.
That Mint!

That Columbine.

And again in "Hamlet" :

Ophelia. There's Fennel for you and Columbine; there's Rue for you ; and here's some for me ; we must call it herb grace o' Sundays.

The Columbine clearly had the interest for great writers which all popular flowers must arouse; and the repeated references to it by Shakespeare may be taken as a measure of its familiarity, for he was too astute a writer to weaken his appeal by drawing illustrations from the garden that were likely to be strange to his readers. His observing eye took in and measured the influence of flowers as it did the power of human emotions.

It is not every botanist who will admit that, popular as the Columbine has been from the earliest times of which we have any floricultural records, it is a true native plant; but we need hardly labour the point, for it would be impossible to give its original habitat. The horticultural dictionaries state that the common Columbine, Aquilegia vulgaris, is a native, while quoting the exotic origin of several species which are themselves comparatively old plants. The Columbine was specialised in the days of Parkinson ( $\left.15^{6} 7-1650\right)$, for he wrote of it as being "carefully nursed up in our gardens for the delight both of its form and colour." Yet we might suppose that it had not been developed very highly, since George Chapman, translator of Homer and playwright, referred to it disparagingly in his bright comedy, "All Fools," which was produced in or about I599, as follows :-

\section{"What's that-a Columbine?}

No. That thankless flower grows not in my garden." 
The Columbine was used in heraldic devices, and John Guillim (or Gwillim) (I565-I62I), scholar of Brazenose, Oxford, official at the College of Arms, London, and author of "A Display of Heraldrie," quotes "a chevron sable between three Columbines," and speaks approvingly of the flower itself, as "pleasing to the eye, as well in respect of the seemly (and not vulgar) shape as in regard of the azury colour." He gave it, too, a good character in another respect-it was "very medicinable for throat troubles."

Select Species and Hybrids.-Aquilegia (pronunciation, Ak-wil-ee'-ji-a) vulgaris was variable in colour, giving red, white, and blue forms. It comprised both single and double flowers. Other species gave larger flowers and a greater range of colours. Alpina is a beautiful blue species from the Swiss Alps, growing about a foot high, and being suitable for the rockery. It is the same as grandiflora. Carulea, blue and white, introduced from the Rocky Mountains in 1864 , is a charming Columbine. It has long, slender spurs tipped with green. The height is fifteen to eighteen inches. Carulea hybrida is the result of crossing carulea with chrysantha and other species. The Columbines were first hybridised by a florist who was later to become famous as a Carnation grower, James Douglas. $\mathrm{He}$ made a large number of crosses, and secured strains with large, long-spurred flowers, embracing many colours. The seedsmen have a strain called Californica hybrida, the petals of which are yellow, and the sepals and spurs orange. It grows about two feet high, and certainly has the blood of chrysantha in it. The latter is one of the noblest of the Columbines, growing three to four feet high; it has yellow flowers. Some botanists do not accept it as a species, but consider it to be a 
variety of leptoceras. The latter is blue and white, and very close to, if not identified with, carulea. Columbinelovers will find a plate of it in the Botanical Magazine, t. 4497 , and also one of chrysantha under the name of leptoceras chrysantha, t. 6073. Aquilegia chrysantha came from California in 1873 . In itself, and also as a parent of the many beautiful hybrids, it is very valuable.

The blue and white species glandulosa is regarded as precious by all lovers of Columbines. The flowers are large and graceful, and the height is about a foot. It is a Siberian plant, and therefore hardy, nevertheless it is short-lived in most gardens, and requires frequent renewal from seed, but that is a simple and inexpensive matter. Jucunda is a variety of it.

There is a lovely little dwarf Columbine named Pyrenaica, introduced from the Pyrenees in $18 \mathrm{I} 8$. It rarely grows more than nine inches high, and may therefore be put on the rockery. The colour is blue. Sibirica, lilac, is another species suitable for the rock garden. Skinneri, red and green, a Guatemalan species, is a popular Columbine, and is illustrated in the Botanical Magazine, $t$. 3919. Stuartii is a hybrid between glandulosa and a variety of vulgaris, raised in 1888 . It is a dwarf grower, with dark blue and white flowers.

A Columbine-lover who wanted to have a thoroughly representative collection might add canadensis, formosa, and fragrans to the foregoing, as all are worth growing; but one may not assume that every flower-lover can find space and time for cultivating a long list of species when there are so many other beautiful plants claiming a share. Nay, one is forced to assume that many gardeners will be driven to the extreme of cultivating Columbines as Columbines, and nothing more. Even in this case they will not do badly if they procure a good strain of mixed 


\section{I24 POPULAR GARDEN FLOWERS}

hybrids, for they will have a beautiful display of flowers in late spring.

Propagation.-The grower of Columbines learns from observation that they do not possess a spreading, fibrous root-stock, like, for example, Michaelmas Daisies and Sunflowers; but form a hard, knotty stock. For this reason they do not lend themselves to propagation by division, although I have resorted to this method of increase on occasion, driving a sharp spade clean through the centre just as the growth started in spring. But the plant comes so readily from seed that division is uncalled for except in the case of double varieties. As a matter of fact, the Columbines sow themselves. The bees buzz around them busily in June, and a few weeks later one sees the peculiar pointed pods discharging their seeds. A word of warning as to this. The hybrid Columbines of the seedsmen are highly bred, and they soon deteriorate in quality when left to Nature ; if it is desired to keep the flowers up to the highest standard, the self-sown seedlings should be weeded out every few years, and a new stock of plants raised from fresh seed.

The Columbines certainly have a good notion of making themselves comfortable in any quarters which they like. I have cleared an herbaceous border to make a shrubbery, been sure that every particle of growth has been removed, and had the soil deeply dug, but a Columbine has come up here and there among the shrubs the following season, and, enjoying the good fare and the partial shade, has grown into a sturdy specimen. Although they grow vigorously in strong loam and clay-as, indeed most plants do-they like chalk, and will make surprisingly tall growth and flower

t profusely in comparatively poor soil overlying limestone. A 
Those who raise Columbines from seed should sow thinly in a drill as soon as it is ripe, if they gather their own; but if buying seed in spring, they had better sow in May. This seed will be of the previous year's sowing, and is often rather slow in germinating; on this account it is worth while to go to the little extra trouble of sowing in a shallow box filled with moist fine loam, leaf mould, and sand. If kept dark, and the soil moist, in a frame, it will germinate in due course, and the plants must then have light and air. When they begin to get crowded they may be set six inches apart in a prepared bed in the garden, and transferred thence to their permanent quarters in autumn.

Lovers of this beautiful plant, who grow it mainly for garden effect, must still make themselves acquainted with the structure of its flowers, for they are of great interest. There are five coloured or petaloid sepals (a sepal is not a petal-it is a segment of the calyxwhile a petal is a segment of the corolla) and five tubular petals; each of the latter terminates in a horn-like "spur" or nectary, which resembles a bird's head. The abundant seeding of Columbines is perhaps due to the numerous series of stamens, which, fed by the nectaries, discharge a great deal of pollen.

Interesting in its structure, a beautiful, hardy, and easily grown garden plant, endeared to us by long association, the Columbine is one of the greatest of our flower-garden favourites. 


\section{XIII}

\section{ON CROCUSES}

THAT cheerful harbinger of spring, the yellow Crocus, which often flashes back a greeting to the pale rays of the February sun, is one of the oldest of our popular garden flowers. Thriving in almost any soil, calling for no skill in culture, cheap, it is truly one of the flowers of the people.

The Crocus is so old a plant, and its derivation so remote, that it has been admitted to the British flora; but the species that grow wild have probably become naturalised.

Old writers spoke of the "Saffron Crocus" in general terms, but the Crocus that produces the saffron of commerce is sativus, a lilac species which blooms in autumn. The saffron is made from the dried stigmas of the flower. It is a very old plant-too old for its history to be traceable. The word "saffron" comes from the Arabic al zahafaran or za'faran. It is easy to trace the old French safran, the Italian zafferano, and the English saffron from this root. The origin of Crocus is hardly less clear. Theophrastus (372-286 B.C.), the Greek naturalist and writer on plants, referred to it. The Greek krokos is probably derived from the Arabic kurkum.

In these days the name saffron is rarely used in relation to the Crocus, but is applied to Colchicum autumnale, the Meadow Saffron; and there are probably 
thousands of cultivators of Crocuses who have lost sight of the association of the flower with the saffron of commerce. It is desirable to recall the fact, because it adds greatly to the interest of the plant, and brings us, through it, into touch with the old writers. How many people are aware that Saffron Walden, in Essex, takes its name from the introduction of the Crocus there? It is the fact, however. Sir Thomas Smith (15I4-I577), Secretary of State to Edward VI., and author of De Republica Anglorum, was a native of that place; and he is credited with having introduced the plant with the object of founding a new industry for the poor. (The reader may safely ignore published statements that Smith introduced saffron into Essex during the reign of Edward III., as that was some two hundred years before his time.)

Sir Thomas Smith may have been the first to start the cultivation of Crocuses for saffron-making in Essex, but it is hardly likely that he was the first to do so in Great Britain. The reader who is interested in the matter may read Hakluyt's references to saffron in the "English Voiages," vol. ii., written only five years after Sir Thomas Smith's death. He says: "Saffron groweth fifty miles from Tripoli, in Syria, on a high hyll, called in those parts gasian, so as there you may learn at that part of Tripoii the value of the ground and the goodnesse of it, and the places of the vent. But it is said that from that hyll there passeth yerely of that commodity fifteen moiles laden .. . If a vent might be found, men would in Essex (about Saffron Walden) and in Cambridgeshire, revive the trade for the benefit of the setting of the poore on worke. So would they do in Herefordshire by Wales, where the best of all England is, in which the soile yields the wild Saffron commonly, 


\section{28 POPULAR GARDEN FLOWERS}

which showeth the natural inclination of the same soile to the bearing of the right saffron, if the soile be manured and that way employed." And Hakluyt goes on to say: "It is reported at Saffron Walden that a pilgrim, proposing to do good to his country, stole a head of Saffron, and hid the same in his palmer's staffe, which he had made hollow before of purpose, and so he brought the root into this realme with venture of his life, for if he had been taken, by the law of the country from whence it came, he had died for the fact." If Hakluyt is accurate, saffron-growing was introduced into Essex long before Smith's time, for the latter was contemporary with him.

Saffron Hill, in London, also derives its name, according to Cunningham, from the crops of saffron which it bore. That delectable quarter is now the home of the Italian colony of organ-grinders, whose efforts turn many a harassed London writer of as bilious a colour as that of the "snipt-taffeta fellow" described by Shakespeare in "All's Well that Ends Well," whose "villainous saffron would have made all the unbaked and doughy youth of a nation in his colour." Flying to the wilds of Cornwall for solitude, the literary man finds nothing worse to remind him of the terrors which he has escaped than the saffron cake, so beloved of the Cornish folk.

The references to the saffron Crocus by Pliny show that it was cultivated in Cilicia, a region in the south-east of Asia Minor, in his time; and later writers, probably taking their cue from the Roman, referred to it as a Cilician plant. Thus Spenser's

"Saffron sought for on Cilician soyle."

It may have been a native of Asia Minor, but it was 


\section{ON CROCUSES}

grown in Persia and Cashmere in remote ages. Birdwood speaks of saffron as a native of Cashmere, and states that "the Saffron Crocus and the Hemp plant followed the Aryan migrations together throughout the temperate zone of the globe."

The writers of the Elizabethan epoch made many references to Saffron Crocuses, and did not limit the application to the lilac-flowered Crocus sativus. In "The Tempest," Act iv. scene I, Ceres cries to Iris-

"Hail, many-coloured messenger, that ne'er

Dost disobey the wife of Jupiter;

Who with thy saffron wings upon my flowers

Diffusest honey-drops, refreshing showers."

And Shakespeare refers to saffron in several other of his plays. Gerard grew several species of Crocus, and was particularly enthusiastic about the yellow, which was perhaps introduced in his own day, as he writes: "It hath flowers of a most perfect shining yellow colour, seeming afar off to be a hot glowing coal of fire. That pleasant plant was sent unto me from Rabinus, of Paris, that painful and most curious searcher of simples." Parkinson described thirty-one sorts of Crocus. Dean Herbert made a careful study of the genus, and published a monograph of the Crocuses in 1847 , in which he described forty-one species, in addition to many varieties. Later, Mr. George Maw also published a monograph of the genus, in which he dealt with upwards of sixty species, besides varieties.

These facts will show amateur gardeners who are tempted to hold the Crocus lightly because it is a somewhat common flower, that it is really one of great importance. Insignificant as it may appear to some, it has its roots deep down in the world's history. It 


\section{30 POPULAR GARDEN FLOWERS}

has been carried by wanderers all over the world, stolen by patriotic adventurers, and has maintained one of the oldest industries known to civilisation.

Educated people will not grow the Crocus less frequently in their gardens for knowing the part that it has played; on the contrary, they are likely to give greater attention to it than they have done hitherto. And, when they have begun to study it, they will find species of a beauty that they had never suspected. Probably seven out of ten of the growers of Crocuses know them only through the "Dutch" varietiespopular yellow, lilac, blue, white, and striped sorts, which are sent over from Holland in autumn in millions, to be sold by bulb dealers and auctioneers at a cheap rate, and to flower in February and March of the following year. The fact that they sell in such enormous quantities is a sufficient proof that they are appreciated, and their beauty is undeniable; but, after all, they give only a very meagre idea of the variety and the beauty of the genus. They do not, for instance, touch the autumn bloomers at all, and they only represent the late winter or spring bloomers with moderate success.

Crocuses for Rockwork and Pots.-In years gone by I grew a collection of Crocuses, which included some of the best species, in a London suburb. I learned thereby two things: that the Crocus is one of the best of town flowers, and that it includes plants the beauty of which far exceeds that of any of the Dutch varieties. I grew some of my Crocuses in the garden, and some in pots in the greenhouse. Their low growth suggests that the rockery rather than the open bed is the place for them outdoors. Given pockets to themselves in the rockery, and labelled, there is no risk of their getting overgrown 
by larger plants, or dug out in general gardening operations. They are both safer and under more complete control in the rock garden than in the mixed border. At the same time the exquisite flowers show up to greater advantage. The species can hardly be compared with the Dutch varieties as garden plants, although equally hardy. It will be conceded that a clump of perhaps half a dozen plants is much more likely to escape observation than a whole row. However, in the absence of a rockery, an amateur who is interested in Crocuses may grow a few specimens in the front of a bed or border, and with a little special care will succeed with them.

In the hope that some gardener has sufficient interest in Crocuses to grow a few species, I give a brief description of the best of those which I have grown myself, classifying them into two sections-autumn and spring, although some of the latter really flower in winter.

Autumn-blooming Crocuses.-One of the prettiest of this class is Boryi, which has white flowers. Hadriaticus is another beautiful white species. Iridiflorus (Iris-flowered) is one of the most exquisitely lovely of bulbous flowers. When expanded it is nearly two inches across, and of a rich blue colour. I found this to be a gem for pot culture, and a charming ornament for the front of the greenhouse stage. There is a large variety of it called major. Longiflorus, purple and lilac, is not only very pretty, but is also sweet-scented ; there are several varieties of it. Nudiflorus, purple, is also good. Ochroleucus, yellow and white, is well worthy of pot culture. Sativus, as we have seen, yields the saffron of commerce, which the old writers dowered with many virtues. Note Gerard: "The moderate use of it is good for the head, and maketh sences more quicke and liuely, shaketh off heauie and drowsie sleepe and maketh a man merrie." 
Sativus has purple or yellow flowers. Speciosus, purplish lilac, is one of the best of the autumn Crocuses; and zonatus, lilac and rose, is also lovely.

Spring-flowering Crocuses.-Aureus is a good orangeyellow species, and has many varieties, including white, cream, primrose, and deep yellow. It has additional interest for us as the parent of the popular Dutch yellow. Biflorus has white flowers, and is not only pretty in itself, but has a family of charming daughters. Another fine species is chrysanthus, orange, which also has a long list of varieties to its name. Fleischeri, white, with purple feathering, is worth growing; and at least as much may be said of Imperati, a large, handsome and early-blooming species, purple within, buff outside. There are several varieties of this splendid Crocus. Olivieri, orange; reticulatus, lilac and white; Sieberi, lilac, a most charming early bloomer; Tommasinianus, lavender; vernus, varying from white to purple; and versicolor, striped, are other good Crocuses. Vernus is the parent of the Dutch white, striped, and purple.

If the Crocus species are grown in pots, five corms (a corm differs from a true bulb in not having visible scales) may be placed equi-distant in a five-inch pot. The soil may consist of loam, with a quarter of leaf mould and some sand. The autumn bloomers should be potted or planted in summer, the spring bloomers in autumn. The pots should be covered with cocoa-nut fibre refuse until roots have pushed freely in the soil, when they may be put in the greenhouse and exposed to light. If planted on rockwork, pockets of loamy soil should be prepared for them, and they may be buried an inch deep.

Cheap Dutch Crocuses. - The following are a few good varieties of Dutch Crocus: Maximilian, lavender; Mont Blanc, white; Purpurea grandiflora, blue; and Sir 


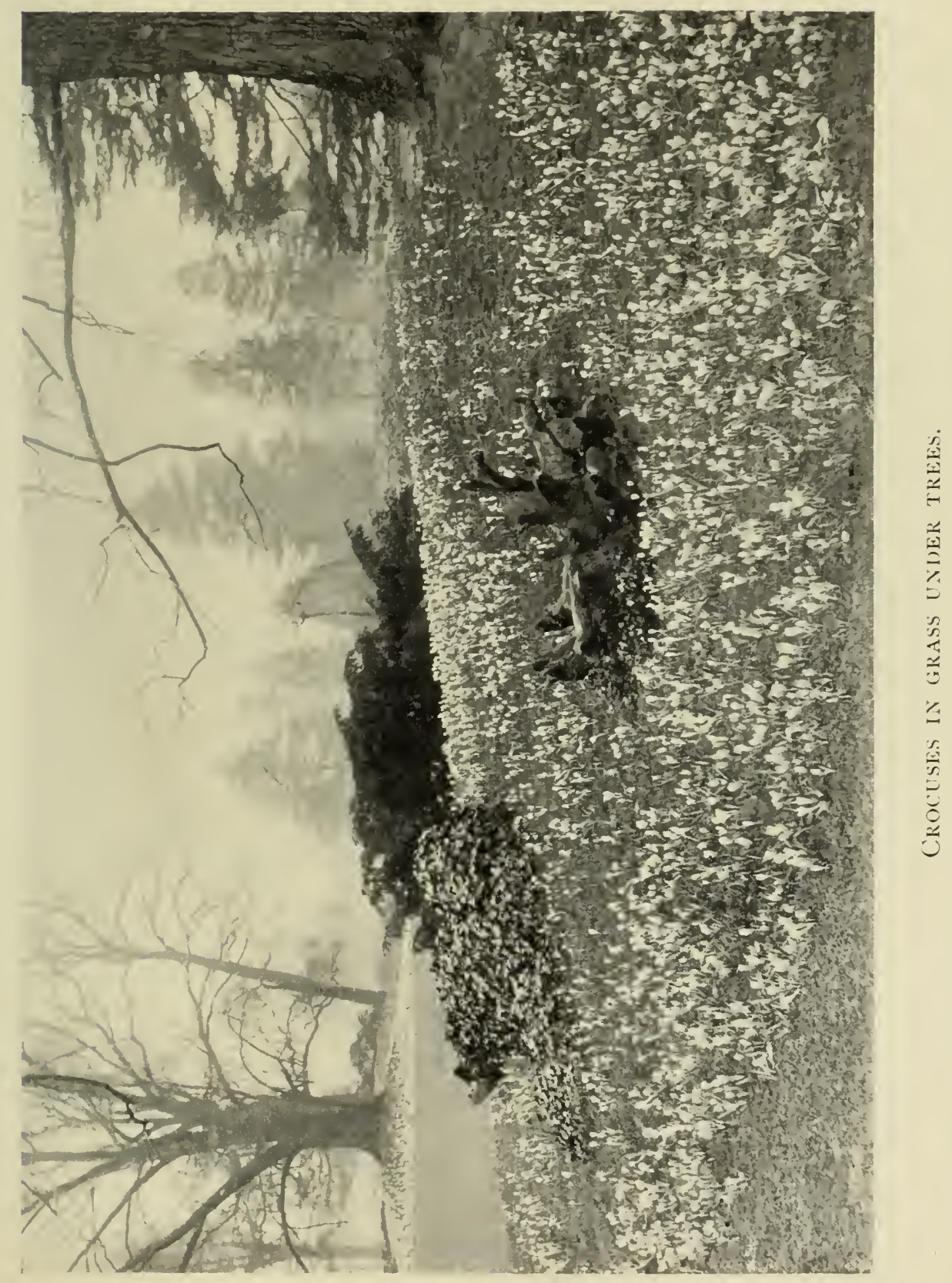



Walter Scott, striped. These cost no more than 2s. 6 d. to 3 s. $6 \mathrm{~d}$. per hundred, and are therefore cheap enough for long lines, masses, or planting in grass. The Yellow is generally sold in three sizes, and the price ranges from 2s. $6 \mathrm{~d}$. per hundred. The colour is the same in each case, but the large corms produce more and larger flowers than the small. Unnamed Crocuses in white, blue, and striped can be bought for is. $6 \mathrm{~d}$. to $2 \mathrm{~s}$. $6 \mathrm{~d}$. per hundred.

Crocuses in Grass.-Many flower-gardeners now plant Crocuses in quantity in grass. They take off the turf, stir the soil below, mix in bone flour at the rate of a handful per square yard, and replace the turf above the corms. It is a pretty idea to clothe a grassy mound with yellow Crocuses; the effect is charming when the flowers are out in February. They will do under trees which are leafless when the plants are in bloom. The Crocuses may be put in six inches apart.

Birds.-The amateur often finds his Crocus edgings spoiled by birds, which pull off the flowers. The suggestion that they do this "for mischief" is of doubtful accuracy. They probably find sweet moisture at the base of the flowers. The simplest plan of baffling them is to fix strings of black thread just above the blossoms.

The amateur may plant his corms three inches deep in well-worked soil and leave them from year to year. When they have dwindled to very small proportions fresh corms can be bought.

Crocuses do well in suburban gardens. 


\section{XIV}

\section{ON DAFFODILS AND NARCISSI}

We cannot think about Daffodils without a lightening of the heart. There is something irresistibly cheery about them. They are infectiously gay and enlivening.

The Daffodils have been popular flowers for many hundreds of years. They are old, old favourites. Their early flowering has much to do with this, and it is interesting to know that some authorities trace the name Daffodil to the old English word affodyle, which means an early object. Another explanation is that it comes from Asphodel, and the Daffodil was certainly confused with that flower by Lyte and others. If the reader repeats the two names one after the other he will be able to appreciate the possibility of confusion arising through careless writing following faulty pronunciation. Asphodel is the popular form of the Greek Asphodelus. The plant is entirely different from the Daffodil, and no confusion ought to have arisen between them. The Asphodel belongs to the natural order Liliacece, and the Daffodil to the Amaryllidacea. Asphodelus comes from $a$, not, and sphallo, to supplant, the intention being to convey that the flowers are so beautiful that they cannot be surpassed.

Whether Daffodil originated from Asphodel or affodyle, it appears to have come into possession of an initial letter which did not belong to it. It would 


\section{ON DAFFODILS AND NARCISSI I 35}

probably be a futile task to endeavour to trace the circumstances in which the " $\mathrm{d}$ " became added.

The Daffodil is not merely the Daffodil, however-it is also the Daffadowndilly; so that at some time or other it not only acquired an extra letter in front, but several additional ones at the end. Dr. Prior thinks that Daffadowndilly is a corruption of Saffron Lily, but it may have been manufactured by a poet to assist a metre. Constable (1562-1613) uses the word-

"Diaphenia, like the Daffadowndilly

White as the sun, fair as the Lilly."

And Milton speaks of "the Daffodillies" that

"Fill their cups with tears."

Our greatest poets have written of the Daffodil. Shakespeare refers to it repeatedly, and no lines relating to a flower are more familiar than those from "The Winter's Tale," Act iv., scene 3, where Perdita cries-

"Now, my fair'st friend,

I would I had some flowers o' the spring that might

Become your time of day; and yours, and yours,

That wear upon your virgin branches yet

Your maidenheads growing : O Proserpina!

For the flowers now that frighted thou lett'st fall

From Dis's waggon: Daffodils,

That come before the swallow dares, and take

The winds of March with beauty."

And in the same play, so rich in allusions, which have now become classical, to flowers, scene 3 of the fourth act begins with Autolycus singing-

"When Daffodils begin to peer,

With heigh! the doxy over the dale,

Why, then comes in the sweet o' the year;

For the red blood reigns in the winter's pale."

Herrick, Keats, and Shelley continued the Daffodil 


\section{36 POPULAR GARDEN FLOWERS}

garland of song begun by Constable, Shakespeare, and other early poets. The first-named wrote the lines-

"Fair Daffodils, we weep to see

You haste away so soon,

As yet the early rising sun

Has not attained his noon."

Keats's famous lines beginning, "A thing of beauty is a joy for ever," proceed-

\section{"In spite of all}

Some shape of beauty moves away the pale

From our dark spirits. Such the sun, the moon,

Trees old and young, spreading a shady boon

For simple sheep; and such are Daffodils

With the green world they live in."

The name Narcissus is scarcely less familiar than that of Daffodil. It stands as the botanical name of the whole genus with the bulk of amateurs, but florists call only the Trumpet Narcissi Daffodils, and use Narcissus for the rest of the family. They speak, for instance, of the Poet's Narciss, not the Poet's Daffodil. This, however, was a Daffodil with the old writers. It is the "chequ'd and purple-ringed Daffodilly" of Ben Jonson. Narcissus was the name of a vain youth who is said to have been turned into this flower-

"That was a faire boy certaine, but a foole

To love himself; were there not maids enough?"

\section{-Two Noble Kinsmen.}

Shelley writes of the flower under the classical name-

"Narcissus, the fairest among them all,

Who gaze on their eyes in the strearn's recess,

Till they die of their own dear loveliness."

We may assume that the Rose of Sharon, mentioned in the "Song of Solomon," was a Daffodil, although some writers believe that it was a Rock Cistus, and may quote the words of Mahomet: "He that has two cakes of bread, let him sell one of them for some flower of 
the Narcissus; for bread is the food of the body, but Narcissus is the food of the soul."

The Jonquil is a Narcissus, and the word comes from juncifolius, which means rush-leaved. The Jonquil is therefore the Rush-leaved Daffodil.

The old English Daffodil, the Daffodil of Shakespeare, is the Lent Lily, Narcissus pseudo-Narcissus of botanists. It is a native of this country. It is a cheap plant, and those who feel an interest in it may, if they like, plant it in quantity. But the modern Daffodils are so enormously superior that the Lent Lily does not receive so much attention as it used to do. It is, of course, thoroughly hardy, and it will grow almost anywhere. In heavy moist soil it multiplies almost too fast.

Classification.-There are so many different types of Narcissus that a person used to the ways of florists will assume that they have been classified. They have. The old system was to group them according to the size of the central cup or crown. They were classified in three groups-Large-Crowns, Medium-Crowns, and Small-Crowns (Magni-Coronati, Medio-Coronati, ParviCoronati). The true Daffodils, in which the crown was so large as to become a "trumpet," were Magni-Coronati, the Chalice-flowered were Medio-Coronati, and the Poet's Narcissi were Parvi-Coronati. This system served until the florists had mixed up the sections by hybridising, when it broke down. Another was formulated, in which eleven groups were made, as follows:-
r. Trumpets.
6. Cyclamineus hybrids.
2. Incomparabilis.
7. Jonquilla hybrids.
3. Barri (including Burbidgei).
8. Tazetta and Tazetta hybrids.
4. Leedsi.
5. Triandrus hybrids.
9. Poeticus varieties.
ro. Doubles.

II. Various. 


\section{38 POPULAR GARDEN FLOWERS}

The trumpet Daffodils bloom early, and the Poet's Narciss late. Between them come the Chalice-flowered varieties. By making a selection from each of these three classes, the grower can have bloom from March to May inclusive. A table of select varieties will put the information which a beginner is likely to require before him clearly and succinctly:-

\begin{tabular}{|c|c|c|c|}
\hline Variety. & Section. & Colour. & $\begin{array}{l}\text { Month } \\
\text { of Flower- } \\
\text { ing. }\end{array}$ \\
\hline Almira . & Poet's & White and orange & May \\
\hline * Barri conspicuus & Chalice & Yellow and orange & April \\
\hline Bulbocodium & Trumpet & Yellow & March \\
\hline Capax plenus & Double trumpet & Yellow & March \\
\hline Cernuus & Trumpet & Cream & March \\
\hline $\begin{array}{l}\text { Duchess of West- } \\
\text { minster. }\end{array}$ & Chalice & White, creamy cup & April \\
\hline Emperor & Trumpet & Yellow & March \\
\hline *Empress . . & Trumpet & Yellow and white & March \\
\hline Glory of Leyden & Trumpet & Yellow & March \\
\hline *Golden Spur . & Trumpet & Yellow & March \\
\hline Henry Irving & Trumpet & Yellow & March \\
\hline *Horsefieldii & Trumpet & Yellow and white & March \\
\hline $\begin{array}{l}\text { Johnstoni Queen } \\
\text { of Spain : } \\
\text { M. Magdaline de }\end{array}$ & Trumpet & Yellow & March \\
\hline Graaff & Chalice & White, yellow cup & April \\
\hline Maximus . & Trumpet & Yellow & March \\
\hline $\begin{array}{c}\text { *Obvallaris (Tenby } \\
\text { Daffodil) }\end{array}$ & & & \\
\hline $\begin{array}{l}\text { Daffodil) } \\
\text { Orange Phœnix. }\end{array}$ & $\begin{array}{l}\text { Tru } \\
\text { Dou }\end{array}$ & $\begin{array}{l}\text { Yellow } \\
\text { Orange }\end{array}$ & $\begin{array}{l}\text { March } \\
\text { Anril }\end{array}$ \\
\hline Ornatus & Poet's & White and orange & April \\
\hline *Pallidus praecox & Trumpet & Cream & March \\
\hline *Poeticus plenus. & Double Poet's & White & May \\
\hline *Sir Watkin . & Chalice & Yellow & April \\
\hline Sulphur Phœnix & Double chalice & Pale yellow & April \\
\hline $\begin{array}{l}\text { Telamonius ple- } \\
\text { nus (Van Sion) }\end{array}$ & Double trumpet & Yellow & March \\
\hline White Pearl & Bunch-flowered & White & April \\
\hline
\end{tabular}

The foregoing comprise twenty-four of the most popular varieties of Narcissus grown at the present time. Those marked with an asterisk are very cheap, 
and, giving considerable diversity of colour and season of flowering, might be chosen for a small collection, or for planting in large quantities. They will not provide sufficient interest for the specialist however, and it may be well to add notes of a few varieties that are more likely to appeal to him :-

Albatross. - White, with orange centre, a lovely variety of the Burbidgei class.

Blackwell.-Yellow Chalice, cup shaded orange.

Bullfinch.-A Barrii variety, with rich red cup.

Cardinal.-Chalice-flowered, red cup.

Cassandra.-A lovely sweet Poet's.

Cavalier.-White, with orange cup. A Burbidgei variety.

Cernuus plenus.-Double cream trumpet.

Elvira.-White and yellow Poetaz, very sweet.

Firebrand.-A red-cupped Burbidgei.

Glitter.-An orange-cupped Barrii.

Gloria Mundi.-Red-cupped Chalice.

Homespun.-Yellow-flowered Chalice of beautiful form, one of the most refined varieties we have.

John Bain.-White, yellow cup, small crown.

Katherine Spurrell.-White Chalice, with yellow cup.

King Alfred.-Grand yellow trumpet.

Lemondrop.-A Leedsii variety, with drooping, primrose flowers.

Lucifer.-A white Chalice-flowered, with large rich orange cup.

Lulworth.-Cream Chalice, with orange cup.

Mrs. Langtry.-A Leedsii, white, with primrose cup.

Nelsoni aurantius.-White, with orange cup.

Sunset.-A yellow Poetaz.

Victoria.-Yellow and white trumpet.

Waterwitch.-White Leedsii, a lovely, drooping flower. Excellent for cutting.

Weardale Perfection.-Yellow and white trumpet.

White Lady.-A beautiful white Leedsii, with canary cup, one of the most charming of all. 


\section{40 POPULAR GARDEN FLOWERS}

It must be remembered that the majority of these are much more expensive than the varieties in the first list.

With respect to the classes mentioned, the Burbidgei and Poetaz both belong to the small-crown section, of which the Poet's Narciss is the most popular example. The Burbidgei varieties are really hybrid Poet's. The Poetaz sorts, of which Elvira is a charming example, are hybrids between the Poet's and the Polyanthus-flowered group, the latter of which is botanically known as Narcissus Tazetta. The Chalice-flowered or Star Narcissi, of the medium-crown section, are the Narcissus incomparabilis of botanists. The resemblance of the crown to the wine chalice at the Lord's Supper table led to the term chalice-flowered being applied to them. The Barrii and Leedsii varieties belong to the same section. The yellow and white trumpets are frequently spoken of by florists as Bicolors.

Hardiness.-After this brief glance at the history and classification of the Daffodil, and list of some of the best varieties, we may usefully consider cultivation. The amateur may wonder whether the work of the florists in improving the flower has led to any loss of hardiness or vigour on the part of the plant. Happily it has not. With one or two unimportant exceptions, all the Narcissi are hardy. All do not, it is true, multiply as fast as the old Lent Lily, but for the most part they are strong, and quite suitable for cultivation in the open air. Only in the case of a very expensive variety need pot culture be regarded as obligatory, and this not because the plant lacks vigour, but because it can be kept more closely under the grower's control in a frame or greenhouse than in the garden, where a careless spade-thrust might destroy it. 


\section{ON DAFFODILS AND NARCISSI}

In Beds.-Where can we grow Daffodils? How can we utilise them so as to get the most individual interest, as well as the finest collective effect from them? Before we put one bulb into the ground, we have to remember that the plants bloom only at one particular season. An amateur who developed an interest in Daffodils might rush a large collection of them into the ground in autumn, and after enjoying them to the full in spring, find himself embarrassed in May onwards by beds and borders full of nothing but decaying leaves.

The Daffodils do not make the garden entirelythey only adorn it for a few weeks. From May to July, inclusive, they are worse than useless as decorative plants for the garden. The flower gardener should do one of two things: (I) Fill the beds with them in autumn, lift the bulbs in May, and lay them in a spare plot, then plant the bed with something else; (2) plant them in groups among the other occupants of beds and borders, and sow annuals, or plant dwarf, freeblooming perennials near them in spring, to come on for summer bloom.

In the public parks the first plan is adopted, and amateurs who do not mind the little trouble of lifting and replanting may follow it also. Let us suppose that an amateur has one flower bed which he wishes to be gay with Daffodils in spring, and with hardy plants-Asters, Petunias, Phloxes, Verbenas, Carnations, Begonias, Zonal Geraniums, or some other popular flower-in summer. He could plant his Daffodils in October, when the summer flowers were over. First, he should clear the bed; then dig it deeply, and work in steamed bone-flour at the rate of four ounces per square yard. He should now plant the Daffodils. 


\section{I42 POPULAR GARDEN FLOWERS}

Assuming that he has a selection of different varieties, he will be well advised to arrange them in groups, the number of bulbs in each ranging from three to a dozen, according to the size of the bed and the number of the varieties available. Six bulbs make a very nice clump. They should be set about six inches apart, and there should be a space of at least nine inches between the different clumps. The larger sorts, such as Emperor, Maximus, and Sir Watkin, may go in the middle, and the bulbs may be covered with four inches of soil. Bear in mind in planting the poeticus varieties that they are May bloomers. Set a neat, unobtrusive label in front of each group, so that the name can be clearly seen when the plants are in bloom. The bed may be finished off by planting a ring of Crocuses round it, or alternate tufts of mauve Aubrietia and white Arabis, or any other favourite edging plant.

The bed will not require much attention throughout the winter. More than once in hard spells of weather, when the ground is frost-bound or deep in snow, the amateur will feel that he and his bulbs are parted for ever. But snow will melt, frost disappear, and warm sunshine come. Then the green shoots of the hardy Daffodils will appear, and soon the bed will be full. Early varieties, like Golden Spur, Henry Irving, and Obvallaris, will be out long before March is spent, most of the other trumpets will bloom in March and early April, and thence to the end of May there will be flowers.

Primroses and Daffodils.--Those who love Primroses as well as Daffodils, may choose to plant the former as a groundwork, placing the groups of Daffodils farther apart to make room for them. Primroses, Polyanthuses, and hardy Auriculas are beautiful little flowers, and 


\section{ON DAFFODILS AND NARCISSI 143}

they can be transplanted in spring just the same as the Daffodils.

After Flowering.-At mid-May, or a little later if there is still a good show of bloom, the bed may be cleared by the simple plan of lifting each group of Daffodils in turn with a fork or spade, taking care to get the implement well underneath, in order to avoid carving up the bulbs, and placing it in a box or wheelbarrow with its label. The clumps may be replanted, as close together as is compatible with distinguishing between them, in a reserve bed. The bulbs and the lower part of the foliage, which will be yellow from contact with soil in the bed, should be covered with earth. The green foliage will droop as a result of the shifting, and, if the weather is very dry, the bed may be given a soaking of water once a week; but, in any case, the leaves will gradually die away as the summer wears on. The bulbs will ripen and be ready for replanting when the summer comes again.

The bed will be thoroughly re-dug in spring when the Daffodils have been cleared away, manured, and replanted with the chosen occupants for summer.

In Town Gardens.-A border under a fence or wall in a town or suburban garden could be treated in exactly the same way as a bed. There is no better springblooming plant than the Daffodil for such borders. It thrives in town gardens, and a collection is both beautiful and interesting. It gives the amateur gardener a good start for the gardening year. It cheers, heartens, and encourages him. He has, so to say, a "good send-off."

If the suburbanist's garden is so small that he cannot provide a reserve bed, he must either grow cheap 


\section{I44 POPULAR GARDEN FLOWERS}

varieties and throw the bulbs away after blooming, or adopt Plan No. 2 of arranging in groups among other plants. Some of the finest Daffodils, such as Sir Watkins, Empress, Barrii conspicuus, Golden Spur, and Pallidus Praecox, are almost ridiculously cheap, and could be discarded after flowering without any sense of wastefulness.

Inexperienced amateurs may consider that the plan of making two separate complete plantings of beds or borders in a year involves considerable time and labour. This is hardly so. A couple of hours will suffice to prepare and plant a bed, unless it is a very large one. The work is easy when once the ground has been broken up thoroughly and the soil brought into a friable state; and the amateur must not measure the two annual diggings by the standard of the first one. When ground is first broken up for gardening it is generally stiff, and the work is rather laborious; but if it is once well done and rendered friable by digging in road scrapings, ashes, and manure, it is ever afterwards easy to manage. The spade sinks in readily, and the whole task is enjoyable and healthful.

Daffodils enjoy a good root run, and the ground cannot be broken too deeply for them. Eighteen inches should be the minimum. Light land should have a dressing of decayed yard manure if this is procurable. In heavy land bone-flour will suffice. They love moisture, and do not object to a shady place.

Now for the second plan-that of treating Daffodils as permanent plants in beds and borders. There is no reason why they should not be used with good effect among perennials, provided that stations are allocated to them and clearly defined. There might be a fairly broad belt towards the front of every large border of herbaceous 


\section{ON DAFFODILS AND NARCISSI}

things, which should be reserved for comparatively dwarf plants. Daffodils and May-blooming Tulips could be made to play an important part among these. They should not be planted in continuous lines, because after they had gone out of bloom and the foliage had begun to turn yellow there would be an unsightly band. They should be put in clumps, interspersed with Pyrethrums, Leopards' banes (Doronicums), Columbines, and other things of about the same height that would be in bloom soon after them and carry on the display.

There is, of course, one perfectly simple way of dealing with clumps of spring bulbs directly they have gone out of flower, and that is to cut them off level with the ground-leaves, flower-stems, and all. Experts do not like this plan, arguing that as the leaves serve as lungs for the plants, the bulbs must suffer if the foliage is removed before it decays naturally. A safer plan is to draw the foliage together and tie it in a neat bunch, then to plant something else near, such as Annual Asters or Snapdragons. A little trouble of this kind is well repaid, as the border always looks fresh and neat.

Daffodils in Herbaceous Borders.-If unskilled labour is employed in the garden, it is wise to keep a sharp eye on a man digging an herbaceous border containing bulbs. He should be taught to observe the position of labels or marking-stakes, and neither to drive a sharp spade into the middle of the clumps nor to put a huge boot on to an upspringing treasure. While splitting bulbs into fragments cannot by any stretch of imagination be made beneficial to them, it does no harm to take the clumps up bodily in early autumn; in fact, it is rather a good thing, as the soil can be freshened up, and the small bulbs separated from the flowering ones. Some of the Daffodils make many new bulbs every year, 


\section{46 POPULAR GARDEN FLOWERS}

especially if they are growing in rich moist soil ; and with the mass of roots produced the soil is impoverished rapidly. Lifting them, digging and manuring the soil, and replanting are beneficial.

Under the conditions, and with the treatment advised, the use of Daffodils in herbaceous borders is all for good.

The smaller Daffodils, such as Johnstoni Queen of Spain, Cyclamineus, Minimus, Nanus, Bulbocodium (Hoop Petticoat), and Triandrus (Angel's Tears), are suitable for the rock garden.

Cheap Gardening.-People who have fairly large gardens, and little spare money to spend on plants and skilled men, are often at a loss to know what to do for the best. Grocers', bakers', and butchers' bills, income tax, rates-all these have to be paid periodically, and when they have all been cleared off, together with odd accounts for clothes, boots, coals, and laundry, there is not a great deal left with which to carry on an acre or two of ground as an up-to-date garden. One way of reducing the expenditure on a garden is to sow a good deal of it down with grass and establish colonies of bulbs in it. They are in bloom in spring before the grass has begun to grow, and so the flowers show up well, even quite small things like Snowdrops and Crocuses making a bold display. It is of the essence of the scheme that the grass should not be regularly mown with a machine and rolled from the time that it begins to grow in April, because that would involve weekly expenditure in labour. The amateur gardener learns from experience that, if grass is kept trim, like a lawn, by mowing, rolling, and edge clipping, it gives as much work as an equal area of cultivated garden. The grass must be left to grow. Not only would the regular cutting cause expense in labour, but it would 
remove the leaves of the bulbs while still green, and we have already seen that experts condemn this practice. Only a belt of grass beside the walks and sufficient for a tennis or croquet lawn need be kept mown. The grass may be cut with a scythe twice in the season, the first cutting being in June, by which time the foliage of the bulbs will be sufficiently ripened to bear removal, and the second in September. These cuttings give crops of hay. The grass loses its fine quality of course, but if at any time the owner becomes "better off" he can soon restore it to lawn condition again by dressing with manure and fine soil, and regular cutting and mowing; or he may make a compromise, by having the grass scythed over once a month throughout the spring and summer. This will be less exhausting to it than taking a hay crop ; but if the Poet's Narciss is planted, its lateblooming and early-ripening throw the first cutting so late that the grass is getting near the flowering stage when the scythe comes into play.

The Poet's Narciss Naturalised.-And the Poet's is one of the most beautiful of all the Narcissi for naturalising. It looks lovely on a shady bank in May-so beautiful that there seems no rhapsody even in the description of Forbes Watson: "In its general expression the Poet's Narcissus seems a type of maiden purity and beauty, yet warmed by a love-breathing fragrance; and yet what innocence in the large soft eye, which few can rival in the whole tribe of flowers. The narrow yet vivid fringe of red, so clearly seen amidst the whiteness, suggests again the idea of purity, gushing passion-purity with a heart which can kindle into fire."

Daffodils in Grass.-Amateurs need not fear that Daffodils will be unable to force their way through if planted under turf. They pierce it with ease; and 


\section{I48 POPULAR GARDEN FLOWERS}

providing that there is a good depth of strong, moist soil beneath them they seem to grow quite as strongly and to bloom as well on grass as on open soil. Where there is only a thin coat of soil over chalk under the grass the case is different, and the best results must not be expected unless the soil is prepared by taking out pieces of turf, stirring the soil, and adding fresh loam and bone-flour. Golden Spur, Henry Irving, Obvallaris, Princeps, Pallidus praecox, the common Lent Lily, Emperor, Empress, Horsefieldi, Sir Watkin, Barrii conspicuus, Telamonius plenus (double yellow), Orange Phonix, John Bain, Johnstoni Queen of Spain, and Poeticus are all well suited for grass, and most of them are so cheap that they can be planted by the hundred, if desired, at no great cost. If planting is done in autumn after the turf has softened under the influence of rain the work is not laborious. The pieces of turf removed to admit the bulbs soon unite again if pressed down and rolled after rain.

In Pots and Bowls.-Lovers of Daffodils may like to grow a few in pots or china bowls for their greenhouses and rooms. The bulbs do well in ordinary potting compost, such as loam with a fourth each of decayed manure and leaf mould, and a liberal admixture of sand; and also in peat moss fibre mixed with broken shell and charcoal. Three bulbs may be placed in a five-inch, six-inch, or seven-inch pot according to their size. They should be plunged in ashes or cocoa-nut fibre refuse until they have rooted freely, and then placed in the full light. When grown in bowls of fibre they should not be plunged, but should be kept in a dark place for six or eight weeks. The fibre should be moistened thoroughly before it is used, and it must never be allowed to get dry. 


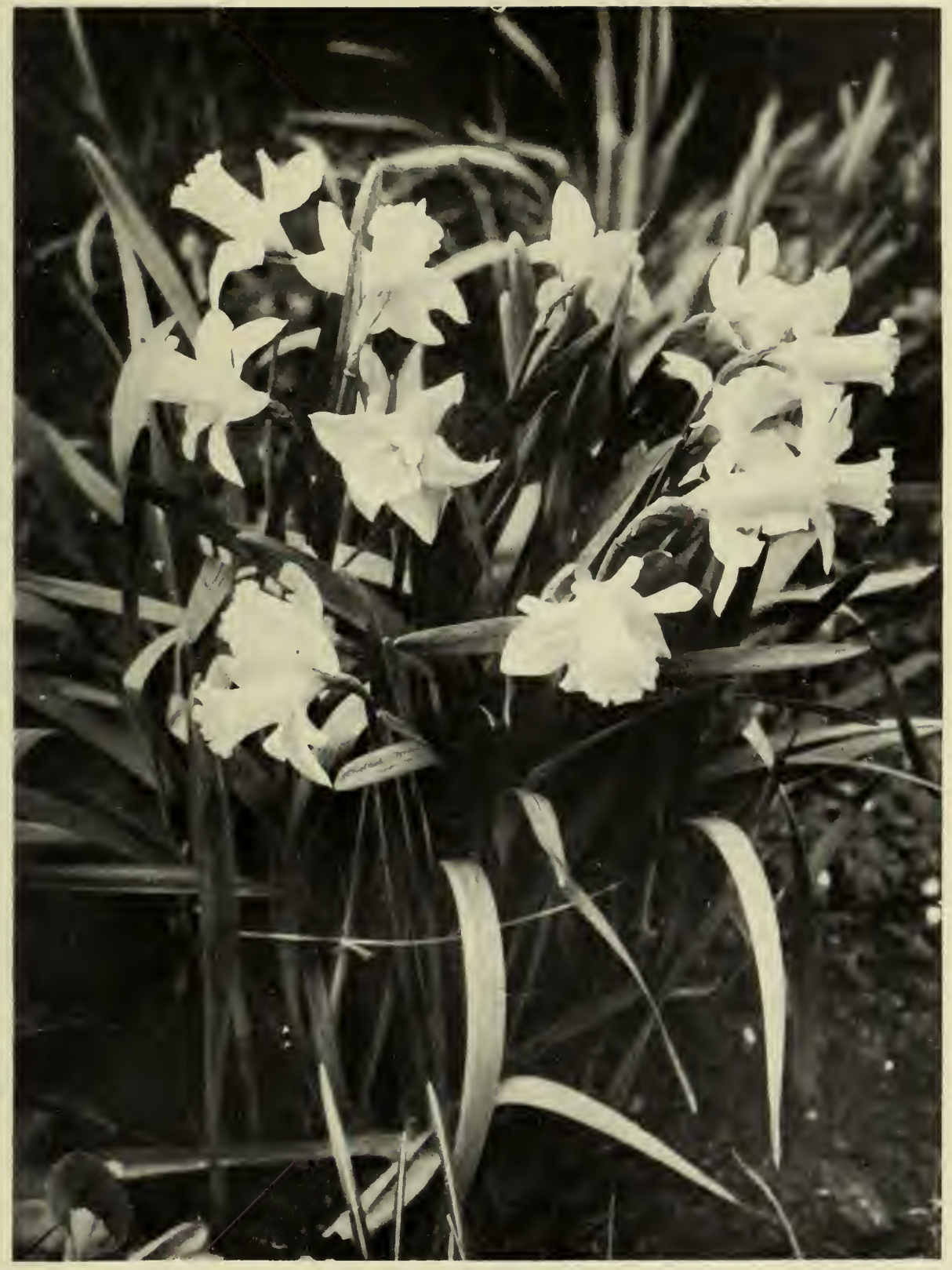

Narcissus Emperor. 



\section{ON DAFFODILS AND NARCISSI I 49}

Daffodils enliven the border at a season when the majority of the larger permanent occupants are only just beginning to bestir themselves. They dance and quiver in the spring breezes. They nod their golden heads joyously. They are on the best of terms with the world, and put the grower on the best of terms with himself. They gleam as brightly as the sun itself. When they are growing vigorously in well-prepared soil they will yield armfuls of flowers for the house and church at Eastertide, and still make a brave show in the garden. 


\section{XV \\ ON DAHLIAS}

THE Dahlia occupies a somewhat peculiar position among garden flowers. It is undeniably in the front rank of outdoor plants, it is a recognised exhibition flower, it has a society devoted to its interests, it is grown by all classes; and yet one can hardly speak of it as a flower that is loved by the people. Perhaps it inspires admiration rather than affection. It is likeable rather than lovable.

Dahlia shows do not draw the public like exhibitions of Roses, Sweet Peas, Chrysanthemums, and Carnations. Truth to tell, the long rows of boxes, with their severely correct blooms-all of which might have been turned out of a mould-are not inspiriting. The big, double flowers of the "Show" and "Fancy" sections are as prim as middle-aged parlour-maids. There is more cheerfulness in the singles, which are exhibited in bunches; and the Cactus section is also interesting. Another thing that tells against Dahlia shows is that they are held at the end of August and in the early part of September, when the holiday season is at its height. Even flower-lovers like to get away to the seaside some-times, and once comfortably established on the beach in flannels, they are apt to be more interested in the children's sand-castles than in exhibitions of Dahlias.

Experts speak of a growing lack of interest in Dahlias 
even as garden plants. The demand for novelties tends to slacken rather than grow keener as the years pass, and that is an unfailing sign of waning interest on the part of the public. What is the reason of it ? Perhaps it may be explained partly by the increased interest in Sweet Peas and early Chrysanthemums, and partly by the development of late-blooming Roses. With the growth of Sweet Peas in public favour more attention has been given to their culture, and it has been found that it is quite easy to continue the display of these beautiful flowers into September. There are many more early-blooming Chrysanthemums than there were, and the range of colours has been extended. As to Roses, the great development of the Hybrid Tea Section has put at the service of the flower-gardener a large number of varieties which bloom well into September, and there is no difficulty nowadays in making a large and beautiful display of Roses in the latter month.

Sweet Peas, Chrysanthemums, and Roses alike have one great advantage over Dahlias-they are more suitable for vases, and perhaps this goes a good way to explain the lukewarmness towards the old autumn favourite which causes florists so much disquietude. The latter, however, have been gravely at fault in one respectthey have developed the Dahlia as a show rather than as a garden flower. Sometimes the two elements run in conjunction. A good Sweet Pea is often, though not always, a good garden plant. In the case of Dahlias the flowers have been made too heavy for the stalks, with the result that the blooms hang down and are half or wholly hidden by the leaves; with this condition a variety is defective as a garden plant.

The remedy is in the hands of the florists. It is possible to breed varieties with strong stalks. At first 


\section{I52 POPULAR GARDEN FLOWERS}

the varieties with this feature may not have such beautiful flowers as the older sorts, but quality of bloom can be developed subsequently. So great is the skill of flower fertilisers that a few years of careful work with a definite object in view would alter the character of Dahlias entirely, and the change would be all for the better.

The Dahlia gives the florist good ground on which to work. It is not a plant of feeble constitution and puny growth, but of abundant inherent vigour. Some plants deteriorate alarmingly under high cultivation. They develop fungoid diseases-a sure sign of weakened constitution. When new varieties are raised and propagated rapidly under artificial conditions, and by unnatural means, such as cuttings, the plants soon become enfeebled. Not so the Dahlia. It is too full of vitality. It has an inexhaustible reserve of strength. The natural method of increase-by seeds - has been practically discontinued for many years except to raise new varieties; and even propagation by division of the roots has given way to the quicker method of striking cuttings; yet the Dahlia shows no signs of diminished strength. It is the same hearty, luxuriant, free-growing plant that it always was. This is encouraging. It tells the florist that he may cross, and cross, and cross again, improve the varieties to his heart's content, propagate his novelties rapidly, and still have a sturdy, healthy plant.

While the Dahlia remains vigorous and responsive it is too early to despair of its future. There may be temporary set-backs, due to special causes (such as the development of flowers too heavy for their stems, as already mentioned), but when they have been removed the plant will get a new lease of life. Nor Sweet Peas, nor Carnations, nor Roses will relegate Dahlias to the 
garden scrap-heap if raisers will frankly acknowledge their mistakes and rectify them promptly.

There is something very flattering to amateur gardeners in the way in which Dahlias respond to cultivation. The plants enter into a hearty comradeship with their growers, and bustle ahead in a breezy way that proves quite irresistible. This is why people keep on growing Dahlias, although fully aware of their defects for cutting. When an amateur once takes up Dahlias he is always strongly tempted to go on with them, although the flowers may not show up well on the plants, and are not in favour with the wielder of the flower-scissors. The fact is they pay him the compliment of growing well, and that goes a long way. Only in poor, thin, chalky soil do they "hang fire." They certainly do not like such soil; it is too dry for them. They have thick stems, large leaves, and huge bulk; consequently they throw off a great deal of moisture by evaporation. In a dry soil the supply is not replenished.

History.-As popular garden plants go the Dahlia is a comparative newcomer. It has only been grown in British gardens since 1789 , when it was brought from Spain by Lord Bute. Compared with such plants as the Rose, the Carnation, and the Daffodil it is a mere boy. The name is a Latinised form of that of a Swedish botanist, one Dahl, after whom it was named; and, as a result of the method of pronunciation which English gardeners insisted on adopting, confusion threatened, inasmuch as there happened to be an existing genus named Dalea. In vain purists expostulated and explained. In vain they ostentatiously pronounced the ah in Dahlia as they would the exclamation "ah!" The proletariat persisted in making it ay. But the Dahlia received another name. The German botanist 


\section{I54 POPULAR GARDEN FLOWERS}

Willdenow called it Georgina, in honour of Professor Georgi, a Russian botanist.

The danger of confusing Dahlia and Dalea was found to be more apparent than real, inasmuch as the latter was an entirely insignificant genus. The name Dahlia was therefore kept in England. Ninety-nine persons out of a hundred pronounce it Daylia, and the hundredth (who is really a pedant under the guise of a purist) calls it Dah-lia.

We have to accept the Dahlia as an entirely modern flower. It gives us no excuse to hasten to our bookshelves and spend happy half-hours over the familiar but ever-delightful passages of our favourite writers. There is no Perdita to thrill us with exquisite lines. Poets have not sung of the Dahlia as they have of the Daffodil, the Lily, and the Rose. Its only literature is the literature of the florists, and that is frigidly exacta brief statement of the "points" of a perfect flower, and a bald description of the system of culture. The only illustration of imaginative treatment is in the trade catalogues, where the new varieties are described in tempting language.

Without a history, without literary associations, without an artistic following, the Dahlia has to satisfy us with whatever it possesses of intrinsic excellence or promise as a garden and exhibition flower. When we have improved it sufficiently to satisfy ourselves, we must make our own literature about it, and so commend it doubly to posterity.

There are very few species of Dahlias, and such as there are have only the interest of parentage. Of no garden value in themselves, we still keep up acquaintance with them out of respect for the good they have done in fathering and mothering modern varieties. The three 
species Variabilis, with purple or red flowers; Coccinea, with scarlet flowers; and Merckii, with lilac and yellow flowers, are the principal parents of the modern double Dahlias. The Cactus class came, however, mainly from Juarezii, a scarlet species with rolled and pointed florets, which was introduced in 1872 . Variabilis was first called Superfua by botanists, not because they wished to place a stigma upon it by conveying that it was superfluous, but to indicate its kinship with the Linnæan section of "composite" flowers, in which the central and outer florets differ. "Variabilis" is in allusion to the variable colour of the flowers.

The species are not often seen now, but any one interested in them may make some sort of acquaintance with them, either through a botanical garden or through illustrations. Coccinea is figured in the Botanical Magazine, $t .762$; and Merckii in the same work, $t .3878$. Coloured plates such as these have an interest for those who like to compare the old forms of popular flowers with modern ones. Probably no plant has suffered more through the duplication of names than the Dahlia. As we have seen, two generic names were given, and there are many synonyms of the principal species. Variabilis has at least four, and Coccinea three. However, as none is of any garden importance, we need not worry about that, but confine our study to the distinctiveness of the garden varieties.

Dahlias as Hardy Plants.-The Dahlia is not hardy in Great Britain. When we learn that its native country is Mexico, we do not expect it to be able to withstand the winters in latitudes so much farther north. It is true that it is sometimes treated as a hardy herbaceous perennial-that is, planted out, left to die down in autumn, pass the winter in the open ground, and spring up again 


\section{56 POPULAR GARDEN FLOWERS}

the following year. In rare cases it plays the rôle thus allotted to it admirably, but in the majority it breaks down, being unsuited for its part. Successes are most numerous in well-drained, light, warm soils in mild districts. In cold localities, and particularly in damp soil, the roots die. Those who prefer to winter their Dahlias out of doors should put a few inches of ashes or dry litter above the stools in autumn.

Apart from want of hardiness, there is another good reason why the Dahlia should not be treated as a hardy herbaceous perennial except in particularly favourable circumstances, and that is that cuttings struck under glass in late winter and early spring make stronger plants and give finer flowers than old stools left in the border. The whole routine of modern culture turns upon this fact. It means the treatment of the Dahlia in an unnatural way, it is true, but there is no doubt about the superior results obtained. The inherent vigour of the plant preserves it from injury. It is under the "natural" system that the plant might be expected to suffer. It forms a large mass of tubers underground, and the roots from these feed so greedily as to impoverish the soil rapidly and make frequent renewal necessary if the plants are to be kept strong and healthy.

After Flowering.-Assuming that the root-stocks are to be taken up in autumn, after the foliage and flowers have been disfigured by cold weather, the stems should be cut back to short stumps. When the roots are lifted it will be found that most of the soil can be brushed or shaken away readily if the soil is friable, leaving the roots quite clean. In this case they will only need to be dried in the sun for a few hours before storing. If, however, the soil is clay, a good deal of it may stick to the 
tubers, in which case the roots should be washed and then turned upside down in the sun and left till dry. This is more important than might be supposed. Dahlia stools often go off wholesale in winter when it is quite certain that frost cannot have affected them, and the explanation is that they have rotted through damp. The winter store should be dry. If a grower finds that he persistently loses stools in winter, he may strike a few cuttings in August, made from young growing tips cut off just below a joint. These will root if inserted in small pots of sandy soil and kept close for a few days, and form small tubers before winter. They should be kept dry in winter; drip would be likely to injure them as badly as frost. The young plants will form a reserve that may come in very useful if anything happens to the stools.

Propagation by Cuttings.-Sound tubers would begin to grow naturally in spring, but florists do not wait for the weather to grow warm enough to start the tubers if a great many cuttings are wanted. They pack the roots in soil in February and put them in a warm house or frame, so stimulating early growth. The shoots that push are taken off when about three inches long. If they are numerous, they may be broken off quite close, but if scarce they should be cut off so as to leave two buds. They will strike just the same, and the buds left will push fresh growth. Several cuttings may be put round the edge of a six-inch pot, or one cutting in a three-inch. They strike root best when plunged in a mild hot bed, giving only just sufficient water to prevent the soil getting quite dry, and shaded from sunlight. They will be growing in twelve to eighteen days, and those in large pots should then be put singly into three-inch or four-inch pots and kept close till they start growing again. 


\section{58 POPULAR GARDEN FLOWERS}

From this time they will be best in an unheated frame, but protection should be kept handy in case of frost. Cuttings which are struck and treated in this way will give sturdy plants by the end of May.

Raising from Seed.-There is no difficulty in raising Dahlias from seed, but flowers of the same quality as the named varieties of the principal florists must not be expected. The seeds should be sown in a pan of light, sandy soil in February or March, and put in a warm frame or greenhouse. The seedlings should be pricked out in boxes when they become crowded, or put singly in small pots. They should be hardened in an unheated frame and planted out in June. If the soil is good they will flower the same year. Sometimes a really good variety comes in a batch of seedlings, and it is propagated by cuttings of the tops in order to keep it true, and to make sure that it is not lost through the decay of the tuber in winter. Florists get their novelties by making selections from seedlings. An amateur who has what he considers to be a promising seedling can always get an idea of its value by showing it to an expert.

Propagation by Division.-Growers of Dahlias who have not much convenience for raising young plants from seed or cuttings may divide the cluster of tubers which make the root-stock or "stool" at the point of attachment to the stem in spring, and put them a few inches apart in a box of soil containing a good deal of sand and leaf mould, in April, with a square of glass fixed just above them. If the soil is kept moist, and protection is put over them in cold weather, they will grow. Early in June they may be taken up and planted where they are to flower. If the tubers are sound, and not very much shrivelled, they make good plants when treated in this way. 
A still simpler plan is to replant all the stools that were lifted in autumn and remained sound through the winter in the garden towards the end of April. If the soil is good they will make strong clumps, but they are not likely to yield such fine flowers as fresh plants raised from cuttings.

Soil and Manure.-Moisture is the first essential for growing Dahlias, and it is easier to provide it by breaking up the soil deeply and hoeing regularly, than by taking a water-pot to the plants day after day. If the soil is loosened two spades deep in winter or spring, and the subsoil disintegrated thoroughly, the rooting area will retain moisture far better than if there is a hard pan a few inches from the surface; moreover, the roots can spread farther. The regular hoeing will check the escape of moisture and keep weeds in subjection.

The process of soil-deepening affords a golden opportunity for manuring, as the dung can be put in the right place-that is, between the top and bottom layers ("spits") of soil. From two to three barrowloads of decayed yard manure may be used to each square rod of ground.

If the subsoil is limestone, the only way of making the soil suitable for Dahlias is to break up the chalk. This is not always so serious a task as might be supposed. In some cases no pick is required, but the chalk can be broken up with a fork more easily than stiff soil can.

It is desirable to avoid a wind-swept site for the Dahlia bed, because the plants get dashed about and badly injured in stormy weather, in spite of care in staking them. Even if the plants are not blown over, shoots carrying good flowers are sometimes broken off. Individual plants may be set in herbaceous borders if 
desired, but Dahlias are hardly suitable for association with hardy plants. Apart from the fact that their great mass of succulent shoots renders them somewhat incongruous, there is the fact that they are such gross feeders, and require so much room, that other occupants of the border fare badly.

Staking.-It is a good plan to make the holes and drive the stakes in before the plants are ready. The stakes should be at least six feet long, so that they can be driven in eighteen inches deep, and still leave a good length above ground. They should be sound and strong, as the plants will need to be tied securely. The stakes may look a little unsightly for a short time, but the plants will soon hide them. Small pots stuffed with hay may be inverted on them later to serve as traps for earwigs, which often do great damage.

Large double, Pæony-flowered, single and Cactus Dahlias should all be planted in hollows five feet apart, but four feet will suffice for the Pompons. A ring of lime or soot should be put round them to keep slugs away.

The plants should be tied to the stakes directly they begin to sway, and later on the side shoots should be tied also. It may be possible to secure the latter to the large stake; if not, smaller ones must be driven down in convenient positions. The tying is particularly important to exhibition growers, as it prevents crowding, exposes the shoots to the sun, and insures fine flowers. If the side shoots come very thickly, they should be thinned, some being cut out altogether. Half-a-dozen branches will be enough for each plant.

For Exhibition. - The exhibitor will have to protect his flowers. Dealers in garden sundries supply muslin cones made to slide on stakes, and these can be fitted above the blooms. But growers can easily make their 


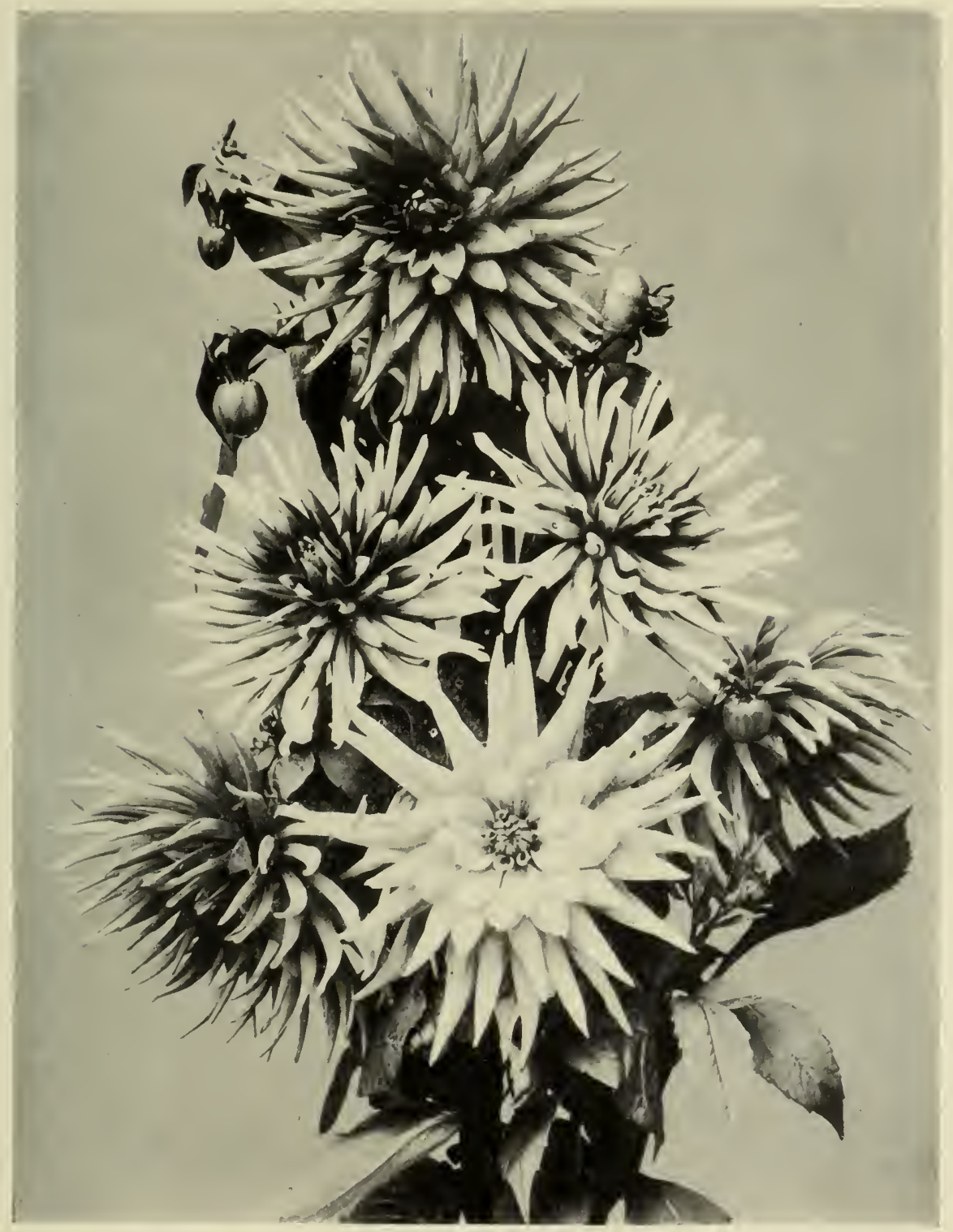

Cactus Dahi.las. 

own protectors. In choosing flowers for exhibition, select those of symmetrical shape, the florets overlapping evenly, and open right to the centre. A flower which displays a hard green centre, or a hollow one, is defective. A show-board for twelve Show or Fancy Dahlias should be two feet long (left to right), eighteen inches wide (back to front), nine inches high at the back, and three in front. It should be perforated with holes large enough to admit the zinc water tubes which hold the flowers, and they may be set equidistant in three rows. A stand for twelve Cactus should be a little larger-twenty-six inches long, and nineteen and a half wide. Cactus Dahlias are often shown in bunches of six blooms each, on a stand sixty inches long, twentyseven inches wide, eighteen inches high at the back, and six inches in front; also in vases. Single and Pompon Dahlias are usually shown in bunches of ten blooms each on a stand. Twelve varieties would require a stand forty-eight inches long by twenty-seven wide, and the same height as the stands for Cactus varieties.

Garden Dahlias.-As garden plants the Pæonyflowered and Pompon Dahlias are superior to the large double and Cactus-flowered varieties. The former is a modern section, and lovers of the prim Show and Fancy varieties look askance at it, because the flowers are very large and irregular in form. The expert calls them coarse. However, the stems are strong enough to lift the flowers right above the leaves, and as the blooms are not only of considerable size and brilliant in colour, but are borne in clusters, the plants make a bold and telling display. At a short distance the imperfect shape of the flowers is not sufficiently noticeable to be remarked even by a trained eye. The Pæony Dahlias are undoubtedly fine garden plants, and they will grow in 


\section{I62 POPULAR GARDEN FLOWERS}

suburban gardens; but, as they are large plants, they are not suitable for small gardens. The garden Dahlia for the suburbanist, and also for owners of small gardens generally, is unquestionably the Pompon. The flowers are borne in clusters, are pretty in form and beautiful in colour, and are well displayed. There are many charming varieties in this section, and many of them only grow a yard high and through. The singles make handsome bushes, but they need as much room as the large sections.

The following are twenty-five beautiful varieties:-

\begin{tabular}{|c|c|c|c|c|c|}
\hline \multicolumn{4}{|c|}{ Variety. } & Section. & Colour. \\
\hline Amos Perry & • & . & • & Cactus & Crimson \\
\hline Bacchus & · & . & • & Pompon & Crimson \\
\hline Baronne de Gra & ncy & . & - & Prony & White \\
\hline Beauty's Eye & . & . & • & Single & $\begin{array}{l}\text { Mauve, crimson } \\
\text { ring }\end{array}$ \\
\hline Britannia . & - & . & • & Cactus & Salmon pink \\
\hline Buttercup . & - & . & & Pompon & Yellow \\
\hline Columbine & . & . & $\bullet$ & Single & $\begin{array}{l}\text { Rose, shaded } \\
\text { orange }\end{array}$ \\
\hline Comedian . & - & & & Fancy & $\begin{array}{l}\text { Orange and } \\
\text { crimson }\end{array}$ \\
\hline Coronation. & . & & & Pompon Cactus & Scarlet \\
\hline Dr. Van Gorkun & & & & Pæony & Blush \\
\hline Floradora. & & & & Cactus & Wine crimson \\
\hline Florence Stredw & vick & & & Cáctus & White \\
\hline Germania. & . & & & Pæony & Crimson \\
\hline Glory of Baarn & . & & & Prony & Rose \\
\hline Guiding Star & . & & & Cactus & White \\
\hline John Walker & 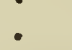 & & & Show & White \\
\hline Leslie Seale & . & & & Single & Lilac \\
\hline Mrs. Gladstone & . & & & Show & Blush \\
\hline Mrs. N. Halls & . & & & Fancy & $\begin{array}{l}\text { Scarlet and } \\
\text { white }\end{array}$ \\
\hline Mrs. Mawley & • & & & Cactus & Yellow \\
\hline Peace. & - & & & Pompon Cactus & White \\
\hline Pearl. & • & & & Cactus & Pink and white \\
\hline Phobe & - & & & Pompon & Orange \\
\hline R. T. Rawlings & - & & & Cactus & Yellow \\
\hline The Bride . & - & . & - & Single & White \\
\hline
\end{tabular}



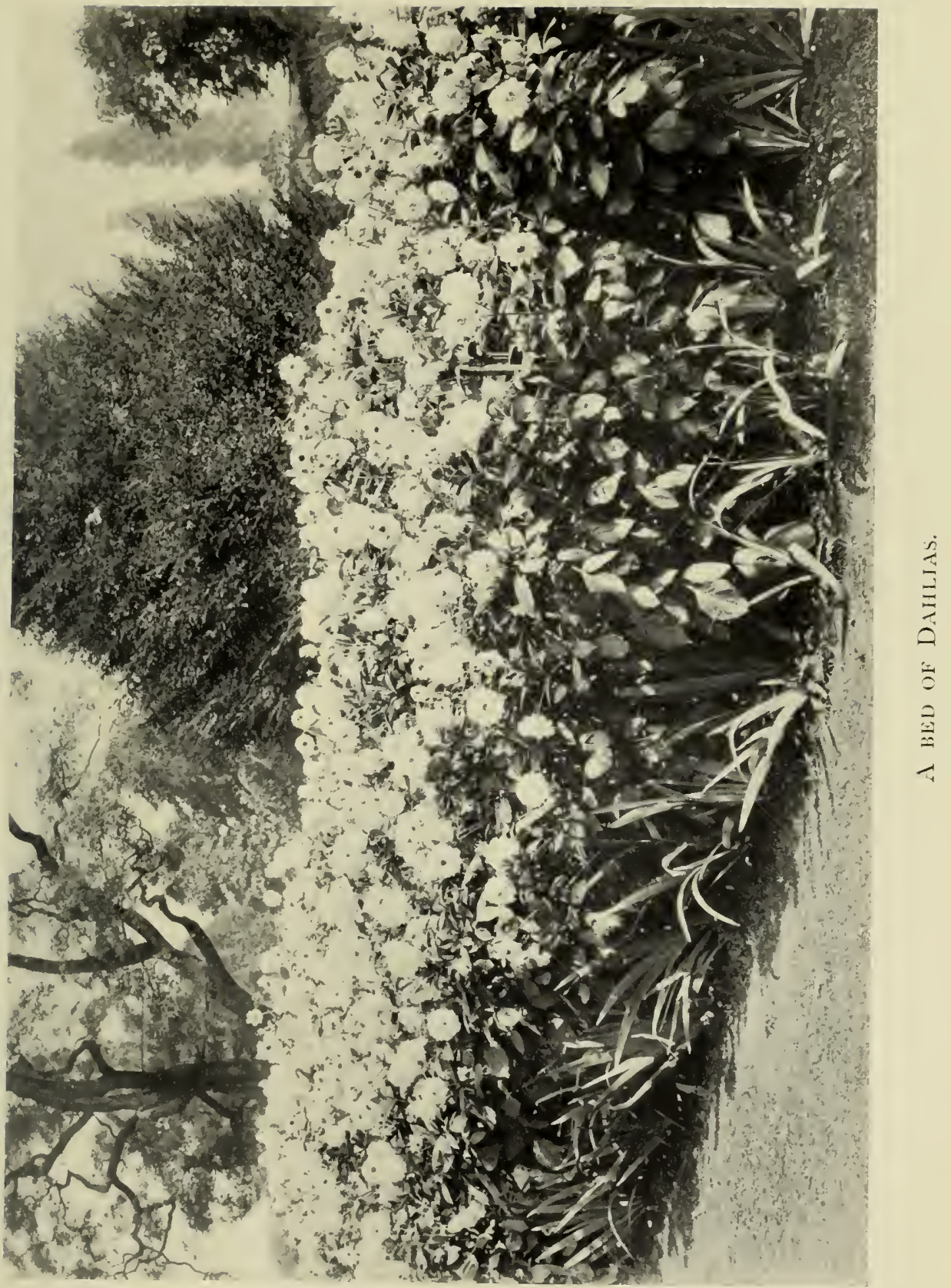



\section{XVI}

\section{ON FEVERFEWS (PYRETHRUMS)}

THERE is so vast a difference between the little Golden Feather of our garden beds and the huge Japanese Chrysanthemums which grace the boards at autumn exhibitions, that the average gardener lacks sufficient imagination to bridge the gap between. They stand on different planes. But we saw in our chapter on Chrysanthemums that the Chrysanthemums and Pyrethrums are related.

In the "bedding out" days the Golden Feather was the most important of the Feverfews, but now that herbaceous plants reign, the single and double-flowered varieties of Pyrethrum roseum stand in front of it. The common name came from the supposed virtues of the plant as a febrifuge, and the botanical one (pronounced Pie-ree'-thrum) from $p y r$, fire ; in allusion to the acridity of the roots.

The great botanists Bentham and Hooker linked Pyrethrum with Chrysanthemum, and if their decision had been accepted by gardeners, the name Pyrethrum would have dropped out; but it became naturalised as it were. It had taken out its papers, sworn the oath of allegiance, and been accepted as sound British stuff. Pyrethrum has become, with Begonia, Gardenia, Stephanotis, and others, as familiar as the Anglo-Saxon names, and it could not be uprooted. 


\section{I64 POPULAR GARDEN FLOWERS}

The carpet-bedder and the ribbon-border maker had definite uses for the Golden Feather, but the modern flower gardener has none; indeed, he had better beware lest it become a weed with him. When used in carpetbedding it was associated with tender plants, and it grew to be regarded as tender also, more especially as it was raised from seed in a warm house or frame every spring. But it is far from being tender, and will seed itself freely in the open border. This would not matter so much if it came naturally as dwarf, compact, and golden as we used to see it in the carpet-beds of long ago; but it does not-it gets coarse, straggly, and green, and much more nearly approximates to a weed than a garden plant. The carpet-bedders kept it close by severe cropping or "pinching."

The modern varieties of the species roseum are, however, wholly admirable. It is difficult to put them in the wrong place except by hiding them behind a spreading bush of some border monster such as a Michaelmas Daisy, Bocconia, or Sunflower. Wherever they are in view they are beautiful. They are so nearly evergreen in mild districts that they are only devoid of foliage for a few weeks, being slow to part with their leaves in autumn and eager to produce a fresh lot before any of their rivals in the border can get started. The leafage is gracefully cut, and has quite a ferny lightness. The flowers are thrown up abundantly in spring, and if the first lot are cut off when they fade, more will follow, so that there will be a succession of bloom.

The original species had single rose-coloured flowers, but natural variation, followed by florists' selections, has given us a wide range of colours. We have white, lemon, yellow, peach, pink, rose, crimson, cerise, scarlet, 
purple, lilac, cardinal, and violet. Better still, we have both single and double varieties. In some of the best doubles the flowers have real individual quality when the plants are well grown.

Town and suburban amateurs who are interested in hardy herbaceous perennials, and want to have a "mixed border" in order to be in the gardening fashion, should have a set of double and single Pyrethrums. The plants have every merit except fragrance. (They have a slight odour, but it is not one of the sweet flower smells which we love.) They will thrive in gardens near towns in almost any soil, and, growing compactly, will have ample room in a small border.

The Pyrethrums should be set near the front of large borders, as they are close, neat, dwarf growers. At the same time, they should not be crowded, as the flowers have long stems and the heads spread out considerably. In fairly fertile, rather dry soil, they may be set 18 inches apart in triangular clumps of three; in rich, deep, moist soil, 30 inches apart. They are so healthy and free growing that they suffer little from enemies, but slugs are apt to be troublesome in attacking the young growths in spring. Dustings of dry, freshly slaked lime at night will stop their proceedings and do no harm to the plants.

The flower gardener who would have these beautiful plants at their best should dig his ground deeply and manure it well, for they love good fare. He should cut off the decaying flowers. He should give them good soakings of water in June if the weather is dry, with an occasional pailful of liquid manure, and he should take them up bodily every other year, divide them, and replant them in fresh soil. I have succeeded with them on a thin chalky soil by keeping as close to this line of 
culture as possible, although the results scarcely equalled those which I had had previously on deep, moist, fertile clay.

Pyrethrum growers often abstain from supporting the plants, but if wet weather should come while they are in bloom, the want of a stake and a band of raffia or string is felt severely. The stems fall over and sprawl about on the ground in all directions. Three flowersticks, with a band of raffia wound round them, will prevent this, and will not be unsightly. When the flowering is over, the stakes should be removed, as the foliage will not need them.

The florists give us new Pyrethrums every year or two, just as they give us new Phloxes and Delphiniums. The amateur may keep a lookout for descriptions of these, and, in these days of hardy flower classes at gardening shows, he may often be able to jot down the names of good sorts at the exhibitions. In the meantime, the following selections will keep him going, and he will find the varieties really good ones that he will be loth to part with :-

Single.

Decoy, scarlet.

Feversham, white.

General Buller, carmine.

Oliver Twist, cream.

Roland, lilac.

Vésuve, blood red.
Double.

Alfred, crimson.

Carl Vogt, white.

King Oscar, scarlet.

Ovid, rose.

Pericles, yellow.

Shotover, pink. 


\section{XVII}

ON FORGET-ME-NOTS (MYOSOTIS)

THE Forget-me-not plays so useful, if modest, a part in the flower garden, that we hardly need the romantic story of the way in which it won its popular name to commend it to us. And yet, having a tinge of sentiment left in us still, we are willing to be influenced mildly by the pathetic recital of the accidental drowning of the lover, and his last despairing appeal to his lass to hold him in remembrance as he flung her a flower and was swept away by the water. We hope that she did not forget him, but named her second boy after him when she had married the other man, and taught him to associate Myosotises with his bulbs in the spring bedding.

It is fitting that there should be water-and water other than the tribute of our tears-in the story of the christening of the Forget-me-not, for it is a plant of marshy places. Its specific name, palustris, indicates this, for paludal or palustral objects are those of the marshes (palus, a marsh). This contains a practical hint for us; it suggests that we should grow our Forget-menots in cool, moist places. Assuredly they do well there, but, happily for us, there are Alpine kinds suitable for cultivation in spots that are normally dry in summer. We need not put them in their flowering positions till autumn; and as they bloom in spring, they have all the moist season of the year in which to do their best for us, 
The name Myosotis (My-o-so'-tis) comes from mus, a mouse, and otos, an ear, in allusion to the resemblance of the shape of the leaf to a mouse's ear. My lady readers have too great a horror of a mouse, probably, to collect a specimen of it for comparison, and they may be disposed to think that namers of plants must have been sadly lacking in imagination to be driven to such straits for names as this case indicates. Let me assure them, however, that it is a mild offence compared with some which botanists have committed.

The cultivated Forget-me-nots are essentially flowers of spring. Having no liking for hot weather, they get the best of their blooming done in May, but it must be said in their favour that they do not scramble through as though in nervous terror of sunstroke; on the contrary, they grow and bloom deliberately for a good many weeks, and often last into June if allowed, provided that the soil is fertile and moist. It is as spring flowers that we ought to grow them, because the growth is healthy and abundant, and the flowers deliciously bright and sparkling in spring; moreover, they associate admirably with Tulips. Until they get the exuberance of manhood upon them they are compact growers, and by the time they break bounds and become straggly the bulbs are over, and the Forget-me-nots can be cleared off to make way for the summer occupants of the beds.

There are few plants so charming for the side of shady banks and dells in cool places. Bits dotted in during October will spread into broad masses in April, and, like their companions, the Primroses and Arabises, they will bloom as they grow. These are the sort of plants that amateur gardeners want. Kinds that give up growing directly they begin to bloom suffer by comparison. 


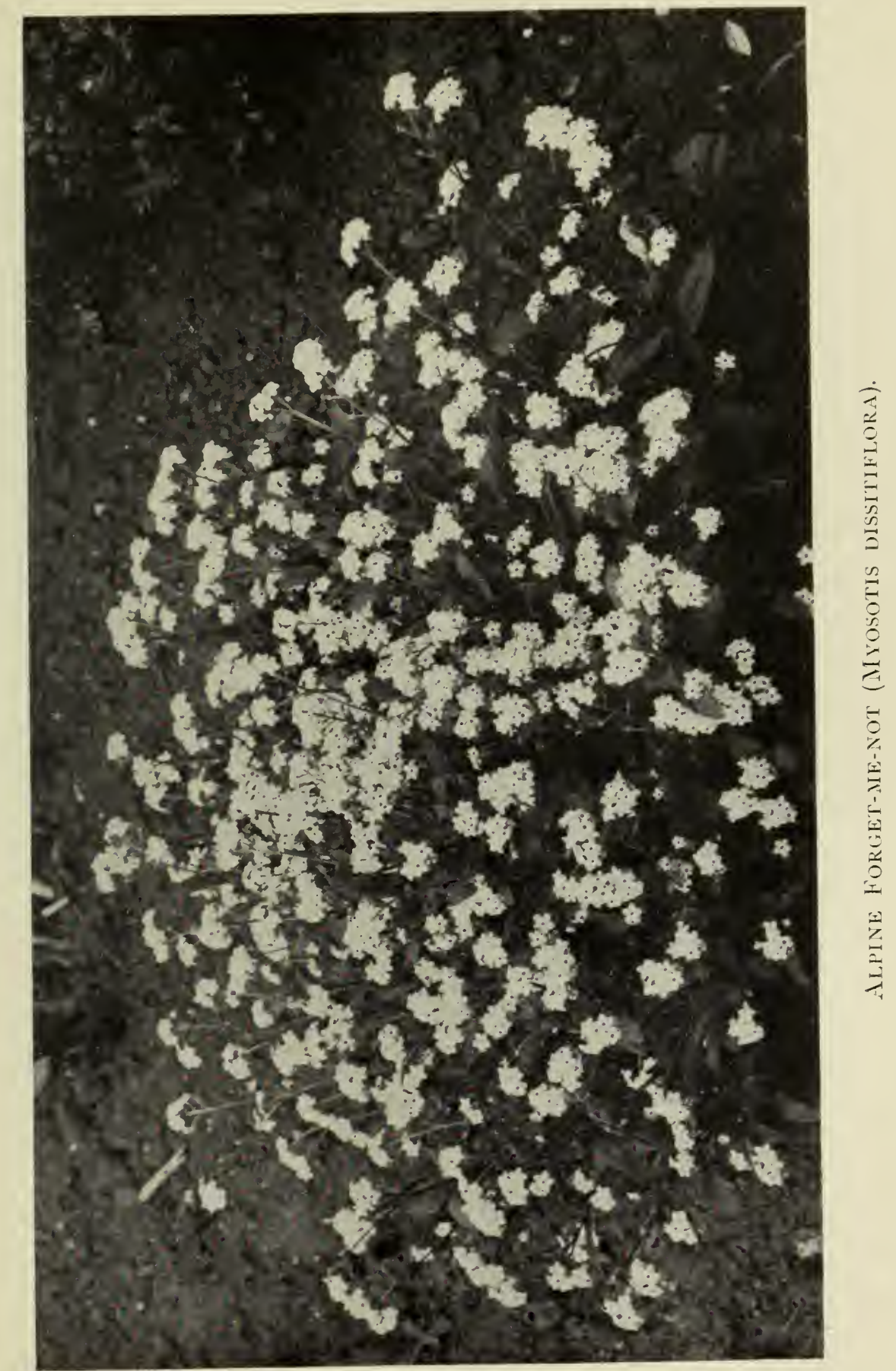



The true native Forget-me-not, "the blue and brighteyed floweret of the brook," has blue flowers with a yellow eye, and the same combination of colours distinguishes that charming Swiss species dissitiflora, which was introduced to Great Britain as recently as 1868 . This comes near to being the best of all Forget-menots for the flower garden, owing to its neat, dense habit and profusion of bloom. The specific name means distant-flowered, and bears reference to the fact that the flowers are disposed more loosely on the stems than those of the older species. Directly flower gardeners saw the Swiss Distant-flowered Forget-menot they fell in love with it, and it has been a prime favourite with them from the moment of its introduction. They were not satisfied until they had raised improved varieties of it. Two of these are called grandiflora and splendens, both blue; then there are alba, white; and elegantissima, the leaves of which are edged with white, and Perfection. Dissitiflora is quite likely to begin blooming in February or March ; directly the winter relaxes it is in flower.

Another useful species is the Wood Forget-me-not: sylvatica. It is of taller growth, and hardly so suitable therefore for carpeting bulb-beds as dissitiflora; but it is a free grower and bloomer in moist soil. There are several varieties of this species, one, compacta aurea, having yellow leaves. Distinction is a fine form also. Azorica, a species from the Azores, is a lovely Forgetme-not, having rich dark-blue flowers; but unfortunately it is somewhat tender. It blooms as late as August. There is a good variety of it called Impératrice Elizabeth.

The one Forget-me-not which will thrive in dry soil is the species Alpestris, which is also called rupicola 


\section{I70 POPULAR GARDEN FLOWERS}

(rock-loving). It is quite suitable for the rockery. I do not suggest, of course, that rock plants should be dry-indeed, the majority love to get their roots down into moist crevices-but the point is that this species will thrive far better than the others in a dry, sunny place.

The Forget-me-nots succeed in pots. They may be potted up in autumn, and with gentle forcing-but it must be gentle-they can be had in bloom under glass in winter. It is hardly worth while to keep them in pots after flowering if a fresh stock of plants is being raised, but if they are retained, the pots should be stood in saucers of water during summer.

Forget-me-nots are so easily propagated that no one need worry about old plants. If it suits his purpose to keep them he may do so, but if not he may divide them, or take cuttings from them, and insert them in sandy soil in a shady place. Most simple of all is to sow seeds with that of the Wallflowers, Canterbury Bells, Arabises, Aubrietias, and other things in May, as by this plan a large stock of plants can be raised at a very small cost. A hot, dry site should be avoided. The species and most of the varieties come true from seed. It is well to dig the soil deeply and reduce it to a fine state on the surface, moisten it thoroughly, and then sow thinly about half an inch deep. The seedlings can be thinned, and the rest pricked off six inches apart when they get crowded. With hoeing, and an occasional soaking of water in dry weather, they will make good plants by October.

This is a very simple and inexpensive procedure with which to be able to provide abundance of so charming a flower, and it commends this dear little plant still further to us, 


\section{XVIII}

\section{ON FOXGLOVES}

Lovers of old English flowers who like to trace the origin of names have an interesting task in finding the reason why Digitalis purpurea came to be called the Foxglove. Even when they give free rein to fancy they fail to see a connection between the tall and graceful wilding with its spotted flowers and the stealthy nocturnal marauder which often plays sad havoc with the drowsy occupants of their fowl-houses. What has the fox to do with flowers, and what does he want with gloves? Did he, cunning rogue that he is, suppose, once upon a time, that if he drew thumb-stalls over his paws he could spoil the scent for his pursuers? And did he experiment with Foxglove flowers? Was he found, when fleet Bay Archer dashed boldly into him and brought him down, with the Digitalis bells upon him? And as he died, a victim of misplaced ingenuity, did he emit a parting howl of disappointment that his device had come to naught?

These speculations once beguiled me when, the very morning after the hunt had dashed through my garden, I saw the fox nonchalantly stroll along the bank on the outskirts of the lawn, and go leisurely to earth within fifty yards of the front-door. I had not seen him previously; the hunt had not seen him. But the hounds must have thought that they had winded him, for they 


\section{I72 POPULAR GARDEN FLOWERS}

had suddenly gathered and tumbled after each other pell-mell along the side of the ditch with one sharp yelp of excitement. A cramped corner, a double ditch, and a nasty hedge combined to check the hunt, so, as it could not follow the hounds, it cut across the garden (to its credit it kept to the drive) to meet the pack in the meadow on the other side. And then it swept away with its own peculiar din, and the pack yelped itself out of hearng, and peace settled on the garden again. With a passing thought for the joy of the maiden who received the brush I resumed my book, and lo! at daybreak there was the unruffled fox creeping along by the very spot where the hounds must have scented him, alive and well, which is more than can be said for a pair of the best chickens of a local grazier. The befooled pack had overshot the fox somehow, and I speculated about him while I walked in the wild garden, where in summer the Foxgloves lifted their spires.

The learned will not acknowledge the connection of the fox with the Foxglove, of course. They state, without any beating about the bush, that Foxglove is neither more nor less than a corruption of Folksglove (folks' glove), and that the "folk" are not the proletariat in this case (the Foxglove flower would be too small for its capacious paw), but the little folk or fairies. The Foxglove, then, is the fairy's glove; but we must go a little farther before we can get the name fully explained, because no one has ever been found who saw a fairy wearing a Digitalis flower, although plenty of people are prepared to sign affidavits, and do other mysterious legal things, to prove that they have seen fairies get into Foxglove flowers and hide there.

The flower of the Foxglove has been likened in shape to a finger-stall - that article which we carve out of an old 


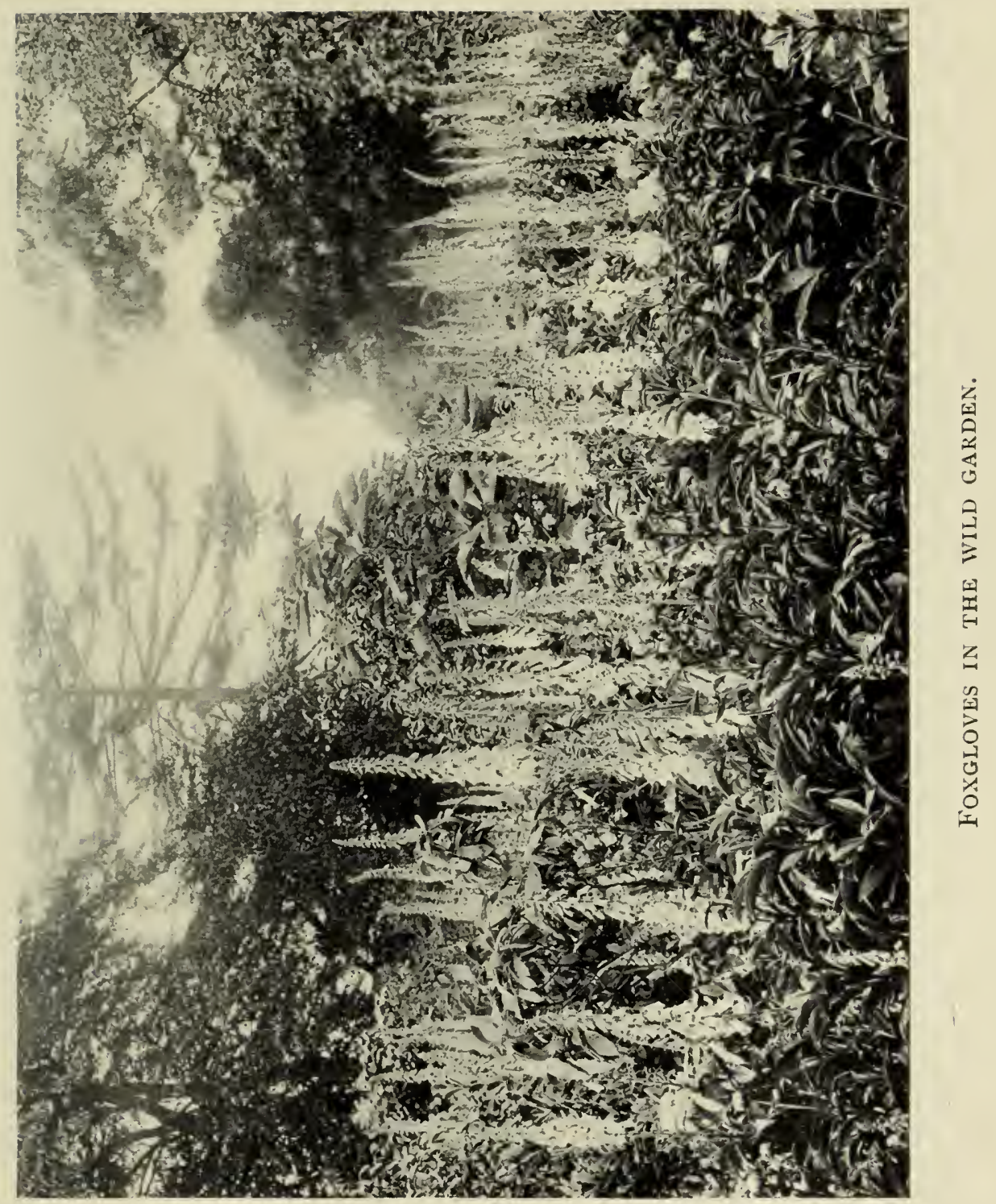



glove in order to protect an injured digit-and it is a somewhat curious fact that the botanical name Digitalis comes from the Latin digitabulum, which means a fingerprotector. The connection between finger-stall and glove is obvious, and so we begin to see things. We see that the flower is either a glove or part of a glove (and it is all the same thing for the purposes of a flower name); we see that the fairies could legitimately claim the gloves as theirs, whether they put them on or hid in them; and, after all, it is not for us to dictate what the fairies shall do. So the Foxglove is really the Fairy's glove beyond all doubt or question.

As everybody knows, it is just when a fact has been established finally that somebody or other questions it. Accordingly, somebody questioned this. $\mathrm{He}$ was not satisfied that fairies ever got into Foxgloves, or had any other connection with them whatever. He dragged out the fact that there was an old musical instrument called a gliew, which was composed of a number of bells suspended on a pole, and invited us to believe that the Foxglove got its name from the resemblance of the flowers on their arching stems to the gliew. I should be disposed to accept this more readily if I could see where the first part of the name came in. Is the "Fox" again a corruption of folks, and are we to understand that the fairies made bell-music out of the flower? It is a rather pretty idea if it goes so far as this, but I do not know that it does.

The Foxglove is a grand old plant, and, wilding or not, we are glad to grow it in our gardens. It generally bears its inflorescence at intervals on a long stem, the flowers opening from below upwards, the topmost occupant being a small bud. Occasionally, however, it bears a large expanded flower at the top. It loves cool, moist 


\section{I74 POPULAR GARDEN FLOWERS}

places, and I have never had it so luxuriant and happy as in a low, mild, sheltered garden on Kentish clay. But it does not object to an elevated site provided that it has moisture. This is shown by its vigour in the Derby dales. It does, however, dislike, and very strongly dislike, a thin, hot, shallow soil in an exposed place. The winds worry it. The soil stints it of moisture.

A London amateur whom I knew once had remarkable success with Foxgloves in a garden at Dulwich by the simple plan of preparing a piece of ground between a shrubbery and a Rose pergola and flinging the seed broadcast over it in June. He had the most glorious colony of Foxgloves that I ever saw in a private garden. The long tall spires rose high above the heads of visitors, and they produced a remarkable effect against the background of shrubs, and, where they rose above the latter, against the sky. One looked through a forest of lofty spikes to the sky-line beyond, broken by the tall towers of the Crystal Palace.

When the plants are established in a position that they like they seed freely, and become an institution which no one will find it in his heart to overturn. They may be grown in the herbaceous border, but under restriction, so that they may not over-ride smaller things. It is an easy matter to keep them within bounds by hoeing out any superfiuous self-sown seedlings.

Seedsmen have raised improved strains of Foxgloves, and whoever proposes to establish the old flower in his garden should make a point of getting a good strain of Giant Spotted in mixture. Separate colours, such as primrose, rose, and white, can also be had. Moreover, some of the larger seedsmen offer seed of the form which produces terminal flowers, and this is not only interesting but beautiful. 


\section{ON FOXGLOVES}

Little skill is called for in raising Foxgloves from seed. It may be sown on a prepared seed-bed, the surface of which has been made quite fine, in May. The seedlings may be thinned when they become crowded, and if they again interfere with each other, may be set out a few inches apart in a spare plot. They may be transplanted to their flowering quarters in autumn. It is a good plan to treat them as biennials, like Wallflowers and Canterbury Bells, in spite of their nominally perennial character, because they are apt to die off after flowering, and the flowers of self-sown seedlings degenerate. 


\section{XIX}

\section{ON GERANIUMS}

IN my remarks on the shrubby Calceolaria I referred to the abuse of the plant in years gone by, when it was used as one of the three items to form "ribbon borders," and also in bedding. It is scarcely necessary to remind readers of an older gardening generation than the present that one of the other components of the "ribbon border" was the scarlet Zonal Geranium, and that it was the most important of the triumvirate which nearly drove lovers of artistic gardening to distraction.

In those days the true Geranium was a wholly unimportant plant. One or two of the native species were admired by lovers of wild flowers, notably the Herb Robert (Geranium Robertianum), with its hairy red stems and pretty pink flowers; but the majority were hardly thought to be worthy of notice. Things have changed so much that the Geranium has now receded into the eminently respectable position of chief ornament of the villas of retired grocers, while the hardy species have been admitted to the borders of advanced flower-lovers.

The Geraniums and Pelargoniums both belong to the natural order Geraniacee, and the confusion of names is not altogether surprising. The name Geranium (Crane'sbill) comes from gevanos, a crane, in allusion to the beaklike projection on the seeds; while that of Pelargonium 
(Stork's-bill) comes from pelargos, a stork, in allusion to the beak-like form of the seed-pod. There is a similarity of derivation here which arrests attention at once, and suffices to show excuse for popular confusion. It is not until we study the structure of the flowers botanically that we get on to safe ground. The flowers of the Geranium are regular, spurless, and with ten stamens: those of the Pelargonium are irregular, spurred, with five stamens or less. Thus we concede a point to the botanist, and admit that, while he sometimes tries our patience, he keeps us right in the main.

Hardy Geraniums. - Several of the true Geraniums are British plants. In addition to the Herb Robert, such species as pratense, purple, the Meadow Crane's-bill; sanguineum, crimson; lucidum, pink; and lancastriense, striped, may be named as wildings. The Zonal Geranium, however, in common with most of the other Pelargoniums, came from South Africa, and is not hardy in Great Britain.

Lovers of hardy plants will gladly admit some of the true Geraniums to their gardens, especially if they have to furnish borders that are partially shaded by trees. I have used these Crane's-bills somewhat largely on a cool, shady border of clay soil in a Kentish garden, and they have proved very useful, spreading into large but not univieldy masses, and providing numbers of brilliant flowers. They proved easy to increase to any desired extent by means of division in spring. In addition to the natives named, I found armenum, a purple species from Nepal; sylvaticum, having purple flowers with crimson veins; cinereum, red, from the Pyrenees; and striatum, striped, an Italian species, good; the collection was strengthened by one or two garden forms of the natives, such as the double and white varieties of pratense. 


\section{I78 POPULAR GARDEN FLOWERS}

The last-named luxuriated in the cool surroundings, as it does in the Yorkshire and Derbyshire dales, but on being removed to a hot, exposed hillside on limestone soon dropped out of existence. The Shining Crane'sbill (lucidum) and the Herb Robert will both thrive on dry sites.

There is a handsome allied plant to the Crane's-bill in the Heron's-bill (Erodium Manescavi), which succeeds on a dry sandy or chalky soil, and is by way of being a favourite with lovers of hardy plants.

The Zonal Geranium.-It would be affectation to attempt to exclude the Zonal Pelargonium from the ranks of the Geraniums, even though it be not a true Geranium botanically. We cannot take one of the people's flowers by the scruff of the neck and thrust it out of the G's into the P's without a word of explanation. We shall find, if we try this, that we shall have shoals of indignant letters demanding to know why we have left out a popular garden plant from our list; and when we explain that we have not left it out, but have merely put it into its proper place, we shall have a fresh shoal of letters, couched in even more scornful terms than before, charging us with pedantry.

As long as the prefix "zonal" is used, there seems to be no harm in referring to the modern varieties of Pelargonium zonale as Geraniums. There are many species of Pelargonium, and they might be classed into two sections-those with wrinkled green leaves and those with flat leaves having a colour zone marked upon them. It is only the latter that can be acknowledged as Geraniums; the others are, always have been, and always will be, Pelargoniums.

The zone-leaved Geranium came from the Cape of Good Hope in ifio. It is a shrubby plant, retain- 


\section{ON GERANIUMS}

ing its stems throughout the year, whereas the true Geraniums are herbaceous, dying down to the root in autumn. The leaf had the distinguishing band, and the flowers were scarlet. But the form was very different from that which we see in the best modern varieties. If the reader examines the flowers of a Pelargonium species he sees that the petals vary in size and are narrow; the upper petals are larger than the lower ones. Such were the flowers of the first scarlet Geranium. Compare the old type with the modern variety. All the petals in the latter are so nearly equal in size that it is impossible to see any difference between them; they are rounded, they overlap each other. Thus, instead of a "truss" (for such the flower head is called) showing gaps, it is an unbroken ring. The beauty of the plant is enhanced greatly by the change, which has been brought about entirely by the efforts of the florists. They have patiently selected good types and raised improved varieties by cross-fertilisation year after year, until they have given us an altogether superior plant.

In due course the public began to take an interest in the improved Zonal Geraniums. Gardeners discovered that the plant had a great fund of vitality, which made it grow in almost any circumstances short of frosty weather, that it bloomed with remarkable persistence, and that the colours were very brilliant. So they began to fuss over it. At first, no doubt, they valued it as a greenhouse plant, and they would like it more and more when they discovered how well adapted it was for winter flowering. But presently they tried it as a summer bedding plant, and found it extremely useful in the open air, where, so long as the weather was warm, it grew and flowered for several months without a break. A craze for "bedding out" and ribbon borders followed, and 
the Zonal Geranium was the hero of it. Flower-gardeners scrambled after novelties eagerly, and paid high prices for them. The introduction of a new variety became quite an event in the floral world.

Flower-lovers of artistic tastes revolted at length. After all, what was there in a border of scarlet, yellow, and blue, the plants in regular lines? And what was there in a bed of red Geraniums with a belt of blue Lobelia round it? It had, and has, its public, like a murder mystery, but it was not a public of educated modern gardeners. Besides, the plants were tender, and had to be wintered under glass.

In the end the bedding-out craze collapsed; narrow ribbon borders disappeared, and broad herbaceous borders took their place. Beds were reduced in number to make room for larger borders in small places, and were enlarged and planted with Roses, Carnations, Chrysanthemums, and other good hardy plants.

Winter Bloom.-The Geranium did not die out-it was far too valuable a plant for that-but it retained favour mainly as a winter plant for warm greenhouses and conservatories. It was, and is, admirably adapted to winter use. Large plants can be secured from cuttings in six months, and with very little attention and no great amount of heat- $50^{\circ}$ sufficing-they will bloom for the whole of the winter. The diversity and brilliance of the colours are unequalled by any other winterblooming plant. A collection of well-grown Zonals is a most valuable asset in winter. It is as sparkling and enlivening as a display of fireworks-a little startling: perhaps, like the rockets, if there is a preponderance of the most vivid colours, such as scarlet, crimson, salmon, and vermilion; but there is no reason why the charming whites and pinks, of which there are so many good 
representatives, should not be used to check any exuberance. Given this provision, the Zonals will restore the most depressed person to joviality. $\mathrm{He}$ has only to throw away the newspaper which contains such melancholy news about his investments, and to stalk resolutely into his greenhouse to be restored to serenity.

The Zonal Geranium is still, of course, a useful garden plant. If it had not been a good plant it would never have become sufficiently popular to be overdone. And the fact that it has been over-used should not, by the force of reaction, lead to its being under-used. It is a capital plant for the amateur to draw upon who begins his gardening year, perforce, late in spring. He can buy it cheaply in boxes, or out of small pots, in May or June. It is equally happy in a town and in a suburban garden. It does not object to poor soil. It will grow almost better than any plant of standing in a dry place. It will never stop flowering, when once it starts, until frost comes. It will throw its flowers well above the leaves, and so be really "decorative."

With all these qualities it is impossible that the Zonal Geranium can drop out of gardens. And those who may not feel that they can spare a place for it in their principal beds or borders, may often be glad to fall back upon it for a dry bank or other unfavourable spot, or to grow large plants in tubs or vases on terraces, near flights of steps, and in other selected positions.

Amateurs who have no glass should not attempt to raise their own Zonals, and it is hardly worth while to keep old plants through the winter. It is true that they will often live in a cellar or frost-proof store if pruned hard both at head and root in autumn; but young 


\section{82 POPULAR GARDEN FLOWERS}

plants are likely to do better the following year, and, cheap as they are nowadays, anybody can afford to buy a fresh stock each season.

Propagation.-Given a greenhouse from which frost is excluded in winter, four-inch flowerless shoots may be taken off the plants in August just below a joint, deprived of their lower leaves, and inserted firmly two inches deep in shallow boxes of sandy soil, or even in a prepared bed outdoors. In any case they should be exposed fully to sun and air. They will have rooted by the time they have to be put under glass in October, but will not have grown much, and it is not desirable that they should, because the more growth they make in winter the more room they will want, and space is generally at a discount. On this account the cooler they are kept the better, provided frost does not touch them. They may be put in unheated frames in April, and hardened-as far as they can be hardened-by full exposure in fine weather.

Plants to flower in winter should be raised from cuttings inserted in small pots in a greenhouse in May, and not allowed to bloom until autumn, all the flowers being picked off as fast as they show. If they are kept thenceforward in a house with a temperature of $50^{\circ}$ to $55^{\circ}$, with $45^{\circ}$ as a minimum, they will bloom continuously until spring. Decaying flower trusses should be picked off regularly, as if the petals fall on to the leaves and stick, disease will develop in the foliage.

The Ivy-leaved Geranium, like the Zonal, is really a Pelargonium. There are many flower-lovers to be found who consider it to be the most beautiful member of the genus, when represented by the modern varieties which the florists have raised. These sorts have come 
mainly, if not wholly, from Pelargonium lateripes, a species with light purple flowers, which was introduced in 1787 . They form charming bedding plants, as the foliage is attractive, the plants ramble freely, and the flowers are brilliant. They may also be grown in stone vases and baskets. Few things look better in pedestal vases on steps or terraces. They are also admirable for pot culture.

Zonal and Ivy-leaved Geraniums alike grow too strongly to bloom well in rich soil and shady situations. They should be grown in unmanured, or very lightly manured, soil, in order to keep down their inclination to rankness. As a chalk-soil gardener I cannot but consider them with gratitude, and would not be without them. Even in a narrow south border under a house wall I can have months of beautiful blossom by the simple expedient of taking out a foot of chalk, and substituting loam from decayed turves-loam none too good in quality, and by no means calculated to satisfy an aspirant to exhibition honours with Roses and Chrysanthemums, but fertile enough for the Geraniums. These accommodating plants will grow, indeed, almost anywhere, and it is a foolish gardener who refuses to admit them, for no other reason than that somebody else grew too many of them twenty years ago.

From Seed.-Can Zonal Geraniums be grown from seed? Assuredly, and flowered in four months to boot. All the larger seedsmen sell selected strains, which will give flowers of good form and colour. The seed could be sown in a pan or box of sandy soil in spring, and placed on the shelf of a warm greenhouse, or in a heated frame. When the plants were an inch high they could be set out, four inches apart, in a shallow box, and kept close to the glass. When they began 


\section{84 POPULAR GARDEN FLOWERS}

to crowd, they could be put into small pots, or planted in the garden. The former would be the better, as it is always well to flower seedlings under glass in the first place, and pick from the batch those of which the habit and colour render them most suitable for the garden.

A collection of seedling Zonals forms a very interesting hobby for the amateur gardener. Very few plants that he could take up would reward him better, by cheerful growth and bloom, for the time he devoted to them. One word, however, to the amateur crossfertiliser: do not start with a poor strain, the trusses of which are loose and gappy, and the "pips" (individual flowers) ragged. To do this means plodding for years along a path that earlier raisers have already trodden, and to creep lamely behind them for a whole lifetime. Begin with the best strain procurable-a strain with smooth, round flowers, and a large, circular truss-then there is a real prospect of getting valuable novelties. Before me, as I write on a dull November day, are several plants representing an experiment on the part of the wife of a well-known florist. This energetic lady gardener thought that it ought to be possible to get extra large pips, with flower-heads as big and handsome as those of the well-known Paul Crampel (many, by the way, will tell you that this is the best Geranium in cultivation, and they are not to be contradicted hastily), and so she set out to do some crossfertilising on her own account, her husband surveying her operations with an affectionate tolerance. Here is the result : some of the pips are four inches across, and all are of huge size, splendid form, and perfect colour. They are a genuine advance, and show the advantage of starting at the top with a high ideal. 
The following are beautiful varieties of Zonal Geraniums :-

\begin{tabular}{|c|c|c|c|}
\hline Variety. & & Colour. & Bedding or Pots. \\
\hline Beckwith's Pink . & & Pink & Both \\
\hline Crystal Palace Gem & - $\quad$. & $\begin{array}{l}\text { Scarlet, leaves } \\
\text { yellow }\end{array}$ & Bedding \\
\hline Flower of Spring & . & Silver leaves & Bedding \\
\hline F. V. Raspail . & - & Double crimson & Pots \\
\hline Gertrude Pearson. & . & Pink & Pots \\
\hline Henry Jacoby & . & Crimson & Both \\
\hline Hermione & . & Double white & Pots \\
\hline John Gibbons . & & Orange & Bedding \\
\hline King of Denmark . & & Double salmon & Pots \\
\hline Mr. Hy. Cox . • & - & $\begin{array}{l}\text { Dark variegated } \\
\text { foliage }\end{array}$ & Bedding \\
\hline Mrs. Pollock • & • & $\begin{array}{l}\text { Light variegated } \\
\text { foliage }\end{array}$ & Bedding \\
\hline Paul Crampel . & - & Crimson & Both \\
\hline Pierre Loti $\quad$ : & - & Double rose & Pots \\
\hline Swanley Single White & - & White & Both \\
\hline Ville de Poictiers & . $\quad$. & Double scarlet & Pots \\
\hline
\end{tabular}

The following ivy-leaved varieties are well adapted for garden culture, and may be propagated from cuttings the same as the Zonals :-

Galilee.-Double rose.

Madame Crousse.-Double silvery pink.

Riyecroft Surprise.-Double salmon pink.

Souvenir de Charles Turner.-Deep carmine pink. 


\section{XX \\ ON GLADIOLI}

THE Gladiolus has never made much progress with a popular name. Nominally it has one, like most other plants, but even those people who prefer "English" to Latin names tacitly ignore it, and it is probable that the great majority would wonder what was meant if a writer referred to Corn Flags. The Corn Cockle they know, the Corn Marigold they have more than a nodding acquaintance with, but the Corn Flag puzzles them, and they are disposed to sum it up as "some kind of Iris." Well, the Corn Flag belongs to the natural order Iridacee, and, therefore, has a botanical kinship with the Irises, but it is really the Gladiolus, and that is a distinct genus.

It is a little singular, perhaps, that the Gladiolus has not a popular name-a popular name, that is, which is really popular, instead of one which nobody knows anything about-because the botanical name is not an easy one for the multitude to cope with, and there are as many ways of pronouncing it as there are of writing a plant label. Of course the scholar has no difficulty in the matter. He points out that the name derives quite obviously from gladius, a sword, in reference to the shape of the leaves; and that, in consequence, the pronunciation must be Glad'-io-lus, the accent being on the first syllable, here accented, the two vowels in the second being run together sharply, and the third being 
disposed of with as quick a pressure of the tip of the tongue on the palate as the music-master insists on in his interminable exercise on lah, lah, lah. When the student has touched the palate with his tongue in order to produce the labial sound, he has to get the organ down into the bottom of his mouth as quickly as he can in order to remove any obstacle to the passage of the vowel sound from his widely expanded throat-so sharply must he dispose of lus.

But flower-lovers are not all word-students. They did not know that Gladiolus came from gladius, and even if they had known they would not have been any nearer knowing how to pronounce it, and so they went their own way. Some called it Gla-die'-o-lus, making four syllables, and accenting the second ; others Glad-e$o^{\prime}$-lus, again making four syllables, but accenting the third. Popular pronunciation hovers between these two, and perhaps to the latter. Both are wrong, but the offence committed is one of those that people who know must deal gently with, rebuking the offender by no more drastic method than taking the first opportunity of repeating the name with the accent in its proper place.

However great our enthusiasm for the Gladiolus may be-and if we have once grown it successfully, that enthusiasm is likely to be warm-we have to acknowledge that it can hardly be classed as one of the great flowers of the people. It is hardy, it is grown easily, it is almost incomparably beautiful, but it just misses greatness. Except in the case of one or two kinds, it lacks perfume, and it is not quite capable of holding its own in the rough and tumble with Nature which garden plants have to undergo sometimes. Perhaps this is more marked in a liability to attack by wireworms than in susceptibility to cold. But a plant must be wireworm- 


\section{88 POPULAR GARDEN FLOWERS}

proof, just as it must be cold-proof, to satisfy us entirely. What amateur florist, operating in a garden that he has made himself from pasture, but mourns the liability of Carnations to be attacked by wireworm? More often than not he is induced to enthrone Chrysanthemums or Sweet Peas or Roses as the queen of his floral loves for, at all events, the first few years of his work; and only after he has worried his underground enemy out of the field can he take up Carnations with any confidence.

Wireworm.-The Gladiolus is as susceptible as the Carnation to wireworm attack. The grubs fasten on the corms (a Gladiolus "bulb" is really a corm, and a corm, as we saw under Crocus, has no visible scales like a bulb) in myriads, and soon make short work of a large collection. If it is planted in new land from pasture the turf should be taken away, not turned in, however deeply; and in spring, before planting, Vaporite or Apterite should be dug in nine or ten inches below the surface.

Grace of form and beauty of blossom distinguish the Gladiolus in a remarkable degree. The habit is somewhat singular. At the ground level the growth is a thick purplish stem, a few inches above it becomes flattened, and there the leaves emerge, the lower part cohering in a flat, plate-like mass, the upper spreading out almost like an open fan. The flower stem rises from the heart of the leaves in July or August, and conical, pointed buds form on it. As it extends, the lower buds thicken, and fresh narrow ones appear on the upper part. Future development finds the same expression - stem-extension and bud-production-going on simultaneously. While buds on the lower part of the stem are bursting and colouring -becoming, in fact, flowers-fresh ones are forming higher up, and so there is a long succession.

For Cutting.-The lady flower-lover will not fail to 
take full advantage of this habit. She will cut the stems when the lower buds are bursting, and carry the spike triumphantly indoors to adorn a tall vase, where, for some three or four weeks, it will be engaged in the delightful task of unfolding a succession of the most beautiful flowers. At the outset she will arouse the unmeasured wrath of her lord, who will loudly bemoan the ruin of his bed; but when he finds that the plants, deprived of their first spikes, straightway proceed to produce more, he will graciously permit himself to be pacified.

It may be stated, for the special benefit of lady readers who like to cut flowers, and in particular Gladioli, that the number of spikes which a plant will produce depends mainly upon the thoroughness of the culture. If the soil is deep and fertile, the plants (always provided that the corms planted are good and remain uninjured by wireworms) will be strong, and will be quite capable of yielding a spike each for the house and still producing a reserve for the garden. It is obvious from this that if an amateur does not get a satisfactory result after his wife has had the first helping, it is his fault, and not hers. She will need no prompting to "rub in" this point if occasion arises.

When it is said that good corms are desirable, large ones are not meant necessarily. Some varieties produce much smaller corms that others, and no cultivation will make them large. They will, however, produce enormous spikes. A normal corm is about two inches across, but in some sorts the corm is less than an inch across the base. It happens that some of the largest varieties have these small corms. If the amateur buys from growers of repute, he need not be alarmed at a small "bulb." He may take it for granted that all is well. 
In the best modern varieties of Gladioli the individual flowers are nearly as large as Candidum Lilies, and they are arranged on the stem in a double row, facing one way, so that they are collectively, as well as individually, beautiful. Such sorts are much superior to those in which the flowers face different points of the compass. If the Gladiolus-grower is one who raises seedlings, he should only choose those which have this desirable trait for future propagation.

The colours are brilliant and varied. We get blush, pink, rose, scarlet, crimson, lilac, salmon, ruby, cream, cherry, mauve, and yellow. Many varieties have a white or yellow throat with a different body colour. Others are flaked or spotted. It was many years before we got a pure white and a self yellow in the large-flowered type; we have these treasures now.

Beautiful Species. - The magnificent modern Gladioli have been developed by hybridising between different species. A few are still grown, and I may touch on the best of them, without, however, committing myself to the assurance that they are all really genuine species : I have grave doubts about several. Blandus, flesh-coloured, is one of the earliest to bloom, opening in June; it may be planted in autumn. Blushing Bride, pale pinky white, blooms early. Brenchleyensis, scarlet, flowers in July from corms planted in autumn. Colvillei, often classed as a species, is really a hybrid between cardinalis and tristis; it is red marked with purple; both it and its white variety, alba (The Bride), but more particularly the latter, are valued for pot culture, being treated like pot Hyacinths and Tulips. Delicatissima, pale pink, spotted, is an early bloomer. Floribundus, citroncoloured, blooms in July. Gandavensis, crimson and yellow, is a hybrid, and one of the parents of our beauti- 


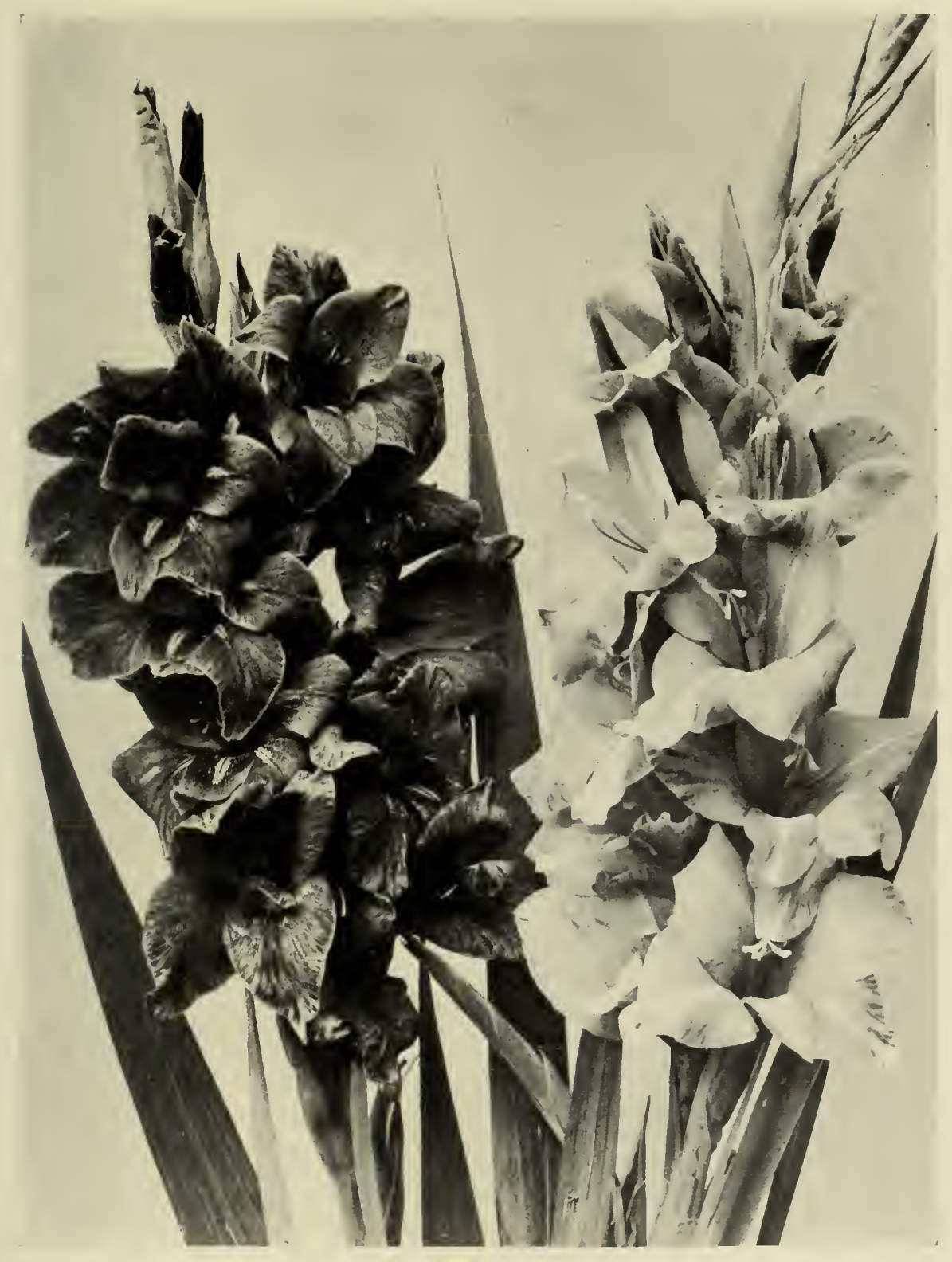

Giadioli. 

ful modern varieties. Ne Plus Ultra, spotted, an early bloomer, is doubtless a hybrid. Psittacinus, red and yellow, blooms in July. Purpureo-auratus, yellow and purple, has been much used as a parent. Ramosus, rose, is a July bloomer. Saundersii, scarlet and white, blooming in August, has been used as a parent. Tristis, with brown and red flowers in July, is not showy, but is scented.

Classes.-Gandavensis, the most important of the foregoing, took its name from the fact that it was sent out by a Ghent (French Gand) florist, but it was raised at Enghien, where it was secured by crossing psittacinus with either cardinalis or oppositiflorus. Variations appeared, and were intercrossed, so that we soon had a large number of varieties bearing the sectional name of Gandavensis. The best of them are distinguished by beautiful symmetry. But the value of the hybrid did not rest in this. It was crossed with the species purpureoauratus, and gave an entirely distinct blotched section called Lemoinei, after the Nancy hybridist Lemoine. It was further crossed with seedlings of Saundersii, and gave us the Childsii section, which are distinguished by very large flowers, albeit set loosely on the spike. Crossing between varieties of the Lemoinei and Gandavensis groups gave the sub-section Nanceianus.

One feels a little apologetic in referring to these various processes and their result, but it happens that some dealers classify the varieties in their catalogues, and without a few words of explanation the reader might be puzzled by the group headings. It really is not necessary to keep the classes separate to enjoy Gladioli as garden flowers. If a variety is beautiful we need not probe its parentage, although this is a proceeding which has its interest for a good many flower-lovers. The 
most that the amateur need do is to keep the earlyflowering section, such as Blushing Bride, Brenchleyensis, Colvillei, The Bride, Delicatissima, Ne Plus Ultra, Psittacinus, and Ramosus separate from the later hybrids. Most of the former are very cheap, and may be planted in autumn; they ought not to be put in later than February. Nearly all may be grown in pots, although Brenchleyensis is a little too robust to make a perfect pot plant. This, one of the noblest of Gladioli, with its massive spikes of brilliant scarlet flowers, is also one of the hardiest and cheapest. It flowers in July and August.

Named Varieties. - The best named varieties of lateblooming hybrid Gladioli are somewhat dear, and many flower-lovers may be satisfied to buy mixtures. Dealers of standing put splendid varieties in their mixtures, and a well-grown bed of them will be a wonderful spectacle of floral beauty. The tall Childsii and the spotted Lemoinei varieties are upstanding plants, and are very hardy, so that the corms may be left out all the winter if it is not convenient to store them. The Gandavensis varieties should be lifted. The following are a few good varieties of this beautiful section :-

Commandant Marchand, ruby.

Enchantresse, rosy lilac.

Formosa, rose.

Grand Rouge, crimson.

Klondyke, yellow, flaked carmine.

L'Incendie, cherry.

La Parisienne, yellow, shaded mauve.

Marie Thérèse, cream.

Maréchal Vaillant, scarlet.

Pascal, rose, white centre.

Pyramide, rosy orange.

Sanspareil, orange, white throat. 
Preparing Soil.-Is the reacler fired by the preceding eulogy of Gladioli to a resolution in favour of buying a collection and giving it the best possible chance? Then let him prepare his ground as follows: In autumn remove the topsoil and break up the subsoil, turning in a dressing three inches thick of decayed manure. If the ground is very stiff, leaf mould and sand may be added. Leave the surface lumpy. In February spread on a coat of wood ashes, with an additional quantity of bone flour at the rate of three ounces per square yard, and fork it in. This operation will simultaneously reduce the lumps to small particles. The soil is now in fine condition for planting.

The corms may be put in a foot apart about the end of March, and may be set in angles (see figure in Chapter VIII., where the same method is advised for planting Carnations). They may be covered with four inches of fine friable soil, and the bed rolled or trodden. By the time they come through weeds will have grown, and a hoeing will stimulate the plants and destroy the weeds. Care must be taken to avoid cutting off the young spikes, but should so sad an event take place, the grower need not become a prey to despair, even though (as is quite likely to be the case) the variety injured happens to be one of the most esteemed, because the plant is almost certain to throw up another shoot. The hoeing should be continued throughout the summer.

If the soil is light and shallow, soakings of water will be helpful in dry weather, and when the flower spikes begin to push up, a drenching of liquid manure, repeated weekly to the end of the flowering season, will do great good. Given these attentions, light soil grows Gladioli well. In clay soil they will not need artificial watering. Heavy ground will give good results provided it is 


\section{94}

\section{POPULAR GARDEN FLOWERS}

well drained and friable, for the Gladiolus is not really exacting, although it dislikes stodgy, cold land. Directly the buds form, stakes should be put to the plants and the spikes tied, or the first storm will break them, especially if the site be exposed; a sheltered though sunny position should be found if possible.

In cold districts it may be found advisable to start Gladiolus corms in pots or boxes in spring, as advised under tuberous Begonias, and to plant them out, well rooted, towards the end of May.

Wintering.-The corms should be lifted in autumn, except when the Childsii and Lemoinei varieties are being grown in a light, warm soil; and it is not wise to wait until the leaves have died away, for that may not be until the New Year, but proceed as soon as the foliage loses its freshness. The plants may be laid in a shed for a few days to dry, and then deprived of stems and roots, leaving only the corms. It will be found that, in many cases, the old corm has begun to decay, and that a new one is fixed on the top of it; they should be broken apart forcibly, and only the new corms, with any young ones, preserved. These can be stored in dry sand in shallow, uncovered boxes till spring. The large ones will flower again the same year as they are planted, the small offsets not till the following year.

From Seed.-To raise Gladioli from seed, sow in pans or boxes in spring, put in a warm frame or greenhouse until germination has taken place, harden the plants in an unheated frame, and stand the pans outside in May. It is hardly worth while to plant them out until the following year, as they will not grow strongly. They can be dried off in autumn like large corms and planted the following spring, to flower in that or the following year. 
I should be glad if I could conclude by saying that the beautiful Gladiolus is suitable for planting in any herbaceous border, but the truth is it does not appreciate the companionship of big, coarse-rooting things, and is best in a bed to itself. However, it will thrive in the border if it is planted in a little colony to itself and protected from the encroachment of greedy giants. 


\section{XXI}

\section{ON THE HOLLYHOCK}

THERE is no finer border flower than the Hollyhock when it is healthy and well grown, and it is not surprising that gardeners still cling to it in spite of the clisasters which sometimes accompany its cultivation. The fact is, sentiment becomes entangled with these old plants, and the nearer we get to our own disappearance from the world's garden, the more affectionately we think of the flowers of our youth. People whose memory is good can recall the halcyon days of the Hollyhock, even it their hair is only as yet half grey, and they are loth to part with the picture which it brings before them of stately groups, seven or eight feet high, clothed with green leaves and studded with large, brilliant flowers.

It is rarély that we see perfectly healthy Hollyhocks in these degenerate days. Even if the plants get to the flowering stage, they still fall short of the Hollyhock beauty of former days, because the lower foliage is discoloured by their hereditary enemy, the fungus called Puccinia malvacearum. The latter name, compounded as it is from Malva, the botanical name of the Mallow, shows at once the "family" nature of the fungus (that is, its particular association with the Mallows) and the kinship of the Hollyhocks with the Mallows. The Hollyhock is, indeed, a relative of the common 


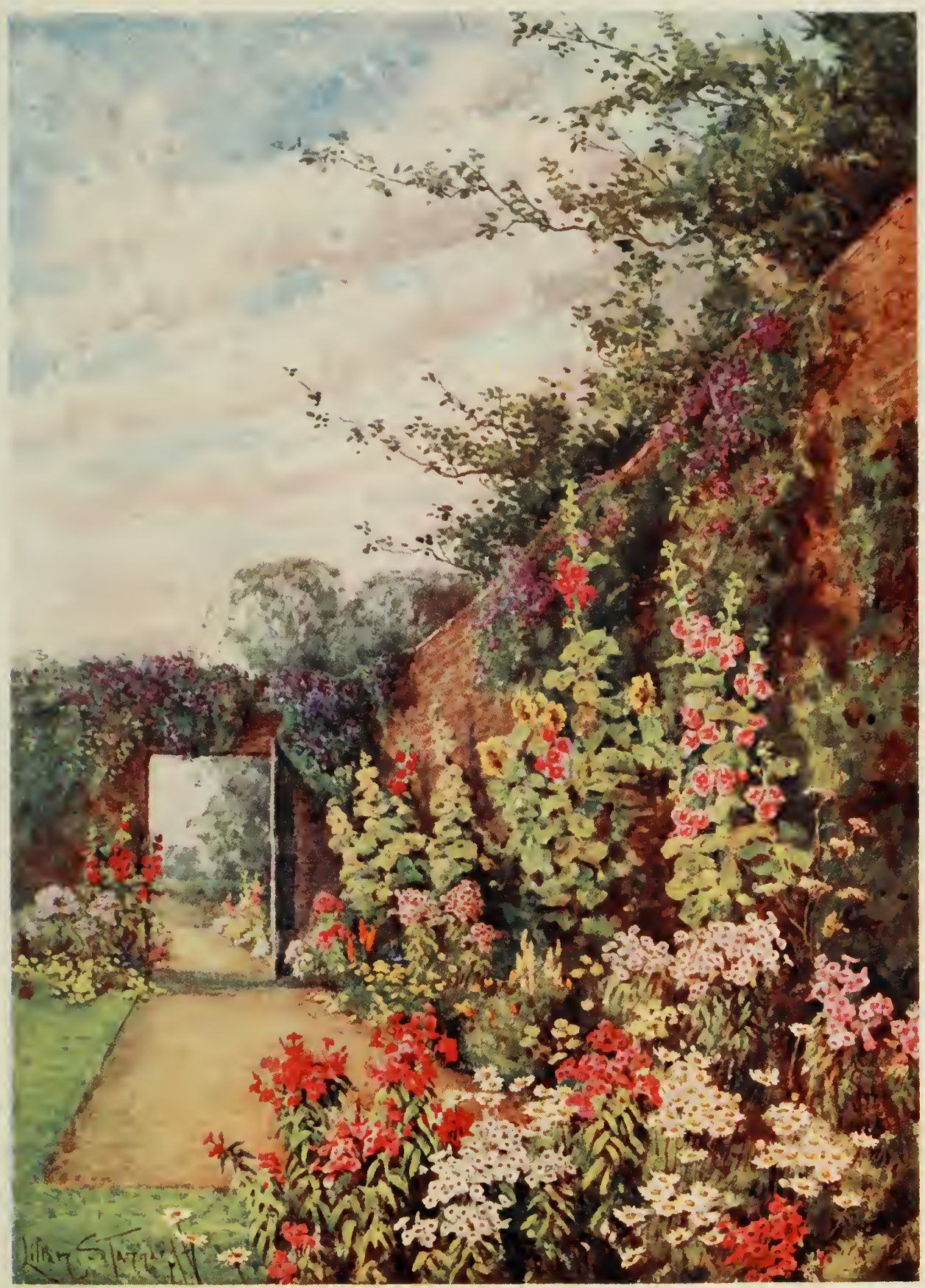

Froma a Water Colour Drareing by Lilian Stannard.

Hollyhocks and Herbaceous Phloxes. 

Mallow, which is known to botanists as Malia sylvestris, grows by the roadsides and in waste places, and bears pale purple flowers in June. It is a closer relative still of the Marsh Mallow, which frequents the sea marshes, grows two to three feet high, and bears pink flowers in August. The Marsh Mallow is Althea officinalis, and the Hollyhock is Althea rosea. Another relative is the Hibiscus, several species of which are esteemed in gardens. Althea frutex is the same as Hibiscus syriacus.

The Hollyhock was introduced in 1573. Botanical works give China as the native country, but it was probably brought to Europe by way of Palestine. Anyway, in striving to find the origin of the popular name, we have a difficulty in escaping from the conviction that it is the "holy mallow," the holi-hoc (Anglo-Saxon, hoc $=$ mallow) of the Middle Ages.

Althæa comes quite obviously from altheo, to cure, in allusion to the medicinal virtues of the plant, which are well marked in the Marsh Mallow.

The Hollyhock was not a familiar plant in mediæval times. The reader will not find it alluded to by Shakespeare, for example; but the common Mallow did not escape the eye of the bard, as witness-

\section{"He'll sow't with Nettle seed, Or Docks or Mallow."}

The Tempest, Act ii. scene I.

Hollyhocks were, however, grown in Elizabethan days, for Parkinson knew them, and actually illustrated a double variety under the name of Malva rosea multiplex. The flowers were improved steadily as the years passed, and in the early half of the last century had been developed so highly as to become among the most important of garden flowers. They were greatly im- 


\section{I98 POPULAR GARDEN FLOWERS}

proved by a trade florist named Chater, living at Saffron Walden, in Essex (see the chapter on Crocuses for a note of the derivation of the name of this old town), and for many years "Chater's strain of prize Hollyhocks" was a feature of the catalogues of the principal seedsmen. Special varieties were grown under name, just the same as Roses, Carnations, and Dahlias, and almost equalled these old favourites in popularity. There were classes for them at all the principal flower shows, and the exhibition blooms were truly remarkable, alike in size, form, and colour.

It was as a garden plant that the Hollyhock was valuable to the great bulk of flower-lovers. They set it in groups at the back of large borders. They even made beds of it. The tall spikes were closely studded with flowers from within two feet of the ground to the tip, and, leaning gently forward, made a gracious semblance of bringing their beautiful blooms nearer to the admiring eyes of the grower.

Cottagers grew the plant, and it did well in their modest gardens. Those who love to ramble in country places, examining the village plots as they pass reflectively along, cannot but heave a sigh of regret that the old-time pictures are seen no more, even though gay Sweet Peas and Dahlias enliven the gardens. The Hollyhock seemed to form an integral part of the cottage. The whitewashed walls of the dwelling formed a background for it, its crest touched the low, thatched roof. It stood in soldierly array at the back of the border wherein the Carnations, Pinks, Snapdragons, and Monthly Roses grew.

The undoing of the Hollyhock came swiftly in $x 873$. A year or two, and its career as a great garden and exhibition flower was at an end. Its kinship with the Mallows proved fatal. A destructive fungus burst like 


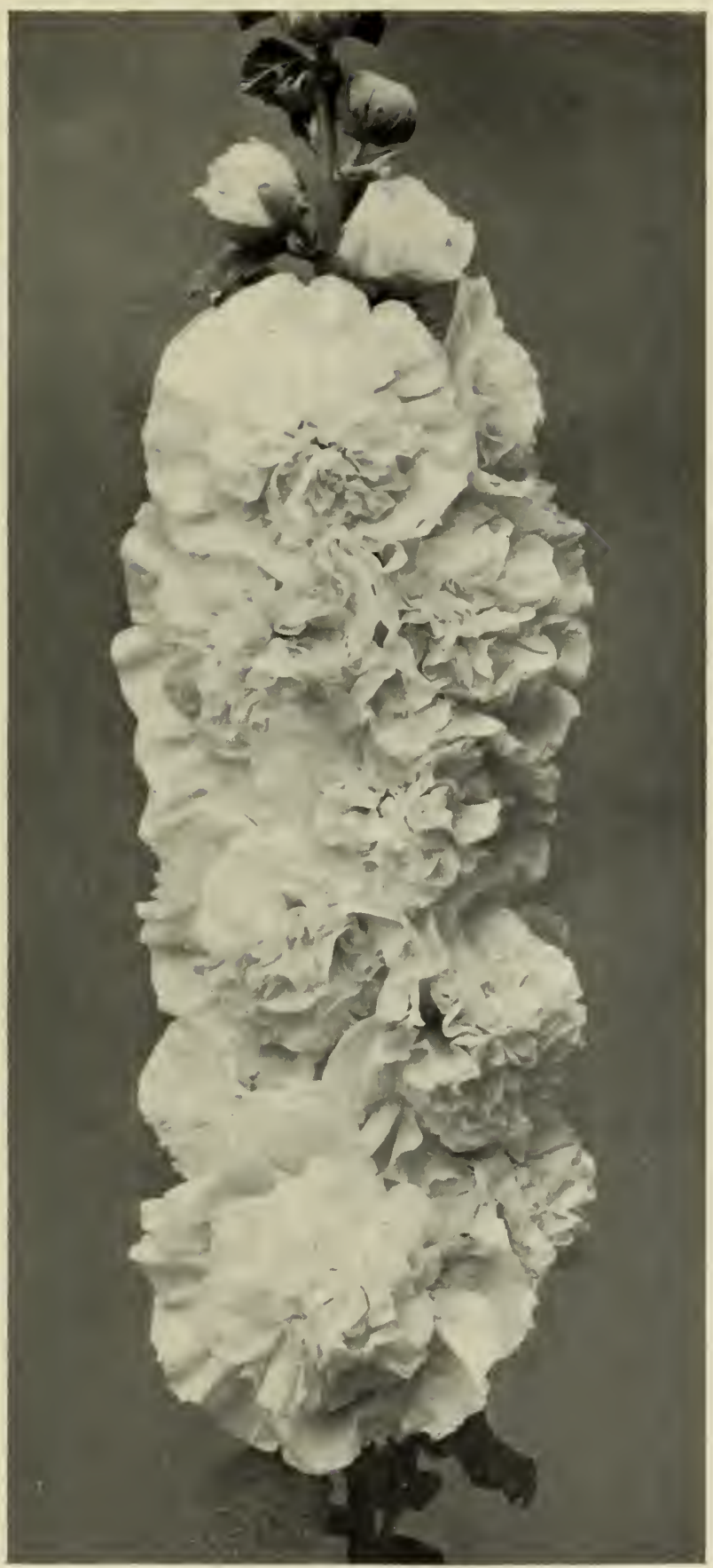

A WEIL-BLOOMEI HOLLYHOCK. 



\section{ON THE HOLLYHOCK}

a pestilence on the wild Mallows, and spread from them to the Hollyhocks. Contemporary writers blamed the railways, pointing out how the wild Mallow established itself and throve on the embankments, and from thence distributed its fungoid poison to the Hollyhocks in the neighbouring gardens. But the railways did not bring it across the seas. It was first observed in South America, whence it managed to get across the Pacific to Australia; and presently it reached Europe. The Hollyhock grower will, as a precautionary measure, destroy any wild Mallows that he sees near his garden, thereby tacitly acknowledging the wisdom of one of old Thomas Tusser's "Five Hundred Points of Good Husbandry."

The spores of the fungus are two-celled. Pustules form on the skin of the leaf, and they are the hyphæ of the fungus bursting through to the surface from within. The pustules spread rapidly, and the affected leaf shrivels. The loss of most of its leaves throws the plant into ill-health, and the flowering is impaired. It is wise to pull up and burn any diseased plant in the early stage of the attack, and to spray the remaining plants immediately with Burgundy mixture, which may be made by dissolving three pounds of bluestone (sulphate of copper) in water in a wooden bucket, three and three-quarter pounds of washing-soda in another vessel, adding the two together, and making the total quantity of water to twenty-five gallons. Smaller quantities of the mixture can be made, of course, by proportionate reductions of bluestone, soda, and water. It should be sprayed on in a fine, dew-like state, so that it adheres; if put on through a coarse hose it will run off again at once. It is useless when the fungus has become well established on the plants. 


\section{POPULAR GARDEN FLOWERS}

The more thoughtful of the florists were not disposed to put all the blame for the Hollyhock fungus on the bloated capitalists who perversely insisted on making railways; they turned the searchlight on to their own methods of culture, and were honest enough to confess that they may have weakened the constitution of the plant, and thereby predisposed it to disease, by propagating the plants from cuttings or grafts in a high temperature. There may have been something in this, although the fact that the disease attacks wild plants shows that cultivation is not at the root of it. However, the impulse to intensive propagation no longer exists, as there is no particular demand for named varieties, and consequently more subdued methods prevail, such as division or seed-sowing.

Most Hollyhock growers trust to seed nowadays, and such of them as buy from seedsmen of standing get a satisfactory percentage of good varieties, even though all may not be doubles. Single Hollyhocks are much inferior to doubles as show flowers, but not so far behind in garden effect, so that a strain which includes a small percentage of them need not be condemned. The seed can be sown outdoors in May or June just the same as that of Canterbury Bells; in fact, the plants may be treated as biennials, being raised from seed every year, bloomed the following year, and then cleared away. But if a particularly good variety should appear among the seedlings it should be preserved, and it may be kept true by taking cuttings or practising division. A simple plan of perpetuating a good sort is to take pieces of the stool in late summer, pot them, winter them in a frame, and plant them out in spring. Or young shoots, three or four inches long, may be taken from the stools when growth starts in spring, 
grafted on to thick pieces of root, tied round and potted, with soil over the union, and put in a close, warm frame. When they have rooted to the extent of filling three-inch pots with roots, they may be planted out.

Seedling plants should be encouraged to make good growth by thinning and hoeing in summer, and in autumn some may be put into small pots and wintered in a cold frame, the rest being planted out to take their chance. It is generally acknowledged by Hollyhock growers that seedlings are stronger and less liable to disease than plants raised vegetatively, and if fresh stock is raised at frequent intervals, and put on new ground, the pleasure derived from Hollyhocks may still be considerable.

The plants like a deep, fertile soil, but rank manure is not safe, and the ground had better be prepared in autumn. It may be dug deeply then, the subsoil being broken up, and a thick coat of manure laid on it. The top soil should be left rough and dressed with woodashes and bone flour or superphosphate in February, just as in the case of Gladioli. The manure will decay, the ground will become mellow, and the Hollyhocks will make healthy growth when put out in May. Strong stakes should be driven in at the time they are planted, as they will need tying.

The yellow and white fig-leaved Hollyhocks (Althea ficifolia) have a widening circle of admirers, and may be grown in addition to the old kinds. Seed is available. 


\section{XXII}

\section{ON THE HONEYSUCKLE}

THE lover of popular names is in high feather with Lonicera periclymenum, for he has two English names for it, and both are charming. "Honeysuckle" and "Woodbine" are used indiscriminately alike by many old and modern writers, but Shakespeare perhaps regarded the former as belonging to the flower and the latter to the plant. Note Titania's injunction in Act iv. scene I of "Midsummer Night's Dream" -

"Sleep, then, and I will wind thee in my arms.

So doth the Woodbine the Sweet Honeysuckle gently entwist. . . ."

Some writers boggle at the difficulty of making Woodbine and Honeysuckle mean the same plant here. Shakespeare clearly refers, they declare, to two; and they conjecture that by Woodbine he must mean Convolvulus. They probably base the opinion on Ben Jonson's figure-

\section{"Behold}

How the blue bindwood doth itself enfold With Honeysuckle, and both these entwine Themselves with Briony and Jessamine."

Would Shakespeare, however, have spoken of the Bindweed as "luscious"? Note those other famous lines in "Midsummer Night's Dream "-

"I know a bank where the wild Thyme blows,

Where Oxlips and the nodding Violet grows,

Quite over canopied with luscious Woodbine." 


\section{ON THE HONEYSUCKLE}

It is not impossible, inasmuch as the old form of the adjective was "lustious," and is derived from lusty. But if Shakespeare used it in the sense of sweet he could hardly have alluded to the Convolvulus. In early times writers referred to several creeping plants as Woodbine. The name was certainly applied to the wild Clematis and the Ivy. On the other hand, note Beaumont and Fletcher's

"Woodbines of sweet honey full."

These writers were contemporaries of Shakespeare, and students of their work associate all three of these men of genius in "The Two Noble Kinsmen," which appeared under the names of Beaumont and Fletcher. With the latter the Woodbine and Honeysuckle were the same, and it is not impossible that they were also identical in the mind of Shakespeare. He uses both names in "Much Ado about Nothing," Act iii. scene 1 . In the first case Hero bids Margaret tell Beatrice-

"Our whole discourse

Is all of her ; say that thou overheard'st us, And bid her steal into the pleached bower, Where Honeysuckles, ripened by the sun, Forbid the sun to enter."

In the second Ursula says-

"The pleasant'st angling is to see the fish Cut with her golden oars the silver stream, And greedily devour the treacherous bait; So angle we for Beatrice: who even now Is couched in the woodbine coverture."

These two references are only a few lines apart.

"Woodbine" derives from zoeden-binde, which later is wude-binde, and the name is in allusion to the habit of the plant. "Honeysuckle" certainly comes from the rich stores of nectar that are sucked from 


\section{POPULAR GARDEN FLOWERS}

it. It may be noted that the perfume is strongest after sunset, and the flower is fertilised by night moths. Its sweetness was known to Mistress Quickly, who, in "King Henry IV.," Part 2, Act ii. scene I, thus apostrophises Sir John Falstaff: "Ah, thou honeysuckle villain! Wilt thou kill God's officers and the king's? Ah! thou honeyseed rogue! Thou art a honeyseed, a manqueller, and a woman-queller."

In applying the adjective "honeysuckle" to the fat knight Mistress Quickly had in mind, perhaps, the persuasiveness of his tongue when he was in a mood to cozen her.

Milton had apparently distinct plants in view when he referred to Honeysuckle and Woodbine, whatever may have been the case with Shakespeare, because he spoke of the "Flaunting Honeysuckle" and the "wellattired Woodbine," thus using two adjectives of quite different meaning. Bullein, in "The Book of Simples," speaks of the "swete and pleasant Woodbine," and of its friendly embrace of "the bodies, armes, and branches of trees with his long winding stalkes and tender leaves, openyng or spreading forthe his swete Lillis."

The embrace of the Woodbine may be "friendly"; it is certainly very close. When the Honeysuckle gets hold it clings tightly, and growers have observed an association so intimate as to leave its mark on the stem of the supporting plant. Gardeners will not give it another plant to cling to, but will plant it to cover rustic fences, pergolas, arbours, and other erections. It is well worth planting in gardens, as the flowers are pretty as well as sweet, and they are followed by red fruit, which gives it attractiveness in autumn. Often, however, the winter quarter is near at hand before the plant ceases blooming. Nominally a summer bloomer, it may flower 


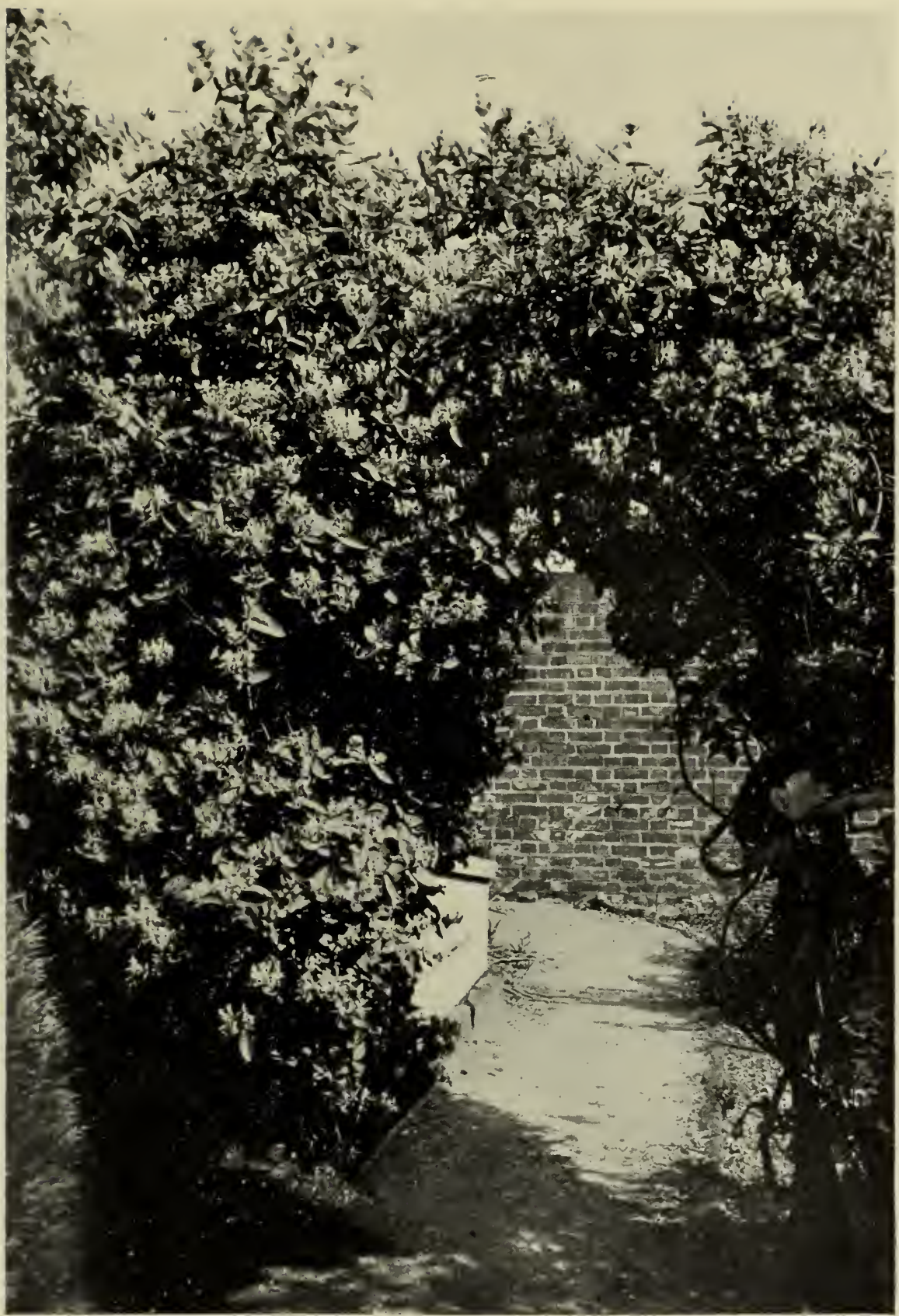

HONEYSUCKLE ON AN ARCH. 

on into the autumn. I have a plant growing over a low rustic fence on thin soil overlying chalk, and as the position is much swept by cold winds spring growth and bloom are retarded. It is sometimes flowering freely in November, despite some very severe autumn weather.

Lovers of Honeysuckles should not plant in thin soil over chalk if they have the choice of a better. The plant thrives best in a deep fertile loam. In such a soil it becomes established quickly, whereas in poor dry ground it is a long time before it gets a good hold and really starts in earnest. If it must be planted in poor ground it would be worth while to make a "station" for it by removing a couple of bushels of soil, breaking up the bottom of the hole, laying on a coat of manure, and refilling with decayed turves. These would induce the plant to make good growth the first year. If the roots received a soaking of water or liquid manure now and then it would be further assisted.

The fact that the Woodbine is a native of Great Britain is sufficient proof of its hardiness, but the sensible grower will not give it a cold site except under pressure.

Although we speak of the Honeysuckle, there are many species in cultivation, and the best of them are as sweet as the old native and finer in bloom. They are known to botanists under the name of Lonicera (Lon-iseer'-a), and this name derived from that of a German physician named Adam Lonicer, after whom they were named in compliment. $\mathrm{He}$ was a good writer on plants.

The best garden Honeysuckle is perhaps the plant known variously as flexuosa, brachypoda, and Japonica chinensis. Most nurserymen list this splendid plant 
under the name of Lonicera flexuosa simply, and although that name would not satisfy a strict botanist, it may be accepted as sufficient for garden purposes. The point is that the gardener must not buy plants under the other names quoted also and expect them to be different. This Honeysuckle was introduced from China in 1869 , and soon became a highly popular plant, owing to its free growth and the profusion, size, and fragrance of its flowers. It is quite hardy. In addition to its value for rustic work, it may be made suitable for a house wall by giving it a framework for support. The flowers are nominally red and yellow in colour, like those of the common Honeysuckle, but they are often yellow and white. Their perfume is delicious.

Another splendid garden Woodbine is the Goldennetted aureo-recticulata. In some catalogues this is classed as a species, in others it is included as a variety of Japonica, which it is. Introduced from Japan in 1862 , it was soon established as a prime favourite in gardensa fact that will in no way surprise those who have seen it well grown. The leaf differs in shape at different stages of growth, sometimes being a plain ellipse with an unbroken outline, and at others lobed or cut into divisions. The colour deepens to red in autumn. One may sometimes see this Honeysuckle covering an outhouse or a frame of rustic poles in a small suburban garden, and it is indubitably a fine amateur's plant. The flowers are sweet. Like its relatives, it appreciates a substantial loamy soil.

Lonicera caprifolium is the pale yellow and white wild Honeysuckle of British hedgerows. It is larger than the other wilding, periclymenum. There is a red variety of it. Another yellow British species is Xylosteum. None of the natives is much esteemed in gardens, however 
much they are loved in a state of nature, because it is recognised that the Eastern forms are finer.

The evergreen and winter-blooming Honeysuckles are worth attention. The former, which bears scarlet and yellow flowers in spring, is called Lonicera sempervirens. It is a North American plant, and not quite hardy. It is the "trumpet Honeysuckle," and there are several varieties of it; they may be tried outside in warm places. The latter bears white flowers towards the end of winter, and its perfume has earned it the attractive name of Fragrantissima. It is a Chinese plant, and is quite hardy, but it is more suitable for culture as a bush than as a climbing plant.

The "Dutch Honeysuckle" sold by florists is a variety of periclymenum, and so are the Belgian and Oak-leaved; but the "French Honeysuckle" is not a Lonicera at all-it is a Hedysarum.

The Honeysuckles may be propagated by seeds, and also by cuttings inserted in sandy soil in a frame in autumn, but the question of propagation need not be dealt with fully, because it concerns nurserymen, and they know their business quite well. Honeysuckles are not plants which the amateur gardener wants to multiply extensively. His requirements in respect to any particular kind are limited, as a rule, to two or three plants, and these he can buy at moderate prices. He will plant them here and there, in selected places, such as on a framework of rustic poles somewhere near the house, or skirting a favourite walk. Or perhaps he will employ them for that part of his pergola which is nearest to his favourite garden-seat or summer-house. There, in the evening, he will read with the perfume of the flowers in his nostrils. And so will the garden gain new charms. 


\section{XXIII}

\section{ON HYACINTHS}

THE Hyacinth is a truly domestic flower, for do we not grow it in glasses and bowls for the adornment of our rooms as well as in pots for our greenhouses? The village widow loves it, and puts it in tall, slender glasses, which she stands on the narrow ledge of the window that she would not open, summer or winter, if she could, and could not if she would. The odour of Hyacinths conceals the mustiness of many a cottage parlour in spring, but for the remainder of the year the latter reigns supreme, a source of criticism in the drawing-rooms of the rectory and the hall, but not of vigorous protest to owners of cottage property, and to ignorant village folk who love "snugness" better than pure air.

The home Hyacinth is an Eastern flower, and is not native, as those might suppose who think of the wild Hyacinths. The truth is, that the "Bluebells," which grow wild in some districts, and are often called Hyacinths, are not members of the genus Hyacinthus at all, but are Scillas. The "azur'd Harebell," mentioned by Shakespeare in "Cymbeline," is Scilla mutans, and not Campanula rotundifolia, the "Harebell" of plant dictionaries.

The full name of the garden Hyacinth is Hyacinthus orientalis, or the Eastern Hyacinth. It came from Syria in 1596 , a year which the diligent piant student will find 
to have been particularly rich in introductions. The generic name is mythological. It is that of a beautiful boy who was killed by Apollo, and from whose blood the flower sprang. Being of noble birth, he was doubtless blue-blooded; anyway, the Eastern Hyacinth was blue, although we have many red varieties at the present day.

When we open an autumn bulb catalogue in these piping times, we find the names of many dozens of different varieties of Hyacinths. Some are single, others double. The colours include light and dark blue, blush, pink, rose, scarlet, crimson, yellow, lilac, lavender, mauve, white, and purple. We find, too, the "white Roman" Hyacinth, and here is a neat little trap for the unwary. There is a species of Hyacinthus called romanus; it has white flowers; it came from Italy. What more natural than to conclude that it is our familiar "white Roman"? One can quite imagine an amateur growling, "Well, if it isn't, it ought to be, if names mean anything." In this case names do not go for much, because the "white Roman" is merely a variety of the Eastern Hyacinth called albulus, and has no connection with romanus. The latter is not a very important plant, but those who are sufficiently interested to turn up the Botanical Magazine will find an illustration of it there, t. 939. They will also find a plate of the original Eastern Hyacinth, which is represented by t. 937. This is of real interest, as it enables the Hyacinth lover to compare the old plant with modern forms and note the progress which has been made.

We have a splendid selection of Hyacinths to choose from to-day, and we owe most of them to the Dutch, who, finding their light, sandy soil particularly adapted to the propagation and culture of the plant, took it up 
as a commercial venture. They succeeded so well that bulb-growing became one of the national industries of Holland.

In view of the splendid quality of the Hyacinths grown in this country, it is often suggested that the industry could be established here with equally good results. This is doubtful. The best plants grown by British cultivators are equal to the best of the Dutch, but it has to be remembered that they came from developed bulbs. To produce the bulbs is another matter. Of the great triumvirate of bulbous flowers, Tulips, Daffodils, and Hyacinths, the two first increase readily in this country, but Hyacinths do not. The reproductive systems of the three plants are the same, in the main-all form fresh bulbs annually; but the offspring of Hyacinths is much smaller than that of Tulips and Daffodils, and much more time is required to grow them to a saleable size. The largest bulb of a set of Tulip progeny is nearly, or quite, as big as the parent. The largest of the Daffodil offsets are big enough to bloom the year following their formation. But the offsets of Hyacinths are very small, and several years are required to get them to a flowering size. The grower observes them springing from the base of the bulbs in autumn. Sometimes one will have become as big as a Scilla bulb, but concave on one side, where it nestles close to the parent, by November. The offsets should be picked off before the bulb is put into the soil.

The Dutch growers can develop flowering bulbs inore quickly than we can, and thus have a commercial advantage which enables them to undersell British growers, but it is not so with Daffodils and Tulips. Consequently, while we find that the Hyacinth trade remains almost entirely in the hands of the Dutch, that of Tulips 
and Daffodils is shared by the British. If Hyacinths could be grown on a commercial scale in this country, it would be in districts where the soil is light, and yet not far above water. The plants thrive in light soil provided that they have abundance of moisture, but not otherwise.

Amateurs, as a whole, are not likely to trouble where bulbs are grown, provided they are large, sound, and ripe. Given these conditions, fine "trusses" of bloom will be had. What is a "large" bulb? Hyacinths are graded and sold at different prices. A bulb two and a half inches through at the thickest part is a "first size" bulb, and will be charged at the highest price for that particular variety, perhaps twopence, perhaps fourpence, perhaps sixpence. But a bulb may be less than two inches through and yet be a "first size." The varieties differ a good deal in this respect. The yellows are nearly all small-bulbed. With respect to soundness, an unfailing test is pressure of the thumb on the flat ring at the base; if this is firm, the bulb is sound; if soft, it is unsound. Ripeness may be assumed if the bulb is firm and the outer skin, in addition to being loose, is tinted with a silvery sheen.

We grow Hyacinths $(a)$ in pots of soil, $(b)$ in glasses of water, $(c)$ in bowls of peat moss fibre, $(d)$ in the open garden; and they do almost equally well in all if the treatment is correct.

As Pot Plants. - They are beautiful as pot plants, for the trusses are handsome, the colours are brilliant and varied, the habit is neat, and the perfume is delicious. One would hardly grow a block of Hyacinths in a greenhouse, because it would look flat; but one would grow Hyacinths in association with other bulbs and spring blooming plants. To have them at their best 
we should pot them by the end of October, and use a fertile compost, such as fibrous loam three parts, decayed manure and leaf mould one part each, and sand in a quantity equal to about one-eighth of the whole. Sand should always be used very liberally for Dutch bulbs; they practically grow in it at home in Holland.

Pots four and a half to five and a half inches across the top, or the size known as forty-eight's, are quite large enough, even for big bulbs. Large pots are unsuitable. They hold so much soil that the plants grow too strongly to flower well, for, singular though it may seem, it is possible to have leaf at the expense of bloom. The soil should be moist when used, and it should be pressed firmly on to the drainage crocks without being made downright hard. The pot need hardly be more than half-filled at first. Make a hollow in the centre of the soil, sprinkle in a little sand, place the bulb in position, and then fill in soil round it, making it as firm as the under soil. When the pot is finished the soil should be an inch below the brim of the pot, and the tip of the bulb should be exposed to the extent of about half an inch.

The amateur sometimes complains of bulbs rising out of the soil, as though thrust upward by their own roots. That is what actually happens, and it is generally due to too hard a soil in conjunction with exposure. The grower must try to strike the happy mean between hardness and looseness, and he must plunge his pots in cocoa-nut fibre refuse for six or eight weeks after potting, heaping the material over them to a depth of four or five inches. This checks top growth, but not root action, and the foundation of success is laid in a healthy root system in advance of stem and leaves. Without 
the plunging the reverse holds good, and the plants do not thrive so well. There is one slight danger in plunging, and that is that the plants may be forgotten, but this presupposes a "slackness" on the part of the grower that he is hardly likely to be guilty of. It can be guarded against by making the entry "Examine bulbs" in the pocket diary on a date six weeks later than that of potting. If at the end of the six weeks top growth has pushed about half an inch, and the roots have got well down the pot (this can be ascertained without causing any injury by inverting the pot with the fingers spread across the soil, tapping the rim on a bench, and lifting the pot right off), the plants should be withdrawn, if not, they may have another week or two.

The interval may be shorter in the case of White Roman Hyacinths, which grow quicker than the others. Bulbs of this variety can often be bought as early as July, and certainly in August. Many people like to pot them in batches from August to October inclusive, in order to get a succession of bloom. Three bulbs may go in a forty-eight pot.

When Hyacinths of whatever variety are withdrawn from the plunging material, the proper course is to put them in a heated but not very hot greenhouse, give free exposure to light, ventilate in fine weather, and water as often as the pots ring sharply under the knuckles. Later on the spike will want tying to a flower stake. From the time that the colour is seen in the truss, which will push up before the leaves have become very far advanced, liquid manure may be given twice a week. It may consist of any of the patent fertilisers sold in small tins by florists, or of home preparations. If the plants are flowering in spring and 
the weather is sunny, they will probably want water every day. Certainly it is much more easy to underwater than to overwater Hyacinths in bloom. With their abundance of thick, fleshy roots they develop a thirst that is almost as difficult to quench as a cement worker's, and he, poor fellow, has a very dry job of it indeed.

In Water. - The success of Hyacinths in water is a proof of what this simple chemical compound means to them. They are able to dispense alike with soil and manure. Perhaps a good bulb does not give quite equal results in the amateur's glass to those that it yields in pots under the hands of a skilful gardener, but it produces a very fine truss all the same. One cannot very well plunge glass-grown Hyacinths, but the same end may be gained by putting them in a dark cupboard until roots have reached the bottom of the receptacles. It does not seem to matter much whether the base of the bulb actually touches the water or not, roots push just the same. Some growers prefer to have the base just clear of the water, on the ground that there is less fear of the bulb rotting. The water should be quite clean, and a couple of small lumps of charcoal should be put in it. If the water remains clear it need never be changed, but if it becomes turbid or slimy it had better be poured away very carefully by tilting the glass, and a fresh supply put in. The plant should be kept steady during the operation.

Glass culture is a little more expensive than pot culture, because there is not only the cost of the glasses, but also of supports for the spikes; however, the whole amount is not very serious. The supports, like the glasses, can be bought of the bulb dealer. They are made for the purpose, with a basal ring to encircle the 


\section{ON HYACINTHS}

neck of the glass, and they render the task of "staking" very simple. Support is really necessary; without it the whole plant would topple over when the truss of bloom became heavy, and might be quite spoiled by the crash.

In Bowls.-Hyacinths do very well in bowls of peat moss fibre, and may be treated as advised for Daffodils in Chapter XIV.

In Flower Beds.-They have declined somewhat as garden plants, perhaps, since the rise of Daffodils, but their day is far from being done. The gardeners in the public parks still find them indispensable, and although private growers may not go to the lengths of the County Council horticulturists, and fill whole beds with Hyacinths alone, they will continue to use them in groups both in beds and borders.

Hyacinths give quite different effects from either Daffodils or Tulips. Their growth is closer and dwarfer. This, combined with the massiveness of the flowerheads, renders them a little dumpy, and it is well to have them surrounded by cushions of white Arabis and mauve Aubrietia, which not only form a pretty carpet, but give the Hyacinths an effect of greater height. The Arabis and Aubrietia are perennials, but they are so easily and cheaply raised from seed out of doors in June, that the old plants can be thrown away when the Hyacinths are taken up.

If many first-size Hyacinths were planted, the cost would be rather serious, but dealers supply a second size suitable for the garden. If the soil is fertile and moist, and the stems are removed directly the flowers fade, these bulbs will very likely develop and bloom well again the following year. But they will not do much good in poor, dry soil after the first year. 


\section{POPULAR GARDEN FLOWERS}

Hyacinths are great lovers of water, and do best in a heavy but friable soil that holds moisture well. Contrary to general belief, they thrive splendidly on clay, provided it is well drained and is reduced to a fine crumbly state. Some sand may be put around the bulbs when they are planted in autumn. They may be set nine inches apart, and covered with three inches of soil. If the soil is light, poor, and dry, it ought to be worked deeply, and dressed heavily with decayed manure.

A few clumps of Hyacinths go far to enliven a mixed border in spring. The bulbs may be set in clumps of three to twelve. The following colours go well together:(I) red, white, and blue; (2) light blue and yellow ; (3) light blue and rose ; (4) pink, blue, and yellow; (5) mauve, red, and white. The same colours could be arranged in beds.

Town and suburban gardeners will find the Hyacinth a good plant for them, and they may mix it in their beds, if they like, with the Chalice-flowered or Star Daffodils (see Chapter XIV.), which are generally in bloom at the same time. Country amateurs may space the Hyacinths out, and give the bed a groundwork of coloured Primroses and Polyanthuses (see Chapter XXXI.). The Hyacinths will go out of bloom before the Primroses, but they will not spoil the bed if the stems are broken off directly the flowers fade. Nothing is much uglier than a batch of Hyacinths with the flower trusses brown. Pale blue Hyacinths look charming amid Primroses.

The "Grape Hyacinths" (Muscari) should not escape the attention of the bulb lover, as they are charming little plants, and thrive on banks or rockeries. The ordinary dark blue only costs Is. 6d. to 2s. per Ioo. 
A clump might be established here and there near the front of the border, the bulbs being set four inches apart and an inch deep; and if they take to the quarters-as they will if the soil is moist and coolthey will propagate themselves, and bloom brightly year after year in April. The flowers have an odour of musk.

Hyacinthus Candicans.-A plant of great beauty which is allied to the Hyacinths is Hyacinthus (sometimes called Galtonia) candicans. It has large expanded white flowers on a long, arching stem, and they appear in August. This splendid plant costs no more than about one shilling per dozen bulbs, and a clump of it in the border, preferably near some brilliant plant of corresponding habit, such as Gladiolus Brenchleyensis (see Chapter XX.), is very striking. It may be planted three inches deep in fertile friable soil in autumn.

The following are beautiful Hyacinths:-

\begin{tabular}{|c|c|c|c|c|c|}
\hline Variet & & & & Colour. & Single or Double \\
\hline Baroness van Tuyll & - & & & White & Single. \\
\hline Cardinal Wiseman & • & 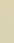 & & Rose & Single. \\
\hline Gigantea . . & . & , & . & Pink & Single. \\
\hline Grand Maître & - & , & . & Medium blue & Single. \\
\hline Isabella. & • & & & Blush & Double. \\
\hline Jacques . & • & & & Pale pink & Single. \\
\hline King of the Blues. & • & & & Dark blue & Single. \\
\hline La Grandesse & - & sina & - & White & Single. \\
\hline Ornément Rose & • & & . & Blush & Single. \\
\hline Roi des Belges . & & & & Dark red & Single. \\
\hline Queen of the Blues & & & & Light blue & Single. \\
\hline Yellow Hammer. & • & & & Yellow & Single. \\
\hline
\end{tabular}




\section{XXIV}

\section{ON I R I SES}

FEw of the popular flowers of our gardens give us such diversity of growth and such richly painted flowers as the Iris. Fewer still include in their ranks species differing so greatly in their habitat, tastes, and season of blooming. Its remarkable beauty makes the Iris one of the finest of garden plants, and its catholicity gives it exceptional interest.

Flower-lovers of all degrees should make the Iris one of their principal plants. Considered collectively, it has almost every merit which they could ask for in a garden plant. It is hardy (except in the case of one or two small sections, to which special reference shall be made), and so may pass the whole of its life in the open air.

Soil.-It is not particular as to soil. Like most plants, it loves a deep, fertile loam, but it will thrive either in heavy or light land. This more particularly applies, as we shall see presently, to the magnificent."Flag" Irises, which give such beauty and character to the border in May and June. But most of the Irises will succeed in the ordinary soil of gardens to which good garden culture (deep digging and manuring) has been given.

$A$ Good Town Plant. - It is almost as good in town as in country gardens when the soil is treated liberally. This naturally attracts suburban gardeners, who may be advised to make the Iris one of their principal plants. 
Propagation.-It is easily propagated by division or offsets. Irises have more than a mere set of fibres as a root-stock. They either have a rhizome (which is a thick, tough, root-like stem, just under or at the surface of the ground, pushing fibres from its under side and leaves from the upper) or a bulb. The rhizomatous Irises include the "Flags," the bulbs include the English and Spanish. It is hard to say which of the two great sections, the rhizomatous or the bulbous, is the more important. Most Iris lovers take care to have the best of each. The clusters of rhizomes may be separated when they get crowded, and individual ones may even be cut through if desired. This work is best done in early autumn. It is wise to practise it, in any case, every third year, as this gives an opportunity of simultaneously increasing the number of plants and improving the soil. When rhizomes are planted, they should be just covered with soil. There will be leaves attached, for the "Flag" Irises are evergreens, but that will not matter. The bulbous Irises are increased by offsets, which grow round the parent bulb. It is not necessary to take them up every year, but they may be lifted in the early autumn of every third or fourth year, the clumps divided, and replanted in fresh soil.

Cheapness.-The Iris is a cheap plant, if we limit it to the German (or other popular "Flags"), the Spanish, and the English. The first may cost Is. 6d. to 2s. 6d. per dozen in mixtures; the second about 3 s. per 100 ; the third about Is. 6d. per roo. A dozen "Flag" Irises, planted at intervals of a few feet, will be enough for many borders, and Ioo bulbous Irises, planted in threes, will give thirty-three nice clumps, and leave an odd bulb for the children's garden. The question is whether the genus can be so limited and still remain well 
represented in gardens? As to this, there are no finer Irises than the German, English, and Spanish. The first flower in May, the second and third in June or July, but the English are generally about a fortnight later than the Spanish. The bulbous Irises love a friable, welldrained soil. The bulbs may be planted in autumn and covered with two or three inches of soil. They may be set about nine inches apart in their clumps.

"Flag" Irises.-In size of flower and beauty of colouring the Irises are excelled by very few. The "Flags" are particularly fine. Strong clumps produce a mass of slender, sword-shaped leaves, and throw up flower-stems a yard high, surmounted by magnificent flowers. In many of them the upright petals, which are called "standards," differ in colour from the drooping ones, which are called "falls." Most have a yellow or orange beard, and many have a golden crest. Every amateur gardener, whether he practise in town or country, should have at least half-a-dozen good, tall "Flag" Irises. The vigour of the plants will delight him, the beauty of the flowers will win his heart. From them he may, if he wish, proceed to make a collection of all the best sorts, many of which are fragrant.

The Iris has a prominent place in literature. It is almost certain the Flower-de-luce of Shakespeare. True, in a passage from the "Winter's Tale," Act iv. scene 4 , which I have quoted under Daffodils, the bard makes Perdita, who speaks so much of flowers, refer to-

"Lilies of all kinds, The Flower-de-luce being one."

This might be thought to convey that the Flower-de-luce was a Lily and not an Iris, but it is not absolutely convincing, for old writers classed the Iris with the Lily 


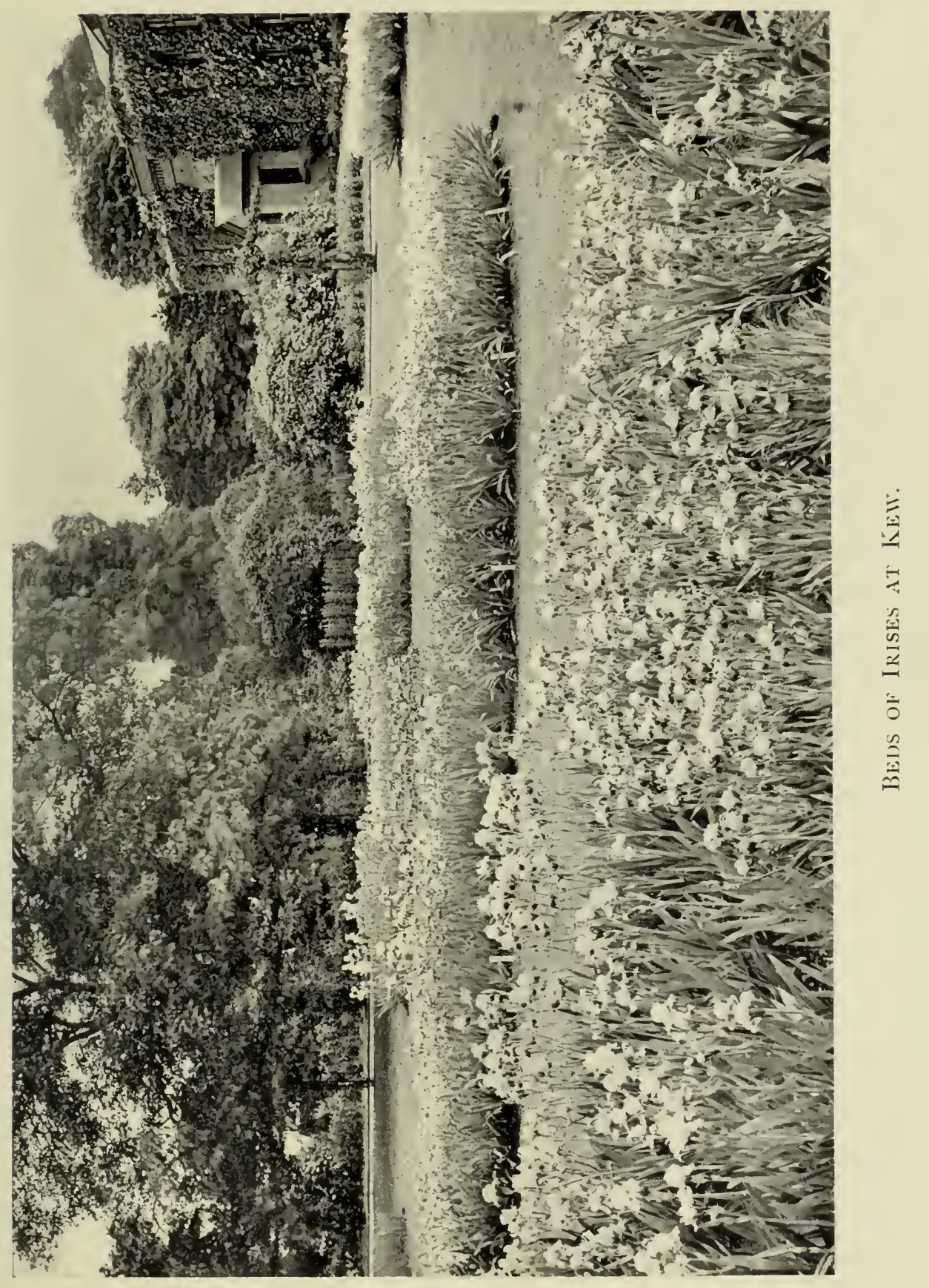



order. Shakespeare made several references to the Flower-de-luce as the cognisance of France in "King Henry V." and "King Henry VI.," but that does not settle the question as between Iris and Lily, for authorities differ sharply as to which flower (if it was really meant for a flower at all) the Gallic arms bore. Was the Flower-de-luce the "Flower of St. Louis"? or was it the "Fleur-de-délices" (it was spelled sometimes "Fleurde-lys" and sometimes "Fleur-de-lis")? In either of these cases it might still have been either Iris or Lily. If Shakespeare's Flower-de-luce was the same flower as St. Francis de Sales wrote of, it was certainly the white Lily, for "the six leaves (petals) whiter than snow" and "the pretty little golden hammers (anthers) in the middle" do not belong to the Iris.

We lean to the belief that the Flower-de-luce was a Lily when we read the foregoing words, and we are pushed further in the same direction by Chaucer's

"Her necke was white as the Fleur-de-lis."

But other writers of the Middle Ages, including literary men such as Bacon, Drayton, Jonson, and Spenser, and botanists like Gerard and Parkinson, all wrote of the Lily and the Flower-de-luce as distinct. Thus Jonson's

"Bring rich Carnations, Flower-de-luces, Lillies."

And Bacon's

"Flower-de-luces and Lilies of all Natures."

Spenser, in the "Shepherd's Calendar," is not the least definite-

"Strow mee the grounde with Daffadown-Dillies,

And Cowslips, and Kingcups, and lovéd Lillics;

The pretty Pawnce

And the Chevisaunce

Shall match with the fayre Flowre Delice." 
While we cannot escape controversy if we decide that the Iris is the Flower-de-luce, we have considerable weight of evidence to support us.

Iris, the mythological daughter of Thaumas and Electra, and messenger to Juno, travelled from heaven to earth along the rainbow, which is called Iris in Greek. The bow and the colours are seen in the iris of the human eye, and so the plant has derived its name from the diversity and beauty of its flowers.

Native Irises. - The Iris is a very old plant in British gardens, and two species are natives. These are the Yellow Flag, Iris pseudacorus, and the Stinking Gladwyn or Gladdon, Iris feetidissima. The Snake'shead Iris is naturalised in a few places. The Yellow Flag grows wild in shallow water almost all over England, Ireland, and the Channel Islands. It blooms late in May and early in June, and grows about three feet high. Shakespeare probably knew this fine old plant quite well, and had it in his mind when he put the following lines into the mouth of Casar:-

"It has been taught us from the primal state, That he which is was wish'd until he were; And the ebb'd man, ne'er loved till ne'er worth love, Comes dear'd by being lack'd. This common body, Like to a vagabond flag upon the stream, Goes to and back, lackeying the varying tide To rob itself with motion."

Iris pseudo-acorus (or pseudacorus, as now compounded) was probably this "vagabond flag upon the stream," and our interest in the flower is strengthened by the splendid figure which these noble words form.

The Gladwyn also grows wild almost all over England, and is naturalised in Scotland, Ireland, and the Channel Islands. It frequents copses, and blooms early 
in June. The flowers are bluish purple, a little over two inches across, and the stem rises from a foot to two feet high. It is not particularly attractive when in bloom, and the odour is so disagreeable that one's first impulse is to uproot it; but the scarlet berries that follow the flowers are ornamental, and come in useful for Christmas decoration.

The Snake'sead Iris, with its greenish and blue-black flowers, is not recognised as a native, and botanical records tell us that it was introduced from the Levant in 1597. This date makes it a tolerably old plant, and it has been found wild near Penzance and Cork. It blooms in March, and the flowers are about two inches across. The plant grows nine inclies high, and has only one flower on a stem. It is illustrated in the Botanical Magazine, t. 53r. And here the numerous coloured plates of Irises in the great plant publication may be pointed to as evidence of the interest which has always been taken in the Iris genus by both botanists and gardeners. A large number of the best species are illustrated in the work. It is expensive, and I may not assume that it is in the possession of many amateurs; nevertheless, I will give the references to the coloured plates in cases where the various species which I propose to name have been illustrated, as flower-lovers may like to refer to the Botanical Magazine in some of the large libraries to which they have access.

The best Species of Iris.-There are many extremely beautiful species of Iris, and from some of them we have obtained our modern varieties of Flags, also of English and Spanish. I will pass the principal members of the genus in review, for the benefit of those readers who may like to form a collection. The winged Iris (alata) is a bulbous species, which produces blue flowers in June, 
and grows only about six inches high. It is cheap, pretty, easily grown, and has several varieties. Bakeriana, lilac, cream, and violet, a comparatively new species, having been introduced as recently as I 889 from Armenia, is a beautiful little plant, and may be grown on the rockery. It is illustrated in the Botanical Magazine, t.7084. Amona, with blue flowers in May, and aphylla of gardens (plicata), white and blue, have many varieties, and have given us some fine Flags (see end). Biflora, growing about eighteen inches high, and bearing purple flowers in June, is worth growing in a representative collection of Irises, although it is not one of the most important species.

A pretty modern "Cushion" species, introduced from Lebanon in 1892 , is Bismarckiana. It grows about fifteen inches high, and has bluish grey veined flowers. Cristata, on the other hand, is a very old species, having been known in British gardens since 1756 . It only grows about six inches high, and produces blue flowers in June. A charming little species, 1. cristata, is figured in the Botanical Magazine, t. 4I2. Danfordice, also grown under the name of Bornmulleri, is a dwarf, yellow, winter-blooming bulbous species, introduced in 1899. Flavescens, pale yellow, sweet, blooms in early summer. The Florence Iris, florentina, introduced from Southern Europe in 1596 , is a handsome plant, and is interesting as yielding the Orris root, or Orrice. This, with its odour of Violets, is used to scent powders; and the French peasantry string pieces of dried root together, pour boiling water on them, and immerse their bed linen in the liquid in order to give it a pleasant odour. After use the roots are re-dried and stored for use on future occasions, care being taken that they are not eaten, as Irises are poisonous. Gatesii is a beautiful silvery 
"Cushion" species dotted with grey, and was introduced from Armenia in I 889. It only grows about three inches high, and blooms in June.

The German Iris.-Proceeding with the species in alphabetical order, we come to germanica, the great German Iris, a blue-flowered species growing two to three feet high, flowering in May and June. This grand old plant, which was introduced as long ago as I573, is illustrated in the Botanical Magazine, t. 670. There are many varieties of it, differing in colour from the type. The German Iris will grow almost anywhere, and is one 1 of the finest of town plants. Smoke and impure air may check its luxuriance, but are rarely able to kill it. The a root is not a bulb but a rhizome, and the plant is much less severely affected by dry soil than most bulbous plants. See the names of some fine German Flag Irises on page 230 .

The Actor Iris (histrio), which grows about a foot high, is a modern bulbous species with lilac and yellow flowers, a pretty plant, and much in demand among Iris-lovers. Iberica, lilac and brownish red, with purple blotches, is a cushion Iris, growing about eighteen inches high and flowering in May.

Japanese Irises.-Kaempferi and laevigata are the now famous Japanese Irises which gardeners call Clematisflowered and plant in moist places. They are magnificent plants, producing large, flattish flowers, painted in the richest manner with a large variety of colours. The type, laevigata, is blue, and came from the Far East in 1836. It flowers in early summer. A coloured plate of it will be found in the Botanical Magazine, t. 6r 32 . Kaempferi is perhaps synonymous with it, or possibly a variety.

Korolkowi, growing a foot high, and bearing white or 


\section{POPULAR GARDEN FLOWERS}

yellowish flowers veined with green in early summer, is a comparatively young species with us, and is one of the most esteemed of the Cushion section. It is one of the "Regelia" Irises of the bulb catalogues, and was introduced from Turkestan, a region of Central Asia, in I874. Another Regelia is vaga, purple, blue, and yellow, which also comes from Turkestan. These Regelia Irises have been crossed with large-flowered Cushion Irises (technically classed as the Oncocylus section), and the hybrids are called the Onco-regelia section, the class names of the plants having been compounded. The flowers are netted on a blue, white, or rose ground. The hybrids are quite new, having been first exhibited in the early part of the present century. Several received awards from the Royal Horticultural Society in 1904. They are expensive as yet, and may be left to Iris specialists. They like a warm position, and light, well-drained soil.

Another pretty member of the Cushion class is Lortetii, which was introduced from Armenia in 1890. It has creamy flowers marked with rose. Another Cushion is the Wolf's Fur Iris, lupina, which has greenish flowers veined with red and bearded heavily. It was introduced from Kharput in I887. Neglecta, two feet high, with pale blue or lilac flowers in May, $t .2435$ in the Botanical Magazine, is a good rhizomatous Iris, and there are several charming varieties of it. Pallida is also a tall "Flag" Iris, and has many varieties. Nigricans, maroon and purple, is a very dark cushion Iris.

We get back to the bulbous Irises again with orchioides, a dwarf grower, with yellow flowers, in April. It is a new species, as Irises go, having been introduced in 1880. See the Botanical Magazine, t. 7III. Persica and reticulata also belong to this section. The former, 


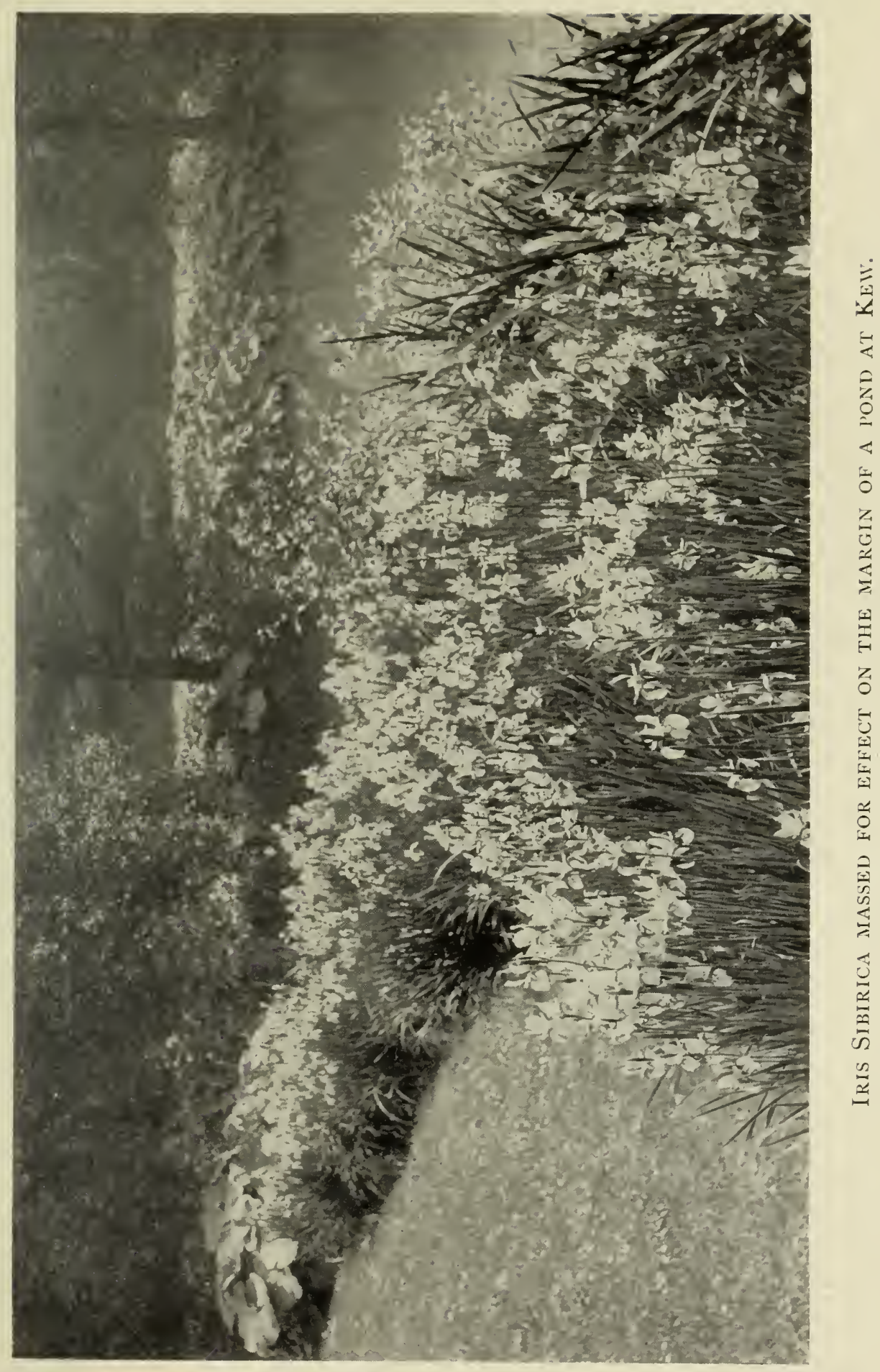



which grows barely six inches high, bears blue and yellow flowers in early spring. It appears in the Botanical Magazine, t. I. It is a very old plant, but is still esteemed by amateurs, and so are its varieties, of which Heldreichii, lavender, violet, and yellow, is one of the best. Reticulata is a lovely Iris, having violet flowers crested with yellow, and is scented with the odour of Violets. It grows about six inches high, and blooms in winter. It is best grown in pots in a cold frame. Krelagei is a variety of it which is much grown, although it is not so bright as reticulata and lacks perfume.

Harking back a little, we find the pretty cushion Iris, paradoxa, the white flowers of which are veined with blue and furnished with a crimson beard. It is a very old plant, and has many varieties. Rosenbachiana is a bulbous Iris, with blue and yellow flowers, which appear in March.

The old blue Siberian Iris, sibirica, is a good species, which I find one of the best of the genus on chalk, although it is reputedly a strong-soil plant. The flowers are not large, but they are borne in great abundance on a healthy clump, and rise nearly three feet above the ground. It is a rhizomatous species, and the root forms a thick mass when established. It is not wise to disturb it frequently. There are several varieties of it, notably a white. Sindjarensis is a bulbous Iris bearing lilac flowers in February or March. It is a very pretty plant, and a plate of it appears in the Botanical Magazine, t. 7145. Sisyrinchium is also a bulb. It grows about nine inches high, and bears lilac flowers, spotted with yellow, in April. It is given in the Botanical Magazine, tt. 1407, 1696. Squalens, an old

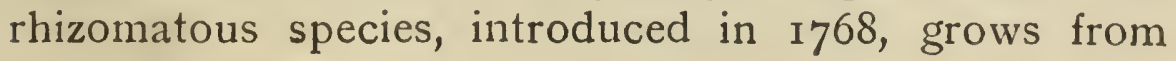




\section{POPULAR GARDEN FLOWERS}

two to three feet high, and bears purplish flowers, bearded yellow, in early summer. It is elder-scented. See the Botanical Magazine, t. 787. There are several fine varieties of it.

One of the most remarkable of all Irises is the Cushion species, Susiana, which is called the Mourning Iris, in allusion to the swarthy hue of its flowers. Although a very old plant in British gardens, it is still grown with interest. The flowers are brownish black, dotted with lilac. See the Botanical Magazine, t. 9I. Tubergeniana, a Cushion species, is a pretty modern Iris, with green and blue flowers. Unguicularis, also grown under the name of stylosa, is a winter bloomer, growing about two feet high, and bearing lilac flowers. It is an oldish plant, and has many varieties. Urmiensis is a Cushion, growing from six to twelve inches high, and with fragrant yellow flowers. Variegata is a very old species, growing about eighteen inches high, and having brownish flowers with a yellow beard. See the Botanical Magazine, t. I6. There are several varieties of it. Vartani is bulbous, and bears lilac, yellow-crested flowers in autumn or winter. It was introduced from Palestine in 1885 . Versicolor, an old claret-coloured species, growing about a foot high, flowers in May and June. See the Botanical Magazine, t. 21. Virescens, growing a foot high, bears greenish flowers in May.

Two famous Irises are hidden away, so far as unversed amateurs are concerned, in the names Xiphioides and Xiphium. The former is the popular English Iris, and the latter the equally popular Spanish. Both are bulbous. Growing about two feet high, thriving in most soils, very cheap, and having a great number of beautiful varieties, which bloom in early summer, they are invaluable plants. The English Iris is figured 
in $t .687$ of the Botanical Magazine, and the Spanish in t. 686. Both have been grown in British gardens for more than three hundred years.

When the amateur has made himself acquainted with a few of the popular Irises, he will probably want to extend his knowledge of the genus, and may even go as far as to have an Iris garden. Arrived at this stage, he will no longer shrink with awe from such a list of species as I have given, but will study it eagerly, and even want detailed information about the various classes.

First, perhaps, he will study the Flag Irises, and he will find that these are divided into two sections, the bearded and the beardless. The former is much the more important, and is sub-divided into tall and dwarf. The following are the principal tall species :-

\section{Tall, Bearded Flag Irises.}

Amœna.

Aphylla (Plicata).

Flavescens.

Florentina.

Germanica.
Neglecta.

Pallida.

Squalens.

Variegata.

The tall, bearcled Irises are very popular, and there are many varieties of all of them except flavescens and florentina. They bloom in May and June, and are distinguished by having large, upright petals ("standards") and long, drooping petals ("falls"). The former are often mottled, and the latter veined; the beards are yellow or orange. The flowers are scented. Here are selections of good sorts :-

\section{Amøna.}

Calypso, white, blue veins.

Duc de Nemours, purple and white. 
Bridesmaid, lilac and white.

Aphylla.

I Madame Chereau, white, frilled blue, exquisite.

Germanica.

Alba, white.

| Kharput, violet.

Neglecta.

Cordelia, "standards" lilac, "falls" crimson.

Hannibal, lavender and purple.

Dalmatica, lavender.

\section{Pallida.}

Princess Beatrice, lavender.

\section{Squalens.}

Harrison Weir, "standards" bronze, "falls" crimson.

Mozart, bronze, white veins.

\section{Variegata.}

1 Gracchus, crimson, white veins.

The foregoing are not expensive varieties.

$$
\text { Tall, Beardless "Flag" Irises. }
$$

The following are a few of the best tall, beardless Flag Irises :-

Cristata, described previously.

Japonica (fimbriata), lavender, yellow crest.

Monnieri, yellow, very strong.

Monspur, a hybrid between Monnieri and Spuria, violet, yellow spots.

Orientalis (ochroleuca), previously described.

" Snowflake, a good white variety.

Sibirica, previously described.

" alba grandiflora is a fine white variety.

" George Wallace, a good blue and white. 


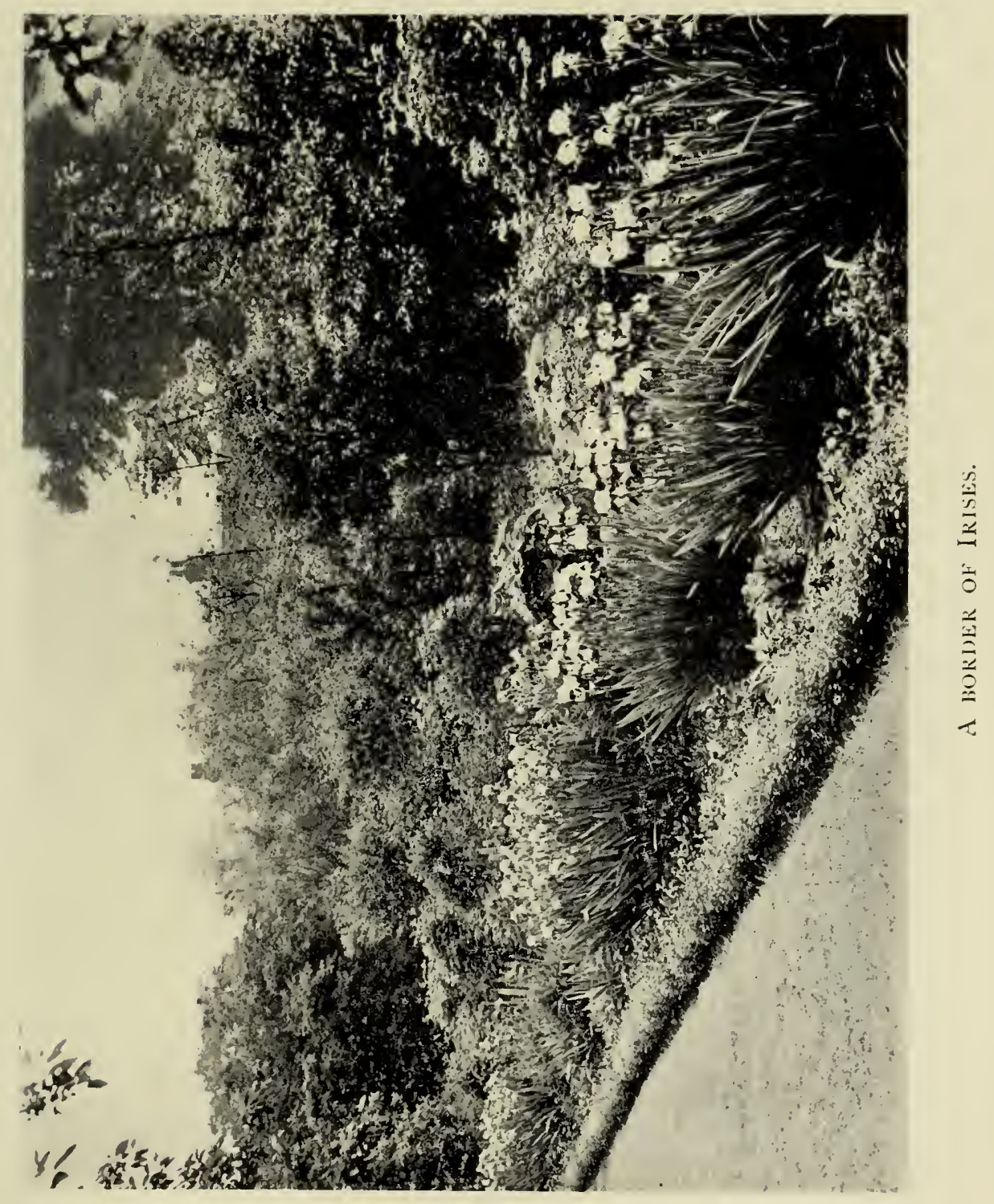



Spuria Notha, violet, blue, and yellow.

Unguicularis (stylosa), previously described. There is a white variety, also a good lilac.

These winter-blooming Irises are charming for cutting. All of them are good for the border and thrive in ordinary soil.

\section{Dwarf Bearded Irises.}

The dwarf bearded or hybrid Crimean Irises are pretty at the front of borders and on the rockery. The following are a few of the best :-

Balceng hybrids, several, of various colours.

Biflora, previously described, and its varieties.

Chamæiris, violet, and its varieties.

Lutescens, yellow, and its varieties.

Pumila, previously described, and its varieties.

The Cushion Irises are not so hardy as the Flags, and require a warm situation. They are best planted at midwinter and covered with heather till spring. After the leaves have withered they may be lifted and ripened in a dry, sunny place.

This survey of the genus Iris may strike the beginner as voluminous, but in reality it is brief and condensed. The fact is, the flower is one on which it would be easier to write a whole book than it is to write a chapter; and special works on the Iris actually exist.

The Iris is a most varied, most fascinating flower. It wins all hearts, with its wonderful beauty and the generous nature which adapts it to almost all circumstances. It is everybody's flower, and will live for ever. 


\section{XXV \\ ON THE JASMINE}

WiTH pretty flowers, vigorous growth, and, in the case of most species, perfume to recommend them, the Jasmines are in the way for being prime garden favourites; but all are not hardy-indeed the majority have to be grown under glass. It would almost seem as though some of the botanists wanted to make Jasmines greenhouse rather than garden flowers, because they are not satisfied with the known tender species, but even claim our old favourite the winter-flowering nudiflorum as an indoor plant. This cannot be permitted. It might be possible to point to cases of the plant being killed by frost (although I have never known one), but it is quite certain that scores of others could be quoted in which it has passed many years in the open air, and remained unscathed by severe frost.

The popular and botanical names of the Jasmine are very similar. All we have to do is to remove the final " $\mathrm{e}$ " of the garden name, and add "um" to be as frigidly accurate as any dictionary. The derivation of the name is not difficult to trace. Behind the English Jasmine we have the French Jasmin, behind the latter the Arabic Ysmyn and the Persian Yasmin or Jassemin. The pronunciation is Jaz-my'-num.

It is too old a plant to have been named after the illustrious "Jasmin," the barber poet of Provence, for 
Jacques Boé was born in $\mathrm{I} 798$, and the Jasmine has been known in British gardens since 1548. "Jasmin," indeed, borrowed his nom de guerre from the plant, and sang his connection with the "stem of Jesse." Our flower is often the "Jessamine," and sometimes even the "Jesse."

The Jasmine does not seem to have attracted the attention of Shakespeare, which is somewhat surprising, for it would be known in his day. Gerard refers to it as in general use for covering arbours, and Shakespeare knew plants well, as almost every play of his teaches us. But Spenser alluded to it, and later poets, such as Cowper and Moore, gladly wove it into their mellifluous verse. The former gave a striking portrait of the flower in the lines-

"The Jasmine, throwing wide her elegant sweets, The deep dark green of whose unvarnished leaf Makes more conspicuous, and illumines more The bright profusion of her scattered stars."

Moore, with lighter touch, deftly conveys a charming picture of childish innocence and rural beauty-

\footnotetext{
"When, o'er the Vale of Balbec winging Slowly, she sees a child at play, Among the rosy wild flow'rs singing, As rosy and as wild as they : Chasing, with eager hands and eyes, The beautiful blue damsel-fies, That fluttered round the Jasmine stems, Like wingèd flow'rs or flying gems."
}

The sweet white Jasmine is known to botanists as Jasminum officinale, and they tell us that it came from the East Indies. Further, they give us-and we are grateful to them for it -a coloured plate of the flower in the Botanical Magazine, t. 3I. Neither in examining 


\section{POPULAR GARDEN FLOWERS}

the illustration nor in looking at the plant in the garden should we describe it as a striking rambler. At its best it is a modest plant, with no size of bloom or brilliance of colour to recommend it. But when well managed it is pretty, and its perfume is all-convincing. We could almost tolerate ugliness in a flower so long as it possessed the delicious odour of the old white Jasmine. Because of this odour we put the plant on our summerhouses, or in other places where we walk or sit frequently, so that we may have it near us for at least a part of every day.

In spite of its odour, the Jasmine has probably receded in public favour during recent years, having given place to the pushful Mountain Clematis. The latter is not scented, but it is a vigorous grower, takes care of itself when once started, flowers abundantly, and has a generally bright, happy, cheerful appearance. The Jasmine wants rather more attention, and attention is just what it does not get, as a rule. It is put into poor soil, never pruned, and rarely watered. The result is that it is often shabby and droopy. Those who set out to grow it should give it a fair chance of showing what is in it. They should give it a bushel of prepared soil, and plant it early in spring, before the hot weather has come on. If it is growing on a hot wall, they should give it a good soaking of water once a week or oftener, and a pailful of liquid manure now and then. A douche with a syringe on the evenings of hot days will freshen it. With respect to pruning, while no regular course of cutting back or spurring in is necessary, the plant should not be allowed to become a tangle of weak shoots. Where there is much crossing and crowding, the pruning knife should be brought into play, and a vigorous thinning resorted to. 
There are variegated-leaved forms of the white Jasmine, which may be grown instead of the greenleaved if desired.

Town gardeners should not overlook this sweet flower, for it will thrive in their gardens quite as well as the Mountain Clematis if it is treated liberally. In dry seasons the flowers, which are generally borne in July, are often followed by a crop of round dark berries, about as large as Peas.

Two hardy Jasmines which are not grown frequently are fruticans and humile. Both are of shrubby habit, and grow about three feet high. They are not without interest, but I would not urge them on the attention of flower-lovers whose gardens are too small to accommodate a large collection of plants-certainly not if their culture meant the exclusion of the yellow winter bloomer nudiflorum. This cheap, easily grown, and most useful plant was introduced from China in I844. It was sent home by the celebrated plant collector, Robert Fortune, who travelled for the Royal Horticultural Society from 1843 to 1846 . It is illustrated in the Botanical Magazine, t. 4649. We can speak of it as the winter Jasmine correctly, for it always blooms in the winter. The amount of shelter which it receives affects the flowering to some extent, naturally, but the amateur need not, because of this, despair because he cannot find a snug corner or a warm aspect, for in mild spells it will flower almost anywhere. It will, indeed, bloom in bursts from week to week, and a hard spell of frost will be needed to keep it out of flower for long.

The winter Jasmine is semi-shrubby, but although in no sense a "climber," a "creeper," or even a rambler, it does best against some kind of support. It may be grown against a pillar, an arch, or a wall. In good soil 


\section{POPULAR GARDEN FLOWERS}

it will probably grow about five feet high. It is not an evergreen, consequently the flowers have no backing save those of the stems, but these are of a rich dark green. The leaves come in spring. The specific name derives from the fact that the plant blooms when devoid of leaves.

The winter Jasmine is a good town plant, and will grow in ordinary soil; but, like most other things, it appreciates fertile ground. Beyond tying or nailing it to its support it will require very little treatment, as much pruning is objectionable. It suffices to cut out some of the older wood when the plant gets crowded.

Several other species of Jasmine are pretty and sweet, notably grandiflorum, which is larger than the white Jasmine; odoratissimum, very fragrant; gracillimum, white, illustrated in the Botanical Magazine, t. 6559; revolutum, yellow (Botanical Magazine, t. I73I); and Sambac, white flowers followed by black berries, the species from which oil of Jasmine is obtained : but these are greenhouse plants. The last three are evergreens.

It is as a garden plant that the sweet Jessamine appeals to most of us, and we ought to grow it better than we often do, thereby insuring it the place in our gardens which it now seems doomed to lose. 


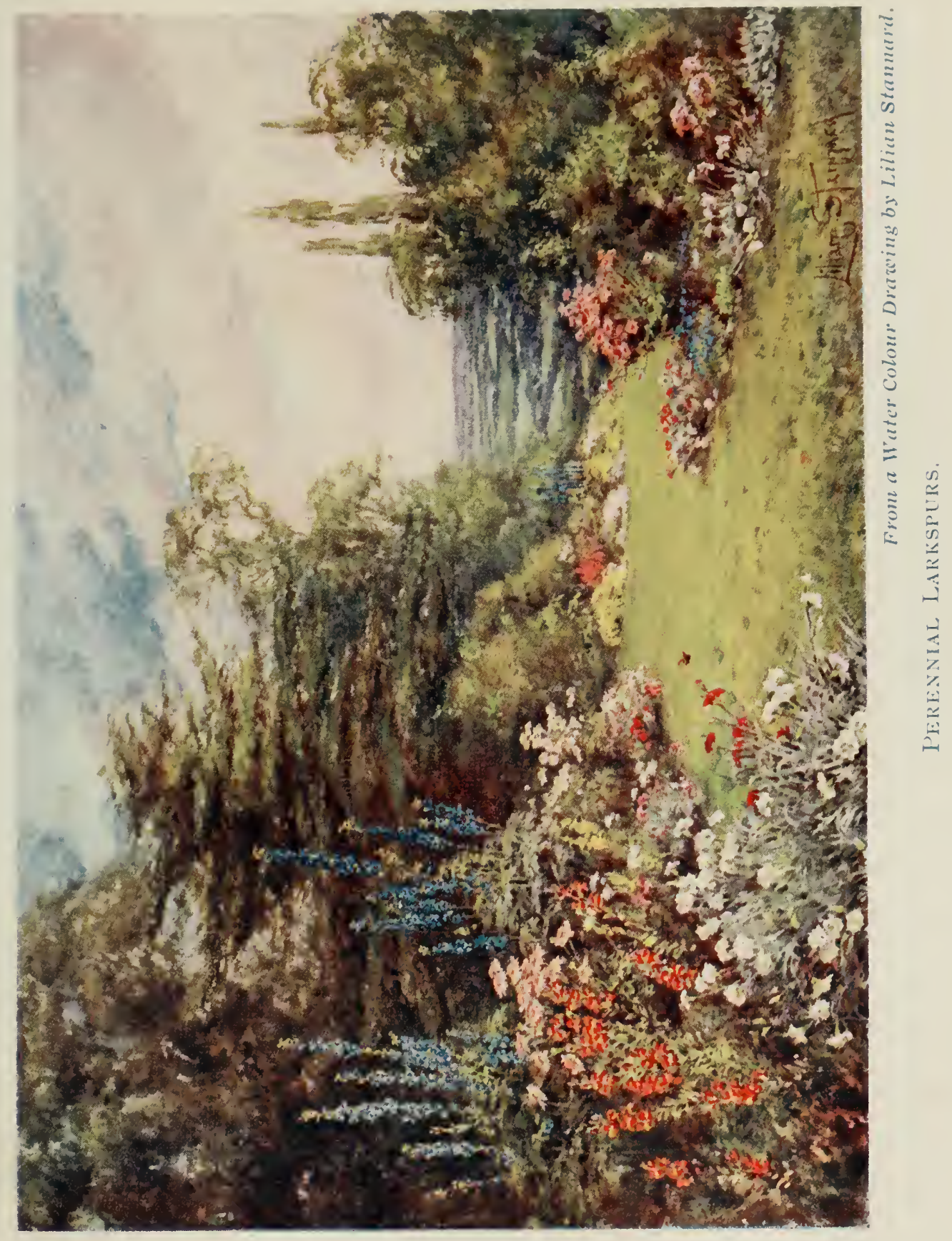





\section{XXVI}

ON PERENNIAL LARKSPURS OR DELPHINIUMS

THE name Larkspur is one of the oldest of popular garden terms, and it is a tribute to the power of the hardy plant movement that we flower-lovers are taking to the botanical name, Delphinium, so readily. The rough-and-ready classification of the garden is that the annual form is the Larkspur and the perennial the Delphinium. As a matter of fact, all Larkspurs are Delphiniums, but the distinction will serve. The extension of borders for herbaceous plants has led to a demand for perennial Delphiniums on account of their tall growth and beautiful spikes of blue flowers, and people seem quite content to know them by their botanical name.

Delphinium (pronunciation Del-fin'-i-um) is formed, according to the usually accurate Chambers, from the Greek Delphinion, Larkspur ; and Larkspur is "so called from the spur formation of calyx and petals." $\mathrm{He}$ takes us back to the Middle-English laverock, the Anglo-Saxon lawerce, and the German lerche. But botanists trace Delphinium to delphin, a dolphin, from a supposed likeness of the spur to a dolphin's head.

Larkspur is not the popular form of the name, for the Delphinium has many garden names. Larks' heels, Larksclaw, and Larkstoes are others; and the first of these was used by Shakespeare, if we may credit him with the introductory song to Beaumont and Fletcher's 


\section{POPULAR GARDEN FLOWERS}

play, "The Two Noble Kinsmen," where the phrase "Larks' heels trim" appears.

The annual Larkspur may be claimed fairly as a British plant, because it would seem to have derived from the two species ajacis and consolida. We are told that the former was introduced from Switzerland in 1573 , but it is naturalised in Cambridgeshire, according to Mr. Thomas Fox. With respect to the other species, it is a true native. Both flower in a wild state in June. There are no wild perennial forms.

The perennial herbaceous Larkspur which all classes agree to call Delphiniums have sprung from the three blue Siberian species, cheilanthum, elatum, and grandiflorum, the blue Italian species percgrinum, and the blue garden hybrid formosum. These have been crossed, and the progeny intercrossed, by Kelway and other wellknown modern florists, to an extent that it would be difficult even to guess at. The varieties so produced have been given distinguishing names, and they have raised the plant to a position of high importance in modern gardening. Delphiniums play a part, indeed, that few other plants are fitted to fill. Their growth is so vigorous, their spikes so tall, that they make noble pictures in themselves; and those amateurs who consider that the most striking form of flower gardening is to make a few bold groups of selected plants, seize on the Delphinium as peculiarly a plant for their purpose. The interest of the perennial Larkspur does not lie wholly in its flowers, for the leaves are distinct and handsome. Kelway likens them, not inaptly, to those of the Acanthus, or Bear's Breech, a plant whose foliage is said to have suggested the Corinthian style of architecture. The leaves are broad and deeply cut, and are set on strong, whitish flower-stems. 


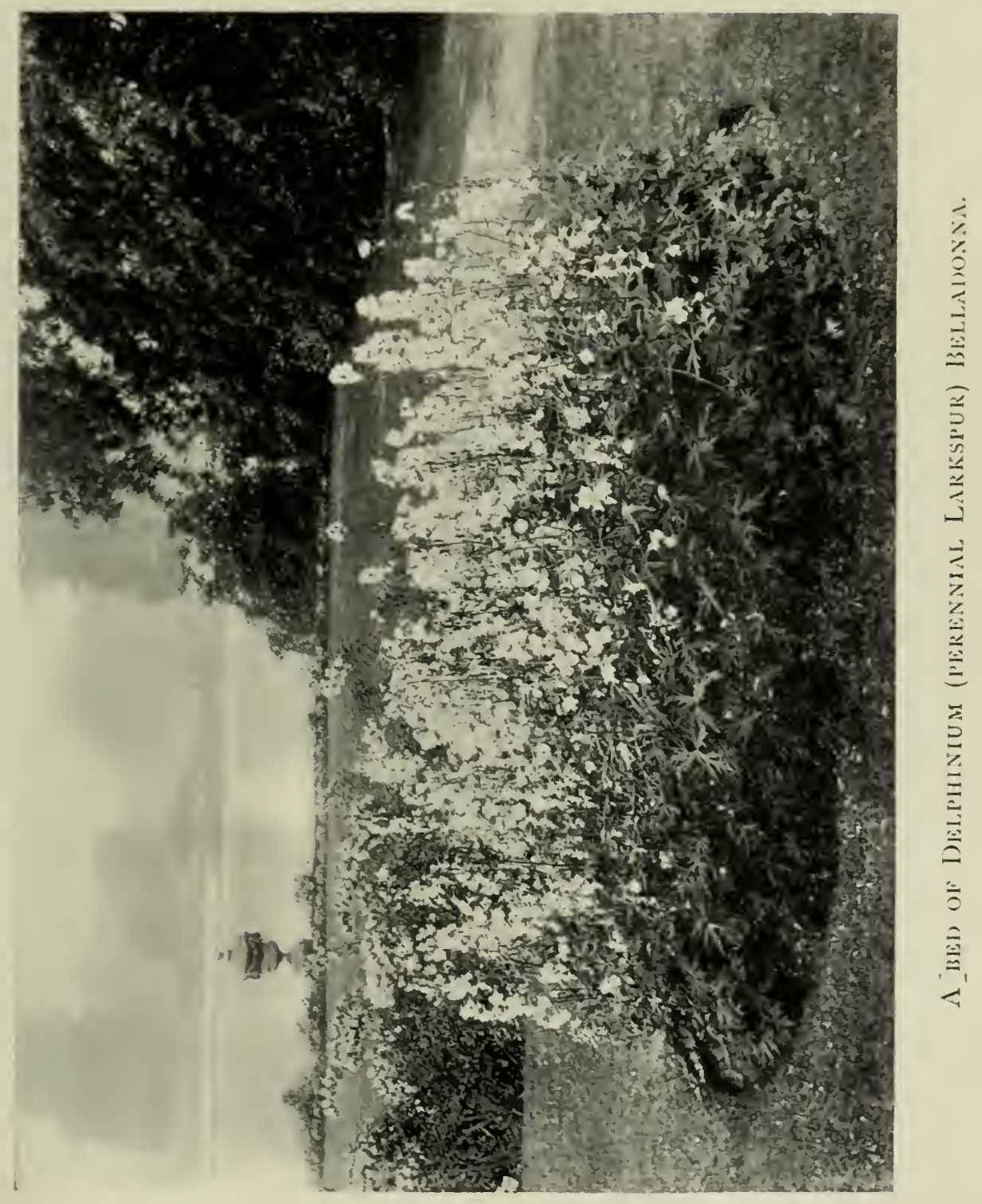



Propagation.--The root-stock is thick and fleshy, the roots differing entirely from fibrous things like Michaetmas Daisies. They resemble the large, succulent roots of the "Bleeding Heart," Dielytra (or, with modern botanists, Dicentra) spectabilis. Somehow, the amateur shrinks from dividing root-stocks thus composed much more seriously than he does from dealing with stools that consist of a thick network of fine fibres; but should he be standing with poised spade, hesitating and doubtful, he may be encouraged to strike home boldly, provided his clumps are strong, and are furnished with distinct "crowns" or growing points.

Soil.-As bought from the nursery, in the first place, the root-stocks are not, as a rule, ripe for division. They consist generally of single "crowns" with a few strong roots attached, and the amateur is not to split them up, but, on the contrary, so to treat them as to get them a good deal larger. With this object in view, he should plant them some time between November and April (both months inclusive) in soil that he has prepared for them. The extent of the preparation may depend, to some extent, on the character of the ground. Deep, moist, "holding" soil is eminently qualified to give fine Delphiniums, but the site ought not to be low and undrained, as they do not care for stagnant ground in winter. Given drainage, and pulverisation to a depth of eighteen inches or two feet, heavy clay will grow Delphiniums to perfection. The bottom soil ought to be broken up when the ground is fairly dry in winter. If the top soil breaks up in a very lumpy state, a coat of decayed stable manure may be spread on it and left for a few weeks. This, in conjunction with the spring rains, will soften the surface, and it will crumble down into a friable state by spring. I have had most encouraging 
results with Delphiniums on heavy land by following this course.

A later experience with light, fibreless land overlying chalk taught me the full value of deep clay. At the same time, it taught me that the perennial Larkspurs can be made to thrive on poor, thin ground. The course to pursue is to break up the chalk and cover it with green refuse, then to dig the surface soil to the last fraction of an inch, and interlard it with rich decayed manure from a stable or farm-yard. It is a good plan to do this in autumn, and add a light dressing of manure in spring, in the form of a mulching over the soil when the plants have been put in. The owner of light, shallow ground is faroured, so far as his plants are concerned, if a wet summer follows the planting. If not, let him give good soakings of water and liquid manure now and again.

The Delphinium is a poor, ineffective plant when badly grown; in fact, it is almost unsightly, as the foliage becomes flabby and dingy, the spikes are small, and the flowers are soon over. In such a state it is not worth the space that it occupies. We must remember that the Delphinium is an early blooming plant, and we can only have it in flower all the summer by giving good treatment and cutting it back after blooming.

At its best it has no rival, for there is no plant of the same character. It gives us the coveted colour blue, and gives it generously. It gives us blues as shining as Salvias, others as dense as Gentians, others as brilliant as Sweet Peas, others as clear of eye as Forget-me-nots. No hardy plant gives the splendid range of blues that we get in the perennial Larkspur. And the plant has lofty stature, massive spikes, to recommend it. The stens rise to six feet high or more in good soil. They are as 
tall and graceful as Hollyhocks, Foxgloves, or Eremuri. In their best condition they are truly noble ornaments of the herbaceous border. They may be set a yard apart, in groups, large or small, according to the space available, and may be blended with pillar Roses, Pæonies, Phloxes, and other good border plants. In the case of small borders, where grouping is impracticable, they may be set in a row at the back, as Hollyhocks were in their palmy days; and they will worthily wear the mantle which the Hollyhock has been compelled to lay down owing to disease. The Delphinium has no specific enemy of any note, and-always given good cultureit is a perfectly healthy and happy plant.

When the plants become dingy in the autumn, they may be cut to the ground. If the root-stocks are not to be divided the soil may be forked up around them, and some manure worked in or laid on the surface as a mulch. Should slugs attack the young growths seriously, some freshly slaked lime may be strewn about.

Seedlings.-Blue is not the only colour which the Delphinium gives us. We have white, pale yellow, and rose. Again, some are semi-double, and some full double. There are, too, scarlet species in cardinale and nudicaule. Both are fine plants, but the latter is a dwarf grower. These are easily raised from seed, and strong plants can be secured by autumn if the seed is sown in a box in spring, and put in a cold frame. If the seedlings are kept thin, put out a few inches apart in summer, and watered in dry weather, they will be in good condition for planting in September or later. If the soil is heavy and undrained, they ought not to be planted before spring, but they must not overcrowd each other in the nursery bed. 


\section{POPULAR GARDEN FLOWERS}

The modern hybrids and varieties may be raised from seed the same as the species, but they will not come true. Those who cannot afford to buy named varieties should procure seed from a good firm, and perpetuate a few of the best varieties which result by means of cuttings. This is an economical way of procuring a good stock. They should select varieties for increase which have large, wide flowers, well disposed on the spike. The colours should be rich and clear. Flowers with dark or light blue sepals and clear white or dark eye are the most desirable. These are really charming as individual flowers, and will well bear close inspection. As much can hardly be said of old varieties.

The following are fine named varieties :-

Autolycus.-Violet, black eye.

Beauty of Langport.-White, black eye.

Geneva.-Sky blue.

Grand Duchess.-Sky blue, black eye.

John Thorpe.-Dark blue, white eye.

King of Delphiniums.-Gentian blue, white eye.

True Blue.-Bright blue, dark eye.

Persimmon._Light blue, greyish centre.

Blue Butterfly.-A dwarf variety, good as an annual. 


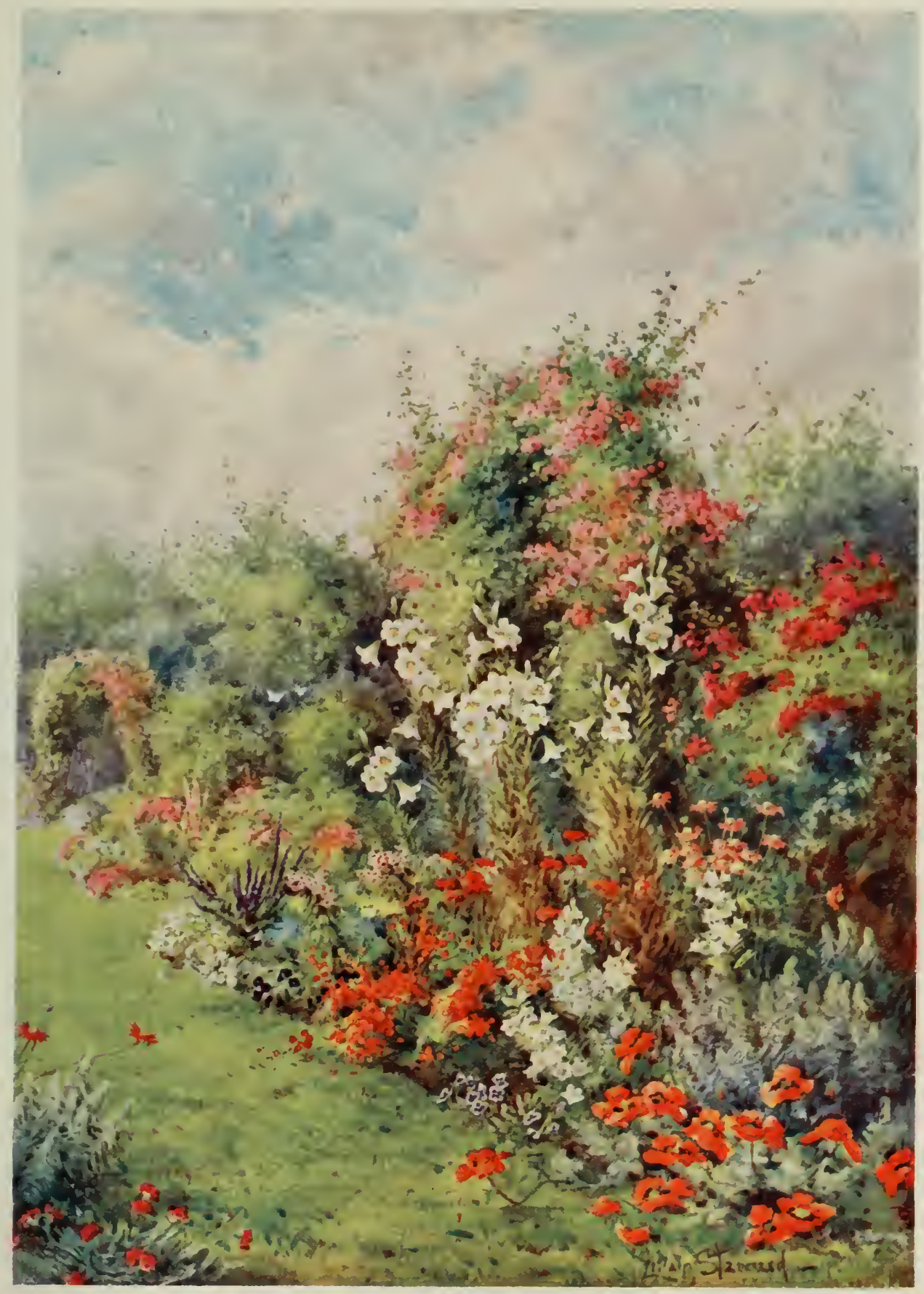

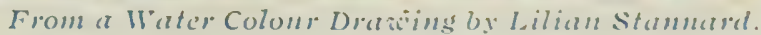

White LILIES. 



\section{XXVII}

\section{ON L I L I ES}

Whether we limit the term "Lily," as many gardeners do, to members of the genus Lilizm, or whether we allow it the wider scope which has been given to it by the popular voice, and include Lilies of the Valley and all other plants grown as Lilies in gardens, it is still a great force. The Lilies appeal to us by large size and handsome form of flower, by purity, and by perfume. They are amongst the noblest of garden plants. Everybody can grow some of them, and the townsman can have his share.

No lover of hardy plants can afford to ignore the Lilies. To do so would be to submit himself to the risk of a heavy blow in summer, when a visit to a friend's garden, a nursery, or a public garden, revealed a beautiful group which could not be matched at home. In gardening an involuntary burst of envy is common. We see something elsewhere that we had fully intended to have ourselves, and, not having it, we of course admire it and long for it all the more. We have to put up with the disappointment for the time being, but we register a vow that another year shall not pass without seeing the plant at home in our own garden.

With the best of intentions we cannot always grow

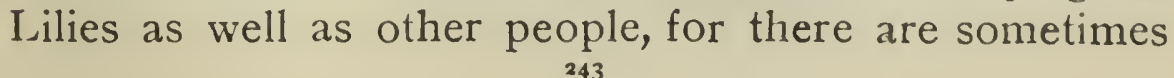




\section{POPULAR GARDEN FLOWERS}

special local circumstances which affect the welfare of the plants, but we can certainly grow some species quite creditably without any special help from fortune.

It is a rare old flower the Lily, and it has stimulated the great minds of all ages. They have seen in its grace and purity the symbols of lofty moral instincts, and have used it repeatedly as a figure of beauty and chastity.

"I love the Lily as the first of flowers,"

wrote Montgomery. This medireval poet gave it, we see, pride of place in the garden. He preferred it even to the Rose.

Later, Cowper pursued a more measured course. He could not choose between the two beautiful flowers, and so he gave them dual sovereignty-

"Within the garden's peaceful scene

Appeared two lovely foes,

Aspiring to the rank of Queen-

The Lily and the Rose.

'Yours is,' she said, 'the nobler hue,

And yours the statelier mien,

And till a third surpasses you,

Let each be deemed a Queen."

Shakespeare dearly loved the Lily, and referred to it again and again. Recall the noble and familiar lines in "King John," Act iv. scene 2-

"To guard a title that was rich before,

To gild refined gold, to paint the Lily,

To throw a perfume on the Violet,

To smooth the ice, or add another hue

Unto the rainbow, or with taper light

To seek the beauteous eye of heaven to garnish, Is wasteful and ridiculous excess." 
He used it repeatedly to give an effect of stainless purity-

"Most radiant Pyramus, most Lily-white of hue."

-Midsummer Night's Dream.

"Now by my maiden honour, yet pure

As the unsullied Lily."

-Love's Labour's Lost.

"A most unspotted Lily shall she pass

To the ground."

-Henry VIII.

"Full gently now she takes him by the hand,

A Lily prison'd in a jail of snow."

-Venus and Adonis.

What was the Lily which Shakespeare had in his mind in making these exquisite parallels? In his day, and later, the name Lily was used very loosely. We have his own

\section{"Lilies of all kinds,}

The Flower-de-luce being one,"

and we have decided already (see Chapter XXIV.) that the Flower-de-luce was the Iris. But the bard could hardly have had any other flower before him than the true old white Lily, Lilium candidum, when he chose a white Lily as a type and symbol of purity. His career ranged from 1564 to 1616 . The White Lily is said to have been introduced to Great Britain in that wonderful year for new plants, I596. (No student can fail to be struck by the number and importance of the plants which botanical records tell us were introduced in 1596 , and the more sceptically inclined among them will incline to the belief that the herbalists resolved to credit 1596 with any plant of whose exact year of introduction they were uncertain.) If that date were 


\section{POPULAR GARDEN FLOWERS}

correct, Lilium candidum could not possibly have become a popular garden plant until after Shakespeare's time, and he must have referred mainly to the Lily of the Valley, which is a British plant; but it is probable that the white Lily came to us much earlier than the year quoted.

The Madonna Lily. - The White, Garden, or Madonna Lily is a beautiful plant, tall in growth, yet not so tall as the massive Japanese Lily, auratum, graceful in habit, pure as snow, and powerfully perfumed. It has long been a much-loved flower in cottage gardens. A cheap as well as a beautiful plant, it has proved to be within the means of the humblest grower of plants. Entirely hardy, not particular as to soil, it has proved its readiness to thrive in the most modest of gardens. It is an early grower, and the principal trade in its bulbs is done at the end of the summer and in the early autumn. Those who propose to plant it might well order it with their Roman Hyacinths, and although it will not be ready quite so early, it will follow them in good time.

The White Lily, however, is not proof against all the ills of plant flesh. It is often attacked by a fungus, and whole clumps die out quickly, the bulbs rotting. The disease is less common in light, sandy, well-drained soils than in heavy, damp ground. Lilies, it is true, love moisture, but they abhor stagnant soil. It is possible, too, for the ground to be made too rich for them. If it is heavy it can be made suitable by drainage, pulverisation, and the addition of bone flour alone. The soil should be dug deeply, left lumpy on the surface, dressed with burnt refuse from the garden fire, and bone flour at the rate of four ounces per square yard. Light ground may have manure, but it should be well-decayed stuff, 
preferably such as has been used for a hotbed. Sand may be sprinkled round the bulbs, and they may be covered four inches deep.

When Lilium candidum is thus treated it generally grows strongly, and bears large clusters of beautiful flowers, well earning such panegyrics as that of Cannart d'Hamale in his monograph of the Lily: "C'est le Lis classique, par excellence, et en même temps le plus beau du genre." "It takes its place naturally," says d'Hamale, "at the head of this splendid group" ("Il se place tout naturellement à la tête de ce groupe splendide"). Many would tell us that it is the Lily of the arms of France, but to this I demur. It is above all the classical Lily, and at the same time the finest of the genus.

The White Lily makes a charming border companion to the blue perennial Larkspurs, and may therefore be grouped near these noble flowers. The two plants are generally in bloom together.

The Scarlet Lily.-If we doubt the accuracy of 1596 as the date of the introduction of the white Lily, what are we to say of 1796 as the year when the fine scarlet species Chalcedonicum was introduced to Britain? It is surely much older. The Scarlet Lily is a brilliant plant, and has long been a great favourite in our gardens. It is illustrated in the Botanical Magazine, t. 30 .

The Golden-rayed Lily, auratum, is a modern plant compared with the species named and some others to which reference will be made, as it was introduced as recently as 1862 . As most people know, it is a Japanese plant, and to this day the principal trade is in Japanese bulbs. Although not so tall as giganteum, it is certainly the finest of all the hardy Lilies, and enjoys widespread popularity with all classes of flower-lovers. When given 


\section{POPULAR GARDEN FLOWERS}

special culture it will grow six to eight feet high, and twelve to twenty magnificent flowers may be produced from one bulb.

The original species had white flowers, barred with yellow and dotted with red. It is illustrated in the Botanical Magazine, t. 5338. But importations yielded varieties differing from the type, and these were given varietal names. There were, for instance, cruentum, which was more heavily marked with red than the species; platyphyllum, with broader leaves and very large flowers; nubro-vittatum and rubrum, forms with a broad crimson band along the petal: tricolor, heavily spotted; virginale, white; and Wittei, with yellow bars. Specialists soon singled these treasures out, and created a special demand for them. They are now sold separately, under names, at a somewhat higher cost than the species itself.

Lovers of Lilies have established Lilium auratum as one of their prime favourites. They have found that it is capable of giving beautiful effects when grouped in the border, especially when it has shelter from shrubs or other plants capable of breaking strong wind. Such shelter is particularly grateful in spring, when the plants are making their first growth; but it is welcome at all seasons, especially in wind-swept districts. Clay is not quite the right soil for it, but it can be made to thrive on heavy land if the site is well dressed with lighter material, such as leaf mould. The thick, soft deposits of the woods have a mellowing effect on stiff land. They should not be expected to do everything, however. The ground should be drained, the subsoil broken up, and the surface layer reduced by exposure in a lumpy state. If peat is available it should be added to the leaf mould which is incorporated, and in any case road grit or coarse sand 


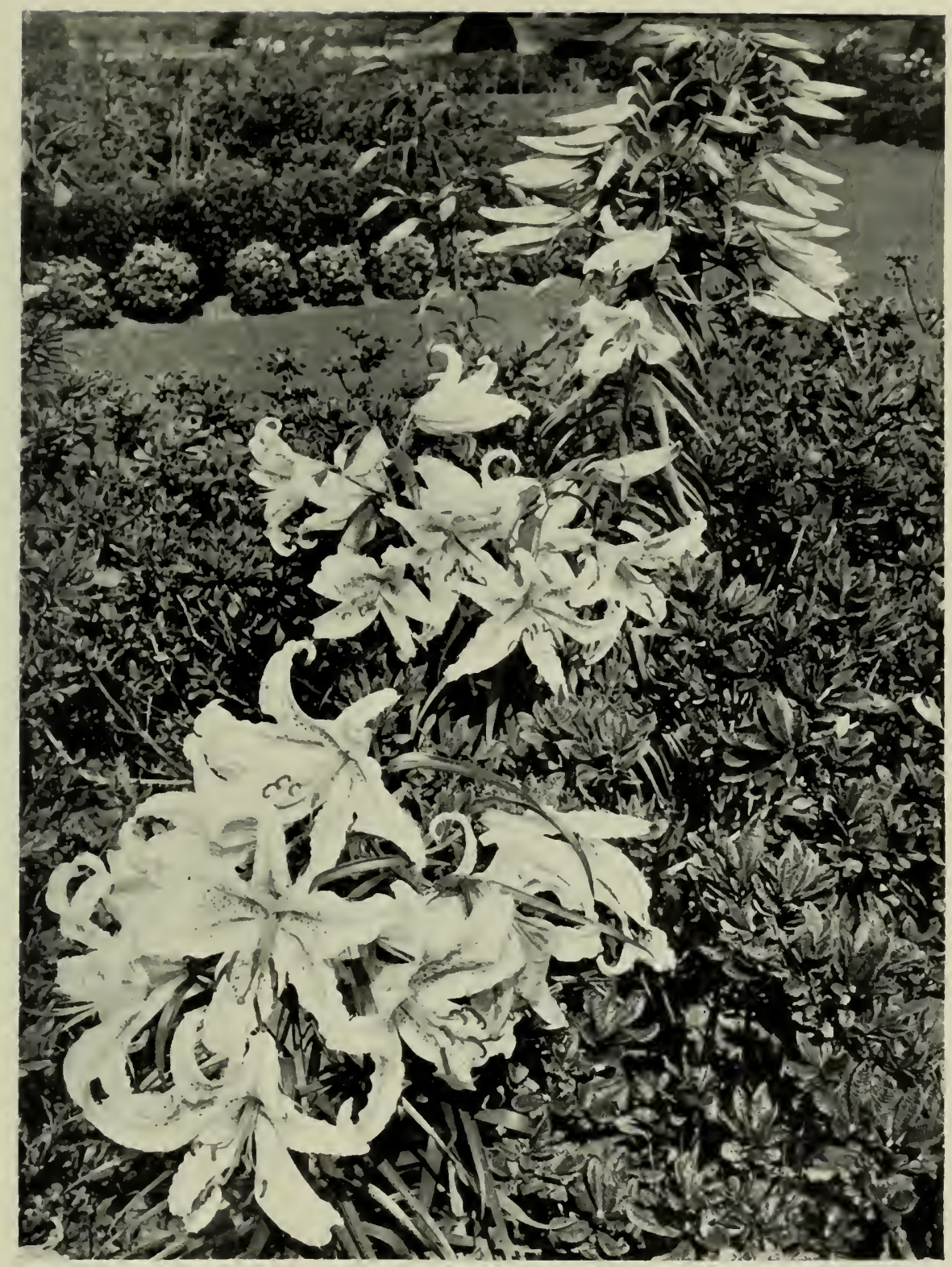

LILIUM AURATUM. 

should be added in sufficient quantity to make the soil crumbly and friable.

Given due preparation of the soil, the golden-rayed Lily will thrive in town gardens, and no finer plant will ever grace the suburbanist's border. Most town gardens have shelter, if only that of walls or fences, and that is no small point in the plant's favour. The town gardener will find that half a bushel of fibrous loam from the nearest florist's and another half-bushel of road scrapings will help him greatly in preparing a site for his clump of Lilies. He might form a group of from three to six, according to the space available, and set the bulbs a foot apart on a base of pure sand in spring. Reliable Japanese bulbs are not available before January.

In large country gardens it may be possible to form a Lily border in a sheltered place, such as along the front of a shrubbery, or under a kitchen-garden wall. If there are large trees near the shrubbery their roots may be expected to make for the spot, in quest of the good things provided for the Lilies, and it may be necessary to keep a trench open at the back to check their advance. If possible, a site near trees should be avoided, because the shade, and still more the drip, from large trees is bad. In the case of a wall border there is no objection to planting creepers to cover the wall; on the contrary, it is advisable, as a flower-covered wall makes a beautiful and appropriate background. Roses are eminently suitable, as, in spite of their vigorous growth, they are not plants which throw out coarse, rambling roots, but produce a mat of fibres immediately around the stem. Warm-coloured Roses, like Bardou Job, Cheshunt Hybrid, and Reine Marie Henriette, must be included in the collection. Clematises also look well 
on a wall at the back of a Lily border. The Passion Flower (Passiflora carulea) may be grown on a warm wall if it is liked, and so may the beautiful Ceanothuses, which produce lavender or blue cones.

In such a Lily border as the foregoing auratum, and possibly some of its varieties, must have a place. On account of its tall growth it must be set towards the back. If the soil is loam it will need little more than deepening and manuring to render it suitable; but even loam needs breaking up to a good depth to render it thoroughly friable, and leaf mould or road scrapings will facilitate the task. The best manure is decayed stuff from an old hotbed. Two barrowloads to the square rod of ground will be a sufficient quantity to apply, and it should be worked underneath the top spit, where it will not touch the bulbs, but where the roots will find it. If the natural soil of the Lily border is light, that is, if it is thin soil over chalk, or merely sand, it ought to be stiffened up with loam. Such soils are good in one respect-they are well drained, but they have not substance enough for Lilies. If chalk comes near the surface it ought to be broken up and covered with garden refuse. Loam, leaf mould, and decayed manure will collectively impart depth and body to the surface layer.

Other Species.-In anything like a representative collection of Lilies possibly Batemanii and Bolanderi, but certainly Brownii, will find places. The first grows about three feet high, and has apricot-coloured flowers ; the second about two feet, and has purplish red blooms, it thrives under the same conditions as auratum; the third four feet, and has white flowers marked with brown or purple. Brownii is one of the finest Lilies, and there are some good varieties of it, notably Chlor- 
aster. It does well under the conditions prescribed for auratum. Bulbiferm is not a very important species, and may be left out of a small collection without much hesitation. It grows about a yard high, and has red flowers. It is not a fastidious sort, and thrives in most soils.

The Hybrid Lily Burbankii, which was raised by crossing the species pardalinum and Washingtonianum (or Parryi) is interesting. It grows about four feet high, and produces apricot-coloured flowers. The auratum treatment suits it. Canadense, a North American species, is worth growing. Three to four feet high, it has orange yellow flowers, with red spots; but bulbdealers offer two varieties of it, one with lighter flowers called flavum, and the other deeper in colour, and named rubrum. The cost of all is about the same7s. to 8s. per dozen. They love peat, and, if a group of them is to be established in the Lily border, a station well dressed with peat should be prepared. The species is illustrated in the Botanical Magazine, t. 800 .

Reverting to candidum and chalcedonicum, both will thrive with auratum treatment, and garden varieties of both are offered by bulb-dealers. A popular form of the White Lily is striatum, but it costs about double as much as the species. Heldreichi is one of the most esteemed forms of Chalcedonicum.

Three newer species, which are offered in some catalogues, are carniolicum, carolinianum, and Catesbei. The first has red, the second orange, and the third scarlet flowers. Like Canadense they are peat-lovers. Catesbæi grows about eighteen inches high, and the others from two to three feet. Colchicum (Szovitzianum) has yellow flowers spotted with brown, and grows about 


\section{POPULAR GARDEN FLOWERS}

two feet high. It is not in the front rank, nor are columbianum, the Oregon Lily, and concolor. The former grows three feet high, and has orange-spotted flowers; the latter grows two feet high, and has red flowers; its variety, Coridion, which has canary-coloured flowers, is offered in the catalogues at a slightly higher price than the parent. The auratum treatment will suit them. Cordifolium, growing four feet high, and bearing white flowers marked with purple, is not much grown.

The old Orange Lily, croceum, is one of the cheapest, brightest, and most easily grown of Lilies. It was introduced as far back as 1596 , according to the records, and has got itself so firmly established that it is likely to last for a good many hundreds of years yet. Growing about two feet high in poor soil, and anything from three to six in rich ground, it is a familiar plant, alike in town and country gardens. The colour is as bright as the oranges that Nell Gwynn sold in the pit of Drury Lane. A hybrid Lily has been raised by crossing croceum with elegans (Thunbergianum or formosum), and is offered in some lists.

Dalmaticum, the Black Martagon of the catalogues, is really a dark variety of Martagon, the well-known purple "Turk's Cap" Lily, and Dalhansoni is a hybrid raised by crossing Dalmaticum and the species Hansoni. It will be seen that the name is compounded of the names of the parents, the first syllable of the one being added to the whole of the other. Dalhansoni is a rather dear Lily. It grows four to five feet high, has purple flowers, and responds to auratum treatment. Dauricum (the same Lily as that sometimes grown under the names of davuricum and spectabile) has red flowers, and grows about a yard high. The auratum treatment suits it.

Elegans is one of the most beautiful and useful of 
our Lilies. It is the same species as that offered in many catalogues under the name of Thunbergianum. The botanists, indeed, appear to be unanimous in giving the name elegans priority, and the dealers have as strong a leaning to the longer name. It is a Japanese species, and has scarlet flowers. The height ranges from a foot to two feet. It is not quite hardy, and although it will thrive in the border with auratum treatment, it, or one of its varieties, is often grown in pots. The varieties cost from two shillings to two pounds per dozen, according to their rarity. The following varieties are offered in many catalogues: Alice Wilson, yellow; alutaceum, orange ; citrinum, pale yellow; flore pleno, double; grandiflorum, blood red; marmoratum aureum, yellow; and Van Houttei, scarlet, a fine variety. Although these varieties of elegans are low growers they have very large flowers, and are extremely handsome plants.

The species excelsum, testaceum, and Isabelinum are the same-a plant growing four or five feet high, with nankeen-yellow flowers. It succeeds with the auratum treatment. Fortunei bears orange yellow flowers, and grows two feet high; it is not an important species.

The tallest member of the whole genus is giganteum, a true son of Anak, often growing twelve feet high, and bearing pure white flowers. This magnificent Lily is a native of the Himalaya, whence it was introduced in 1852. It is illustrated in the Botanical Magazine, t. 4673 . It is by no means the plant for an exposed place, as it is somewhat tender, and is soon spoiled by a cold wind. It thrives with the auratum treatment in a sheltered place, and also luxuriates in a deep, peaty soil among shrubs. There is nothing more gratifying to the flowerlover than to see Lilium giganteum starting on its career 


\section{POPULAR GARDEN FLOWERS}

in spring, for it pushes a huge growth through the soil, and appears as robust as a young Oak. It is a somewhat expensive Lily, and bulb-dealers often supply it in various sizes at different prices. Two shillings is the average price of a bulb four inches through.

The species Grayi, orange, dotted with purple, is not very important; but Hansoni is a good plant, and is not expensive. It grows about four feet high, and, having yellow flowers, is sometimes called the yellow "Turk's Cap." It will succeed with the auratum treatment.

Harrisii is a highly important Lily. It is really a variety of the species longiflorum, but is grown commercially as a species. It is the famous white Easter Lily so much used as a pot-plant for forcing. Growing from two to three feet high, and bearing its long, pure white flowers freely, it is a charming plant for greenhouse and conservatory decoration in spring, and is very useful for cutting. If it were not an abundant bloomer, the flowers would be rather too expensive to use in quantity for wreath-making and church decoration, as the bulbs cost from $8 \mathrm{~d}$. to Is. $6 \mathrm{~d}$. each, unless bought in considerable numbers, in which case they are much cheaper. It thrives in a compost of loam, leaf mould, and sand. If grown out of doors, it should have a sheltered place and the auratum treatment.

The species Henryi, which was introduced from China as recently as $\mathrm{I} 888$, has become a popular Lily. It has orange flowers, and grows four to five feet high. The auratum treatment suits it. Humboldtii is a very good Lily. It is a Californian species, growing about four feet high, deep yellow in colour, with purple or brown spots. Two varieties are offered in many catalogues, the first being magnificum, a very deeply coloured variety; and the second ocellatum, yellow, 


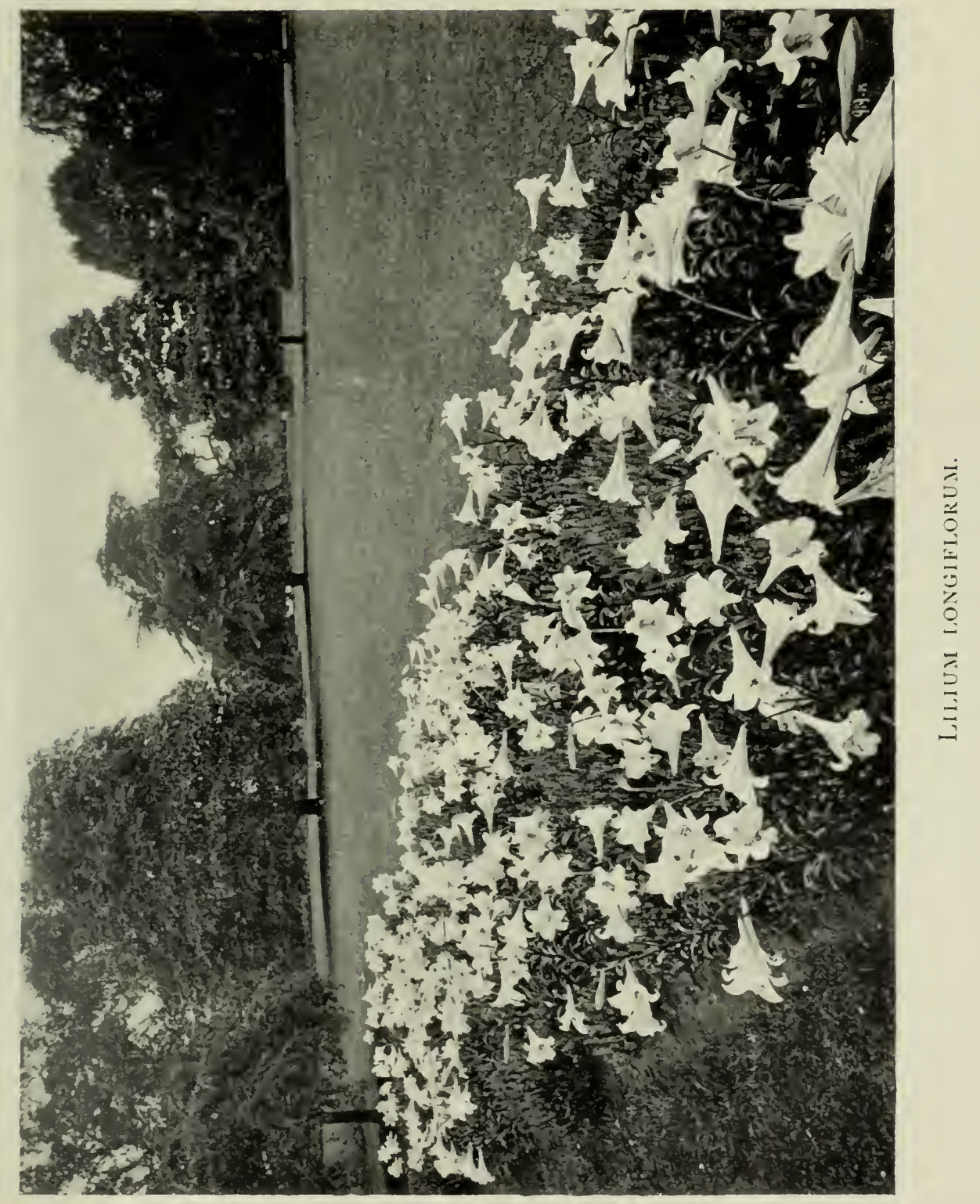



with purple spots. They are not the best natured of Lilies, and need a good loamy soil. Japonicum is the same as Elizabethe and Krameri. It is a charming Japanese Lily, growing two to three fect high, and with pink flowers. There is a white variety called Alexandræ. The auratum treatment suits these charming Lilies. Kelloggii is a Californian species with pink flowers, and, being rare, is somewhat expensive. It grows three or four feet high. Kewense is a hybrid, raised at the Royal Gardens, Kew, from a cross between Henryi and Brownii Chloraster. The flowers are white and buff in colour. The auratum treatment suits it, but it is generally grown in pots. Lancifolium is the same as speciosum. Leichtlini is a Japanese species of no great importance. It is yellow, with purple spots, and grows about two feet high. The auratum treatment suits it.

We have a charming pot Lily in longiflorum, which grows about three feet high, and has long, tubular, pure white flowers. Japanese bulbs of it are very cheap. It will thrive out of doors with the auratum treatment in a sheltered place, but, like its variety, Harrisii, it is grown generally in pots. There are several varieties of it besides the Easter Lily, including one with variegated leaves; that called Eximium is the same as Harrisii.

Lowii, white, with purple blotches, growing two to three feet high, is an Indian species, and requires potculture in a warm house. We find another interesting hybrid in Marhan, which resulted from a cross between the white "Turk's Cap," martagon album, and Hansoni. The name is compounded of the first syllable of the names of the parents. The flower is orange in colour, with brown or purple spots. It is a tall plant, and may go near the back of the border, where it will thrive under the auratum treatment. Forms of it are offered in some 
of the catalogues, notably G. F. Wilson, yellow, with carmine tips; and Miss E. Willmott, orange, with purple spots, but they are dear. Maritimum, orange, with dark spots, is a Californian Lily, and loves peat. It grows about three feet high.

The famous purple "Turk's Cap" Lily is the species known to botanists as Martagon, and was reputedly introduced from Germany in 1596. It is illustrated in the Botanical Magazine, tt. 893 and 1634 . It grows about three feet high, and will thrive almost anywhere. It is often seen in the cottager's border, where it practically looks after itself. With the auratum treatment it is luxuriant. The common "Turk's Cap" is one of the cheapest of Lilies, but its best varieties are rather dear. Album, the white, is a beautiful plant, and dalmaticum, claretcoloured, is also fine. These varieties are not quite so accommodating as the type, and had better have good auratum treatment.

The Japanese species, Maximowicziz, is a bright but not very important Lily. It is scarlet in colour, grows about three feet high, and thrives with auratum treatment. Nor is medeoloides of any great value. It has orange flowers, grows about eighteen inches high, and likes auratum culture. Monadelphum is more valuable. This handsome yellow species grows about three feet high, and thrives with auratum treatment. Neilgherrense is a pretty sulphur-coloured Lily growing about three feet high, but, being an Indian species, is not hardy, and had better be reserved for pot-culture, if grown at all. Nepalense is also lacking in hardiness. It has white flowers, and grows about three feet high. It is not important. Nitidum, yellow, with reddish spots, is a Californian species, and grows about two feet high. It thrives under the auratum treatment. 
The Panther Lily, pardalinum, is a Californian species of some importance, having orange flowers marked with crimson. Several varieties of it are offered in the catalogues, such as Bourgei, Californicum, Johnsoni, and Red Giant, the last somewhat expensive. They grow four to five feet high, and are peat-lovers. Parryi, a yellow-flowered Californian species, growing three to four feet high, should have peat. Parvum has small yellow flowers spotted with red, and is the same as Alpinum. As a Californian species, it is a peat-lover. A yellow variety, called luteum, is offered by bulb-dealers. Philadelphicum, scarlet, two to three feet high, is a NorthAmerican species that should have peat. It is a cheap Lily: Cheaper still is Philippinense, which grows two feet high, and has long, white, trumpet-shaped flowers. It is not hardy, and should be grown in pots. Polyphyllım, white, with purple spots, grows about three feet high, and thrives under auratum treatment. Pomponium, two to three feet high, with small red flowers, is a hardy and accommodating Siberian species which needs no special treatment. It is a cheap plant. Pulchellum, scarlet, is a rather dear and not very important Lily. Pyrenaicum, which has deep yellow flowers, and grows about three feet high, is a pretty Lily that thrives under auratum treatment. A red variety, rubrum, is offered in the catalogues. Roezlii, orange, with purple spots, is a hardy but not important species.

Rubellum, with pink flowers on stems eighteen inches to two feet high, is a charming and not expensive Lily that blooms early, and is often grown in pots. Rubescens, a tall species with white flowers, is rather dear, and not very important.

One of the most beautiful and valuable of Lilies is speciosum (lancifolium), a Japanese species, growing three 


\section{POPULAR GARDEN FLOWERS}

to four feet high, with white flowers spotted with red. There are many charming varieties of it, among which album and album Kratzeri may be named as beautiful and cheap white forms, well adapted for pot-culture. Album novum is a lovely variety, but somewhat dear. Other good and cheap varieties are roseum, rubrum, rubrum inagnificum, and Melpomene. Although Lilium speciosum and its varieties are not reputedly hardy, and are generally cultivated in pots, they may be grown out of doors in a sheltered place with the auratum treatment.

Sulphureum (which is the same as Wallichianum superbum) is a fine but expensive Lily, and is not hardy. It grows five to eight feet high, and has pale yellow flowers with a brown exterior. Superbum, orange with red spots, growing six feet high or more, is an American species, and loves a damp, peaty soil. It is quite hardy and very cheap. Sutchuenense, orange with dark spots, growing about two feet high, is somewhat dear, and is of no importance. Tenuifolium, scarlet, a Siberian species, growing about two feet high, is cheap and hardy. We have seen that testaceum is synonymous with excelsum, and Thunbergianum with elegans, under which names they are described.

The orange black-spotted 'Tiger Lily (tigrinum), which grows four to six feet high, is one of the cheapest and most easily grown of Lilies, thriving under the auratum treatment. Several varieties are offered in the catalogues, such as flore pleno (double), Fortunei, and splendens. They cost about the same as the type, except Fortunei, which is rather dearer, but still a cheap plant. Umbellatum, which has red flowers, grows two to three feet high, and thrives under the auratum treatment, is an excellent Lily, and there are several 


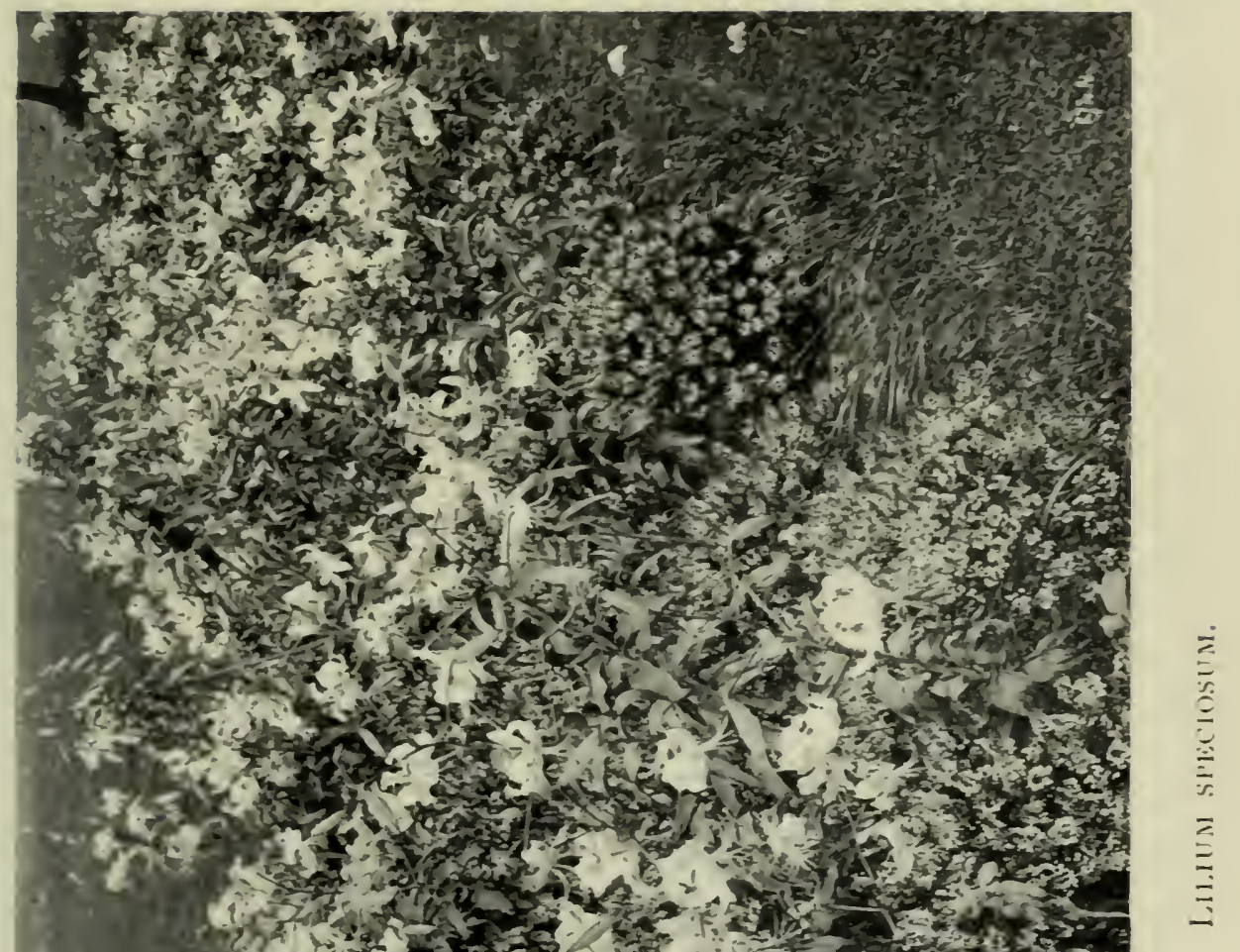



varieties of it in the bulb catalogues, such as Cloth of Gold, erectum, and Incomparable. They are very cheap. Wallichianum, an Indian species with white flowers, growing three to four feet high, is not hardy, and should be grown in pots if wanted.

The last species to be named is Washingtonianum, a Californian Lily, growing three to five feet high, and having white flowers. It thrives with the auratum treatment. A dark variety called purpureum is offered in the catalogues.

The list of species given is a long one, and few readers are likely to require the whole; nevertheless, many will grow some, and the descriptions and hints on culture may be useful to them.

As to soil and culture, we see that the great majority are suited by that suggested for auratum, but that a few species (and notably the Californians) enjoy peat. Few Lilies like wet ground, but superbum is one that does, and the magnificent giganteum loves a cool, sheltered site.

Culture in Pots.-Such popular Lilies as longiflorum, its variety Harrisii, speciosum and its varieties, such as Krætzeri, thrive in a compost of three parts loam, and one part each leaf mould and decayed manure with one-tenth sand. As they generally throw out roots from the stem, it is well to place the bulbs low down in deep, well-drained pots, and nearly to cover them, but not to fill up until the stem roots appear, when more soil should be placed on. The pots should be stood in a sheltered place, and covered with ashes or cocoanut-fibre refuse after potting, and they should not be withdrawn until roots have pushed freely. They will enjoy abundance of air and water when in growth, and 


\section{POPULAR GARDEN FLOWERS}

may be syringed to keep them fresh and subdue insects. They may be potted in autumn, winter, or spring, according to the season when the bulbs are available. They may also be grown in peat-moss fibre.

Propagation.-Lilies may be increased by offsets, which form at the base; by bulbils, which form on the stems of such species as have the habit of producing them; and by scales, which should be inserted in a box in a compost of leaf mould and sand, with some cocoanut-fibre refuse added in spring, and planted out when they have formed bulbs.

Among other plants grown under the name of Lilies are the following :-

African Corn Lily, Ixia.

American Wood Lily, Trillium grandiflorum.

Belladonna Lily, Amaryllis Belladonna.

Brisbane Lily, Eurycles Cunninghami.

Day Lily, Hemerocallis.

Guernsey Lily, Nerine sarniensis.

Herb Lily, Alstromeria.

Jacobean Lily, Sprekelia formosissima.

Lent Lily, Narcissus Pseudo-Narcissus.

Lily of the Nile, Richardia (Calla), Africana (Ethiopica).

Lily of the Valley, Convallaria majalis.

Mariposa Lily, Calochortus.

Peruvian Lily, Alstromeria.

Plantain Lily, Funkia.

St. Bernard's Iily, Anthericum Liliago.

St. Bruno's Lily, Anthericum Liliastrum.

Scarborough Lily, Vallota purpurea.

Snake's Head Lily, Fritillaria.

'Torch Lily, Kniphofia (Tritoma).

Water Lily, Nymphaa.

Most of these plants do not quite come within the scope of the present work, and as they are nearly all 


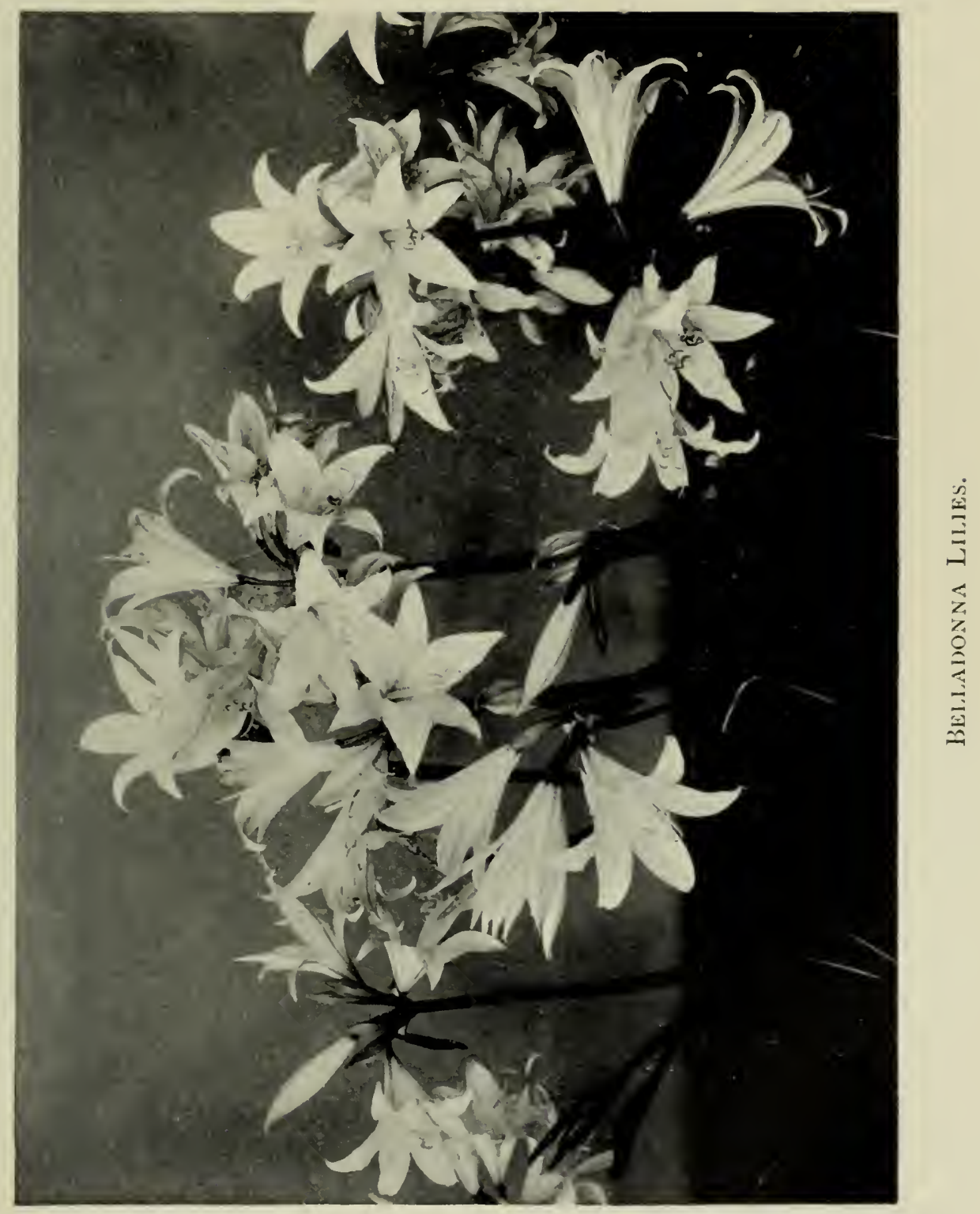



dealt with, according to their merit, in the companion volume, The Garden Week bv IVeek, it is not necessary to devote space to them herein.

The flower-lover will find the Lilies a most interesting as well as beautiful class of plants. He should grow at least one variety-auratum, and he should endeavour to provide it with such beautiful associates as candidum, chalcedonicum, speciosum, and umbellatum, with such of their varieties as come within his means and space. They will give stately growth, graceful foliage and habit, and beautiful flowers. Their beauty is of a type that no other hardy plant provides, and so we may say that they are indispensable in the garden.

Home and Imported Bulbs.-Lest the references to imported bulbs in the foregoing notes should lead to the inference that I regard them as the "stock article," I may say that I do not do so. Foreign bulbs and late planting do not make for the most successful results with Lilies. The bulbs of all Liliums are much more liable to lose their freshness than such things as Hyacinths and Tulips, and even these are best potted or planted early in autumn, before they start to grow. Lilies ought really to be planted in late summer or early autumn, when the bulbs are quite fresh. But the imported bulb undoubtedly meets a want. It suits the amateur who cannot very well afford the price of homegrown bulbs, or do his planting before the spring. The Japanese bulbs are large and cheap, and as they are encased in moist earth they do not become dry speedily. If, when they reach the hands of the grower, they have shrivelled, and have loose scales, they had better be laid in cocoanut-fibre refuse for a fortnight before planting, as this will freshen them. A soft, yielding bulb, with loose scales, is hardly worth using. 


\section{POPULAR GARDEN FLOWERS}

Lovers of Lilies will not shrink from the little trouble involved in carrying out the hints given herein; on the contrary, they will adopt them gladly. They will give of their best to a flower whose beauty they admire so much, and whose associations they reverence so deeply. Its appeal to them is a special one. It is not merely the flower of their gardens, it is the flower of the Sermon on the Mount, and as such it stirs thoughts and emotions which can nowhere find better expression than in the endeavour to add more beauty to the world. 


\section{XXVIII}

\section{ON PÆONIES}

THE modern Pæony may on no account be omitted from a list of popular garden flowers, for during recent years it has advanced by leaps and bounds. Visitors to the great flower shows gaze in wonder at the magnificent flowers which represent the florists' latest achievements in Pæony development-flowers almost as large as huge show Chrysanthemums, brilliantly coloured, and in the case of many varieties, richly scented.

A grand old plant this Pæony, whether we consider it as a shrub or a herb. We have sections of both types, and the herbaceous Pæony is the older, so far as British gardens are concerned. The modern leaflosing Pæony has sprung from two species, the white albiflora and the red officinalis, and botanists tell us that both were introduced in 1548 ; whereas Moutan, the shrubby Prony, did not arrive until 1789 . The latter is illustrated in the Botanical Magazine, t. I I54.

With some writers the typical Pæony is corallina, a red herbaceous species, stated to be a native of England. Fox records it as found on May 23 rd at Steep Holmes, Severn, and states that it produces red, pink, or white flowers. It is probable that this was the Pæony of the poets-if we allow them to have named a Pæony at all. It is not every student who will admit that Shakespeare had the Pæony in mind when he puts into the 


\section{POPULAR GARDEN FLOWERS}

mouth of Iris ("The Tempest," Act iv. scene I) the words-

"Ceres, most bounteous lady, thy rich leas

Of wheat, rye, barley, vetches, oats, and pease,

Thy turfy mountains, where live nibbling sheep,

And flat meads thatched with stover, them to keep;

Thy banks with pioned and twilled brims,

Which spongy April at thy hest betrims

To make cold nymphs chaste crowns."

And it must be confessed that there is some justification for their scepticism, since pioner or pyoner (forerunner of our modern word pioneer) was used to indicate digger in mediæval times. Shakespeare himself used it in this sense in "Hamlet." But it is at least as probable that he alluded to the plant, for, after all, Nature's banks are not "digged," but left to look after themselves.

The Pæony was esteemed by the botanical writers of Shakespeare's time. Parkinson, for example, had it, and what is more, said that the double Pæony produced seed with him, which, being sown, "bringeth forth some single and some double flowers." The double Pæony does not often do that in these days. Gerard also knew the Pæony quite well, and records it as growing wild at Southfleet, near Gravesend, although there is an unkind suggestion that it was first deliberately planted, and then hailed as a wilding by the planter. Southfleet is a parish of fruit in these days, and its market-gardens spread for many miles.

The modern Pæony is one of the greatest of all border plants. It is of vigorous growth and hardy constitution, soon establishing itself, and spreading into large bushes. When it has made itself at home it bears its great brilliant flowers in abundance, moreover, it 


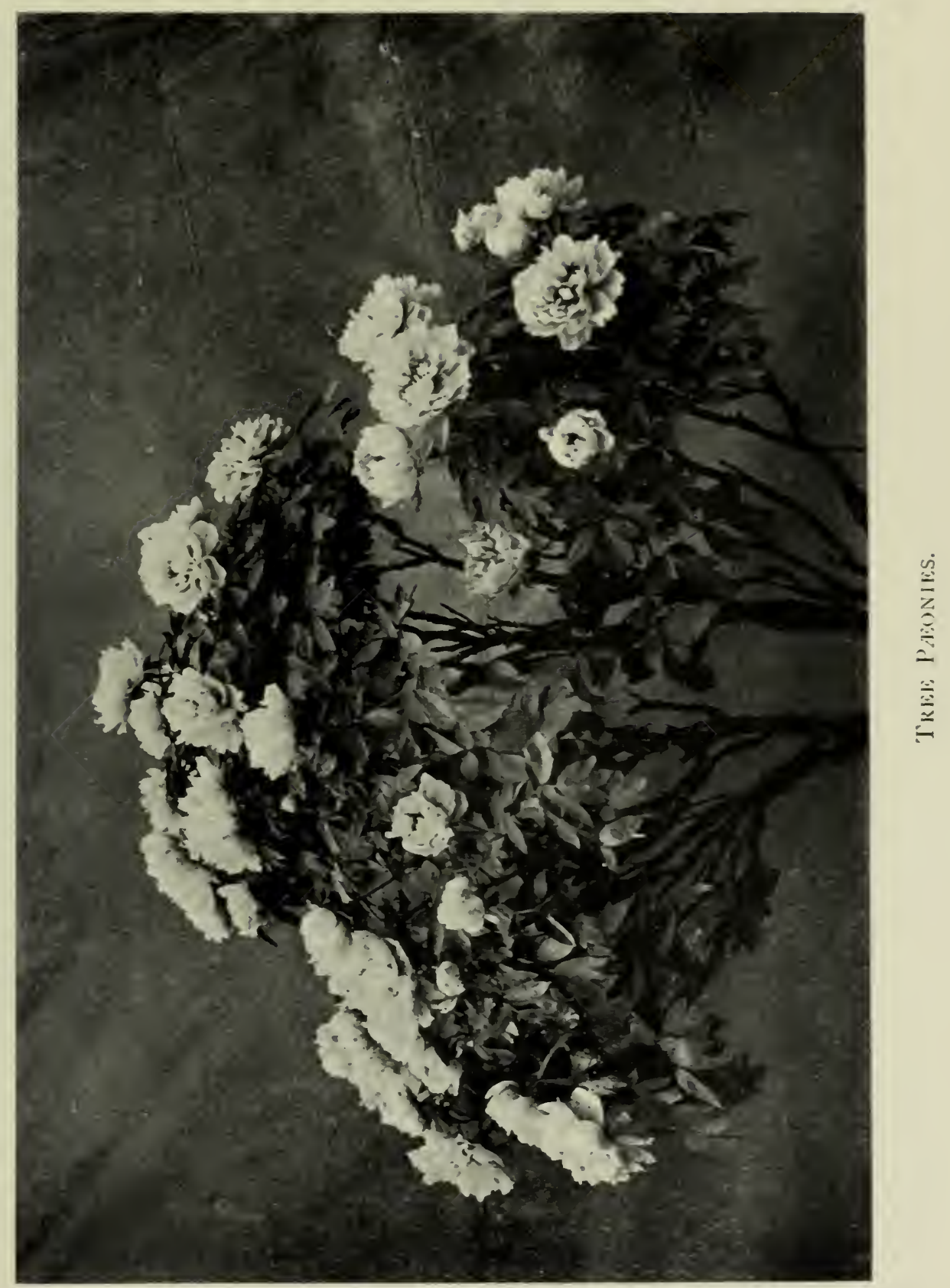



throws them up on thick, strong stems, quite clear of the leaves. It is both an early grower and an early bloomer. The ruddy stems of the herbaceous varieties push up in March, and in a warm spring a bed is a rich mass of colour in April. These spring tints of the Prony growth give it an undeniable value, for they brighten up the border at a dull period, and afford a pleasant foretaste of the good things in store.

When a clump of Pæonies has spread to three or four feet across, and is bearing a broad mass of leaves and two or three dozen brilliant flowers in June, it is an object with which few plants can vie.

A minor point in favour of Pæonies is their healthy nature and freedom from insects and diseases. Slugs may do damage to the young shoots in spring if left unchecked, but dustings of lime soon reduce them to impotence.

Soil.-The Pæony, then, has several things to recommend it: a healthy, hardy nature, vigorous growth, handsome spring tints, beautiful flowers, fragrance. Can it now be added that the plant will thrive anywhere? Hardly that. It does not care for shallow, dry soils, nor situations swept by cold winds. It loves a deep, fertile, moist soil; and if there is a fence, or a bank of shrubs between it and the east winds of spring, all the better. Given the deep soil there is no plant more easy to manage, for it practically needs no culture. I have succeeded with it on shallow, chalky ground by loosening the chalk, dressing the top soil liberally with decayed manure, and giving occasional soakings of water, plus a weekly drenching of liquid manure throughout the summer. If the soil of a suburban garden is made fertile to a depth of eighteen inches by digging up the under soil and manuring 


\section{POPULAR GARDEN FLOWERS}

it, also the top soil, it will grow Pronies successfully.

Planting:-The best time to plant Pronies is towards the end of winter-say February or March. But they may be planted any time between October and April. After a mild winter the planting had better not be deferred until late spring; it should be done as soon after growth starts as possible. It will be seen that Pæonies have not a spreading, fibrous root-stock, but form a few thick, fleshy roots, which have a tendency to strike down deeply. They may be planted in clumps if desired, but as the habit is spreading, the components of a clump ought not to be nearer than eighteen inches. Single plants will suffice for small borders, as, if the soil is good, one plant will spread to anything from two to five feet across.

Propagation.-Owing to the strong, fangy root-stock of which I have spoken, Pæonies do not lend themselves to propagation by division, the popular method of increasing most herbaceous plants; moreover, they do not exhaust the soil nearly as much as plants with spreading fibrous root-stocks. On both these counts frequent propagation by division should be avoided. But when the clumps have become established thoroughly, and have spread so much as to encroach on the preserves of other plants, they may be cut up while dormant with a sharp spade. Florists propagate the majority of their best Tree Pronies by grafting small pieces on to the roots of common herbaceous kinds. The latter cannot very well be divided. They do not die down to the ground every autumn like the herbaceous Pronies. They retain their stems, but not their leaves, like an Apple tree. In sheltered places and rich soil they grow into large shrubs, like Rhododendrons. Pronies can 
be raised from seed, and the best plan is to sow in a box in September, and put it in a cold frame. The seedlings will probably appear in spring, and when they are strong they may be set out in rows a foot apart, and hoed between to keep down weeds. If the soil is good they will be strong plants by autumn. By using seed bought from a firm which specialises in Pæonies the grower may rely on getting good varieties, some single, others double.

Species and Varieties.-The name Prony is said to derive from one Pæon, a physician. Albiflora (whiteflowered) was a Siberian plant, and we should therefore expect its offspring to be hardy, as, indeed, the Pæonies are. Officinalis cannot be located with certainty. It is described in the records as of "European origin," which is pleasantly vague. The old double red Prony of cottage gardens is the officinalis rubra plena of the botanists. It is a fine, and at the same time a cheap, plant. The old double white and double rose are respectively officinalis alba plena and officinalis rosea plena. There is a handsome species called by botanists tenuifolia, which is illustrated in the Botanical Magazine, t. 226. This is often grown under the name of the Fennel-leaved Prony. It has red flowers, and there is a double form of it. The Anemone-flowered Prony (anemonaflora) is a variety of officinalis. Wittmanniana is a notable though rather expensive species, with primrose-coloured flowers. It is illustrated in the Botanical Magazine, t. 6645 .

While the Prony-lover likes to know of the species of his favourite flower, his interest lies mainly in the modern varieties, and to those we may turn, for the list of species is short and (considered from the garden standpoint) unimportant. 


\section{POPULAR GARDEN FLOWERS}

When the amateur opens a hardy plant catalogue and turns to Prony he may be dismayed to find that plants are quoted at as much as half a guinea each; but if he reads closer he learns that the varieties offered at this price are the latest novelties, and he has only to turn over a page or two to find sorts offered at prices falling by stages to eighteenpence or a shilling each. If the price still seems rather high, he may be reminded that Pæonies are not plants which can be propagated rapidly, and can never, therefore, be sold as cheaply as some plants. Moreover, being large plants, he will not need to buy many of them. In case he is swayed by the fear that cheap varieties are necessarily poor ones, I may reassure him by saying that the standard of Pæonies has been a high one for so many years that a six or even a ten-year-old sort is still a good one. The following, for instance, are fine double Pæonies, although inexpensive :-

Denis Helvé, dwarf red, very sweet.

Dr. Brettoneau, dark rose.

Duchesse de Nemours, white, delicious Rose perfume.

Festiva maxima, white, red tips.

François Ortigal, purplish crimson.

Humei carnea, peach, white centre.

Louis van Houtte, crimson, yellow anthers.

Lucrece, pink, white centre.

Madame Vilmorin, blush, Rose scented.

Magnifica, white, flushed yellow, fragrant.

Ne Plus Ultra, light rose, very fine.

Virginie, rose, white centre, Anemone-flowered.

They may not be so fine as the best of the modern varieties which the amateur sees at a great show, the highest product at once of the skill of the hybridist and the experience of the professional grower; but, when all 
is said and done, there is less difference between them than there is between half a guinea and a shilling to a person of moderate means.

The principal reason why I describe double instead of single varieties is that they last longer. As the Pæony is naturally an early blooming plant we want to get as much out of it as possible before it passes for the season. Seedling Snapdragons or Pentstemons may be planted near it in May to give beauty when it is over; or a group of Gladioli may be planted close by, to give beauty when the Pxonies have faded. Without some such provision there may be a dull patch in the border late in summer; with it, the display of colour is maintained until the autumn frosts arrive. Single Pæonies are somewhat fleeting; still, they are beautiful flowers, and amateurs who fancy them in preference to the doubles will find no difficulty in obtaining varieties at corresponding prices. 


\section{XXIX}

ON PANSIES, VIOLAS, AND SWEET VIOLETS

ELSEWHERE in this work I have remarked that there are some flowers whose appeal is so intimate and irresistible that they do more than stimulate interest and admiration - they arouse our love. The Pansy is one of them. Its flowers may be excelled in beautyas they certainly are in size-by those of many plants, but it is winning where they are no more than brilliant, and so it probes deeply into our hearts, and finds an abiding resting-place there.

People sometimes speak of the popular names of the Pansy, as though the names of the books and catalogues were a scientific one. Pansy is itself a "popular" name, and it has become generic by mere right of long usage. It is a corruption of pensée, the French word for thought, but why the French gave this name to the little flower is not obvious. Was it supposed to stimulate reflection? Were the thoughts pleasant or painful? We should say that they were agreeable if we knew of one other common name only, "Heartease," but there is another, "Love-in-idleness," and this really meant love in vain.

Perhaps we should not be far wrong if we assumed that it was originally "the flower of one's thoughts," for la dame de ses pensées, or "one's lady-love," is a phrase that might have been copied. As an abbre- 
viation of la fleur de ses pensées, the use of pensées as a name for the flower becomes intelligible. The Pansy has always been associated with tender thoughts, such as those of love. It is the "Cupid's flower" of Shakespeare in the "Midsummer Night's Dream" -

\section{“ Dian's bud o'er Cupid's flower Hath such force and blessed power."}

Shakespeare knew, too, of the origin of Pansy, for in "Hamlet," Act iv. scene 5, Ophelia exclaims: "There's Rosemary, that's for remembrance ; pray you, love, remember; and there is Pansies, that's for thoughts." To which Laertes responds: "A document in madness, thoughts and remembrance fitted."

Shakespeare was familiar with the folk-name, Lovein-idleness, for in "The Midsummer Night's Dream," Act ii. scene I, we find-

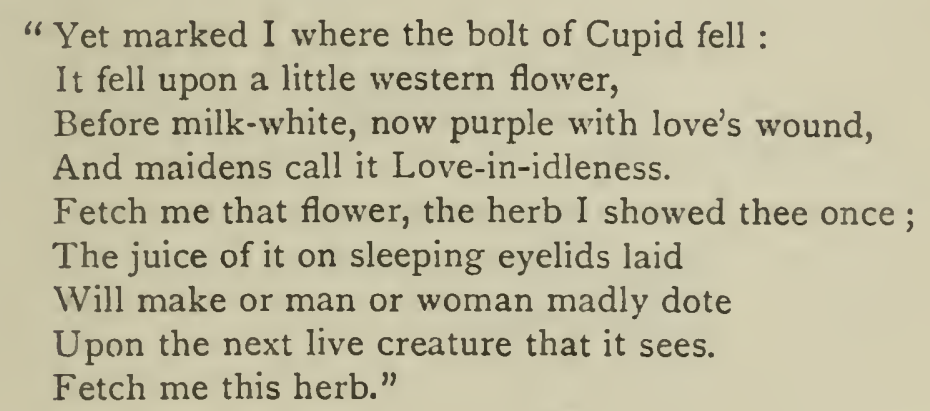

The Pansy, then, was a "western" flower, and it was a component of love potions. As regards its habitat, it is a British plant, found in Scotland, Ireland, the Channel Islands, and by many English waysides. It is purple and pale yellow in colour, so that the Bard was not far wrong in his description of it. The wild mountain Pansy, found on many moors and hills, is yellow.

We have found already three folk-names for the 


\section{POPULAR GARDEN FLOWERS}

Pansy, but that number is added to greatly by Dr. Prior in his "Popular Names of Flowers." He gives the following: Herb Trinity; Three-faces-under-ahood; Fancy-Flamy; Kiss me-Cull me, or, Cuddleme-to-you; Tickle-my-fancy; Kiss me 'ere I rise; Jump up and kiss me; Kiss me at the garden gate; and Pink of my John. All, it is to be noted, are of an amatory nature. Prior thought that the quaint names given to the flower arose partly from its habit of "coquettishly hanging its head and half hiding its face." Whatever the cause, the Pansy has many endearing cognomens, and their number, allied to their affectionate character, may be taken as some measure of its popularity.

The wild Pansy is a five-petalled flower, about three-quarters of a inch across. The lower petal is the largest, and, as in other wild flowers of which the petals vary in size, it has what the florists would describe as a "ragged" appearance. Florists do not like flowers with petals that have gaps between them, and one of their first objects in improving a flower is to fill up the gaps. By steady selection they increase the size of the smaller petals until they get them as large as the biggest. They not only fill up the gap, but secure a margin, so that the petals overlap each other a little. If the outline of the petals is uneven, indented, or flat, they pursue their operations until they have got it slightly convex, and this, in conjunction with the closingup of the petals, gives a well-rounded flower; in other words, the upper outline of each petal unites to form a circle. It all sounds mysterious and surprising to the novice, but it is mere finger-and-thumb routine to the experienced florist. Working by cross-fertilising one variety with another, by selecting those of the offspring 


\section{PANSIES, VIOLAS, SWEET VIOLETS 273}

for parents in future crosses that come nearest to his ideal, and by taking advantage of any natural variation, he gets gradually nearer to the goal.

It would be as difficult to say when the work of improving the Pansy began, as to trace the stages by which it advanced towards the form of the best type which we have at the present day ; but that the way has been a long one may be judged by comparing the wild Pansy with a modern Scotch prize flower. The blooms which the specialists stage are nearly three inches across, the outline is perfect, the petals are thick and substantial, the colour markings are exquisite. Perhaps the amateur who only knows the Pansy as a garden flower is a little startled when he first sees a stand of prize flowers at a show. He may be "doing Scotland," and, seeing an announcement of a big flower show in Edinburgh or elsewhere, and recalling the high reputation of Scotch gardeners, may decide to drop in and see what the Scotchmen can really do. Whatever the latter is or is not capable of in other directions, he can certainly grow Pansies. The flowers will be a revelation to the novice, who will hardly know them at the first glance. However, a closer inspection will convince him that the flowers really are Pansies, for though much larger, rounder, thicker, and more beautifully coloured than any Pansies that he has ever seen before, they will have the same bright, winning, affectionate faces.

There may be two different types of flower at the show, one having much smaller flowers and more sedate colours than the other. These comparatively small flowers (which, however, will be larger than the ordinary garden Pansies) may have one colour only, or they may have a dark central blotch and an outer band of the same colour on a white or yellow ground. These are 


\section{POPULAR GARDEN FLOWERS}

all termed Show Pansies. The section with much larger flowers, and with more brilliance and variety in the colours, are called Fancy Pansies, and they have become so popular that their smaller sisters have to play the part of Cinderella. Here is a description of a typical Fancy Pansy: "Brownish purple blotches, laced with yellow and crimson; upper petals lemon yellow, with dark blotches and broad band of purplish crimson." What a gay fellow have we here!

Propagation.-The prize Pansies are grown under names, and they are kept true to character by propagating them from cuttings. Any good garden Pansy which an amateur has raised from seed may be perpetuated in the same way. The process is very simple. Shoots are taken off in September, and young, solid stems are chosen which are not, and have not been, in bloom. Sometimes suitable shoots may be found springing quite from the base of the plant, and this is the more likely to be the case if the grower has placed some rich soil round the plants in July. The cuttings should be inserted, just clear of each other, in sandy soil in boxes, which may be put in a frame. Air should be given when the weather is fine throughout the winter, and if brown aphis attack the cuttings it should be brushed off. The cuttings will grow in spring, and may be planted out. Although prize Pansies are propagated by cuttings, a stock of plants has to be bought in the first place, and they will cost $4 \mathrm{~d}$. to $2 \mathrm{~s}$. $6 \mathrm{~d}$. each, according to their variety. Very good varieties can be bought for $6 \mathrm{~d}$. a plant. If the grower does not wish for named varieties, he can buy a good strain for 8s. a hundred, or approximately Id. each. London and other amateurs can often buy boxes of plants even cheaper than this, for some of 
the market gardeners grow them by the thousand for spring planting. The plants are sold through florists' shops and off costermongers' barrows. The cheapest plan of all is to raise plants from seed at home. Some dealers supply seed as cheap as Id. a packet, and specialists offer it as low as $6 \mathrm{~d}$. The following strains of seed can be bought amongst others: (I) Exhibition Fancy; (2) Bedding Fancy; (3) Masterpiece ; (4) Peacock; (5) Odier's Blotched or Spotted; (6) Bedding, in separate colours and in mixture; (7) Show; (8) Trimardeau ; (9) Bugnot's veined; (ro) Cassier's. Nos. $5,8,9$, ro are Continental strains. Probably No. 2 (Bedding Fancy) would suit the amateur as well as any, but No. 4 (Peacock) is a richly coloured strain. Masterpiece has curled flowers. Whichever is chosen the seed may be sown in boxes of sandy soil in March, and put in a frame or on a greenhouse shelf. Heat is not absolutely necessary, but it is an advantage if the garden soil is poor and dry, because stronger plants can be got by a given time. If the seed is sown in February, and the plants hardened in a cold frame, they will be ready to plant early in May. Another plan of securing early plants is to raise the seedlings without artificial heat in July, winter them in an unheated frame, and plant them in April. However, in most cases it suffices to sow without heat in March, and plants so raised will be in bloom in July if treated well.

Soil. - The Pansy chooses cool places as a wilding, and possibly one reason why it does well in Scotland is that it enjoys the cool, moist climate. This affords a hint to the cultivator. He may grow it in the full sun, but he should not plant it in dry, sandy soil. If the soil of the garden is of that character he should add loam and decayed manure liberally, and he should 


\section{POPULAR GARDEN FLOWERS}

further mulch the bed with cow manure. This, combined with water and liquid manure in summer, and with systematic removal of fading flowers, will insure success almost anywhere. In fact, with this treatment Pansies may be grown successfully in town gardens. They like rather than dislike clay soil. If well worked, clay soil is both fertile and moist, so that it suits Pansies well. If fine, fresh flowers are wanted for exhibition, the plants had better be grown in a bed to themselves, where special attention can be given to them. The buds may be thinned to get increased size of bloom, and the bed may be shaded with tiffany (a thin canvas) when show day approaches. But in ordinary garden use Pansies may be used in a less formal way. Clumps of them may be set near the front of herbaceous or shrub borders, and they may be used as margins for beds.

Violas or Tufted Pansies. - When bedding or bordering for garden effect is in view, the amateur may well consider the Violas or Tufted Pansies, which are more popular than the Pansies proper in these days. They are of hybrid origin, and probably some varieties of the garden Pansy have been used as parents of them. At all events, while there is a wide distinction between an exhibition Fancy Pansy and a Viola, it is sometimes difficult to distinguish between garden Pansies and Violas. The latter are supposed to have a more bushy habit, to throw up more shoots, and to produce more flowers than the Pansy. The blossoms are nominally smaller, however. They may be raised from seed and cuttings in precisely the same way as Pansies. Named varieties must be kept true by propagation from cuttings, but good mixed strains, also self blue, white, and yellow, can be raised from seed. The great popularity of Violas or Tufted Pansies is not at all surprising, for they are 


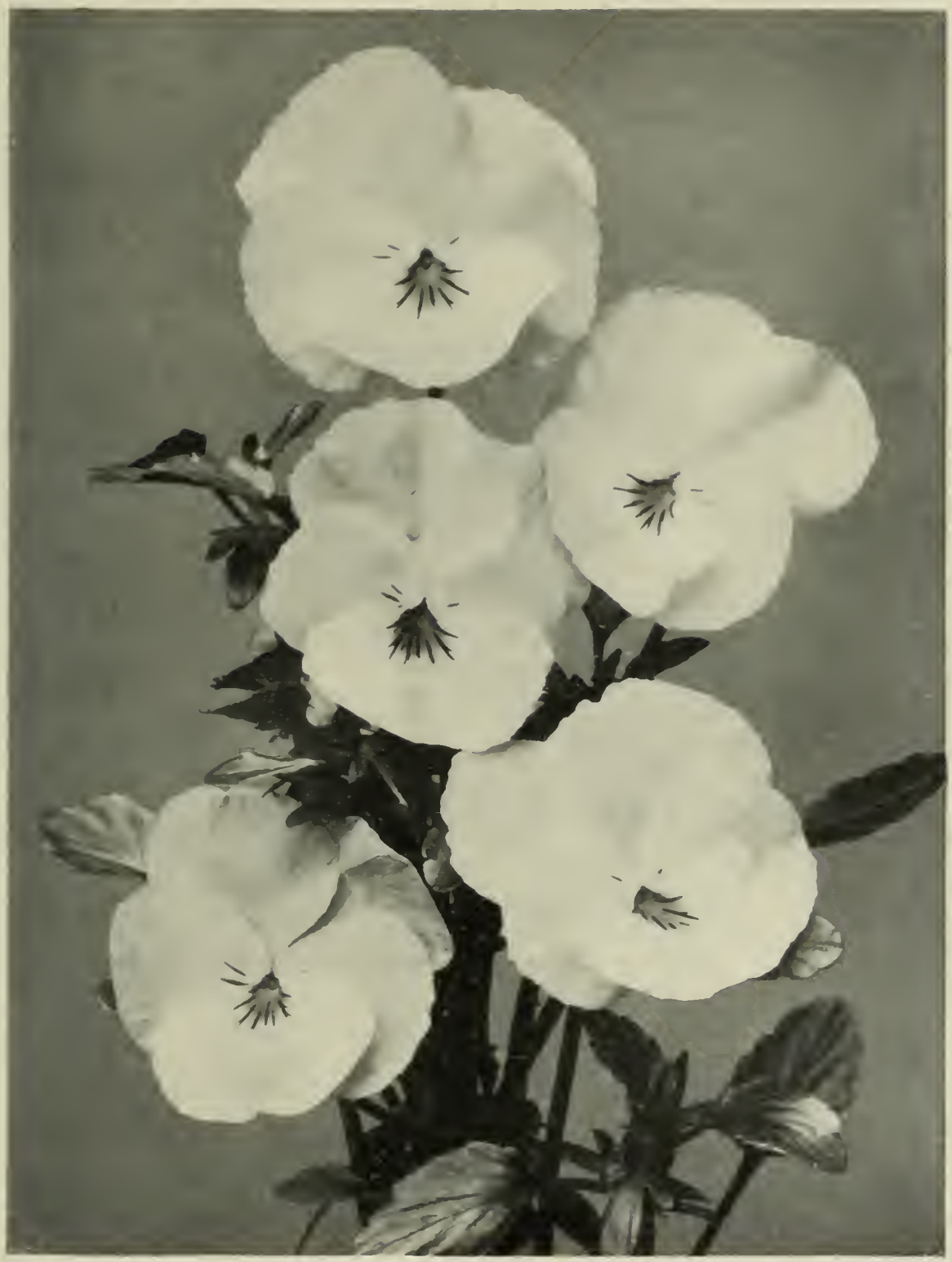

Violas oR TUfTei) Parsies. 

PANSIES, VIOLAS, SWEET VIOLETS 277

valuable plants in many ways. They grow freely, and flower abundantly for several months.

It is mainly owing to its profusion of bloom and dense, tufty habit that the Viola has got ahead of the Pansy as a garden plant. It has not the rich colouring of the latter, and could not be shown individually on a board like the Pansy. When exhibited it is set up in bunches like single Dahlias, most of the flowers being arranged so as to face the spectator. A series of such bunches, set up on green boards, forms a beautiful exhibit, far more striking and attractive to most flowerlovers than a board of Pansies, the blooms of which lie singly and flat on the show-board, however appealing the latter may be to the specialists. Viola exhibits are made at many of the principal shows both in England and Scotland. If there are not classes for them they may still be found, because trade florists set up noncompetitive stands in the hope of arresting the attention of visitors, and so gaining orders for plants or seeds.

As Town Flowers. - Speaking broadly, the Viola thrives best with the same soil and general culture as the Pansy, and enjoys similar conditions. But owing to its greater vigour it can make a better fight against adverse conditions. Those who see the beautiful bands and beds of Violas in the London parks will appreciate this advantage fully. These displays bring home to them the fact that in spite of the reputation which members of the Viola family enjoy of being bad town plants, they can be made to succeed in town gardens. If the soil is well prepared, if planting is done by mid-May, if watering is attended to in hot, dry weather throughout June, if the flowers are picked, and if the plants are given a mulching of fresh soil and decayed manure in July, they will succeed. Let the suburbanist bed them among his 
standard Roses, or band them along the front of his Sweet Pea border. Nor Roses, nor Violas, nor Sweet Peas are nominally the right plants for him, yet if he has the root of floriculture in him he may make a tolerable success of all of them.

The Sweet Violet.-We cannot think of the Viola genus without thoughts of the sweet Violet, Viola odorata, coming into our minds. Who does not love this delicious denizen of the hedgerows? Who does not long to have it naturalised in his garden, and likewise giving him winter flowers from a snug frame? That time of the year

"When Daisies pied and Violets blue, And Ladysmocks all silver white, And cuckoo-buds of yellow hue

Do paint the meadows with delight,"

is one of enjoyment to every Nature-lover.

The Sweet Violet comes with the Dog Violet, Violet canina, in March. The latter, paler in hue and not scented, sometimes deceives the inexperienced eye, and surprise and disappointment blend after an eager spring forward to gather the flowers. Both have five petals of unequal size, of which the lowest has a spur.

The Sweet Violet was one of the prime favourites of Shakespeare. Note how he refers to it again and again, and always in language that breathes freshness and fragrance.

"Who when he lived, his breath and beauty set

Gloss on the Rose, smell to the Violet."

-Venus and Adonis.

"The forward Violet thus did I chide:

'Sweet thief, whence didst thou steal thy sweet that smells

If not from love's breath? The purple pride

Which on thy soft cheek for complexion dwells 
In my love's veins thou hast too grossly died.

The Lily I condemned for thy hand,

And buds of Marjorąm had stol'n thy hair.'"

-Sonnet xcix.

"They are as gentle

As zephyrs blowing below the Violet,

Not wagging his sweet head." -Cymbeline.

"If music be the food of love, play on ;

Give me excess of it, that, surfeiting,

The appetite may sicken, and so die.

That strain again! it had a dying fall :

$O !$ it came o'er my ear like the sweet sound

That breathes upon a bank of Violets,

Stealing and giving odour."

-Twelfth Night.

And it was not Shakespeare alone of the great writers who loved the Violet. Its appeal was equally powerful to all. It made the same impression on Chaucer as on Milton.

One would expect so old a British flower to have a common name. That it has not may be attributed to the natural charm of the Latin name Viola, of which Violet and Violetta (the latter applied to a miniature strain of garden Violas) are affectionate diminutives. Cockneys sometimes perpetrate the atrocity Voylat in naming it, but for the most part it is pronounced correctly. Speaking of pronunciation, it may be well to point out that Viola is frequently rendered incorrectly. It is pronounced Vi-o'-la; it should be $\mathrm{Vi}^{\prime}-\mathrm{O}-\mathrm{la}$, the accent being on the first syllable.

That grand old mediæeval gardener Gerard used brave words of the Violet: "There be made of them garlands for the head, nosegaies and poesies, which are delightfull to looke on and pleasant to smell to, speaking nothing of their appropriate vertues: yea, gardens themselves 
receive by these the greatest ornament of all chiefest beautie and most gallant grace, and the recreation of the minde which is taken thereby cannot but be very good and honest; for they admonish and stir up a man to that which is comelie and honest, for floweres through their beautie, variety of colour, and exquisite form, do bring to a liberall and gentlemanly minde the remembrance of honestie, comelinesse, and all kindes of vertues."

If this leaves us a little breathless, we nevertheless perceive the point of it all, and are impressed with a respectful sympathy.

Propagation of Sweet Violets.-Violets for the garden may be raised from seed in the same way as Pansies and Violas. It may not be known to all that the Violet bears its seed on a sort of supernumerary flower, devoid of petals and perfume, which is produced in autumn. Plants with this habit are spoken of by botanists as cleistogamous. But the fine modern varieties of Violets are rarely grown from seed; they are propagated by runners, cuttings, or division, according to their habit. Some varieties throw out offspring on "runners," like Strawberries, and these can be struck in the ground around the parent if a little good soil is put to them and they are pegged down. Others, more Pansy-like in their habit, produce basal shoots devoid of flowers, and these can be taken off and treated as cuttings. Plants which spread and form a thick rootstock with many fibres are best divided. Whichever method is chosen it is generally practised in spring, for the plants make most of their growth in that season.

Culture for Winter Bloom.-It is to yield winter bloom that Violets are generally grown in gardens, and they play their part generously when well treated. 
PANSIES, VIOLAS, SWEET VIOLE'TS $28 \mathrm{I}$

They must have protection, of course, and this is generally provided in the form of a glass frame, set up on a mild hot bed of manure and leaves. The plants are taken from the ground in September or October, and planted in a bed of good soil, made up about nine inches deep on the top of the hot bed. The addition of an equal quantity of leaves to the manure insures a mild, steady heat, which is what is wanted. With fermenting manure alone there would be a fierce heat at first and coldness soon afterwards. The plants are put about a foot apart. Any dead or diseased leaves, and any side shoots, are removed. The lights are kept open in fine weather. Watering is done when the soil becomes dry, and a little special manure is watered in once a week. With this treatment the plants grow and bloom throughout the winter and spring. They will not yield many flowers in very severe weather, but there will not be many days on which a few flowers cannot be picked; while in mild spells there will be abundance of fragrant blossoms. Frame Violets are sometimes a failure through an attack of red spider, which may be suspected at once if the foliage becomes thin and rusty; but this enemy rarely puts in an appearance when plenty of water is given and ventilation is sufficient. The plants remain healthy, the leaves are abundant, substantial, and dark in colour. The side shoots and suckers which form may be removed regularly until the end of March, so that the plants may concentrate their energies on flowering; but after that time the plants may be allowed to grow naturally, in order that they may produce material for propagation.

Species and Varieties. -It would probably be impossible to trace the exact parentage of modern Pansies, Violas, and Sweet Violets, although we know that most 
of the Pansies have sprung from Viola tricolor, and the Violets from Viola odorata. As we have already seen, the flowers of the former are purple and yellow, and those of the latter purple; and both are British plants. There is a white variety of Viola odorata called alba, and this also is a Sweet Violet. Another variety, called pallida plena, or pale double, is the double lavendercoloured Violet that we grow under the name of Neapolitan, and which is loved so much for its large flowers and its perfume. It is valuable for forcing. There are several other charming varieties, and a selection of them is given below. The Siberian Violet, Viola altaica, has purple flowers, and is illustrated in the Botanical Magazine, t. I776. A more important species is cornuta, which has blue flowers, and is illustrated in the Botanical Magazine, t. 79I. This species, which came from the Pyrenees in 1776 , is the parent of many of the strains of bright, free-blooming "bedding Pansies" sold by seedsmen; moreover, it has probably been used as a parent in raising our bedding Violas. There is a white variety of it. Calcarata, blue, and its varieties; cucullata, violet; lutea, yellow; and pedata, blue, and its varieties, are other well-known Violas, and may have been used as parents in producing the fine varieties named and briefly described in the following lists :-

Truelve Fancy Pansies.

Alice Lister, violet, French white, and pale mauve.

Carrie Nation, violet, white, purple.

Constance Abercromby, claret, yellow, and purple.

Hall Robertson, purple, brown, and yellow.

James McNab, yellow, dark blotches.

John Harle, cream and purple.

Mrs. Ferguson, crimson, violet, and pale yellow. 
PANSIES, VIOLAS, SWEET VIOLETS 283

Mrs. J. Sellars, violet and yellow.

Mrs. William Sinclair, violet and pale yellow.

Neil M'Kay, yellow, crimson, and purple.

Nellie Curson, yellow, brown, and mauve.

Robert M'Caughie, violet, rose, and yellow.

Tuelve Violas or Tufted Pansies.

Archie Grant, indigo blue.

A. J. Rowberry, yellow, rayless.

Countess of Hopetoun, white.

Duchess of York, white.

Helen Smellie, white, blue edge.

Ithuriel, azure.

Lark, cream, edged heliotrope.

Mrs. C. McPhail, heliotrope.

Mauve Queen, mauve.

Royal Sovereign, deep yellow.

True Blue, deep blue.

William Neil, rosy lavender.

\section{Single Sweet Violets.}

Amiral Avellan, purple.

Mdlle. O. Pages, pale rose.

Princess of Wales, deep blue.

The Czar, violet.

\section{Double Sweet Violets.}

Comte de Brazza, white.

Marie Louise, lavender and white.

Mrs. J. J. Astor, pink.

Neapolitan, lavender, white eye.

This brief glance at the Viola genus shows us that although its members are of lowly habit, they have great value and charm for the flower gardener. Small as the plants are, they have such qualities of abundant 


\section{POPULAR GARDEN FLOWERS}

blooming and brilliant colour as to make them capable of producing bright effects in the garden, while their delicious perfume endears them to us at all stages of our lives. In their modern ennobled forms the Violets are as sweet as they were when they prompted the inspired muse of Shakespeare in the glades of Arden. 


\section{XXX}

\section{ON PHLOXES}

Beautiful as a flower, and magnificent as a garden plant, the Phlox is fortunately in a position to arouse interest by its own merits. I say "fortunately," because tracing its history unfolds no pageant of the past. It cannot appeal to patriotism as a native, or to sentiment as one of those sweet old favourites which have been linked with the lives of centuries of generations. It is a modern plant. True, some of the species have been grown for a hundred years or mort, but they are of little historic interest or garden value, and only concern us as parents of the beautiful varieties which we grow in our gardens to-day.

The name Phlox comes from flame, in allusion to the brilliance of the flowers. Short, simple, easy of pronunciation with the national custom of turning the first two letters into " $F$ " brought into play, it soon became familiar, and no folk-name was required to facilitate popularity. No sooner had the florists given us good varieties than the plants spread from garden to garden, and in a few brief years Phloxes were grown everywhere. They are now so abundant and familiar that they are associated in the public mind with old favourites like Snapdragons, Columbines, Lilies, and Michaelmas Daisies, and it comes as a surprise to 
flower-lovers to know that they are as modern as florists' Chrysanthemums.

The facts being thus, it is useless to send our thoughts rambling among the book-shelves in search of references to Phloxes by the old writers. When the giants of the Elizabethan epoch were sharpening their quills, the Phloxes grew only as weeds in the untrodden wilds of North America. We must think out our own poetry about them, as we survey them in our borders on fiery August days, and in the cooler hours of September. They stand in bold masses, the tall, strong, woody stems, clothed with short, narrow leaves, bearing huge clusters of brilliant flowers aloft. When good culture and good varieties are in union the flower-heads may be a foot long and eight or nine inches through, the individual flowers as large as florins. Here, surely, is the wherewithal to inspire poetry, if rather of the martial than the amorous stamp.

The botanist does not speak of "clusters" and "flower-heads" in connection with Phloxes. These are loose garden phrases, fit only for the man in the street. He calls them "panicles." A panicle is an inflorescence, the branches of which are divided irregularly, as in the Lilac. And we bow to the superior knowledge of the botanist, and we feel what fundamentally inferior ćreatures we are, when we turn up a plant dictionary and find that the parent (or one of the parents at least) of our late blooming Phloxes is Phlox paniculata, a North American plant, with purplish pink flowers, that was introduced in I782. Another species which is credited with the parentage of the late Phloxes is maculata, introduced from North America in I740, and having purple flowers. Phlox maculata has another namedecussata-and this explains why it is that the reader 


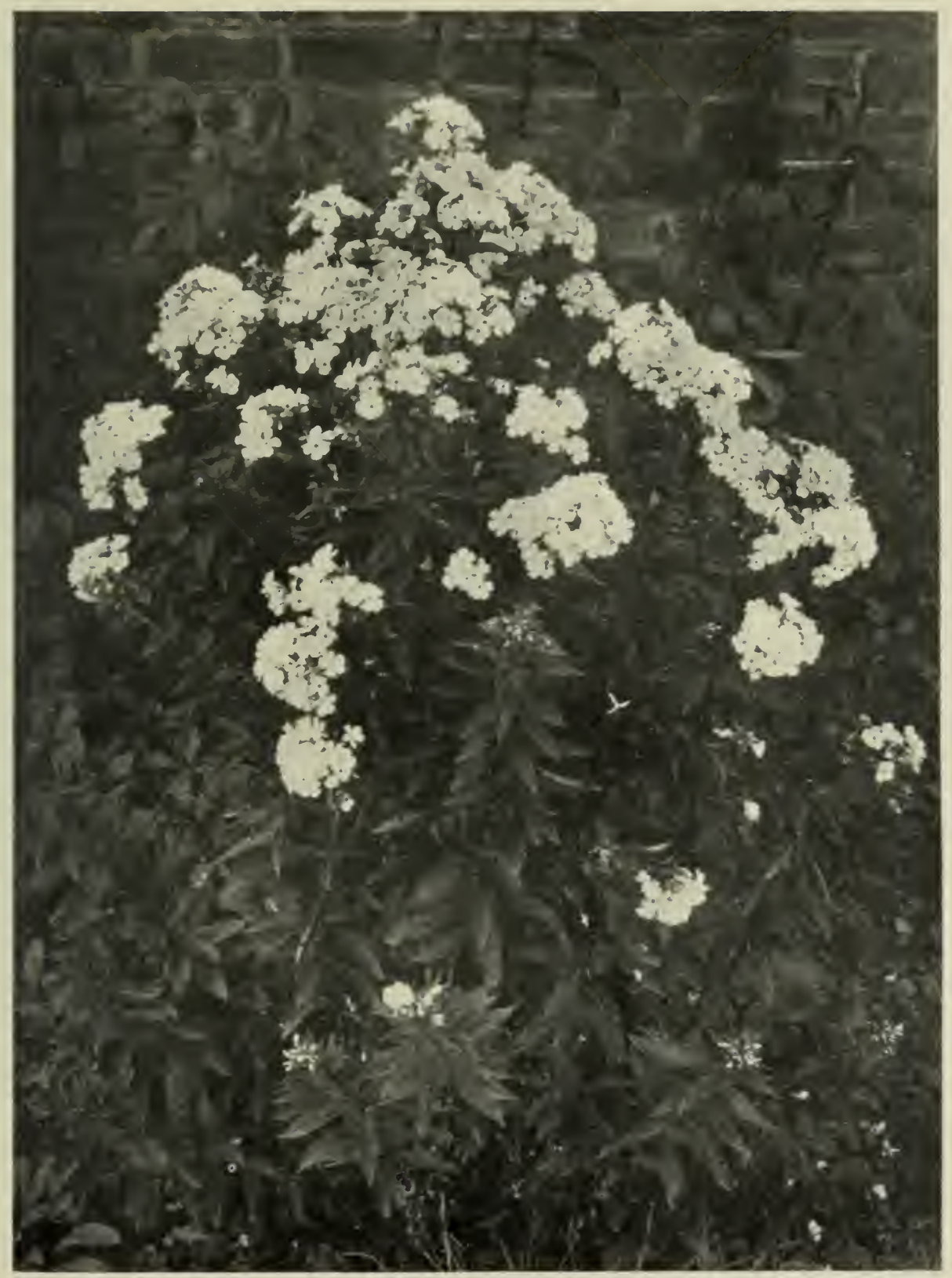

Plikenciat, Phloxes. 

sometimes sees a set of Phloxes referred to as "belonging to the decussata section." Since decussata is a synonym, or at the most an almost identical form of, maculata; and since maculata has only shared a part with paniculata in parenting the modern late-blooming Phloxes, the phrase "decussata section" is unfortunate. However, there is no need to use it, as "late flowering" suffices. We need only teach ourselves what it amounts to, and then drop it for good.

The use of "late-flowering" as a sectional term suggests that there are at least two classes of perennial Phloxes. As a matter of fact there are three, but one of them is a distinctly spring-blooming group. There are two which flower in summer, and the earlier set has derived from a different species, as might be supposed. Phlox glaberrima (from glaber, smooth, devoid of hairs; glaberrima means very smooth), a red species introduced in 1725 , had a form named suffruticosa (a suffruticose plant is one that loses its leaves every year, but retains its stems, and Phloxes growers will observe that Phloxes hold their stems much longer than their leaves), which bore pink flowers. This variety is figured in the Botanical Magazine, t. 1555. The flower-lover now understands why it is that he sees a section described as the "suffruticosa group," and rightly assumes that they have derived from Phlox glaberrima suffruticosa. Nominally the parent does not bloom earlier than the parents of the decussata group; but the varieties are earlier, and the section is usually spoken of as the Early-flowering Phloxes.

There are many beautiful varieties of both sections, and each ought to be represented in gardens. Most of the members of the early group grow two to two and a half feet high, and bloom in June and July. The 
colours are varied, and the flower-heads are of good size. The late bloomers are at their best from August to October, and are rather taller in the main than their early sisters, although some, notably the magnificent white, Tapis Blanc, are quite dwarf. They are very vigorous plants, with strong stems, and when established in suitable soil spread into glorious masses. They present a considerable range of colours, some of which are brilliant in the extreme. One of their most powerful recommendations is the long period during which they remain in bloom. They are often beautiful until November.

The spring-flowering varieties (as distinct from species) of Phloxes have come from the "Moss Pink," Phlox subulata (from subulate, awl-shaped) species, growing only about six inches high, and having purple flowers, introduced from North America in I786. With its prostrate stems and dense mass of flowers this little Phlox is a real carpetter, and is suitable for the rockery. Frondosa and nivalis are forms of it. The former, with its rosy lilac flowers, is a great favourite. It grows rapidly, and so spreads into a broad mass. There are now many charming varieties of subulata, giving much variety of colour, and they form pretty cushions in the border or on the rockery.

There is yet another important section of Phloxes, namely, the annual forms grown under the name of Drummondii. Phlox Drummondii is a free flowering annual, growing about a foot high, with purple blossoms, which was introduced from Texas in 1835 , and is illustrated in the Botmical Magazine, t. $344 \mathrm{I}$. It was soon seen to be a useful plant, although it was neither perennial nor hardy, and distinct forms of it were soon raised and offered by seedsmen under dif- 
ferent names, such as cuspidata (from cuspidate, pointed); fimbriata (fringed); flore pleno (double); grandiftora (largeflowered); and nana compacta (dwarf compact). We are not yet at the end of these novelties in Annual Phloxes. The modern selections are very beautiful, and have had much to do with the exclusion of Verbenas from gardens. They do nearly all that Verbenas can do except yield fragrance, and are easier to manage. The colours are varied and beautiful, and the wetter the season the more abundant and beautiful the flowers are.

Mention of one or two good species of Phloxes may conclude my description of the genus, and I can proceed to culture and selections of varieties. Divaricata, a spring bloomer with lilac flowers, growing about a foot high, is a very pretty Phlox, and has charming forms in canadensis, blue; and alba, white. It is illustrated in the Botanical Magazine, t. 163. Ovata (triflora) illustrated in the Botanical Magazine, t. 528, has red flowers, and grows a foot high or a little more. Reptans is a creeper with violet flowers. Verna has pink flowers, and grows about six inches high. There are several other species, but these are the only ones that are grown to any extent, and they are all fairly popular. They are spring bloomers, suitable for the front of herbaceous borders or rockwork.

Propagation.-The Phloxes are easy plants to increase. The annuals are raised from seed in spring in the same way as Asters (see Chapter II.), but they may also be propagated by cuttings in autumn, the Phloxes being one of the few annuals which can be propagated in this way. The plan is only desirable when plants are wanted for pot culture, to bloom in spring. When they are required for garden use propagation in autumn, which 
entails the care of the plants throughout the winter, compares unfavourably with raising from seed in spring. No heat is required for raising seedlings in April, as the plants come readily in a cold frame. They should be pricked off four inches apart when they begin to crowd in the seed-box, and lime should be sprinkled around them when they are planted out, as slugs are very fond of them. The plants may be put in a foot apart. Unless the summer is very dry they are likely to keep on blooming till October, as they last remarkably well. The perennial summer Phloxes, both early and late blooming, can be propagated by division, cuttings, or seed. They must not be expected to spread sufficiently at the root to be strong enough for division at the end of their first year; but if the soil is good and the summer moist they will probably be ready for division the second year. The root-stocks may be divided into several pieces with a sharp spade in winter or spring. Cutting-propagation may be effected either with the young shoots that start in the spring, which should be inserted in boxes of sandy soil and put in a frame, or by cutting some of the old roots into small pieces and putting them in boxes of soil in spring just before growth starts. Any of these methods will keep named varieties true to character. Seeds afford a cheap and ready means of getting a stock of plants, and if saved from the best varieties will give a good type, but seedling plants will differ from their parents. The seed may be sown in boxes, and wintered on a greenhouse shelf or in a frame. The young plants will be ready for planting out in May, but except in very good soil and in a wet season they will do no more than just flower the first season; they will not make really strong plants until the second year. The spring-flowering Phloxes are propagated by cuttings 
after flowering. The shoots should be inserted in boxes of light sandy soil, and kept in a frame until they start growing.

Soil.-Phloxes will thrive in the ordinary soil of most gardens if it is not very stiff, but they do not like cold, adhesive, undrained clay. In growing them on heavy land I found it important to drain the ground with pipes so as to prevent moisture lying near the surface in wet winters, and to add sand and leaf mould to the stations when planting, in order to increase the friability of the soil. I am of opinion that they favour light soil, for pieces planted in light land a foot above chalk made magnificent clumps in eighteen months, far excelling those which I had previously had on clay. It is true that the second summer was wet, and therefore in their favour. Although they do not relish stagnant moisture in the soil while at rest in winter, they love water in summer, and grow the faster the more they have of it. One must get a good deal of growth in Phloxes to get much bloom, as the flowers are borne on the top of the stems, and one must have strong shoots before one can have large panicles. This, of course, points to the advisability of watering them in dry weather. Liquid manure is also beneficial. They will thrive in light, loamy soils. When the borders are dug in winter a dressing of decayed manure should be worked in around the plants.

Phloxes for Beds and Borders. - Phloxes are among the finest of plants for both beds and borders. Owners of large gardens who like to plant a bed entirely with Phloxes have only to supply good soil and adequate moisture to see the bed become one of the greatest successes of the garden. Early and late varieties may be planted in the same bed if desired, and there will 


\section{2 POPULAR GARDEN FLOWERS}

then be bloom from July to November. When planted in mixed borders the Phloxes should go at the middle or back if the soil is rich, as most of them will grow three to four feet high ; and they should be planted four feet apart, as they will spread considerably. If old stools are not divicled some of the shoots may be thinned out in spring, as better flowers will result from the fewer number. Phloxes will thrive in suburban gardens if the soil is friable and abundance of moisture is given in summer, but most of them are hardly suitable for small town gardens, as they take up more room than can be spared.

The following are beautiful varieties:-

\section{Early Summer Phloxes.}

Attraction, white, crimson eye.

Fantasy, pink, suffused crimson.

James Hünter, rose.

Lady Napier, white, sweet.

Shakespeare, magenta, white edge.

The Shah, purplish rose.

Late Summer Phloxes.

Atala, rose, white centre, $3 \mathrm{ft}$.

Coquelicot, orange, $3 \mathrm{ft}$.

Crépuscule, white, dark centre, $3 \mathrm{ft}$.

Eclaireur, carmine, primrose suffusion, $3 \mathrm{ft}$.

Etna, scarlet, $3 \frac{1}{2} \mathrm{ft}$.

Eugène Danzanvilliers, rosy lilac, white eye, $3 \frac{1}{2} \mathrm{ft}$.

G. A. Strohlein, orange, carmine eye.

L'Aiglon, carmine rose, $3 \mathrm{ft}$.

Mrs. W. P. Wright, rosy carmine, crimson eye, $4 \mathrm{ft}$.

Pyramide, white, $3 \frac{1}{2} \mathrm{ft}$.

Rossignol, rosy mauve, white eye, $2 \frac{1}{2} \mathrm{ft}$.

Sylphide, white, $3 \mathrm{ft}$.

Tapis Blanc, white, $2 \mathrm{ft}$. 


\section{ON PHLOXES}

293

Dwarf Spring Phloxes.

Atropurpurea, rosy purple.

Frondosa, dark rose.

Grandifora, pink, crimson eye.

Newry Seedling, white, rose eye.

Vivid, brilliant rose. 


\section{XXXI \\ ON THE PRIMULAS-AURICULAS, OXLIPS, POLYANTHUSES, AND PRIMROSES}

NATIVEs and exotics alike, the different species of the Primula genus hold our affections in sure bonds. Does not the very name appeal to us-Primula, from primus, the first, in allusion to the early flowering of the plants? They are the harbingers of Nature's year, and in the meadow and woodland, as well as in the rockery and garden border, their pretty blossoms fill us with pleasure and hope.

Auricula, Cowslip, Oxlip, Polyanthus, Primroseall are Primulas. Botanically the Auricula is Primula auricula, the Cowslip Primula officinalis (or veris), the Oxlip Primula elatior, and the Primrose Primula vulgaris (or acaulis). The Polyanthus is a hybrid between the Primrose and the Cowslip. All except the Auricula are natives, and that is an Alpine plant, although it has been grown in British gardens for more than three hundred years. The type is illustrated in the Botanical Magazine, t. 6837 .

It is scarcely necessary to say that these popular Primroses are hardy. Not merely do they withstand the cold as cheerfully as an Oak, but they retain their leaves through the winter, and take every opportunity afforded by mild spells to grow and flower. They play a sort of cat-and-mouse game with Jack Frost, darting into growth 


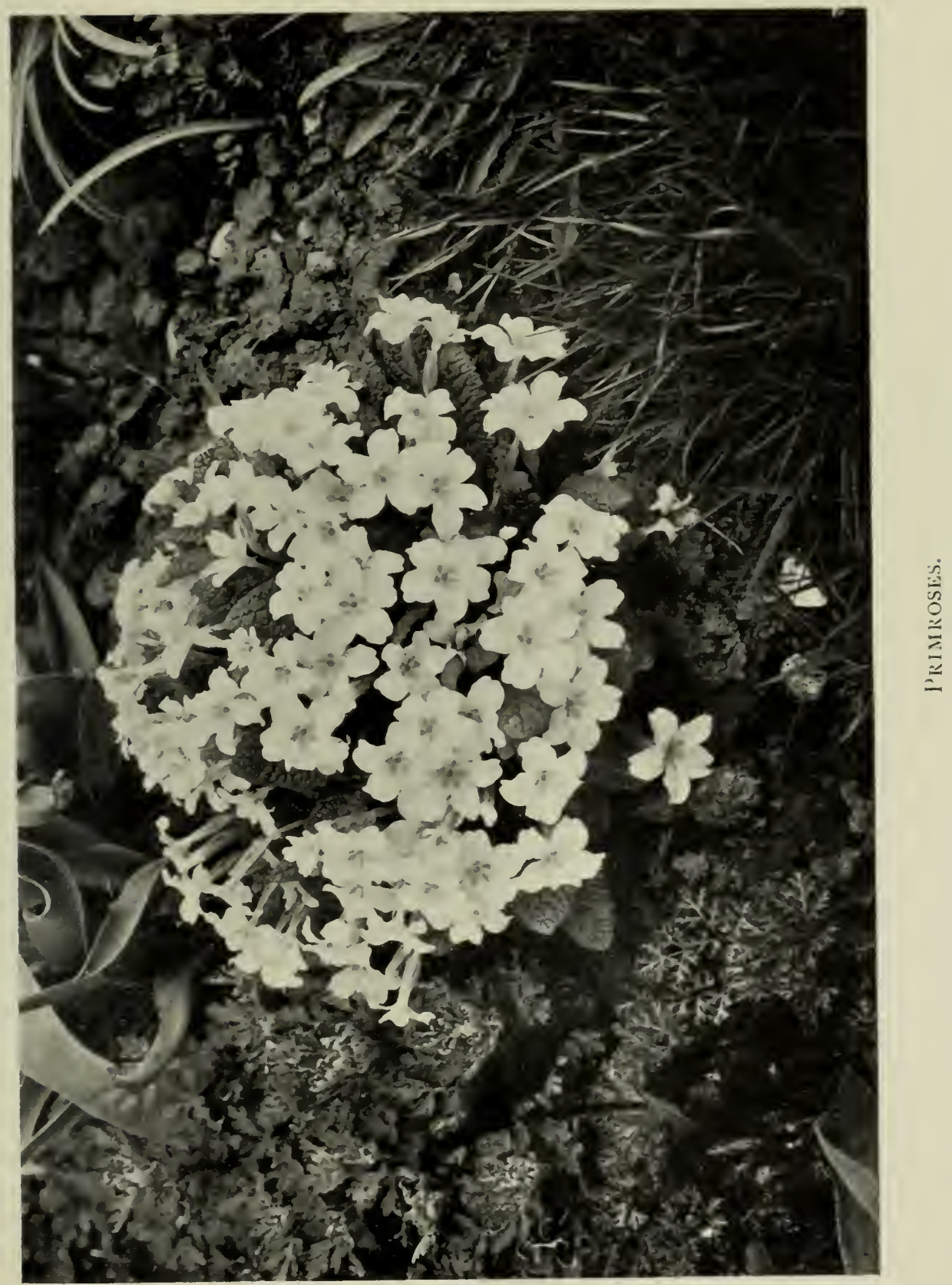



if he relaxes his grip for a moment, discreetly retiring when he renews his pressure, and eke flinging out a flower or two in orcler to show how little impressed they are by all his efforts.

The Cowslip is not a garden plant, but we give a grateful thought to it every time our eye falls affectionately on the beautiful Polyanthuses of our spring beds. We see that these exquisite little flowers differ from the Primroses in bearing several flowers in a cluster at the top of the stem (poly-anthus, many-flowered), and we understand that they acquired the habit from the Cowslip. We love the latter as a meadow plant, and we rejoice that we have it in a glorified form-larger, richer in colour, more varied, and yet sweet, in the garden. As the Cowslip is not a garden flower, we need not thresh out the vexed question of its popular name, which still remains unexplained. There is a natural association between "cows" and "lips," since it grows in the pastures, and this derivation satisfies most people, although so great an authority as Dr. Prior will have none of it. We must leave it to the children and the fairies, for the flower belongs to them.

"Where the bee sucks there lurk I,
In a Cowslip's bell I lie." -The Tempest.

The truc Oxlip has pale yellow flowers. It is accepted as a good species by botanists, but the Oxlips of our gardens are probably hybrids. Shakespeare refers to the Oxlip several times, and few lines about flowers are more familiar than those from "A Midsummer Night's Dream"-

"I know a bank whereon the wild Thyme blows, Where Oxlips and the nodding Violet grows." 


\section{POPULAR GARDEN FLOWERS}

The Primrose is equally interesting as a wild and as a garden flower. Etymologists trace its name from flor de prima vera (first flower of spring), through the abbreviation prima vera and the affectionate Italian extension primaverola. Thus the latter became primeverole (French) and primerole. From this stage the end is soon reached, as primeroles readily become Primroses. The name "rose" disappears, as it must inevitably do, for it derives from rhod, red, and has no natural connection with primrose.

Students of folk-names are often struck by some similarity, the meaning of which is not obvious. Thus, my attention was arrested by hearing the peasantry of East Kent speak of the hedge plant Privet (Ligustrum) as Prim. Singular to say, Primrose was an old name for Privet, and it has lasted in an abbreviated form to this day. Tusser, in his "Five Hundred Points of Good Husbandry," tells us that-

\section{"Now set ye may \\ The Box and Bay, \\ Hawthorn and Prim, \\ For clothes trim."}

Privet is the accepted popular name of Ligustrum vulgare, L. ovalifolium, and other species in these days, and Primrose is reserved for the beautiful little spring flower in which the great writers of the past delighted. Dozens of extracts trom the poets could be made to show their love of the flower.

Beaumont and Fletcher wrote of the

$$
\begin{aligned}
& \text { "Primrose, first-born child of Ver, } \\
& \text { Merry springtime's harbinger, } \\
& \text { With her bell's dim," }
\end{aligned}
$$

in "The Two Noble Kinsmen." 
Shakespeare referred to it again and again-

"In the wood where often you and I Upon faint Primrose beds were wont to lie."

-Midsummer Night's Dream.

"Pale Primroses

That die unmarried ere they can behold Bright Phœbus in his strength."

-Winter's Tale.

"Thou shalt not lack

The flower that's like thy face, pale Primrose."

-Cymbeline.

It is clear from these and other references that the pale colour of the flower had impressed itself on Shakespeare's mind as the distinguishing feature of the Primrose. Perhaps this gave a cue to Milton, for its pallor seems to have influenced him also. He speaks of the

and the

$$
\text { "Rathe Primrose that forsaken dies," }
$$

"Soft silken Primrose fading timelesslie.'

The light colour and the alliteration combined seem to have been too strong for both poets, and "pale primrose" crops up in their writings with a frequency that becomes a little wearisome.

Withal the Primrose is a checrful flower. Country children, and townsfolk of all ages, love to gather great bunches of it from the banks and woodland glades in spring. It enjoys coolness and shade, like the Violet, and this should be borne in mind by gardeners. It is essential that a warm, dry position should be chosen for the flowering, as that takes place in spring, but it is not advisable for the propagation which follows the blooming. Divided plants do better when planted in 


\section{8}

POPULAR GARDEN FLOWERS

a cool, moist, shady place for the summer, than when planted in a hot position.

Propagation.-I have mentioned division, but a start may be made with seeds. The larger seedsmen supply seeds of the following: Auriculas-Show, Alpine, Border, and Giant Yellow; the first two classes are grown in pots, and named varieties are perpetuated by offsets; the others are grown in the garden. Polyanthuses-Goldlaced, Mixed Border, White, Yellow, and Crimson, Munstead strain, Galligaskin or Jack-in-the-green (each floret in which is surrounded by a green leaflet), and Hose-in-hose (each flower of which has another set within it). All of these Polyanthuses are hardy garden flowers, although the Gold-laced is sometimes grown in pots. Primroses-Giant Mixed, White, Blue, and Common Yellow. The number of kinds will not alarm the Primrose-lover, and he will be eager to try them all; but if it tends to perturb the amateur, let him rest assured that he can reduce it to Mixed Border Auriculas, Mixed Border Polyanthuses, and Mixed Border Primroses without losing one jot of garden beauty. He may keep them separate in his beds if he likes, or he may mix them. The seed may be sown as soon as it is ripe, and seed of the current season's saving can be bought in early summer. If sown in fine, moist soil in the shady part of the garden it will soon germinate, but it is safer to sow in boxes and put in a frame. In either case the seedlings must be kept uncrowded and planted out in autumn. The stock of plants can be increased in late spring when the flowering is over by dividing them with a trowel, and planting in rich, friable soil in a shady place, from which the plants can be transferred to the beds in autumn. If they are kept as permanent plants at the front of mixed 


\section{ON THE PRIMULAS}

beds and borders annual transplanting is not necessary, but they may be split up sometimes.

Primroses for Beds. - These beautiful hardy Auriculas, Polyanthuses, and Primroses are charming for spring beds, and many use them in addition to Wallflowers, Daffodils, Tulips, and other spring flowers. Easily and cheaply raised in quantity from seed, they bear transplanting with impunity, so that they can be put into beds in autumn when the summer flowers have faded, and moved out again in late spring when they pass out of flower to make room for summer and autumn-flowering plants. So delightful are they, with their masses of foliage and sheets of brilliant flowers, that few spring flowers can vie with them, and they are pleasantly, although not powerfully, scented. It is much to be regretted that they are not quite suitable for town gardens, but the truth is that they dislike the grime of a smoke-laden atmosphere.

Auriculas.-The townsman who is enamoured of the Primula genus might do worse than grow a collection of Auriculas in pots, for they are refined and interesting flowers. But the culture is special, and the plants somewhat expensive. It is customary for Auricula-lovers to devote a frame to their favourites, which they set to face the north in summer and the south in winter. The plants bloom in late spring, and are re-potted after flowering, when such offsets as have formed are taken off and potted separately. They are given abundance of air throughout the summer, and also in fine spells in winter, but are kept close in foggy weather. The varieties in the show section are classified according to the prevailing ring of colour, e.g. Green-edged, Whiteedged, Grey-edged. The Alpines are larger, and have a broad belt of purple, 
Named Border Primroses. - Several beautiful hardy border Primroses are grown under distinctive names, and included in the collections of amateurs who specialise these charming spring flowers. The following are a few of particular interest: Alba Plena, double white; Cloth of Gold, double yellow ; Old Double Crimson; Crimson Velvet, double crimson; Harbinger, large single white; Lilacina Plena, double lilac; Miss Massey, crimson, yellow eye, single; Purpurea Plina, double purple ; and Rosea Plena, double rose. Seed is not offered, and plants have to be bought.

Beautiful Species of Primula.-The student of Primroses finds that there are many beautiful exotic species which are quite hardy, and are charming for rockeries and borders. One of these is cortusoides, a Siberian plant with rose flowers in summer; seeds are procurable. Denticulata, with lilac flowers in spring, comes from the Himalayas; it grows about nine inches high, and bears its flowers on a rounded head, as the illustration in the Botanical Magazine, t. 3959, shows ; it has several varieties, including alba, white; cashmeriana, pale purple; purpurea, purple; and variegata, white-edged leaves. Farinosa, purple with yellow eye, is pretty. Japonica, a Japanese plant with rose or crimson flowers, introduced in $I 87 \mathrm{I}$, is a splendid species for a cool, moist spot, growing about eighteen inches high, and can be raised from seed; it is illustrated in the Botanical Magazine, t. 5916. Marginata is a tiny plant, only three or four inches high, with violet flowers; it is illustrated in the Botanical Magazine, t. I9r. Rosea is a beautiful species, introduced from Cashmere in 1879 , and illustrated in the Botanical Magazine, t. 6437 ; the colour is rosy carmine; the plant loves a cool, moist spot; there are varieties of it, notably grandiflora, very large. Seed of the type, if 
not of the varieties, is procurable. Sikkimensis, which grows about eighteen inches high, and blooms in summer, has pale yellow flowers; it is illustrated in the Botanical Magazine, t. 4597. Viscosa (villosa), illustrated in the Botanical Magazine, t. I4, is an Alpine species with rosy-purple, white-eyed flowers, and grows only three or four inches high. Sieboldii, a splendid Japanese species with rose and white flowers, grows about a foot high, and blooms in April; several varieties are sold under names, such as Alba magnifica, large white-fringed flowers; Beauty of Sale, white, edged with rose; Distinction, white, shaded rose ; Fascination, white, lavender exterior, fringed; Grandiflora, creamy white and rose; Harry Leigh, lilac, with white eye; Lilacina superba, lilac; Magenta Queen, magenta; and Violacea, violet. Seed of the type is procurable.

Greenhouse Primulas.-Sieboldii and its varieties are nominally hardy, but they are apt to die out in wirter, and they are generally grown in pots for greenhouse decoration, like the Chinese Primula (varieties of sinensis); the Star Primula (stellata); the lilac obconica, a freegrowing, free-blooming plant admirably adapted for amateurs, but with the unpleasant peculiarity of causing a painful rash on the hands of many people who handle it ungloved; and such minor but still beautiful sorts as floribunda, yellow; Forbesii, lilac, with yellow eye; and kewensis, a yellow hybrid raised by crossing floribunda and verticillata. The beautiful fringed Chinese Primulas are splendid plants for blooming in warm greenhouses in winter, and are of the easiest culture, coming readily from seed sown for succession in late spring and summer. They are purchasable in mixture or in separate colours. Every seedsman of any standing specialises 


\section{POPULAR GARDEN FLOWERS}

them, and supplies strains which produce large trusses of handsome flowers.

Those who specialise hardy Primulas will get the newer species, such as Bulleyana, Cockburniana, and Littoniana, which have aroused much interest in recent years.

While the foregoing notes do not exhaust the Primroses, they may serve to show how much interest and value lie in the lovely denizen of the woodland and its garden sisters. Early, sweet, gay, neat in growth, and profuse in flowering, they are full of delight for the lover of flowers. 


\section{XXXII}

\section{ON ROSES}

A-SPRAWL along the hedges where, earlier in the year, the tawny hazel catkins hung, and the white cymes of the Wayfaring Tree stood out against the tender green of the new May leafage; sending a swaying tracery of slender shadows up and down the grass path of the pergola; making a bold block of colour around the stained sun-dial within the Yew hedges; throwing a flower-starred tangle over the stones and stumps of a rough bank; peering and tapping at the windows of the house-everywhere the Roses charm us.

It is a quality of the Rose that wherever it grows healthfully it seems a part of its surroundings. There could hardly be a greater contrast between the wild exuberance of a country copse and the trim order of an old garden in the Dutch style, with its straight, Boxlined walks and its tall, sombre hedges; but in each the Rose picture seems perfect. The natural grace of the wilding is not more in keeping with its environment than the cultured refinement of the garden plant. Each leaves an impression of propriety on the mind. The plants fit in with their circumstances and conditions in a way that creates a sense of natural suitability.

There are many conscious reasons why people plant Roses in their gardens-for beauty of bloom, for fragrance, for the harvest of material which the plants 


\section{POPULAR GARDEN FLOWERS}

yield for vases; and there is this subconscious one-that Roses fall into soft, gentle, and beautiful harmonies without deliberate effort on the part of the grower, giving him, out of the rich stores of their natural beauty, a reward that he had hardly dared to hope for, much less actively aimed at.

It is hard to put Roses in wrong places in gardens, provided they are such spots as the plants can grow vigorously and cleanly in. The plants make their own "circle." They create "atmosphere." They form at once a home for themselves and a peaceful, perfumed retreat for the garden owner. They may not form a "Rose garden" in the accepted sense, but where they are, in health and beauty, the garden is.

Year by year we learn to love Roses more. Year by year the Rose nurseryman extends his acres, and gives us a larger and more varied selection. We delve for pillars, we erect arches, we build summer-houses less to sit in than to form supports for rambling Roses. We form beds for Roses, we even put them in our borders. For every Rose that is planted in good soil the garden grows in grace. The old blazing Geranium garden is gone, and in its place we have the garden of tender-hued foliage, ruddy stems, and flowers that we can gather for every purpose. Whether we have a Rose garden, or a garden with Roses, our sense of beauty and fitness is equally gratified.

If there is one touch of pain in connection with Roses, it is that we have to forgo so many beautiful varieties from sheer want of room. The raiser multiplies sorts, and proves to us that his novelties are superior to existing varieties; but the older we grow, the harder it is to part with old favourites. They have grown into our lives, and cannot be turned out without laceration. 


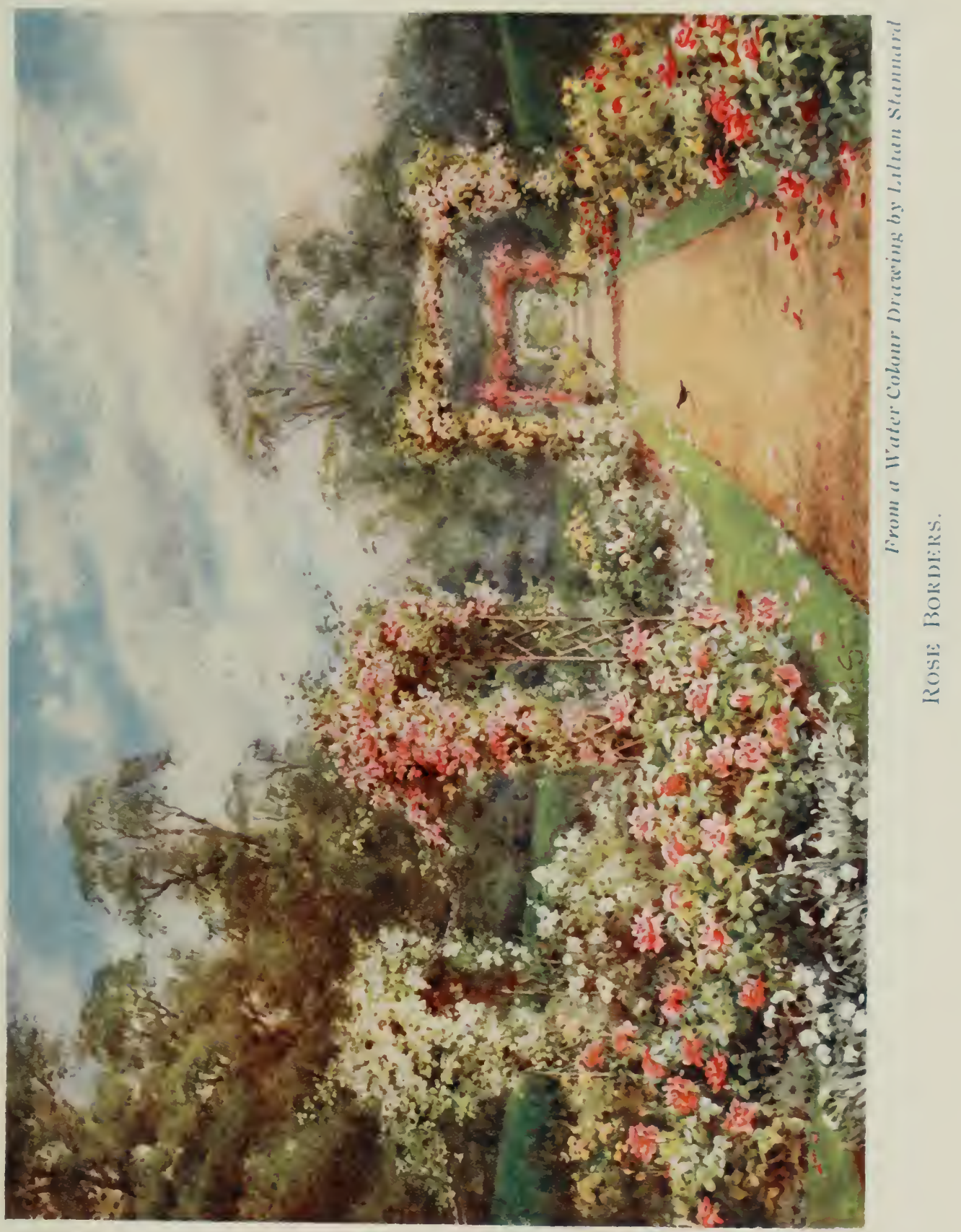





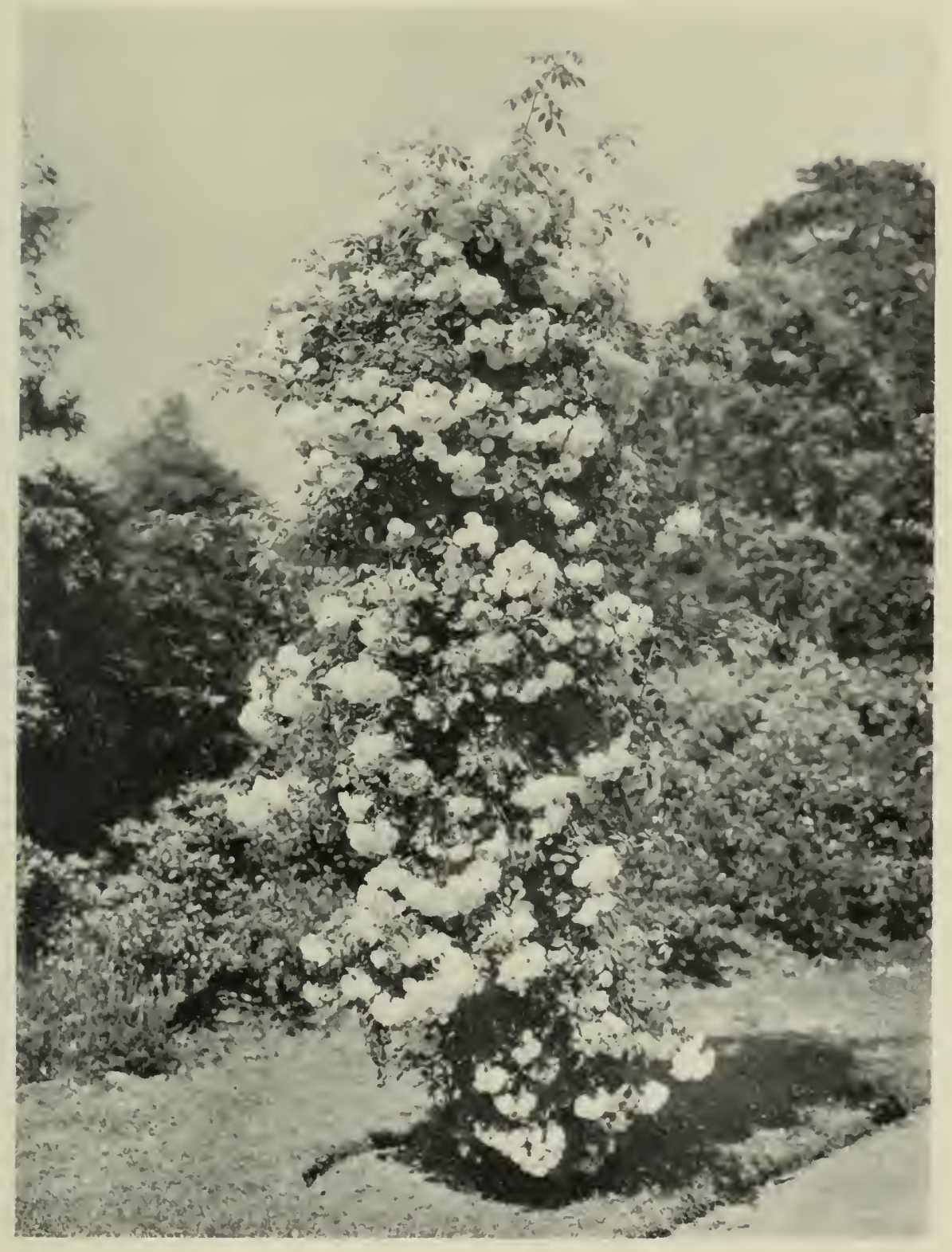

Rose Félicité-PERP'T́tUe. 

Those moments of poignant pathos which come to every human being at times when the path of youth falls away into ever vaguer distance are rendered more acute by the memory of old flowers, parted with reluctantly, and still loved. There comes a stage of life when it is easier to transfer admiration than affection. The old Roses may be superseded, but they cannot be forgotten. In the warmth and perfume of the summer garden the spell of their successors may be complete, but on those winter evenings when we turn the pages of diaries and sketch-books, or at moments when the pain of a great bereavement is upon us, the power of the old flowers comes back. And the worst thing that we can do in such circumstances is to re-grow them!

How beautiful some of those old Roses wereDundee Rambler, with the long, slender streamers that it flung from pole to pole, encroaching on the space of its sisters; Félicité-Pérpétue, a column of snow against its oaken pillar; Aimée Vibert, loose of bloom, but of a most royal prodigality; Maiden's Blush, tinting a wall that knows it no more, for both wall and Rose, heart and hearth, have gone; Céline Forestier, with its canary blossoms; Gloire de Dijon, imperfect in form, but oh! so free and gay and sweet! It is the old Roses of pillar, arch, and wall that are so hard to part with. The bedding Roses do not cling so tightly. Perhaps it is that they do not come so near to the home.

In dipping into the past the Rose-lover sometimes finds that the old Roses are even older than he thought-older, far older, than himself; and then he begins to realise how old a plant the Rose really is, and how closely it is entwined in the national life. The name, he is told, comes from the Celtic word 


\section{POPULAR GARDEN FLOWERS}

rhod, meaning red, and from this he assumes that red must have been the prevailing colour of the Rose.

Shakespeare made numerous references to a flower that he clearly knew and loved well; and some of them are of great beauty, as the following excerpts will show :-

"Of Nature's gifts thou may'st with Lilies boast And with the half-blown Rose."

-King John.

"So sweet a kiss the morning sun gives not

To those fresh morning drops upon the Rose."

- Love's Labour's Lost.

In the exquisite Sonnet LIV. Shakespeare makes beautiful use of the odour of the Rose, and of its distillation to form the famous attar of Roses, which has been manufactured for many centuries in Turkey and elsewhere. The fragrance of the Rose is indeed one of its greatest charms, and it lives in most of the newer varieties. It is true that a scentless sort wins favour now and then, owing to exceptional beauty of bloomthe varieties Her Majesty and Frau Karl Druschki are cases in point-but they are few. From the "tea" scent of the varieties of Rosa indica to the rich, full perfume of the Damask, Monthly and modern Hybrid Perpetual Roses all are deliciously sweet.

Some Species of Roses.-It is a pleasurable but an involved task to trace the origin of modern Roses. We have a number of classes, the distinctive names of which convey a definite meaning to experts, but are none the less indefinite. Few amateur growers realise how numerous these classes are. With many Roselovers there are only Hybrid Perpetuals, Teas, and Hybrid Teas; all the rest are "climbers." But even climbers must be classified. Let us glance at a few 


\section{ON ROSES}

of the species, including wildings and modern varieties. The creamy-white trailing Rose, with flowers fivepetalled, about two inches across, which rambles over the hedges in June, is Rosa arvensis, or repens, and is illustrated in the Botanical Magazine, t. 2054. This is the Ayrshire Rose. A form (perhaps double) of arvensis is supposed to be none other than the White Rose of York, which Plantagenet gathered in the Temple Gardens with the following appeal-

"Let him that is a true born gentleman, And stands upon the honour of his birth, If he suppose that I have pleaded truth, From off this brier pluck a white Rose with me."

The Red Rose which Somerset plucked to point his reply-

"Let him that is no coward and no flatterer, But dare maintain the party of the truth, Pluck a red Rose from off this thorn with me,"

could hardly be other than Rosa centifolia, the sweet old pink Cabbage Rose. A variety of this called muscosa is the original Moss Rose.

The Ayrshire must not be confounded with the Scotch Rose. The latter, Rosa spinosissima, sometimes called the Burnet-leaved Rose, blooms in May, and may be found wild on the heaths in Scotland, Ireland, and the Channel Islands. It has creamy flowers an inch and a quarter across, tinted with pink; the buds are pink. The Dog Rose, Rosa canina, with its pink or other-coloured flowers (it is a variable plant, and there are many forms) is a familiar object in the hedges in June, as are its red fruits in the autumn. The downyleaved Rose of the hedgerows, with pink flowers in June, is Rosa villosa, and it has scarlet fruits. The true 


\section{POPULAR GARDEN FLOWERS}

Sweetbrier, with its foliage that has so delightful a pungency, especially in the evening after rain, is the Eglantine of Shakespeare-

\section{"Quite overcanopied with luscious Woodbine, With sweet Musk Roses and with Eglantine, There sleeps Titania ...."}

This is the Rosa rubiginosa of the botanists, and there are many forms of it. It is fond of the heaths and of the chalk hills of southern England. The smaller-flowered Sweetbrier of Scotland, Ireland, and the Channel Islands is Rosa micrantha.

Beautiful Briers. - These wild Roses are not without garden interest, as improved forms have sprung from them. For instance, there are the beautiful hybrid briers of Lord Penzance, which have the leaf fragrance of the dear old Eglantine with larger and more brilliant flowers. They are splendid pillar plants, and alike in the beauty of their flowers, the brilliance of their large hips, and their perfume, they are remarkable. A few of the best of these fine singles, with their spicy leaves, are worth adding to any collection of pillar Roses.

Damask and Hybrid Perpetual Roses.-Old Roses other than wildings which the garden-lover feels a special interest in are the Damask, the Monthly (China), and the Bourbon. The first, the Rosa damascena of botanists, is reputed to have come from Syria in 1573 , so that there is no reason why Shakespeare should not have known it and made use of it in the line-

"Gloves as sweet as Damask Roses."

It bears pink. flowers in June, and was certainly one of the parents of the modern Hybrid Perpetual Rose, with its large, richly coloured, powerfully scented flowers. The Old China or Monthly, which is in bloom most of 
the summer, has red flowers, and this has also been used in raising hybrids. One of them is the Bourbon Rose (Borbonica). It would be useless to endeavour to trace the stages by which our modern Hybrid Perpetuals have been raised from these old Roses, as no records of the various crosses have been, or are ever likely to be, published; but the fact that the old species named were the parents of them invests them with special interest in our eyes.

Tea and Hybrid Tea Roses.-Greatly as modern Tea Roses differ from Hybrid Perpetuals, having for the most part smaller, more conical and lighter-coloured flowers, thinner stems, and deeper colour in the foliage, they are nevertheless supposed to have derived from a variety of the Monthly Rose called Rosa indica odorata. The Hybrid Teas are intermediate between the Hybrid Perpetuals and Teas, and have sprung from crosses between varieties of these two sections. It is interesting to note that the most remarkable additions to the Hybrid Tea section, which is now the most remarkable of all, have been made by Irish raisers. It is hardly too much to say that in the twenty years between 1890 and I9Io they revolutionised Rose-growing. In spite of their name, the Hybrid Perpetual Roses are not, as a class, continuous bloomers, and they only held priority over the Teas owing to their larger flowers, richer colours, and reputedly superior hardiness. The Hybrid Teas bloom much more continuously than the Hybrid Perpetuals, and as they equal them in brilliancy of colour, they hold an advantage as garden plants.

The Musk Rose is the Rosa moschata of the botanists, who tell us that it was brought from Bömbay in 1596, and had white flowers. This may be correct, as it has been found in Nepaul, but Hakluyt (Voiages, vol. ii.) 


\section{0 POPULAR GARDEN FLOWERS}

says that it was brought out of Italy, and Redouté declares it to be a native of North Africa. It is a loose grower, making large, straggling bushes, and bearing white flowers. It has no value as a garden plant, but its scent is highly agreeable.

Shakespeare made several references to Musk Roses-

"Come, sit thee down upon this flowery bed

While I thy amiable cheeks do coy,

And stick Musk Roses in thy sleek smooth head,

And kiss thy fair large ears, my gentle joy."

- A Midsummer Night's Dream.

Literary flower-lovers may trip in deciding that the Provincial referred to in "Hamlet" is the Provence Rose- "Would not this, sir, and a forest of feathers, if the rest of my fortunes turn Turk with me, with two provincial Roses on my razed shoes, get me a fellowship in a cry of players, sir?"-as it probably referred to ribbons. The Provence Rose may be the same as the Cabbage Rose-the Rose of Lancaster. Certainly the Rosa provincialis of the old writer Philip Miller is the same as the Rosa centifolia of Linnæus, and the " hundredleaved" Rose is also the Cabbage Rose. This richly coloured, strongly scented Rose came from Asia (the botanists say from Mount Caucasus), but it has long been grown in southern Europe. Chaucer probably had the Provence Rose in his mind when he wrote-

"Of Roses there were grete wone,

So fair were never in Rone";

for "Rone" would mean the Rhone, at the mouth of which river Provence lies.

The "canker-Rose" of Shakespeare-

"The canker-blooms have full as deep a dye As the perfumed tincture of the Roses," 
is, if a Rose at all, the wild Dog Rose, Rosa canina. But may he not have meant a flower attacked by caterpillars? Note in the ninety-fifth Sonnet-

"How sweet and lovely dost thou make the shame

Which, like a canker in the fragrant Rose,

Doth spot the beauty of thy budding name."

Rose-lovers will read with interest the suggestion of Pliny the Elder that the old name for England, Albion, originated in the abundance of white Roses that grew wild in it. The botanist has his Rosa alba, but that is not a native. The white corn Rose, with its yellow stamens, Rosa arvensis, is.

The Austrian Brier.-With a brief word of explanation as to some other of the old Roses whose names crop up from time to time, we must pass on to modern varieties and culture. The reader sometimes hears of the Austrian Brier. This is the Rosa lutea of botanists, has yellow flowers in June, and grows about three feet high.

Variegated Roses.-The variegated Rose, "Quatre Saisons" of the French, red and white, is the York and Lancaster Rose, a variety of Rosa damascena. Shakespeare may have known of this variety when he wrote in the "Sonnets"-

"I have seen Roses damask'd, red and white, But no such Roses see I in her cheeks."

There is another variegated Rose, the Rosamundi or Gloria Mundi (Rosa Gallica versicolor). This was mentioned by Ray, but not by Parkinson or Gerard. The Macartney Rose is Rosa bracteata, a dwarf species, bearing white flowers in July. The Evergreen Rose is Rosa sempervirens, a white rambler, a native of Southern Europe, and included in the London Catalogue as a wilding in Great Britain. Rosa Wichuraiana is a Japanese species, 
with white flowers, of comparatively recent introduction, and important as the parent of our most valuable pillar, arch, and bank Roses, such as Dorothy Perkins, Lady Gay, and Alberic Barbier. The name should be Luciz.

The Banksian Rose is Rosa Banksice, a white-flowered species introduced from China through Sir Joseph Banks in 1807 , and illustrated in the Botanical Magazine, t. I954; there is a yellow variety of it. These pretty Roses are grown on walls, but often spoiled by over-pruning. It is only the wood of more than two years old that should be removed.

The Fairy Rose is a double form of the small Monthly Rose, Rosa indica minima.

The Boursault and Seven Sisters Roses are both varieties of Rosa multiflora, the "many-flowered" Polyantha Rose-a section which includes no less important a plant than the Crimson Rambler, as well as other popular Roses. The Boursault Rose (Rosa multiflora Boursaultii) enjoyed considerable favour as a wall Rose fifty years ago; pink flowers were borne profusely.

The Japanese Rose is Rosa rugosa, which has red flowers and large, rough leaves; it was introduced from Japan in 1845 . There are several good garden varieties of it. The Japanese Roses are well liked for forming bold, dense clumps in large gardens, as the single flowers are bright in colour, and are followed by very large brilliant fruits.

The Cherokee Rose is Rosa laevigata (sinica), a whiteflowered Chinese plant, introduced in I759, and illustrated in the Botanical Magazine, t. 2847. The variety of this called Anemone, which has pale pink or white flowers, and holds its leaves so persistently as to be 
practically evergreen, is a valuable plant for covering a rustic fence. It blooms abundantiy in June.

The Noisette Rose (Rosa Noisettiana) is a bybrid between the China (indica) and the Musk (moschata). Several important cluster-flowered Roses belong to the Noisette group, notably Maréchal Niel and William Allen Richardson.

It is pleasant to make acquaintance with Roses, and to reflect on the part that they have played in national life. They have been known for many centuries in British gardens, and were used in heraldry at a very early period. The "rose gules barbed vert and seeded or" of the heralds would be a flower with green sepals and golden stamens. There were Roses on the Great Seal as early as I340.

Employed as a badge, the Rose was also used by the herbalists. It was made into Rose water and pot-pourri-

"Let one attend him with a silver basin

Full of Rose-water and bestrewed with flowers."

- Taming of the Shrew.

It was doubtless the use of the dried petals which Shakespeare referred to in "Romeo and Juliet" :-

"A beggarly account of empty boxes,

Green earthern bladders and musty seeds,

Remnants of packthread, and old cakes of Roses

Were thinly scattered to make up a show."

The phrase sub rosa, or under the Rose, reminds us that the Rose is the flower consecrated to Harpocrates, the God of Silence, by Cupid; and that it was worn as a chaplet at gatherings where the conversation was to be regarded as confidential. Chaplets of white Roses, with kid gloves attached, were once carried before the funerals of virgins in England. 


\section{I4 POPULAR GARDEN FLOWERS}

It is fitting to conclude this brief excursion into the literature and history of the Rose with Herrick's lines-

"Gather ye Roses while ye may,

Old time is still a-flying,

And the same flower that smiles to-day

To-morrow will be dying,"

for they remind us that we must not spend all our time over the pages of the past, however pleasantly scented they may be, but come to the present, realise that time is fleeting, and make haste to fill our garden with Roses.

Rose Gardens.-Almost all country dwellers-alas ! that it cannot be said of townsmen-are Rose-growers, for even the cottager, whose garden is crowded with Potatoes, Onions, Beans, Cabbages, and other vegetables, contrives to get an arch for Roses in an angle of his house. One sees the pink Monthly Rose in hundreds of gardens, large and small. In many cases no one seems to know how it got there, for it has no local history. It looks after itself. It is never pruned, and the most that it receives is a spadeful of manure now and then. Villa gardeners grow Roses, generally with some pretence of skill; anyway, the plants are labelled and pruned. And, needless to say, Roses are a feature of every Vicarage and Hall garden. In many places there is a special Rose garden extending to two or three acres, but a Rose garden may be much smaller than that; indeed, one may be formed within a garden, the whole of which does not extend to an acre. A small Rose garden is before me as I write. A hedge has been utilised as one side of the enclosure, the others are formed of rustic Oak placed diagonally on Chestnut uprights, the base of which was barked, painted with tar and dusted with sand. In one angle of the rustic fence a semi-circular rustic summer-house has been 
made. In another corner, to which a grass walk leads, is an Oak seat. Roses are grown on the fencing and summer-house. The main path is paved with irregular, open-jointed paving stones, in which dwarf plants grow. A small pool for Water Lilies has been made in the middle of the garden, and a Rose arbour constructed round it. The body of the garden is occupied with small beds of selected Roses, which include autumn as well as summer bloomers. Could not some such plan be adopted in many gardens which now know Roses only in a spasmodic way? A Rose garden! The very mention of it calls up memories of summer days, sunshine, beautiful flowers, and sweet smells.

\section{FRAGRANT Roses.}

Wherever and however we grow Roses, we must include many varieties that are really sweet. I shall presently give some selections of Roses, but so important do I think it is to have rich perfume that I am tempted to anticipate these lists and give a special table of fragrant Roses, putting the names in alphabetical order. H.P. $=$ Hybrid Perpetual ; H.T. $=$ Hybrid Tea.

\begin{tabular}{|c|c|c|}
\hline Variety. & Section. & Colour. \\
\hline 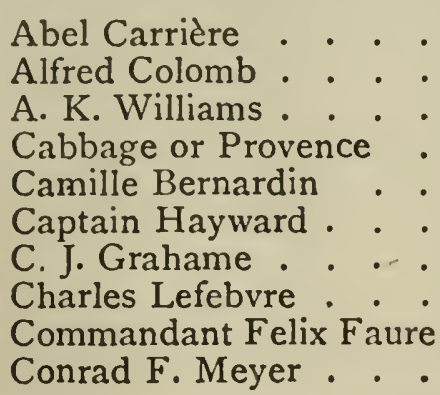 & $\begin{array}{l}\text { H.P. } \\
\text { H.P. } \\
\text { H.P. } \\
\text { Species } \\
\text { H.P. } \\
\text { H.P. } \\
\text { H.T. } \\
\text { H.P. } \\
\text { H.P. } \\
\text { Rugosa }\end{array}$ & $\begin{array}{l}\text { Dark crimson. } \\
\text { Light red. } \\
\text { Carmine. } \\
\text { Rose. } \\
\text { Light red. } \\
\text { Scarlet. } \\
\text { Scarlet. } \\
\text { Crimson. } \\
\text { Crimson. } \\
\text { Pink. }\end{array}$ \\
\hline
\end{tabular}




\section{I6 POPULAR GARDEN FLOWERS}

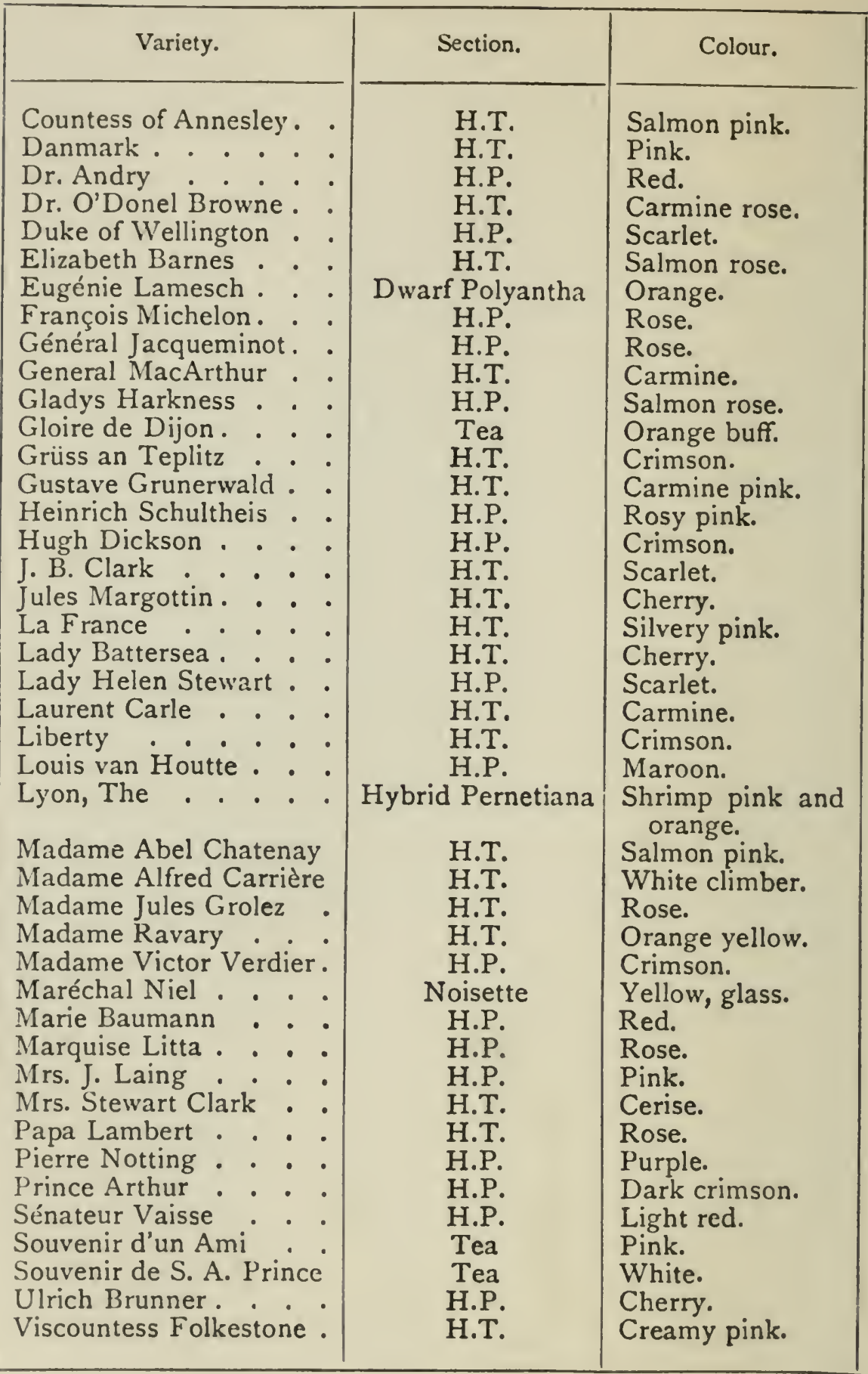




\section{ON ROSES}

\section{Good Hybrid Perpetual Roses.}

The reader may wonder whether the Roses named in the foregoing list of fragrant varieties are good in other respects-whether they are strong growers and have handsome flowers. They are excellent in every way. Such varieties as Hugh Dickson, Mrs. John Laing, and Charles Lefebvre are splendidly vigorous, and, with Alfred Colomb, Prince Arthur, Duke of Wellington, A. K. Williams, Ulrich Brunner, and others, are quite good enough for exhibition. The following newer sorts may be added to them :-

Bent Cant, rich red.

Comtesse de Ludre, light red.

David R. Williamson, rose.

Duke of Edinburgh, scarlet.

Earl of Dufferin, maroon.

Frau Karl Druschki, white.

Helen Keller, cerise.

Lady Overtown, pink.

M. H. Walsh, crimson.

Madame G. Luizet, bright pink.
Mrs. Cocker, pink.

Mrs. R. G. Sharman Crawford, pink.

Rosslyn, pink.

Susanne Marie Rodocanachi rose.

Ulster, salmon rose.

Victor Hugo, crimson.

Xavier Olibo, dark crimson, late bloomer.

\section{GOOD HyBRId TEA ROSES.}

The same question and answer as that put in connection with the Hybrid Perpetual Roses might be applied to the Hybrid Teas. The following may be aclded to those in the list of specially fragrant sorts :-

Augustine Guinoisseau, silvery pink

Avoca, crimson.

Bessie Brown, cream.

Betty, coppery rose.

Caroline Testout, pink.
Dean Hole, carmine with salmon shading.

Earl of Warwick, salmon pink. Ecarlate, scarlet.

Edu Meyer, coppery red, orange shading. 


\section{I 8 POPULAR GARDEN FLOWERS}

Elizabeth Barnes, salmon rose.

Florence Pemberton, cream.

Frau Lilla Rautenstrauch, silver.

Grace Darling, cream, shaded pink.

Gustave Regis, nankeen yellow.

Instituteur Sirdey, yellow.

Killarney, pale pink.

Lady Ashtown, pink.

Lady Helen Vincent, pink, yellow base.

La Tosca, silvery pink.

Le Progrès, nankeen.
Madame Mélanie Soupert, salmon.

Madame J. W. Budde, carmine.

Madame Ravary, orange.

Marquise de Sinety, orange.

Mildred Grant, ivory, exhibition variety.

Mrs. A. M. Kirker, cerise.

Pharisaer, blush, salmon shade.

Prince de Bulgarie, flesh.

Richmond, scarlet.

Warrior, scarlet.

Wm. Shean, pink.

\section{GoOd TEA Roses.}

The following charming Tea Roses might be added to the list of sweet sorts :-

Catherine Mermet, pink.

Comtesse de Saxe, white.

Corallina, coral red.

G. Nabonnand, blush.

Harry Kirk, sulphur.

Hugo Roller, lemon.

Jean Ducher, salmon.

Lady Roberts, apricot.

Mrs. Dudley Cross, chamois yellow.

Mrs. E. Mawley, carmine, salmon shade.

Mrs. B. R. Cant, rose.

Mrs. Myles Kennedy, silver.
Maman Cochet, flesh.

Marie van Houtte, lemon and rose.

Niphetos, white, good in pots.

Peace, white to lemon.

Souvenir de Pierre Notting, apricot.

Souvenir de Stella Gray, orange to yellow.

Sulphurea, yellow.

The Bride, white, pots.

White Maman Cochet, white or lemon.

\section{A Selection of Free-blooming Roses for Beds.}

The Rose-lover who wants to fill large beds with Roses, whether mixed or of separate varieties, will be 
wise to choose strong, free-flowering sorts. Out of the following and foregoing lists we might select a few varieties particularly good for beds. Here are some-

*Augustine Guinoisseau, silvery H.T.

Betty, coppery rose H.T.

*Caroline Testout, pink H.T.

*Corallina, coral Tea.

Ecarlate, scarlet H.T. (dwarf).

Edu Meyer, coppery H.T.

Eugénie Lamesch, orange dwarf

Polyantha.

Frau Karl Druschki, white H.P.

General MacArthur, carmine

H.T.

*Grüss an Teplitz, crimson H.T.
G. Nabonnand, blush Tea.

Hugh Dickson, crimson H.P.

Irish Elegance, orange single.

La France, pink H.T.

Laurette Messimy, china rose, yellow base.

* Madame Abel Chatenay, rose H.T.

Mrs. W. H. Cutbush, pink Polyantha.

Mrs. John Laing, rose H.P.

Peace, white Tea.

Those marked with an asterisk are exceptionally vigorous-in fact Grüss an Teplitz is sometimes used as a wall Rose.

\section{GOOD WaLl Roses.}

Roses do no more delightful work than that of covering the walls of dwellings, and there is no home but looks brighter for their presence. Old Roses, like Gloire de Dijon, William Allen Richardson, Maiden's Blush, Céline Forestier, Cheshunt Hybrid, the Banksian, and the Boursault gained their popularity as much for the suitability of habit which made them good wall varieties as for the beauty and fragrance of their flowers. There were other rambling varieties as beautiful-nay, more so, but their growth was not suitable for walls. Thus the home use of certain Roses gave them a popularity somewhat beyond their merits as flowers. The Roses 
named have not lost any of their good qualities. They are as they have always been-vigorous, spreading, freeflowering. Possibly those who have cold aspects to cover, such as east or north, would still find Gloire de Dijon and William Allen Richardson as good as any for their purpose. But new climbing varieties assert their claims, and have to be considered for south and west aspects. Many, accepted at once as beautiful pillar and arch Roses, have to be rejected at once for walls. The mighty Crimson Rambler is one of the poorest of wall Roses, falling a ready prey to mildew. Carmine Pillar, most beautiful of early-blooming climbers for a pillar or summer-house, is too strong of cane and too devoid of spray to make an ideal wall Rose. Dorothy Perkins will thrive-it thrives almost anywhere-but it goes to the other extreme, and by producing an enormous mass of long, thin shoots and slender laterals, gives the Roselover a hard task in pruning and nailing before it can be made to cover the wall. We want for our houses Roses which, like Gloire de Dijon, branch freely, yet strongly, from a central stem, producing a moderate yet not excessive amount of laterals, and flowering freely on them. Let us glance at a few Roses that fulfil these conditions-

Alister Stella Gray.-A charming Rose, small-flowered, yet invaluable owing to its neat but spreading habit and the remarkable continuity of flowering which keeps it going right into the autumn. The flowers are horne in clusters, and the colour is pale yellow.

Bardou Job.-A rich crimson Rose, not large in bloom, and semi-double.

Bouquet d'Or.-Strong and free, yellow flowers, tea-scented.

Cheshunt Hybrid.-Bright red, a very profuse bloomer. Madame Alfred Carriere. - White or blush, a strong grower. 
Maréchal Niel.-A glorious yellow Rose, but not hardy enough to grow out of doors, except in very warm, sheltered places.

Reine Marie Henriette.-A splendid variety on rich soil on a warm aspect, long, deep flowers, rich rose in colour, powerfullv scented.

Madame Bérard.-Fawn, tea-scented.

Rêve d"Or.-A strong grower, with brown canes, flowers yellow, holds its leaves well.

This selection should suffice for most places, and the old stagers, such as Gloire de Dijon, William Allen Richardson, and Maiden's Blush, can be added or substituted at discretion.

It should be understood that the soil under the walls must be dug deeply and manured generously. If it is very poor it must be taken away altogether, and a bed of loam, leaf mould, and manure substituted. If the site is a hot one, it is advantageous to cut the Roses hard back after planting, and to water in dry weather. This insures good plants the second year.

\section{Good Roses for Pillars, Arches, Pergolas, ARBOURS, AND SUMMER-HOUSES.}

The course is much clearer in selecting climbing Roses for comparatively open situations. Whatever the supports may be, plenty of Roses can be found for them, provided there is a good depth of soil and a free circulation of air-conditions which do not prevail against a wall as a rule. Crimson Rambler and its sisters, the blush, the pink (Euphrosyne), the white (Thalia), the yellow (Aglaia), and the dark crimson (Philadelphia) become available at once. Dorothy Perkins, Lady Gay, Alberic Barbier, and the rest of the Wichuraianas come in. Carmine Pillar and its splendid later counterpart 


\section{POPULAR GARDEN FLOWERS}

The Lion are at our service. Lovely singles, such as Leuchstern, Hiawatha, and the Penzance Briers await our pleasure. If these are not enough, we can draw upon the old evergreen Roses Félicité-Pérpétue and Rampant, the Ayrshire Dundee Rambler, the vigorous Noisettes Aimée Vibert and L'Ideal, the Hybrid Tea Grüss an Teplitz, and also on Longworth Rambler and Reine Olga de Würtemberg. A selection from the preceding might consist of the following :-

Alberic Barbier, cream.

Blush Rambler, blush.

Carmine Pillar, carmine, single. Dorothy Perkins, pink.

Leuchstern, rose, white centre.
Penzance Brier Meg Merrilees. Philadelphia Rambler, dark crimson.

The Lion, crimson single.

\section{TRAILING ROSES FOR BANKS.}

The Wichuraiana Roses are charming for trailing over rough banks, and many an unsightly spot on the outskirts of gardens could be made beautiful by planting Wichuraiana itself, which is white with yellow stamens; rubra, deep red; Alberic Barbier, cream; Dorothy Perkins, pink; Gardenia, yellow; and René André, orange. They should be put several feet apart, as they ramble afar. The leaves are shining green, and hang so long that the plants are almost evergreen.

\section{ROSES FOR STANDARDS.}

The Wichuraiana Roses make beautiful standards, owing to their habit of producing a great amount of fine spray. Alberic Barbier, Dorothy Perkins, and rubra may be mentioned as particularly good. They far exceed the old Hybrid Perpetual Roses as standards, owing to their freer growth and bloom and greater 
grace. The single red and white pillar Rose Hiawatha makes a charming standard. Of the older Roses, Caroline Testout, Général Jacqueminot, La France, Maman Cochet, Mrs. John Laing, Mrs. R. G. Sharman Crawford, Charles Lawson, and white Maman Cochet may be mentioned as making good standards.

\section{Roses For INDOOR CUlture.}

The owner of a conservatory often likes to grow Roses under glass for the sake of early bloom, and the following are good varieties (those marked $(p)$ may be grown in pots, and those marked $(c)$ planted out for climbing):-Anna Ollivier $(p)$, Bridesmaid $(p)$, Captain Hayward $(p)$, Caroline Testout $(p)$, Climbing Niphetos $(c)$, Climbing Perle des Jardins $(c)$, La France $(p)$, Liberty $(p)$, Madame Lambard $(p)$, Maréchal Niel $(c)$, Mrs. John Laing $(p)$, Mrs. Sharman Crawford $(p)$, Niphetos $(p)$, Souvenir de S. A. Prince $(p)$, Souvenir d'un Ami $(p)$, The Bride $(p)$, Ulrich Brunner $(p)$, and White Maman Cochet $(p)$.

The most important items in Rose culture may be dealt with under the following heads :-

$\begin{array}{ll}\text { Soils and Manures. } & \text { Fxhibiting. } \\ \text { Planting. } & \text { Under Glass. } \\ \text { Pruning. } & \text { Insects and Diseases. } \\ \text { Propagation. } & \text { Calendar for the year. } \\ \begin{array}{l}\text { Material for arches, pillars, } \\ \text { pergolas, \&c. }\end{array} & \end{array}$

Soils and Manures.-If there is one fact about Roses more strongly established than another, it is that they love a substantial soil, such as heavy loam or clay, and that they luxuriate in rich manure-coarse fare for 


\section{POPULAR GARDEN FLOWERS}

such refined flowers, it must be admitted, but very welcome to the plants all the same. Flower-lovers who find their lot cast in clayey places are sometimes tempted to repine, but it cannot be other than cheering to them to know that it is just such soil as this which Roses love. Clay, clay, and again clay! Dark greyish soil that works stiffly uncler the tools, and gets putty-like when wet, is clay. If such a soil were ploughed it would be seen that the surface of the ridges turned over by the ploughshare shone almost like steel. Farmers do not plough, and gardeners must not dig, such land when it is very wet. It is best broken up after frost, as then it crumbles. Dug two feet deep, and well manured, it makes grand Rose soil. But loam, which is a mixture of clay and sand, is also a good soil for Roses, and, fortunately for Rose-lovers, loams are common. Is your soil of a brownish or reddish hue, reader? Then it is probably loam. If it is a very pale brown, can be dug easily, and crumbles up readily when first shifted with the tool, it is probably a sandy loam, and will need deep working and a liberal dressing of decayed manure-not less than two heaped barrow-loads for every square rod-before it will grow Roses well. A sandy loam is not so good as a clayey loam, but it will produce satisfactory Roses if it is treated as suggested, and if manure is dug in every year afterwards. A light, shallow soil overlying chalk is nominally bad for Roses, but after some experience with it I am able to assure readers that it can be made to produce very fair results. The procedure is to remove the top soil in sections, break up the chalk to the depth of nine inches, lay on it a thick coat of decayed stable manure, replace the top soil, and lay another coat of manure on that after planting. If the top layer of manure is considered 


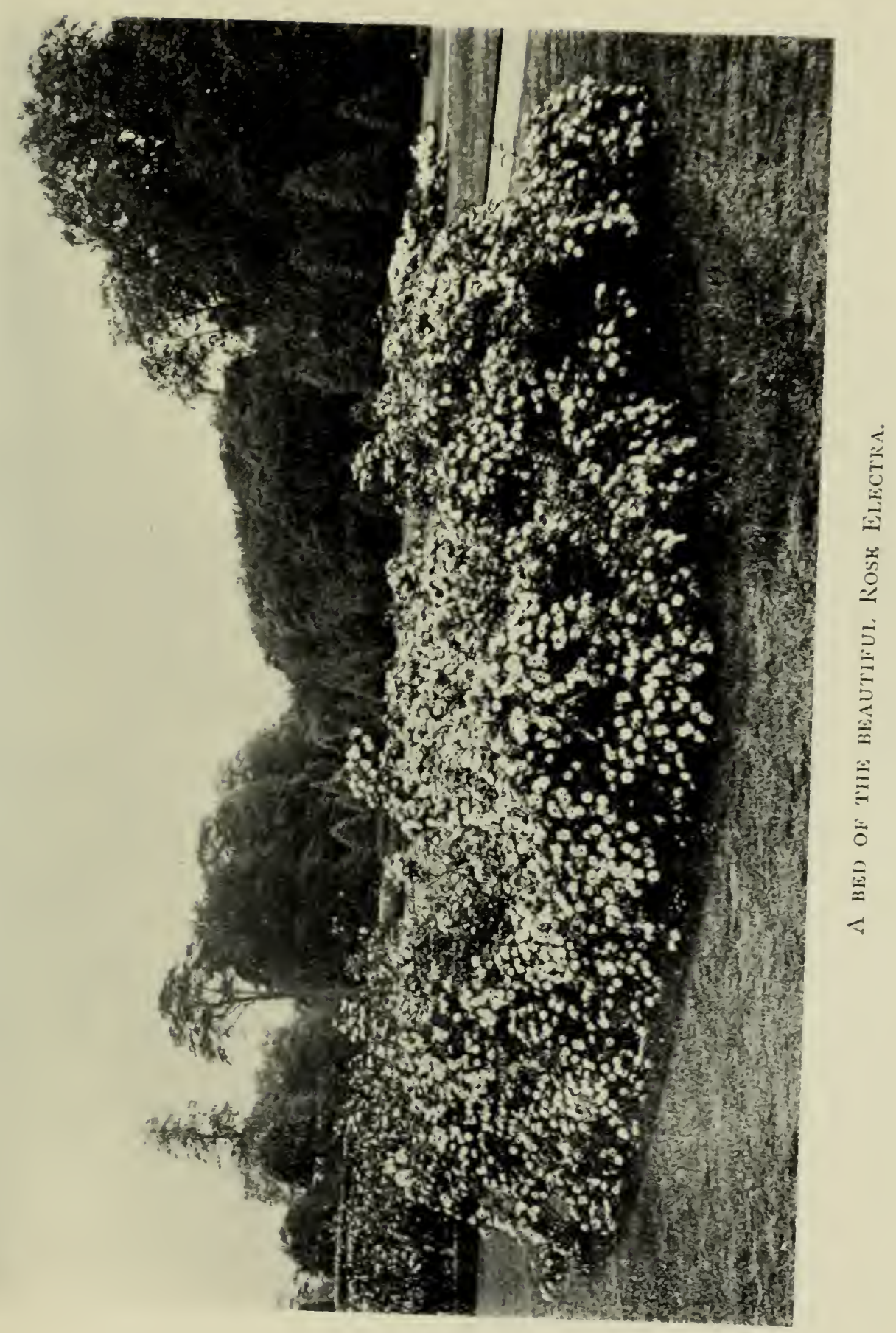



unsightly, it may be turned under the surface. Loosening chalk may be regarded as very heavy work, but as a matter of fact it is generally easier than breaking up a subsoil of clay. Manure from cowyards may be used for heavy soil, but manure from horse stables is best for light soil.

Planting.-There is one advantage which light soil has, and that is, it can be prepared and planted in almost any weather; there is no weary waiting after rain as in the case of clay. The Rose-lover appreciates this in a wet autumn. It is generally understood that November is the best planting month, and the rosarian grows discontented if that month merges into December, and incessant rain keeps the soil too wet for culture. In any case, the plants should be ordered for delivery early in November, so that they can be laid in a row with soil over their roots, ready for planting out at the first opportunity. Even if the whole winter should pass they will be safe; and spring planting should be preferred to autumn in stiff soil when the ground is puddly in November. While waiting, the labels should be prepared and written. They may be bought ready painted, or they can be made of builder's laths cut up into ten-inch lengths and pointed. The upper part should be planed with a stroke or two of the knife, and then lightly brushed over with white paint, as this gives a good writing surface. I have the lower half of my labels painted with Stockholm tar, a pint of which, purchasable at a gasworks or builder's for a trifle, will suffice for hundreds. It acts as a preservative, and obviates the necessity for renewing labels frequently. With trees and labels all ready, planting is performed speedily. It is convenient for two to work together, one making capacious holes with a spade, deep enough to cover the 


\section{POPULAR GARDEN FLOWERS}

roots and no more, while the other sets the plants in and treads the loose soil which the spadesman throws in until it is quite firm. The Rose-lover need not be half-hearted about the treading owing to fear of injuring the roots. Weak growers may be set two feet apart, and strong ones a yard.

Pruning.-Pruning follows as naturally on planting as planting on soil preparation, because it is generally advantageous to let the first course of pruning accompany the planting. When Roses are received from the nurseries they contain far more wood than any prudent grower would care to leave, and at the end of March it is pruned back hard. Why not remove part of it in autumn, in order to reduce the area exposed to the wind, and so prevent excessive wind-sway, with its loosening influences? There is no good reason. There is, I admit, an excellent reason why autumn pruning should only be a part, and not the whole-why it should be restricted to removing about a third of every long shoot, and not extend to cutting back to the ground buds, as will be done in spring. This reason is that mild weather at mid-winter often starts Roses into growth, and if there were only a few basal buds, and these started growing, the plants might be thrown back seriously owing to a severe late frost cutting the tender young growth. If a foot or more of growth is kept through the winter, it is the upper superfluous and not the lower necessary buds which start; the latter remain dormant while their brethren run the risk. The spring pruning of newly planted Roses should be severe. Done at the end of March, it may be safely carried to the point of cutting to within four inches of the ground - weak shoots lower still. A Rose-bed looks rather subdued after this drastic treatment, but it gladdens the 
grower's heart to see how nobly the plants leap into life-what strong shoots they throw up, how beautiful the tints of the fresh young leaves are, especially of the Teas, and how quickly they speed into bloom. Strong-growing climbers, like Crimson Rambler and its sisters, Dorothy Perkins and her progeny, and Carmine Pillar, need not be cut to the ground if the soil is substantial and rich, but they certainly should if it is poor, light, and shallow. Without cutting back, the roots have a double duty to perform : they have to feed the existing shoots and to throw up fresh ones, and the latter is the more important, for no pillar and arch Roses can be thoroughly satisfactory unless they throw up new shoots annually like Raspberries. With the original shoots cut away, the roots can concentrate on the task of forming new shoots, and they do it to such purpose that the pillars are soon covered. The annual pruning of established Roses is a task which will interest the grower, and prompt him to a study of the varieties. He will learn quickly what sorts are benefited by severe and which by light pruning-how the strong growers may be pruned much less hard than weak ones. The quality of the soil governs pruning much more than most people know. It governs it, because if it is heavy and fertile it prompts much stronger growth than if it is light and poor.

The more natural growth there is in a Rose the more the grower may prune, as he is sure of a constant supply of good new wood, and good new wood gives the best flowers. The exhibition growers know this quite well. They plant in rich soil and prune severely. It is dangerous, however, to prune hard in a soil that does not prompt free growth, as the plants break feebly from the back buds to which they are cut. In such soil it is best 


\section{POPULAR GARDEN FLOWERS}

to prune lightly, and when, after a few years, the bushes have become too straggly, to plant fresh ones. Roses are cheap enough in all conscience, and changes give opportunities of trying fresh sorts. All this comes with experience and observation, and while knowledge of the varieties is being acquired, the amateur may lean to severe pruning. The annual pruning and training of pillar and arch Roses is a matter that puts no small strain on the courage of the grower. He examines the plants in autumn, and he finds that each plant consists of several old and several new canes, the former grey or brown in colour, the latter brownish green. So far good. All that has to be done is to cut out the former at the base of the pillar, and tie up the latter (which in the case of very vigorous varieties are quite likely to have started off on a roving expedition among adjacent shrubs) in their places. Doubt creeps in when it is discovered that there are several young shoots on the upper part of the old ones, and that most of the pretty sprayey shoots that clothe the top of the pillars are dependent on them. What is to be done? It is a choice between tangle and order. Personally I never hesitate. The old canes go if there are young ones to take their places, and although I grieve momentarily to see the top spray disappear in a mass, my feelings are assuaged directly it is out of sight and the young canes are tied in, for I can see clearly that as soon as growth begins there will be abundance of fresh flowering growth. When tying in the young canes the grower will find that it is best to have his first band about a foot above the ground. From this point he can begin to work the canes round the pillar, until, a foot or eighteen inches higher up, he has got some at the sides and the back as well as in the front, so that the whole pillar is clothed. No canes are to 
cross each other. It is hardly practicable to treat wall Roses on this plan, as there is rarely a sufficient supply of new wood to re-clothe the space, and to cut out the old canes at the base would be to leave the whole wall bare for a considerable time. Nearly all the summer growth will be from the upper branches, not from the root-stock, and this considerably modifies the annual pruning. If an area of wall near the ground is to be covered, the plant may be trained with three or four main shoots tied in two or three feet apart; the side shoots which break from these will be the flowering shoots, and can be treated like the dwarf plants, being pruned back in spring, so that a fresh supply of young wood is secured every year. If the upper part of a house wall is to be covered, the plant may be trained up with one tall stem past the lower windows, and three or four main shoots taken from it. Strong-growing wall Roses, such as Gloire de Dijon and William Allen Richardson, will need a good deal of thinning annually if they are to be kept neat. I once had a "William Allen" on an east wall in deep clay soil, and the growth it made every year was prodigious. Alister Stella Gray, Bardou Job, and other modern varieties are not so rampant.

Propagation-(a) by budding; (b) by cutting.-When amateur Rose-growers hear that the beautiful new varieties which they see with gold medal cards attached at the shows are seedlings, they may wonder whether it is not equally open to them to raise good Roses from seed. I am afraid it is not. It is true that new varieties are raised from seed, but it is also true that they are raised from a special strain of seed, impossible to buy, and, even so, that they merely represent one or two selections from many hundreds of plants. We must look to purchase of plants as our first source of supply, 
and increase subsequently by propagation from buds or cuttings. (a) Budding.-This interesting operation may be practised by any amateur who will bring intelligent practice to bear on the necessary raw material at a suitable time. He can then turn Briers into Roses. If he wants dwarf plants he should insert cuttings of Briers, made of pieces of the current year's growth about eight inches long and deprived of all except the top buds, two inches apart, in September, burying them nearly to the top and treading the soil firmly against them. At the end of a year the plants so raised (which are termed "stocks") can be planted eighteen inches apart. In the second summer afterwards they should have stems about a third of an inch thick, and buds can be put in them low down. It facilitates getting the buds in later on if the soil is drawn up to the stems in June, as it softens the bark. A quicker way of getting stocks is to take straight Briers about three feet long out of the hedges in November, prune them in root and branch, and plant them eighteen inches apart, but these will be standards, not dwarfs. They will push side shoots in early summer, and buds can be put in these low down, in fact, close to the base, where they spring from the main stem. In either case the time and method of budding is the same. Showery weather from mid-July to mid-August provides a favourable opportunity to bud, as the wet causes a vigorous flow of sap, and the buds are easily manipulated. A current year's shoot of the Rose to be multiplied should be cut off, the thin tip removed, and the leaves cropped in to short stumps. An average shoot will yield several buds, as a slice of wood suitable for the purpose can be cut out at each leaf-stalk. The bud nestles at the base of the stalk partly outside and partly inside the bark. The inner part must be exposed, 
as it has to be brought into close contact with the stem of the Brier ; and as the inner part is covered by the pith from the body of the shoot, it follows that this woody matter must be picked away with the finger and thumb, and that it must be removed without tearing the bud, to which it is attached, out with it. The operation is undoubtedly a delicate one, and it becomes almost impossible when the wood is hard and sapless; but with plenty of sap the pith is pliable and yielding, and very little practice enables the operator to prepare the buds properly. The slices may be cut out thinly, and about an inch and a half long. Not a moment must be lost when they are prepared, as they dry quickly; they must be slipped into cuts made with a sharp knife-point in the stems of the stocks, the edges of the bark being carefully raised to admit them. They must be tied in with strong, soft material. The Briers must not be pruned until the buds start growing the following spring, when they may be cut back. (b) Bycuttings. - An amateur who has a favourite Rose may try to increase it by cuttings. Many of the strong-growing sorts, including climbers like Dorothy Perkins and Crimson Rambler, strike readily, and make nice plants in two years. The time and method recommended for striking cuttings of Briers may be practised with Roses. Shoots which have borne flowers are quite suitable.

Making Pillars and Arches. - I hope that the Roseloving reader has a special leaning towards rambling Roses. I hope that he or she is bent upon breaking up the stiffness of his garden by putting in plenty of pillars and arches. A series of straight, flat, unrelieved lines is all very well in a kitchen garden, but we can improve upon it in the flower garden. A few pillars and arches need not cost a great deal, and they will 


\section{2

certainly doubly repay the outlay upon them. Those Rose-lovers who would like to have a complete Rose garden could form an enclosure with a rustic fence, planted with Roses, or a Sweetbrier hedge, or with pillars connected with chains or top pieces. Otherwise, a series of pillars, connected at the top either with chains or lighter poles, could be set alongside a walk leading to a summer-house. If there was no arbour, an arch at each end would be both beautiful and appropriate. Whatever timber is used should be well seasoned. Nominally oak lasts many years, but "green" oak may rot in two or three seasons. On the other hand, with seasoned wood even larch and chestnut, which are not potentially so durable as oak, may remain sound for eight or ten years. Nine-feet poles will be long enough, two and a half feet in the ground, and six and a half feet out. They may be anything from six to nine inches thick. The bark should be stripped off the part to be plunged, which may be painted with melted tar and dusted with sand to assist in preserving it. Four-inch poles will be large enough for the top (and also for the sides in the case of a pergola), but old chains are often used; they are not drawn tight, but are allowed to sag in the middle. Strong Roses may be expected to cover them in two seasons if the soil is good. If suitable timber for arches is difficult to get, the ironmonger's wire arches need not be despised, as very little metal is exposed when the Roses have been established a year or two. Specially long nails or spikes should be used to connect top and side poles with the pillars, as it is necessary that they should be well secured.

Exhibiting.-It often happens that after a year or two of Rose culture the charm and interest of the 


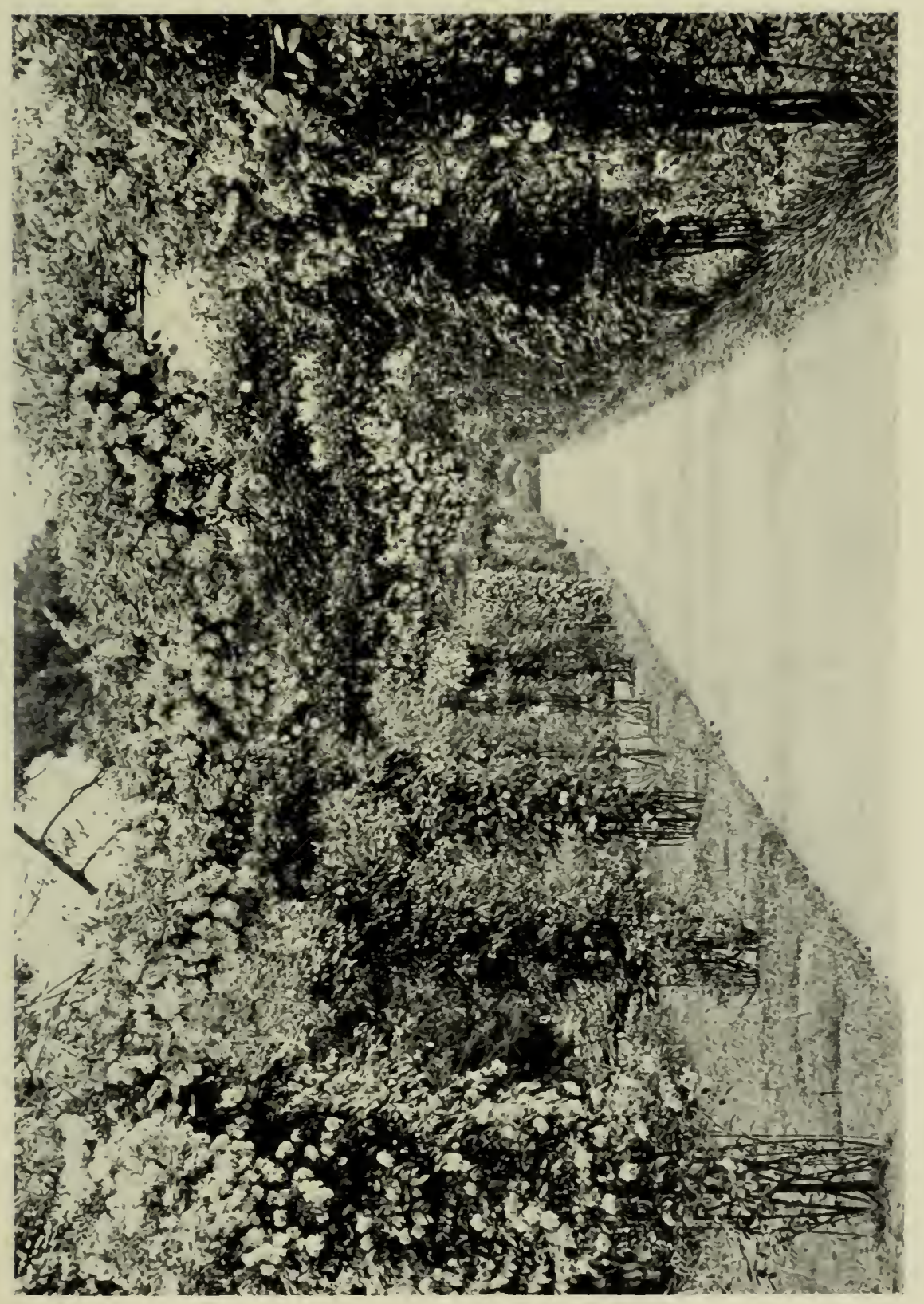



flower get so tight a hold of the amateur that he specialises it. He reads the Rose notes in his favourite gardening paper eagerly, and he visits shows. He sees prizes won by flowers that are not a bit better than his own, and he is encouraged to try his hand at showing. When he gets to this stage he is wise to join a local Rose society, or the National Rose Society, the rules and other publications of which, and the intercourse with special members, will give him much useful information. The small grower need not feel that he will be overweighted by the large one, as at most shows the classes are divided into sections according to the number of plants grown. An amateur who has less than a hunclred plants will find himself protected from the attack of men who cultivate more than a thousand. But even with no more powerful competitors than those of his own class, he will have to grow his plants well to succeed, as competition among the smaller amateurs is as keen as it is among the "big men." Strong plants put into deep, well-manured soil and pruned hard will yield large, handsome flowers, especially if they are restricted to three or four shoots, and the buds on these thinned. If the plants are left to grow naturally, and not disbudded, they will produce a larger number of smaller flowers. The plants should be looked over the day before the show, and plump young flowers just on the point of full expansion chosen. A strip of raffia should be slipped round the heart and tied firmly, but not so tightly as to compress the flower severely. In the evening or very early morning the flowers should be cut, put in water, and kept in the shade. When they are set up for the judges the raffia should be cut, and the outer petals drawn away from the centre with tweezers and evenly disposed, one overlapping the other. 


\section{POPULAR GARDEN FLOWERS}

This is called "dressing," but care should be taken to avoid giving the flowers a very stiff appearance, or the judge will condemn them as "over-dressed." Boxes painted green of the following sizes are suitable for staging exhibition Roses in :-

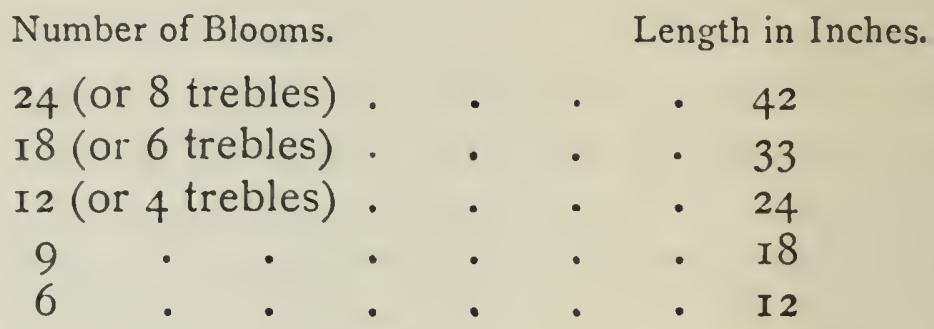

All the boxes must be 18 inches wide (back to front), and 4 inches high at the front.

Roses under Glass.-In our selections we saw that some varieties of Roses are particularly adapted for culture in pots. Amateurs with a large greenhouse or conservatory have an advantage over their glassless brethren, as they can have Roses in spring. In a corner of the house they can plant out a favourite climber, such as Climbing Niphetos or Maréchal Niel, and on the stage they can have a few pots of selected sorts. A cool house is better than a hot one. A winter temperature of $45^{\circ}$ to $50^{\circ}$ is ample. Those who have two houses, one warm and the other cool, may force a few pot plants if very early bloom is wanted. The plants may be stood outside on a bed of ashes after flowering, and pruned, re-potted, and replaced in the house in separate batches in autumn and winter. Three parts of fibrous loam, one of decayed manure, and some coarse sand form a suitable compost for Roses under glass. Both the dwarf and climbing forms of Niphetos are beautiful indoor Roses, producing abund- 
ance of long, pointed, pure white, delicately perfumed buds. Maréchal Niel is an enduring favourite. The most successful growers cut this glorious, fragrant yellow Rose hard back after flowering, and get entirely new canes for the next season's blooming.

Insects and Diseases. - The Rose is often attacked by green-fly. This can be destroyed under glass by fumigating the house with a vaporising cone, and outdoors by syringing with water in which soft soap and quassia chips, at the rate of a pound and half a pound respectively per gallon, have been boiled. Grubs and small caterpillars may be picked off when seen, and their attack checked by dusting the bushes with flowers of sulphur while moist. Sulphur is also a good remedy for mildew and red rust-indeed, the Rose-grower should always keep a supply by him. Probably mildew will prove to be the most dangerous enemy. The shining-leaved Roses of the Wichuraiana class (Dorothy Perkins, \&c.), are generally free from this pest, but Crimson Rambler and other beautiful pillar Roses are very subject to it. An attack mars their appearance by coating the leaves with a greyish powder, and impairs the flowering. To be thoroughly effectual, the sulphur should be used in a finely powdered state, and dredged on directly the attack begins. For pillar plants it is convenient to have a pair of Malbec bellows, which many seedsmen sell.

\section{The Rose-Grower's Year-A Summary.}

January and February. - If the garden Roses were not planted in autumn owing to the soil not being ready, they should be kept prostrate with soil heaped over the roots. Take an opportunity of preparing and manuring 


\section{POPULAR GARDEN FLOWERS}

the ground. Heavy soil often crumbles readily after frost in these months. Planting may be done when the soil is ready. Prune and pot a few selected plants, and place in the greenhouse. Delicate dwarf Teas in the open ground may be protected by drawing a few inches of soil up to them in January, and standards by placing some bracken in the branches. Tender varieties on walls may be protected by being covered with a mat. This protective work may be done in January or earlier, according to the weather.

March.-Complete planting this month. If the winter has been mild, and the Roses have consequently broken into growth at the upper part, it will be well to shorten them about half-way to the point of ultimate pruning early in the month, and complete the pruning at the end. Cut newly planted Roses hard back at the end of the month. Look out for green-fly on indoor plants, and vaporise the house to prevent its spread.

April.-All pruning may be completed early in this month. Teas and Hybrid Teas sometimes start later than Hybrid Perpetuals, but the pruning can be completed by the middle of April. Look over wall Roses and cut out superfluous growths. Crowding should not be permitted. Fasten the main shoots to the walls with cast-iron nails and shreds or other approved means. Prune back the shoots of budded Briers when the Rose buds begin to grow. Attend to the watering of indoor plants, and give liquid manure once a week. Give abundance of air.

May.-Plants will now be growing fast, and the first tints will be much admired. Keep a sharp lookout for grubs, and examine any curled leaves. Thin the shoots of plants which are wanted to give fine flowers. Put pot plants that have finished flowering in the open air on 
a bed of ashes. Maintain the supply of water in dry weather. Cut back Maréchal Niel after flowering.

June.-The plants will be in full growth this month, and the earlier varieties will form buds. Disbud plants which are to yield show flowers. A soaking of liquid manure once a week will do good. Continue to watch for grubs and green-fly. Mildew may appear, and should be promptly attacked with sulphur. Prepare boxes and tubes if intending to exhibit. Tie the growths of climbers to the pillars.

July. - This will be the principal flowering month of the year. Most varieties will be in full beauty. Cut freely while the flowers are young, as it encourages the plants to continue blooming. Water and liquid manure will be beneficial in dry weather. Take the opportunity of wet weather to commence budding, which can often be done with advantage in the latter part of the month. Should frothy tufts appear on the plants, caused by the "cuckoo spittle" insect, brush them off.

August.-Most of the wall and Hybrid Perpetual Roses in the beds will be past their best now, but the Teas and Hybrid Teas will continue flowering. Complete budding; if it has to be done in dry weather, give the plants a soaking of water the day before removing the pith. Tie the growths of climbers, which will now be strong, to the pillars. Continue to attack insects and fungi.

September.-The Hybrid Perpetuals will give a few more flowers this month, after which most of them will finish blooming for the year. The Teas and Hybrid Teas will continue. Towards the end of the month insert cuttings of Briers or selected Roses.

October.-Complete the insertion of cuttings. Start preparing soil for planting, and order the trees required 


\section{POPULAR GARDEN FLOWERS}

for delivery when ready. Work the soil two spades deep and manure it liberally. Procure material for pillars and arches. Renew labels which are becoming illegible.

November.-Endeavour to get all planting done this month, as it is the best of the year as a rule. If very wet, planting on clay soil may have to be deferred. While the plants are waiting to be put in they should be laid prostrate with soil banked over the roots. Go over climbing Roses, cut out as much old wood as can be spared, and tie the new canes to their supports.

December. - Complete soil preparation, planting, thinning old wood, and tying or nailing. Protect delicate varieties with soil, bracken, or mats (see January). 


\section{XXXIII}

\section{ON SNAPDRAGONS AND SWEET WILLIAMS}

Two prime favourites of our great-grandparents, as they are of ourselves. Their very names speak of past centuries. They lead us back into medireval gardens, which knew not of Begonias, Zonal Geraniums, and other fiery modern flowers.

And whence came these names? The Snapdragon is the Antirrhinum majus of botanists. It is a plant which grew wild on old walls in Great Britain long before Linnæus was born. The name Antirrhinum came from anti, like; and rhin, a snout, in allusion to the fact that the flowers resemble the snout of an animal in form. And we may very well suppose that the common name arose from the wide mouth and heavy lower jaws of the flower, which gave it a devouring air.

The Sweet William is the Dianthus barbatus, or bearded Jove's Flower, of the botanists. It is closely related to the Carnation - the Gillyflower of old gardeners. These good florists had to subdivide their Gillyflowers, and from that necessity we get our names of Stock and Wallflower. It was perhaps the same necessity for more minute distinction which induced them to give separate names to the fragrant bearded Pinks; they called the narrow-leaved varieties Sweet Johns, and the broad-leaved ones Sweet Williams. 
The name Sweet John has not lived, but Sweet William survives, and may be expected to live for ever.

Botanical authorities do not attempt to fix a date for the introduction of the Snapdragon to Great Britain, and they tell us that it is a native. That is open to doubt, but it has certainly been a wilding for a period which runs into centuries. Of the Sweet William they tell us that it came from Germany in I573. A coloured plate of the plant appears in the Botanical Magazine, t. 207.

There was a time when the Sweet William was specialised by florists, who grew a strain called Auriculaeyed, and were disposed to make the plant almost as great a favourite as the Auricula itself. The movement subsided, and the Sweet William no longer enjoys status as a florist's flower. It is the turn of the Snapdragon to be exalted. The florists-and particularly Scottish florists-have devoted a great deal of attention to raising improved varieties, and have even given special names to them.

Both plants have shared in the increased popularity of hardy flowers generally, and that is of much greater moment than a rise and fall in the favour of a limited number of florists. It means that as garden plants they enjoy the favour of thousands.

Those flower-lovers who have to garden on chalk ground learn fully the value of Snapdragons. These are the plants which never fail, however poor and shallow the soil may be, and however dry the season. They are $\mathrm{a}$ boon and a blessing on chalk. They never tire, they never flag. They may be planted at almost any season, and they will remain in bloom when almost everything else in the garden has gone. Even if the flowers possessed no particular charm, these qualities 


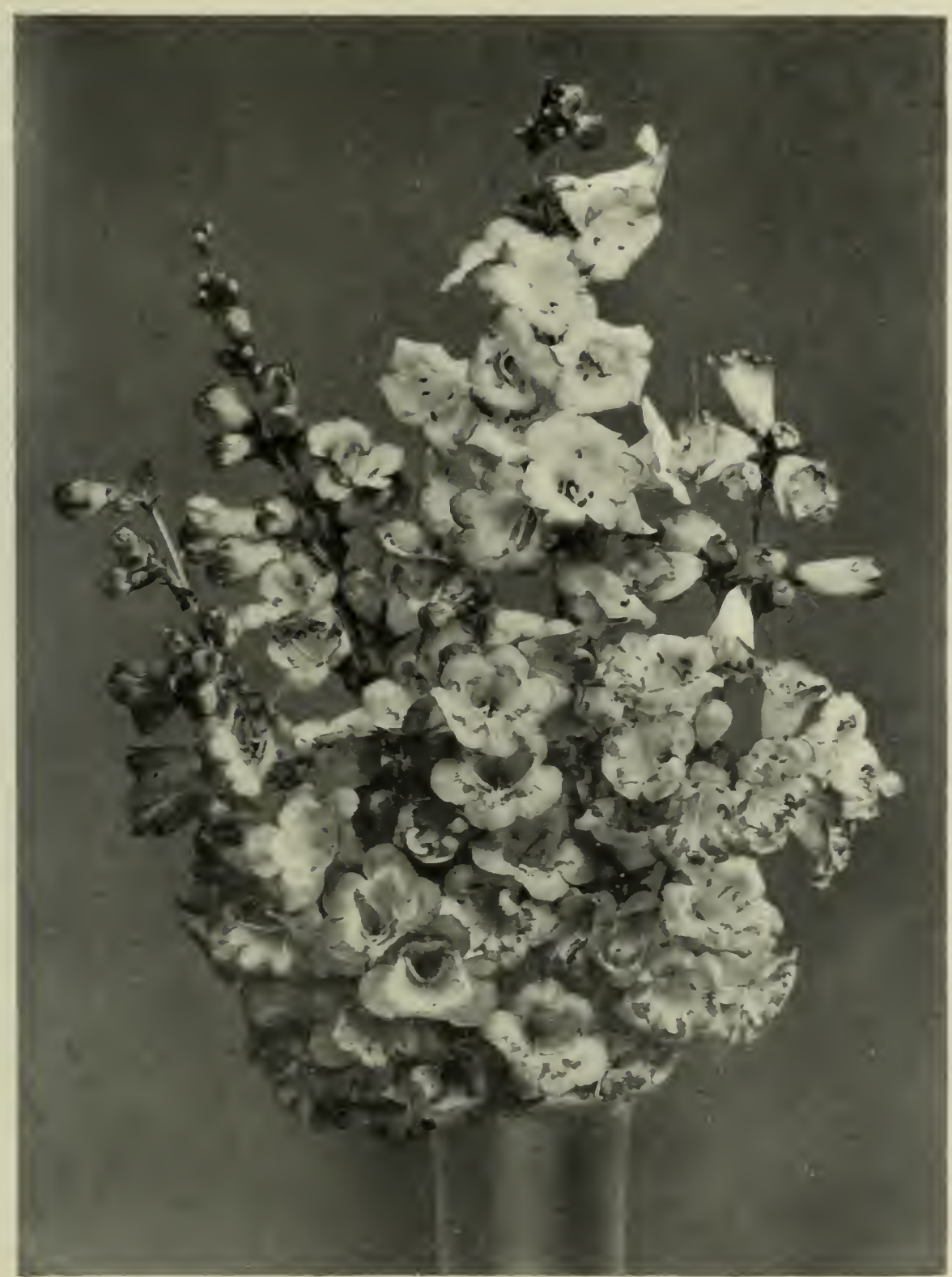

Pentstenons. 

SNAPDRAGONS, SWEET WILLIAMS 341

would render Snapdragons valuable, because they are so rare. But the fine modern types are very beautiful. There are both self and striped varieties. The latter flowers are of immense size, and most of them have broad flakes of rich velvety colour beside the narrow lines. It is this type that the doughty Scottish florists love, and with which they encounter each other in prize competitions.

There are many selections of self-colours which come true from seed. Nearly all seedsmen offer two strains, the tall and the Tom Thumb, the former growing two to three feet high, the latter only eight or nine inches. But some offer a third called Intermediate, the height of which is twelve to fifteen inches. The latter strain is better than the Tom Thumb, even for the front of borders, as the growth, while not excessive, is a little freer, and the flowers are larger.

With respect to colours, nearly all seedsmen offer crimson, yellow, and white separately, most add carmine, some include coral, pink, apricot, orange, and rose. No varieties are more beautiful than those with a blending of two colours, such as rose and white, red with white margin, pink with yellow lip, scarlet with white throat, crimson and yellow, pink and gold, white tipped with yellow, and crimson with white throat. Few flowerlovers, even those with considerable experience of hardy plants, are familiar with these exquisite bi-coloured Snapdragons. The more closely a collection of seedlings is examined the more exquisite the variations that are found.

While those who are anxious to have particular colours will do well to procure separate packets of seed, it generally happens that a mixed packet from a good seedsman gives a considerable number of them. 


\section{$34^{2}$ POPULAR GARDEN FLOWERS}

The gardener of limited means need not repine, therefore. If unable conveniently to buy a separate collection, let him trust his fortunes to a mixture. He may mark the varieties which he likes best, and increase them another year by seeds or cuttings.

While the Snapdragons are true perennials, flourishing for years on old ruins and in the driest crevices of walls, it is both simple and adequate to treat them as annuals. No small advantage of growing them thus is that a supply of sturdy seedlings can be got ready for planting by mid-May, and thereby come in useful for planting near bulbs which are to be left in the ground, and the leaves of which are fading. It is unwise to cut off the bulb foliage, nor is it necessary, for if the leaves are tied in a neat cluster they do their work of feeding the bulbs below them, and they are not conspicuous when the Snapdragons get fairly into growth.

To have the Antirrhinums ready for planting in May they ought to be sown in a box of fine, moist soil in January or February, and put in a warm frame or greenhouse. With abundance of light and air after germination, and thinning and pricking out as required, they will make sturdy plants. They should be hardened in a cold frame before they are planted out. Plants may be raised without heat in March, and will flower the same year if all go well with them, although they will be later. Some growers sow seed out of doors in early summer, and plant the seedlings out in autumn, to bloom the following year. The distance apart should be from six to eighteen inches according to the type.

It would hardly be wise to trust to late spring planting for establishing Snapdragons on walls. It would be better to sow the seed in autumn, and put 
a little soil over it, in order to give the plants a chance of getting good roothold before the hot weather came on.

Cuttings may also be struck in autumn, and may consist of the young shoots which healthy plants are continually forming. These may be struck in a box of sandy soil in a cold frame, or even outdoors.

The Sweet William is generally treated as a biennial, like the Wallflower-that is, raised from seed in May, thinned, set nine inches apart in a nursery bed in summer, planted out in autumn, and cleared off after flowering in early summer. If, however, a particularly good variety results, it is often kept true by taking young basal shoots as cuttings and inserting them in moist soil in a shady place. But the Sweet William is not, like the Snapdragon, a chalk-lover, and in poor soil there is little enough growth suitable for cuttings. In this respect the gardener who practises on a rich loamy or moist clay soil is in a much better position than he who works on chalk.

The Auricula-eyed Sweet William should have a large truss of flowers which possess the qualities of roundness, smooth edges, and clearly defined eye, surrounded by a dark band. The Pheasant's Eye, crimson with white eye, is also a beautiful selection. Selfcolours, such as pink, scarlet, dark crimson, and white, are also available. Pink Beauty is an exceptionally charming variety. Bright salmon-pink in colour, growing only twelve to eighteen inches high, of neat habit, free blooming, and lasting well, it is perhaps the most valuable of all the Sweet Williams as a garden plant. The various colours come true from seed, and so does the double white.

As in the case of Snapdragons, mixed seed from a 


\section{POPULAR GARDEN FLOWERS}

good firm will give a considerable diversity of colours, and any particularly good varieties may be perpetuated by means of cuttings.

With their beauty, their ease of culture, their hardiness, and the charm of old association which they possess, Snapdragons and Sweet Williams must ever be favourites in the garden. 


\section{XXXIV}

\section{ON SWEET PEAS}

THE Pea is one of the oldest of garden plants, but the Sweet Pea has only been grown in British gardens for a little more than two hundred years. The first Sweet Pea of which any record exists was sent to Dr. Uvedale, a schoolmaster at Enfield, who took great interest in plants, by a Sicilian monk, named Franciscus Cupani, in 1699. It was received with interest rather than enthusiasm. The flower, though fragrant, was small and irregular, and the colour-purple-was not brilliant. It is probable that Uvedale's interest in the plant was that of the botanist rather than the gardener. It was a new plant, and he would experience a certain pride in the reflection that he, and not such mighty predecessors as Ray, Gerard, and Parkinson, had had the honour of being the first recipient. $\mathrm{He}$ would draw the attention of botanists to it complacently, dissect it, describe it in great detail, fuss over it generally, and never, probably, form the slightest conception of its great future.

To-day the Sweet Pea is one of the most popular of garden flowers. It is grown by more people than any other plant. All classes cultivate it. Everybody loves it. It is charming in form, beautiful and varied in colour, deliciously sweet, and open to culture by everybody. The most successful growers of Sweet Peas are found in the owners of small gardens, with only a 


\section{POPULAR GARDEN FLOWERS}

few square rods of ground, and none too much of either money or leisure.

If Sweet Pea lovers want to compare the modern with the original Sweet Pea, they can do it best by placing a photograph of a good spray of to-day beside one of the original Sweet Pea which they will find in the National Sweet Pea Society's Annual for r9o8. The latter was taken from a specimen in Plukenet's Herbarium in the Natural History Museum, South Kensington, London, and portrays a weed-like plant with insignificant flowers. But many people living at the present time can remember the old-fashioned Sweet Pea, with its small, irregular flowers borne in pairs, either white, purple, striped, white, carmine, or pink and white. The flowers of the present time, two inches across, the petals overlapping so that no gaps are shown, and exquisitely frilled, borne in fours and fives on the stem, with a range of colours that comprises almost everything except yellow, are a remarkable advance. They are not sweeter than the older ones, but in every other respect they are immensely superior.

Flower-lovers who grow Sweet Peas have good grounds for their action. Well-grown plants yield a constant succession of bloom from June to November inclusive if the flowers are gathered regularly, and no blossoms are more delightful for house decoration. Moreover, the cultivation is inexpensive, so that all this floral charm can be gained without any great outlay. One may, it is true, spend a good deal of money on Sweet Peas by growing a large collection of the newest varieties and exhibiting them; but that is not in the least essential to garden beauty. The great fact is that a splendid display of charming flowers can be had both in garden and house with very little outlay. 


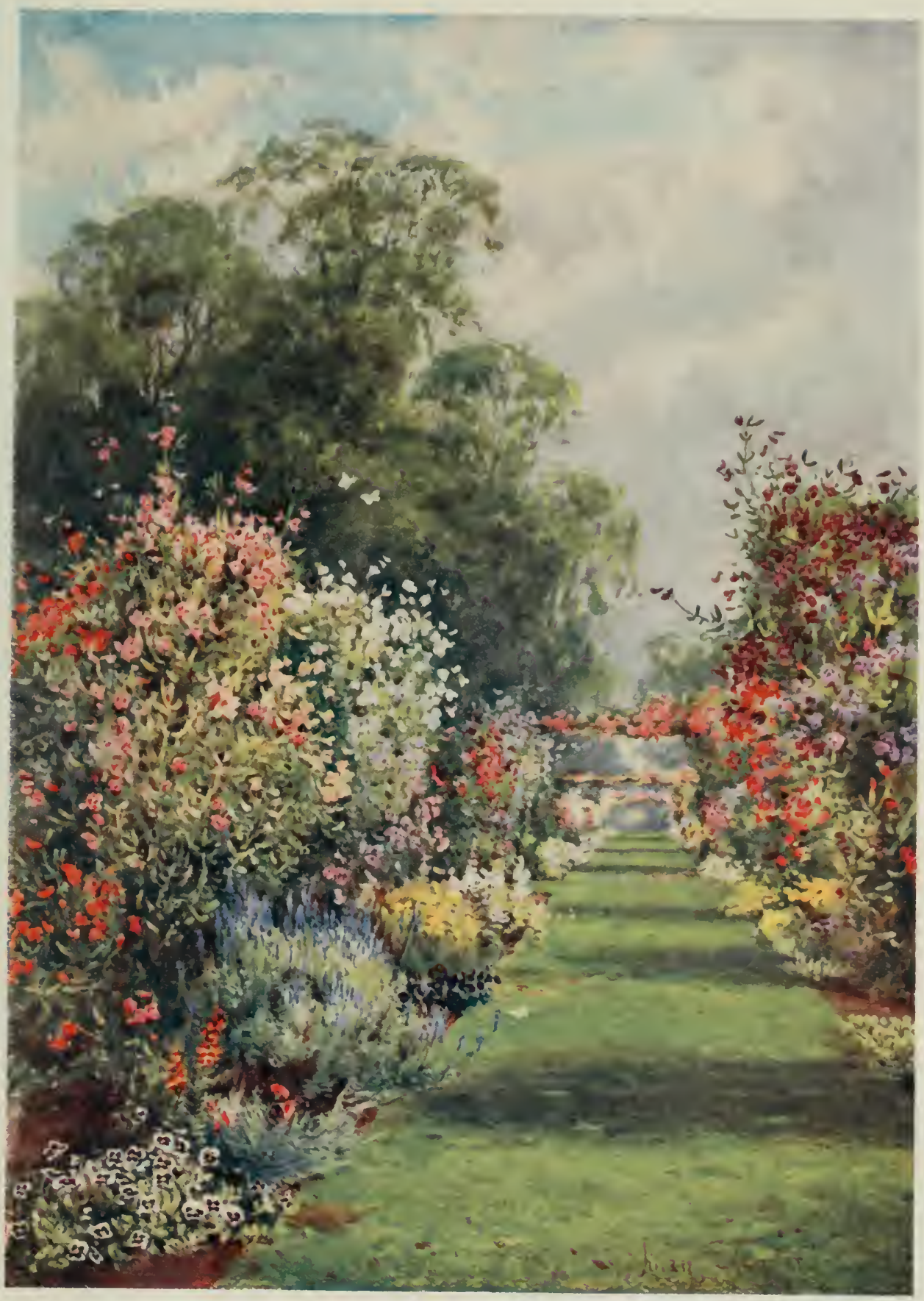

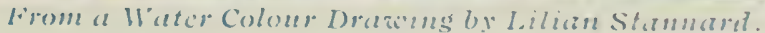

SWEET PEAS. 

Let us put into small compass a few facts about the Sweet Pea. It is known to science as Lathyrus odoratus, the name given to it by Linnaus. It belongs to the order Leguminosæ, or pod-bearers. It is a hardy annual-that is, a plant which may be sown out of doors to complete its life-history within a year. It differs from most annuals, however, in being amenable to propagation by cuttings. The flower consists of a large upright petal called the standard, two smaller side ones called the wings, and a bottom one folded in called the keel. The organs of sex are enclosed within the keel, and consist of ten stamens, each with its anthers or pollen case at the top, the pistil with ovary at the base, and stigma at the top. Nominally each Sweet Pea flower is self-fertilised, because the pollen is ripe and the stigma viscid to receive it before the flowers have opened sufficiently for wind or bees to come into play; in this also it differs from most flowers. When the flowers fade the fused carpels are seen in the form of a boat-shaped body, which extends, and is presently seen to be the seed pod. Each pod contains from eight to twelve seeds. The pods are ready for gathering when they change colour and begin to open.

Had the Sweet Pea been known in the days of Chaucer, Shakespeare, Spenser, and Ben Jonson, it would have prompted some beautiful images and delightful rhyme. John Keats fell in love with the flower, and wrote of-

"Sweet Peas, on tiptoe for a flight, With wings of gentle flush o'er delicate white, And taper fingers catching at all things, To bind them all about with tiny rings."

Varieties.-The number of varieties of Sweet Peas is 


\section{POPULAR GARDEN FLOWERS}

now enormous, but it has developed almost entirely within the past fifty years. The reason why Sweet Peas did not multiply naturally is that the habit of self-fertilisation made for constancy. When florists had satisfied themselves that it was possible to improve Sweet Peas, and that there was a public waiting for new varieties, they pursued an active course of artificial cross-fertilisation, opening flowers while still in the bud, so as to anticipate self-fertilisation, removing the anthers, and applying pollen from another flower to the stigma. These crosses resulted in the production of a large number of different varieties. The best were retained, and selected again and again until they kept true to character. The raiser has found that although the Sweet Pea was one of the most constant of flowers naturally, yet it is extremely variable when crossed, and is some time in settling down. The seed of every plant raised from a cross should be kept separate and sown by itself under its own label; this renders the task of getting any particular novelty fixed much easier than when the seeds of different plants are mixed; even when the latter appear to be absolutely identical they may throw dissimilar plants another year. The old varieties had a smooth-edged or plain standard with a notch in the centre, the modern ones have frilled standards; as there are admirers for both, I will include them in the table of selected varieties on page 349 .

All those named are suitable for exhibition. They include representative sorts of the principal colours which we now possess, but the reader should recollect that new, and in some cases improved, varieties are being brought out annually, and he who specialises should inquire about novelties from his seedsman in order to be in a position to keep up to date. 


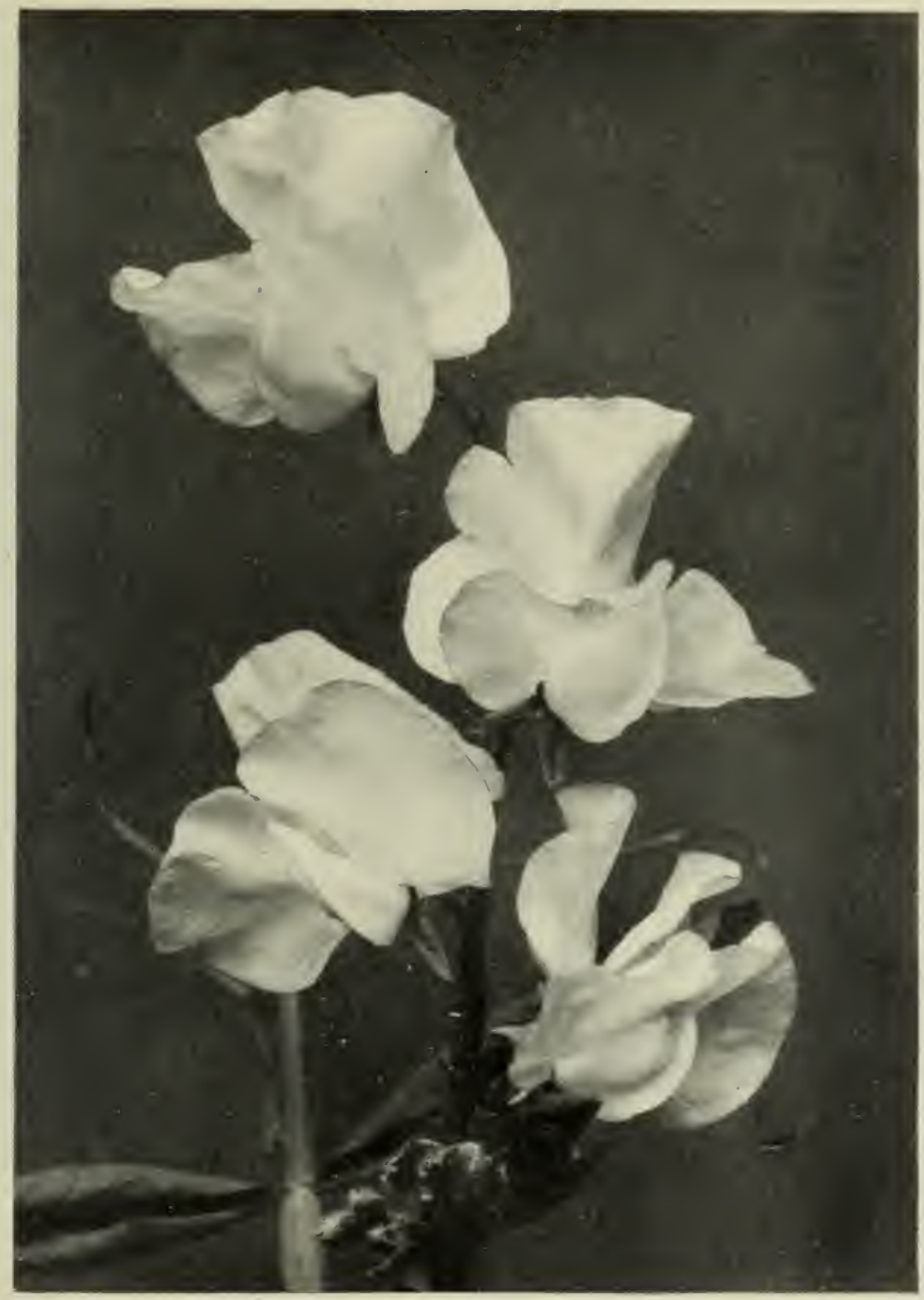

SWEET PEAs. 



\begin{tabular}{|c|c|c|c|c|}
\hline \multicolumn{3}{|l|}{ Variety. } & Colour. & Standard. \\
\hline *A. J. Cook ～. & - & & Pale mauve & Frilled a little. \\
\hline Asta Ohn & - & • & Lavender & Frilled. \\
\hline Aurora Spencer & - & • & Striped & Frilled. \\
\hline *Black Knight & - & & Maroon & Smooth. \\
\hline Cherry Ripe . & - & . & Cerise & Frilled. \\
\hline *Clara Curtis : & - & • & Cream & Frilled. \\
\hline * Constance Oliver & . & . & Pink & Frilled. \\
\hline *Countess Spencer & . & . & Pink & Frilled. \\
\hline Dora Breadmore & - & . & Buff & Smooth. \\
\hline *Dorothy Eckford & . & • & White & Smooth. \\
\hline Douglas Unwin. & · & • & Maroon & Frilled. \\
\hline *Duke of Westmin & ster & • & Claret & Smooth. \\
\hline Earl Spencer & - & • & Salmon & Frilled. \\
\hline *Elsie Herbert & - & & White, pink edge & Frilled. \\
\hline Etta Dyke . & . & & White & Frilled. \\
\hline *Flora Norton Spe & ncer & • & Bright blue & Frilled. \\
\hline *Frank Dolby. & - & & Lavender & Frilled a little. \\
\hline Gladys Burt. & . & & Cream, rose border & Frilled. \\
\hline * George Stark & . & & Scarlet & Frilled. \\
\hline *Helen Lewis. & - & & Orange & Frilled. \\
\hline *Helen Pierce. & . & & Blue veined & Smooth. \\
\hline *James Grieve. & - & & Cream & Snooth. \\
\hline John Ingman & & & Orange carmine & Frilled. \\
\hline *Lady Grisell Ham & ailton & & Lavender & Smooth. \\
\hline *Lord Nelson & - & & Dark blue & Smooth. \\
\hline *Marjorie Willis & - & & Rosy magenta & Frilled. \\
\hline Masterpiece & & & Lavender & Frilled. \\
\hline * Mrs. Andrew Irel & and & & Rose and blush & Frilled. \\
\hline * Mrs. C. IV. Bread & more & & Cream, rose edge & Frilled. \\
\hline Mrs. Hugh Dicks & on & & Cream pink & Frilled. \\
\hline * Mrs. Walter Wrig & ht & & Mauve & Smooth. \\
\hline * Nora Univin. & . & & White & Frilled. \\
\hline Nubian. & . & & Maroon & Frilled. \\
\hline *Paradise Ivory & . & & Ivory & Frilled. \\
\hline Princess Victoria & . & & Blush & Frilled. \\
\hline *Queen Alexandra & . & & Scarlet & Smooth. \\
\hline Stirling Stent & . & & Salmon & Frilled. \\
\hline * Sunproof Crimson & . & & Crimson & Frilled. \\
\hline Tennant Spencer & . & & Mauve & Frilled. \\
\hline Zarina . & . & - & Salmon & Frilled. \\
\hline
\end{tabular}

* These are particularly good garden varieties. 


\section{POPULAR GARDEN FLOWERS}

Propagation.-The great majority of growers, for garden and exhibition alike, raise their plants from seed, and this is the method to be recommended. Cuttings made out of the tips of young plants may, however, be used if desired. They should be about three inches long, and inserted firmly in moist, sandy soil in a box that is covered with a square of glass and put in a shady part of the greenhouse. The removal of the tips does not hurt the plants, indeed some growers systematically stop their plants, not because they want cuttings, but in order to make them break from the base. Seed-buyers will find that the seed of all varieties is not alike. In the case of some it is plump, round, and smooth, in others small and wrinkled. Most of the blues have insignificant seed, but it gives equally as strong plants as large seeds. Outdoor sowing may be practised in autumn or spring, according to soil and requirements. If early flowers are wanted, the seed may be sown in September or October, provided the soil is well drained and friable. In heavy, stiff, stodgy soil autumn sowing does not answer. An ounce of seed may be sown for every seven or eight yards of row and covered an inch deep. Seed may be sown in March or April in the ordinary course. The exact time should depend upon the state of the soil. If it is in a friable state the first good shower may be taken advantage of. It is desirable that the soil be damp, but not sodden. It is the custom of growers to raise expensive novelties in boxes or pots under glass in order to be able to provide conditions which will insure every seed germinating. A compost of loam, leaf mould, and sand is prepared, and the seeds put in quite clear of each other half an inch deep. Where pots are used six seeds are often sown in a five-inch pot, but very careful growers sow singly in three-inch pots, because 
then there is no disturbance of the ball of soil and roots when planting time comes. The receptacles are put in a frame or on a greenhouse shelf. Some exhibitors sow in autumn, and keep the young plants almost dry through the winter. Certainly the raiser must be very careful not to keep the soil wet during the dull season. Others sow in January or February. Hard-skinned seeds often germinate slowly, and growers chip the shell with a knife.

Soil, Manure, and Planting.-The plants raised in the manner described are generally put into the open ground in April. The soil should be prepared previously by digging it two spades deep and incorporating a dressing of decayed horse manure equal to from two to three barrow-loads per square rod. Light soil should be prepared in autumn, and heavy ground after the first severe spell of frost. The surface should be left lumpy, and in February a dressing of dry wood ashes, with superphosphate equal to seven pounds per square rod, may be spread on. The soil will crumble after the spring showers, and be ready for the seeds or plants in April. If seeds are to be sown in rows, draw drills two inches deep six feet apart; if in clumps, draw circular drills four to five feet across at intervals of a few feet. Young and sturdy plants from pots or boxes may be set nine inches apart. Some dry lime may be sprinkled round them to keep slugs off. The grower should be carefui to get his plants sturdy by keeping them uncrowded and near the glass, and he should plant them out as soon after they show tendrils as possible.

Sticks, Water, Stopping:--The sticks should be put to the plants as soon as they start growing. They should be sharpened, and forced well down a few inches from the plants. In their early stages the plants 


\section{POPULAR GARDEN FLOWERS}

may be tied to the sticks, but when they get to be eighteen inches high they will form tendrils freely and get a tight hold, twining round every stem and twig. Should the weather be dry, a good soaking of water, in which nitrate of soda at the rate of half an ounce per gallon has been dissolved, may be given twice a week. This, with the good soil under the plants, will insure their making rapid progress. Exhibitors practise various plans to insure strong stems and continuity of flowering. One fancies stopping the plants when a foot high by pinching off the tips, in order to encourage side shoots from the base. Another believes in letting them grow naturally till the end of July, and, after winning a number of prizes, cutting the plants right back to the ground for a new break. A third stops half his plants at four feet high. The general grower need not trouble about any of these devices, but there is one thing that he must do if he wants to have a long succession of flowers, and that is to gather regularly. Weekly drenchings of liquid manure will help the plants to continue growing and flowering until autumn : the food will also help to keep the stems long, and this is a great advantage to those who want flowers for room decoration.

Exhibiting.-Sweet Pea competitions are general in these days, and as the flower is not an expensive one to exhibit, many amateurs try their luck in the show tent. Stands and tubes are not wanted, as they are in the case of Carnations, Chrysanthemums, Dahlias, and Roses; Sweet Peas being shown in vases. At many exhibitions these are hired to exhibitors by the committee at a small charge; if not, any slender vase from eight inches to a foot high, with a mouth wide enough to hold about twenty stems without crowcling, will do. 
With the aid of a little moss the stems can be fixed in the mouth of the vase in such a way that the flowers are displayed in a well-spread circle, each clear of its neighbours. Crowding should be avoided. Stems about fifteen inches long, carrying four large, fresh flowers each, give the exhibitor his greatest chance of success. Old, dingy flowers stand very little chance, however large they may be. Freshness is so important that the exhibitor must take pains in selecting and packing his sprays. He should select sprays of which some flowers are only just opening, cut them the day before the show, and stand them in water in a cool, shady place till he is ready to pack them up. He should then wrap them quite dry in soft paper and pack them firmly in shallow boxes with nothing more than a little moist paper round the base of the stalks. They will pass several hours in the boxes quite safely, and open fresh and clean when placed in water. If the show is near they may be cut early on the same morning. The exhibitor should make himself acquainted with the rules by reading the regulations in the schedule, and conform to them. He should place neat cards clearly inscribed with the name of the variety in front of each vase. How charming a flower the Sweet Pea is for decoration, the vases and epergnes which the lady exhibitors arrange at the shows prove conclusively.

Enemies.-Sweet Peas have no dangerous insect enemy peculiar to themselves, and when they are given suitable conditions they generally grow healthfully, but slugs, wireworm, caterpillars, and various fungi assail them at times. Freshly slaked dry lime, and lime water, check slugs. Wireworm may be reduced to impotence by dressing the ground with Vaporite, which, however, must be placed well below the roots in spring, 


\section{POPULAR GARDEN FLOWERS}

previous to planting. Caterpillars should be picked off, or deterred by syringing the plants with soot-water. If the grower has a hose he may give the plants a drenching through the rose of this occasionally. It is weak plants that suffer most from fungi, and the best preventive is good soil and careful culture. Should disease attack the plants, spray the foliage with a solu-

i tion of liver of sulphur, at the rate of half an ounce per gallon of water.

Every flower-lover should grow Sweet Peas. If he does not care to specialise them under names, let him sow mixtures, preferably of the giant Waved or Spencer type. Let him grow these in rows, in clumps beside a favourite path, in his borders, or against fences and trellis-work. Their beautiful blossoms will enliven the garden and brighten and perfume the house. Flowers of exceptional charm and grace, fragrant, easily grown, they appeal to gardeners of all classes with overwhelming force. 


\section{XXXV}

\section{ON STOCKS AND WALLFLOWERS}

Bотн of these perfumed flower-garden favourites shared with Carnations the common name of Gilliflower (or Gillyflower) in the Middle Ages. We have already seen (Chapter VIII., Carnations) that Gilliflower is not, as is commonly believed, a corruption of July flower, but of caryophyllon or caryophyllus, and that the latter, the generic name of the Indian Clove tree, is also the specific name of the Carnation, having been given because of the clove perfume of the flower.

Although old-time gardeners called Carnations, Stocks, and Wallflowers by the common name Gilliflowers, we can well imagine their finding it convenient to devise subsidiary names, and looking for them in the habit of the plants. They would perceive a natural distinction between a grassy plant like the Carnation and a shrubby one like either of the others. So they would draw upon the good old word "stock," indicating a hard stem, for the Gilliflowers that were not grassy. This would make both Stocks and Waliflowers Stock Gilliflowers, and a further sub-division being desirable, they would bring in the word "wall" to distinguish that member of the Stock Gilliflowers which commonly grew on walls. Gillyflower (Burrow), Gillowflower (Parkinson), Gillofre (Holland), Jereflouris (Douglas), and Gillyvor (Shakespeare, "The Winter's Tale"), are all variations of Gillyflower. 


\section{POPULAR GARDEN FLOWERS}

The Wallflower is the Cheiranthus (kyer-an'-thus) cheiri of botanists. The generic name comes from cheir, the hand, and anthos, a flower, in allusion to the general use of the flowers as nosegays.

There are flowers, as there are people, which, without possessing remarkable beauty, have a distinctiveness and force that cause them to stand out from their fellows; and the Wallflower is assuredly one of them. Without exceptional vigour of habit or brilliance of colour to recommend it, it nevertheless holds a sure place in the affections of flower-lovers. We may attribute its popularity partly to its being evergreen, partly to its habit of blooming freely in spring, and partly to its powerful perfume. Retaining its foliage throughout the winter, it gives life and colour to what would otherwise be bare soil; blowing in spring, it gives brightness at a season when flowers are none too plentiful; diffusing delicious fragrance, it adds an unfailing charm to the neighbourhood of a house.

Belonging to the Cruciferæ, or cross-shaped flowers, the Wallflower is a member of a large order, which comprises 172 genera and $\mathrm{I} 200$ species, and consists of flowers with four sepals, the same number of petals, six stamens, four of which are long and two short, with glands at the base, and an ovary divided into two sections. The seeds are borne in a long pod (siliqua).

The common Wallflower is a native of Southern Europe, but has become naturalised in Great Britain, where its orange-yellow flowers bedeck the crumbling walls of many an old fortress. Its success in shallow limestone crevices, and on chalky cliffs, should warn the flower gardener that it does not require rich soil. Larger plants can be grown in such ground, but they 
are apt to be succulent, and to succumb to severe and prolonged frost. If bigger plants than the wall seedlings are wanted there is no difficulty in getting them in combination with a tough, frost-resisting habit by sowing seed in some spare part of the kitchen or flower garden in May, and setting the plants out nine inches apart in rows a foot asunder after a shower in July. Nothing need be done to them save hoeing until October or November, when they may be planted a foot apart all ways in flower-beds from which summerblooming plants have been cleared, in borders under the house windows, in window-boxes, and near the front of herbaceous borders. The soil should not be manured before planting, as it is desirable to maintain the hard, woody habit which has developed as a result of the thin culture.

The Wallflower is a true perennial when growing as a wilding; its stems are seen to be woody and its leaves few. In such a state it will live many years and flower fairly well; but garden plants treated as biennials-that is, raised and planted as suggested, and thrown away after flowering-are much finer in their season, having much more foliage and therefore filling beds better, and producing larger flowers. The seed is cheap and the culture simple, consequently it is of no advantage to let the plants assume their natural character of perennials.

Many seedsmen offer the following strains of Wallflowers :-

Annual.-Brown, may be sown under glass in spring to bloom the same year.

Belvoir Castle.--Pale yellow, one of the best, being a free grower, an abundant bloomer, very bright, and highly perfumed.

Blood Red.-Dark red or brown, very sweet. 
Cloth of Gold.-A good yellow.

Eastern Queen.-Chamois, paling to salmon.

German, double.-Various colours, sweet, somewhat taller than most of the singles; a good plant for pots as well as the garden.

Golden Tom Thumb.-Another useful yellow.

Harbinger.-Brown, rather taller than Blood Red, early.

Old Castle.-Orange yellow, a selection of the wilding, and one of the best for dry places.

Ellen Willmott.-Ruby.

Belvoir Castle and Blood Red will meet the requirements of most amateurs admirably. To establish plants on walls, sow seed in the chinks in spring and cover with soil.

Botanically the Stock, Mathiola (Math-e-o'-la) is very close to the Wallflower, but the flowers are purple instead of orange, the stigmas erect instead of spreading, and the seeds slightly winged instead of wingless. The plant was named after an Italian botanist, Mathioli. As we have seen, there has been an association centuries old between the two plants, although both have lost, by abridgment, the distinguishing name of Gilliflower. The Stock is a native of Western Europe and the Mediterranean littoral, but one species, incana, is a native of Great Britain, and is considered to be the parent of the Brompton Stock, which, with its hoary leaves and large flowers, ranks as one of the most popular of our hardy biennials.

The Stock is equally as fragrant as the Wallflower, but blooms later, and has a much greater range of colours. All classes of it should be grown-the annual ten-week, Wallflower-leaved, Queen, and Brompton in the garden, the Intermediate and East Lothian in pots. The Ten-week Stocks came from the annual 


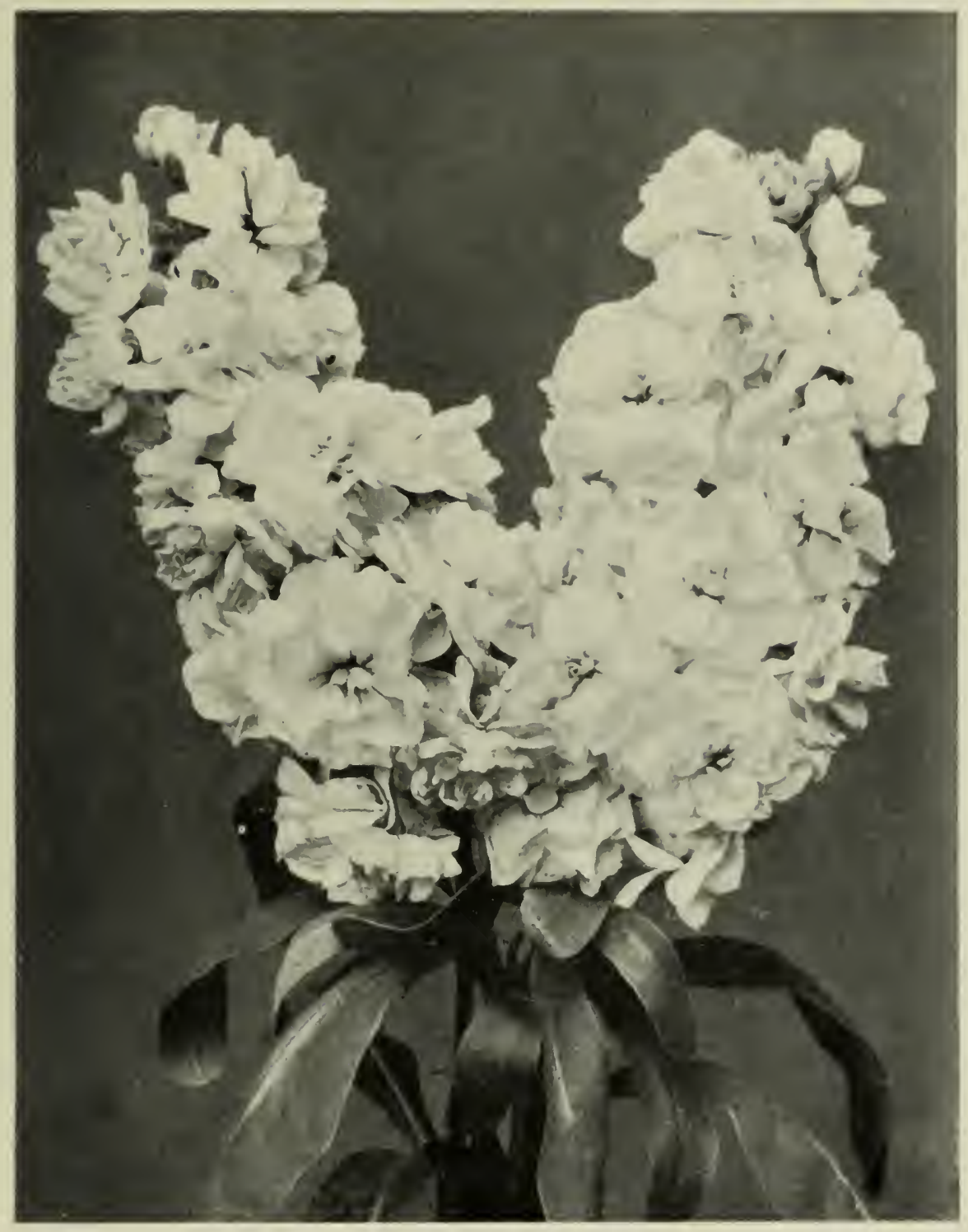

TEN-WEEK STOCKS. 



\section{ON STOCKS AND WALLFLOWERS 359}

species annua, a various-coloured plant; the Wallflower-leaved (which has green instead of hoary leaves) from the white-flowered annual species graca; the Queen and Brompton both from the evergreen species incana. The hardy annual lilac-coloured species bicornis is the plant popularly known as the Night-scented Stock, from its peculiarity of emitting its sweet odour only at night. The flowers of this plant are not particularly attractive, even when they are fully open at night; in the daytime they are commonplace, while the whole plant has a draggly look.

Single Stocks have no charms for most flower-lovers. The blossoms are poor and the habit of the plant is straggly. But florists have attained such skill in selecting the flowers from which to gather seed that, although the seed-yielding blossoms are themselves single, eighty to ninety per cent. of their progeny are double. If the grower buys from a seedsman of repute he may calculate on not having more than fifteen plants single in each hundred. It is a good plan to put the plants in clumps of five or six in the beds and borders, so that if a single plant appears it can be pulled out without leaving a serious gap. The plants may be raised and grown in the same way as China Asters. The one serious difficulty in raising Stocks from seed in spring is the liability of the plants to damp off, and they sometimes do this in thousancls. The remedy is culture in a frame, abundance of air in favourable weather, and only enough water to prevent flagging. Should the trouble persist in spite of care, it would be well to sterilise the soil by heating it over a fire and letting it cool before sowing.

The Dwarf German Ten-week, height about a foot, and the Giant Perfection Ten-week, height about 


\section{POPULAR GARDEN FLOWERS}

eighteen inches, are two excellent strains of annual Stock for garden culture. They produce large spikes of fragrant flowers in a great variety of colours, which can be bought separately or in mixture. If greenleaved Stocks are preferred, the Wallflower-leaved may be grown instead. They grow about a foot high, and have several distinct colours. Princess May, primrosecoloured, is a charming variety of this class; it may be grown as a Ten-week garden Stock, or in pots for the greenhouse. Mont Blanc is a splendid white garden Ten-week of robust habit, growing about eighteen inches high.

A bed or broad band of Ten-week Stocks beside a walk or near a summer-house, or clumps in a part of the herbaceous border near the doors or windows of the house, should form a feature of every garden. The plants are handsome and the flowers persistent, as well as highly perfumed; alike for garden and cutting they will prove delightful. But to have them in really fine condition they must be strong as seedlings, planted in soil that has been dug deeply and manured well, and given water or liquid manure in dry weather.

The Brompton Stock, which grows about two feet high and branches freely, is generally treated as a hardy biennial, being sown outdoors in May or June, together with Wallflowers, Canterbury Bells, and Sweet Williams, thinned, and planted out in autumn or spring. As a rule it gets hard and woody enough to stand the winter when treated in this way, but it is often killed during severe winters in cold districts or on damp soil; and if disappointment is experienced from this cause, it would be well to sow under glass in June, put the plants in small pots later on, and winter them in a frame, not planting them out until the spring. 
ON STOCKS AND WALLFLOWERS 36I

Several distinct colours of the Brompton Stock are available.

The Intermediate Stocks, of which the East Lothian is a form, are generally grown in pots and treated as biennials, being sown in a frame in August, potted, and put in a heated house in autumn to bloom in winter and spring. But they may be flowered in the garden in summer if desired by sowing in a warm house in February, hardening in a cold frame, and planting out in May.

Riviera Market, Beauty of Nice, Christmas Pink, and other charming strains of Stocks offered by the large seedsmen are suitable for the same culture as the Intermediates. Three plants may be grown in an 8-inch pot.

Wallflowers in spring, Stocks in summer, shall represent in our gardens the Gilliflowers of the olden days. They will give us the same delicious odours as they gave to the flower-lovers of the Elizabethan period, and they will give us larger blooms, richer colours, and a greater proportion of doubles. In so far, then, we have the advantage of the amateurs for whom Parkinson, Ray, and Gerard wrote. 


\section{XXXVI}

\section{ON T U L IPS}

THERE is no writer on Tulips who does not love to recall the great mania. It was the one outstanding event in the history of the flower. It lives not merely in gardening records, but in tables of the world's great events. In a paper read before the Royal Horticultural Society on March 9, I909, by Mr. W. S. Murray, and published in the Society's July Journal of the same year, some highly interesting information about this extraordinary craze was given. The bulbs became so valuable that they were sold by weight like diamonds. The weight was calculated in azen, an azen being less than a grain. A large bulb would weigh between 500 and I 000 azen, and sell for sums varying between $\mathrm{I} 500$ and 3500 florins. (A florin was Is. $8 \mathrm{~d}$.) The highest price recorded is 5500 florins $\left(£ 45^{8}, 6 \mathrm{~s}\right.$. $8 \mathrm{~d}$.) for a small bulb weighing only 200 azen (about ten grammes) of the variety Semper Augustus. But payment was sometimes in kind, and here is a table of goods, with their estimated value, paid for one bulb of the variety Viceroy-

Value in Florins.

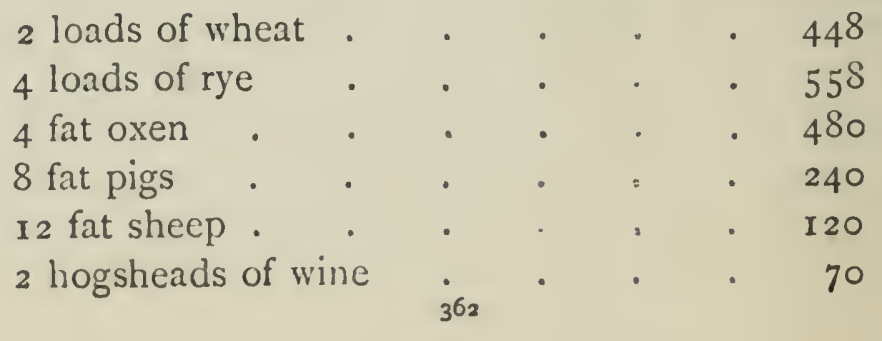




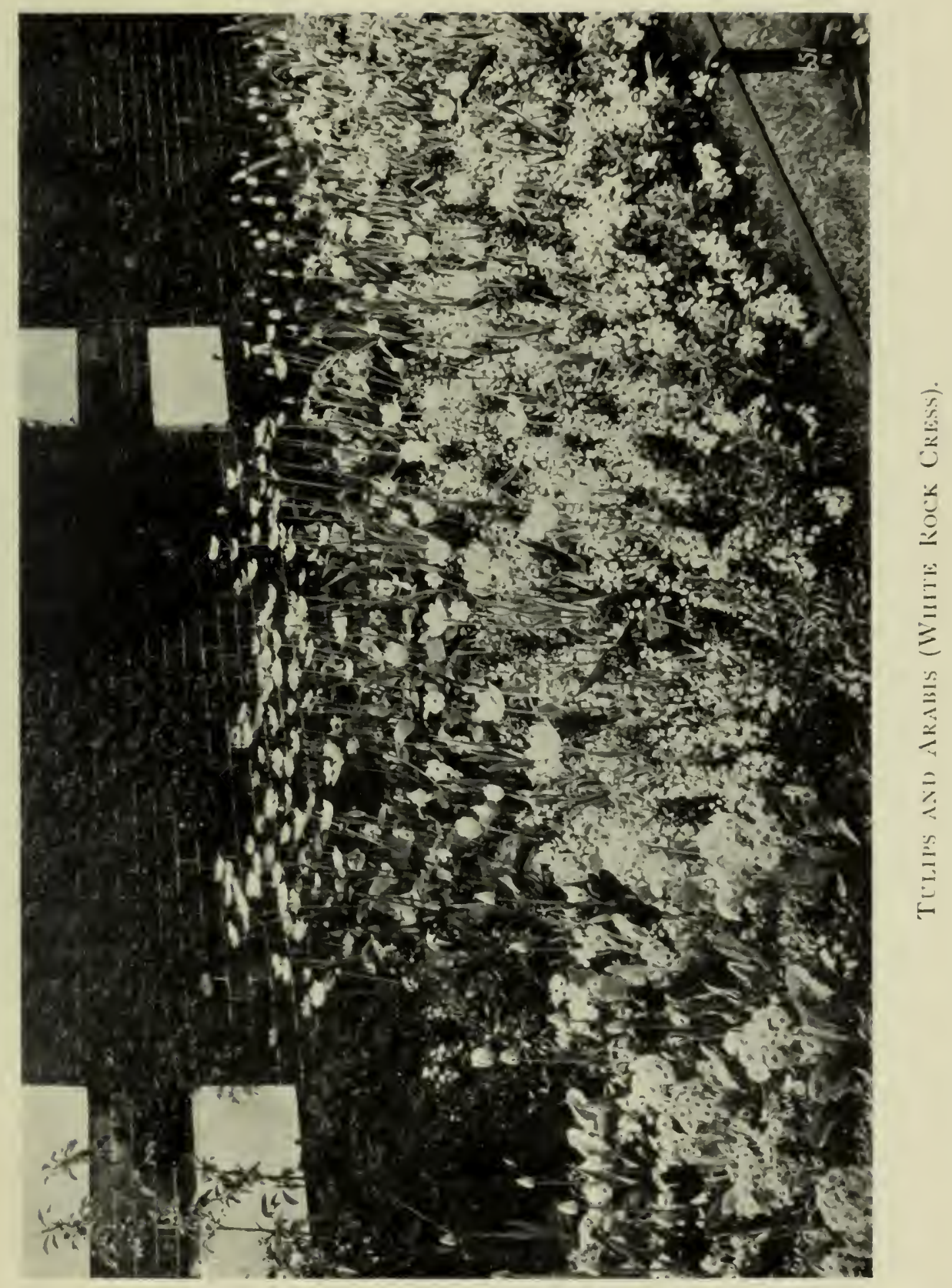



4 barrels of beer. . . . 32

2 barrels of butter. . . . 192

1000 lbs. of cheese . . . . 120

A complete bed . . . . . 100

A suit of clothes . . . . . 80

A silver beaker . . . . . 60

Total value $\cdot \overline{2500}$

Was it some Tulip-loving farmer who made this remarkable bargain? Country doctors tell us that the farmer of the present day has a way of offering to settle a bill with a sack of grain and a side of bacon!

The centre of the mania was Holland, but Mr. Murray quotes Munting as declaring that it originated in France, where the nobility, evidently moved by the spirit of reckless and selfish extravagance which led, later on, to the Terror, paid sums amounting to hundreds of pounds for a single bulb. Many of the Dutch buyers were mere speculators, and bargains involving large sums of money were made without the Tulips ever leaving the ground.

Tulips were grown in Holland as early as 1590 , and the period of the mania is suggested as $1634-1637$. The eagerness of the Dutch to get possession of bulbs was amusingly satirised by Alexandre Dumas in La Tulipe Noire, but his description of the act of an unscrupulous amateur in endeavouring to steal the bulbs of a fellow grower was not imaginary. It was based on fact. Dr. Clusius, whose name is enshrined in the well-known species Clusiana, took Tulips to Leyden when appointed Professor of Botany there, in I593, and as his prices for bulbs were high, his compatriots prepared a deep-laid scheme and stole them. 


\section{POPULAR GARDEN FLOWERS}

There are few popular flowers in which some of the old species are as highly esteemed as the most modern varieties, but the Tulip is certainly a case in point. Gesneriana and its yellow variety lutea both date back more than three hundred years as cultivated plants, and both are highly esteemed at the present day. The species must have been named in compliment to Conrad Gesner, who described some Tulips growing in Austria in 156r. Mr. Murray says that these originated from seed carried from Turkey by Busbequius, an ambassador sent by the Emperor Ferdinand I. to the Sultan, and who saw Tulips for the first time in Turkey in I554. But he thinks that suaveolens, a dwarf fragrant red and yellow species flowering in April, which was introduced to Great Britain in 1603 , and is illustrated in the Botanical Magazine, $t .839$, must have been seen among these seedling Turkish Tulips by Gesner in view of his description of the flowers, because their perfume is particularly mentioned, and there are few fragrant Tulips. Busbequius himself commented on the absence of perfume in the Tulips which he saw.

The Tulip probably came from Persia, and it is somewhat curious that the name can be traced from the same Persian word, thoulyban, tulbend, or dubbend, as gave "turban." The Persian used this word to describe the nettlecloth worn by the Turks as a fez, probably in allusion to the shape of the flower. The old name for Tulip was Tulipan, and the descent of this from thoulyban is easily followed.

We see that the Tulip is an Oriental plant, and we perceive Eastern splendour in the brilliance of its flowers. The remarkably rich and glowing colours, the large size and massive substance of the great floral urns, the dusky sheen of some varieties, the 


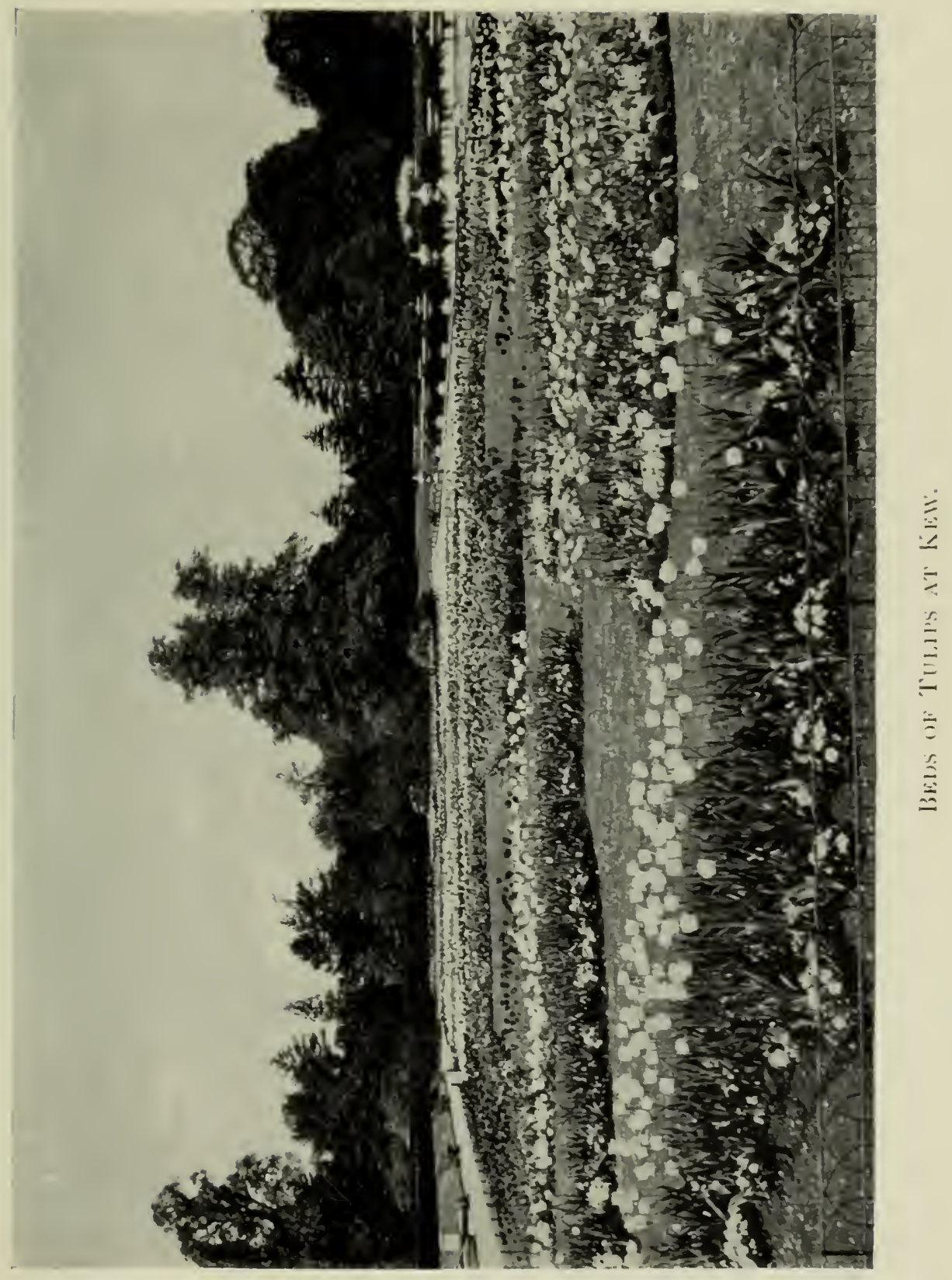



metallic sparkle of others, have a truly Oriental magnificence.

Tulip Species.-The lover of Tulips who may be curious to know what the species are like may buy bulbs of many through the ordinary dealers, and may make acquaintance with some at one of the large libraries through the medium of the great works in which faithful coloured plates and accurate descriptions of the plants appear, such as the Botanical Magazine and the Botanical Register. Here are the names of some of the best: Australis or Celsiana, yellow, flushed with red, appears in the Botanical Magazine, t.7I7. Batalini is pale yellow. Biflora, yellow, introduced in 1806 , is shown in the Botanical Magazine, t. 6518, and also in the Botanical Register, t. 535. Clusiana, a white and purple species, said to have been introduced from Sicily in ${ }_{16} 66$, is shown in the Botanical Magazine, t. 1390. The fine bright red species, Didieri, introduced from the Alps in 1882, is represented by $t .6639$ of the Botanical Magazine; the yellow variety of this called Billietiana is one of the most popular of late-blooming garden Tulips. Eichleri, crimson, black, and yellow, introduced from Georgia in 1874 , is shown in t. 6191 of the Botanical Magazine. Fosteriana is a magnificent vermilion species, exhibited in 1906. Gesneriana is shown in the Botanical Register, $t$. 46.' The variety of Gesneriana called Dracontia, which is also known under the name of Turcica, gave us the Parrot Tulip, with its singularly cut and contorted petals. Another variety called spathulata, brilliant red, is one of the finest of garden Tulips.

The dwarf scarlet species Greigii is much in demand as a garden Tulip. It has been grown in British gardens since 1873, and is shown in the Botanical Magazine, 


\section{POPULAR GARDEN FLOWERS}

t. 6r77. Hageri, scarlet, blue, and yellow, is shown in the Botanical Magazine, t. 6242. Kaufmanniana, red and yellow, introduced from Central Asia in 1877 , and shown in the Botanical Magazine, t. 6887, is grown by many Tulip-lovers; and the same may be said of the red and yellow Kolpakorskiana, introduced from Turkestan in I878, and shown in the Botanical Magazine, t.67ro. Leichtlini, purple, white, and yellow, introduced from Cashmere in I889, is a charming little species, and the same may be said of linifolia, scarlet and black, brought from Central Asia in I886. Primulina, introduced from Algeria in I882, a very dwarf grower with primrose-coloured flowers, is illustrated in the Botanical Magazine, t. 6785. Pulchella, Botanical Magazine, $t .6304$, is a pretty, small species from Asia Minor, with rose and lilac flowers. Retroflexa, with yellow recurved flowers, is regarded as a hybrid. Stellata, white, a tall Himalayan species, somewhat rare, is shown in the Botanical Magazine, t. 2672. Sylvestris or fragrans is the sweet yellow English Tulip. Triphylla, lemon to orange, Botanical Magazine, t. 6459, is beautiful but expensive. Vitellina, pale yellow, is a hybrid.

The foregoing are the principal Tulips, other than varieties, which are offered in the catalogues of bulb dealers. They are not grown by the majority of amateurs, but Tulip-lovers are a large body, and in their ranks are to be found a sufficient number of specialists to provide a considerable demand for most of the kinds named.

Early and Florists' Tulips.-The botanists formed three sections-early (pracoces), medium (dubia), and late (serotina). The scarlet species procox represents the first, and Gesneriana the last. The middle section was never taken very seriously, and dropped out. In modern 
flower-gardens Tulips are grown either as Early or Late. The former, both single and double, are the cheap and popular "Dutch" Tulips. They include the dwarf very early Duc Van Thols, which are in great demand for forcing in pots, and originated from suaveolens. The late section includes the Darwins, the May-flowering or Cottage Tulips, and the old florists' show Tulips. The last, which are subdivided into Bizarres (yellow-ground flowers marked with purple I or scarlet), Byblœmens (white-ground flowers marked I with violet or purple), Roses (white-ground flowers I marked with rose, scarlet, or crimson), and Breeders (one-coloured or self flowers which after several years break into Bizarres, Byblœmens, or Roses, and are then called "rectified"), are only grown by a few specialists. Those who want to study them might refer to the Journal of the Royal Horticultural Society, vol. xv., 1893, and vol. xxvii., I902, where articles by experts appear. It was varieties of this section which formed the principal objects of the Tulip mania, but early varieties were also in demand. They might also refer to Robert Sweet's Florists' Guide, published by James Ridgeway, of Piccadilly, in I827-29, in two volumes, for this work contains a large number of beautiful coloured plates of Bizarres, Byblœmens, and Roses. Handsome flowers, of great substance, with rounded, exquisitely coloured petals, are shown in these splendid plates.

Late Tulips. - Although the early Dutch Tulips are popular for pot culture, and are also used a good deal in spring bedding, the great body of amateurs have given most of their attention to the Darwins and cottage Tulips during recent years. These glorious plants are taller, larger, and finer in every way than the early Dutch. They form noble clumps in the borders. The 
flower stems rise to two feet high, or even more, the flowers have as much substance as the florists' varieties, and the colours are very rich. Flower-lovers plant these grand Tulips near the front of the mixed borders, and generally leave them in the ground the whole year, although some prefer to take them up and dry them after the foliage has ripened off, replanting in early autumn. When Tulips are thus taken up it will be found that in most cases the old bulb has decayed, but that a new one, nearly or quite as large, has formed within the scales. There may also be offsets, which will require two years' culture before they are large enough to flower. Flower-lovers need not feel under any cultural obligation to replant the Tulips every year, but they should take care that if the borders containing them are dug in autumn or winter, when the bulbs are dormant, a careful workman acts, and that he replants the clumps as he proceeds.

Planting.-Early and late Tulips alike are best planted in October or November, in friable, deeply dug soil. A light dressing of well-decayed manure may be dug in ten or twelve inches deep, and supplemented with bone flour at the rate of a quarter of a pound per square yard; this may also be dug well in. The plants are likely to do better in heavy soil than in light, provided it is made friable, as they will appreciate the moisture such ground holds. Leaf-mould, sand, road grit, and old hotbed manure may all be used to improve heavy land. Cow manure may be used freely in light ground. The bulbs should be planted in clumps of from three to twelve, according to means and space; and the components of the various clumps should be about nine inches apart. The bulbs may be covered with three inches of soil. 


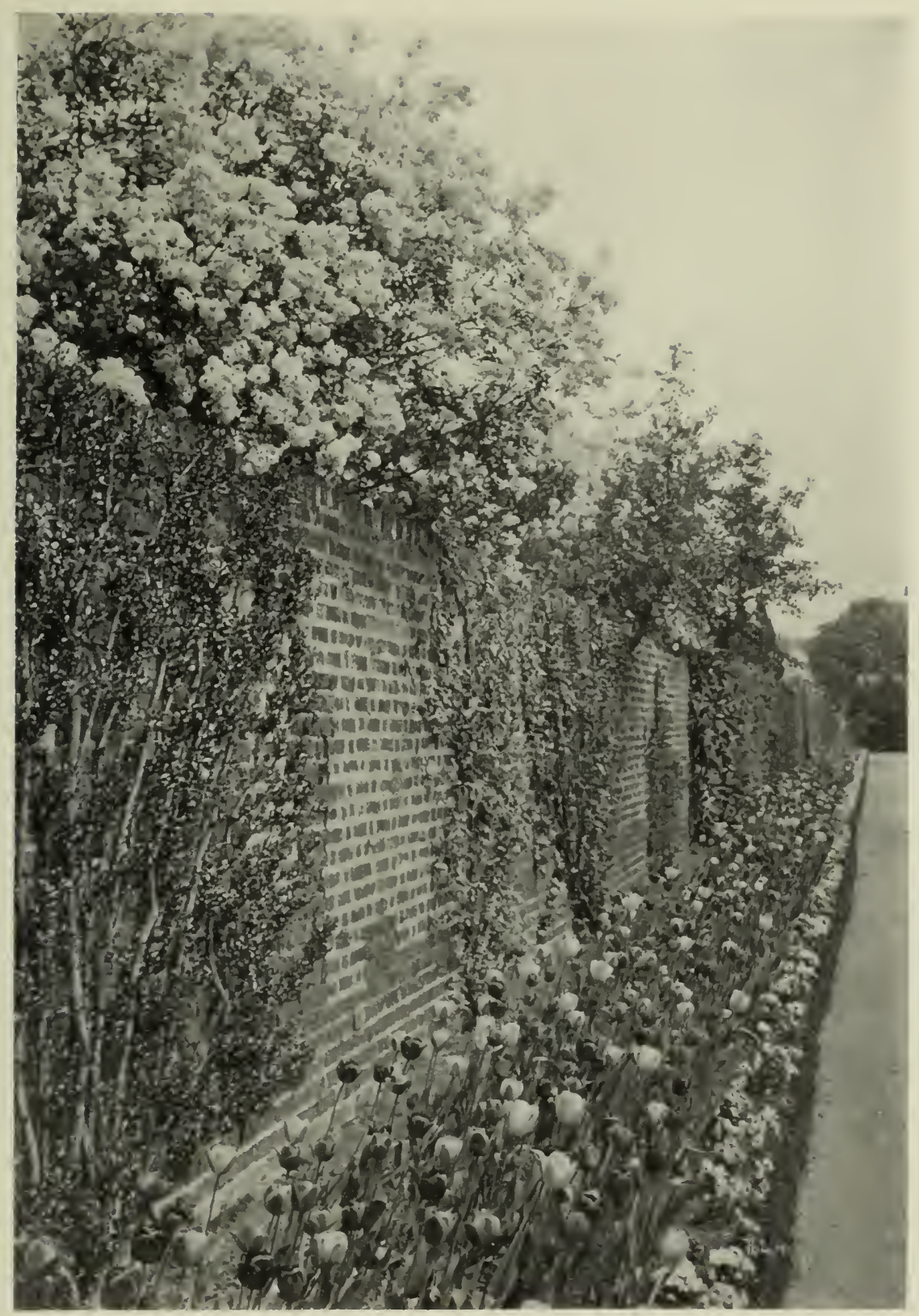

A BORIER OF TULIPS WITH LILAC ABOTE. 

Growers of florists' Tulips generally put their plants in a special bed, the soil of which is prepared carefully, and over which an awning of light canvas is fixed during the flowering period for the purpose of shading the flowers from the sun.

Pot Tulips are grown similarly to Hyacinths, being put into 5 -inch or 6-inch pots in autumn, in a compost of loam, decayed manure, and sand, and plunged in cocoanut fibre refuse until they have made a good lot of roots, then brought out and put in the greenhouse. The only difference is that three bulbs are put in each pot instead of one. By putting some in a warm house and keeping others in a frame or cool house, a succession of bloom can be secured. All the early Dutch Tulips are suitable for pot culture, and the Duc Van Thols are the earliest of them.

The following are beautiful Tulips, and the table shows the class to which they belong, their colour, and the month of flowering. It will be noted that several fragrant varieties are included.

\begin{tabular}{|c|c|c|c|}
\hline Variety. & Class. & Colour. & $\begin{array}{l}\text { Month of } \\
\text { Flowering. }\end{array}$ \\
\hline Annie Macgregor & Rose & Rose and white & May. \\
\hline Attraction . & Byblœmen & Rose and yellow & May. \\
\hline Bessie . . & Byblœmen & Rose and yellow & May. \\
\hline Billietiana . & Cottage & $\begin{array}{l}\text { Yellow, splashed } \\
\text { red }\end{array}$ & May. \\
\hline Bridesmaid. & Cottage & Rose and white & May. \\
\hline Brunhilde . & Early single & Flamed buff & April. \\
\hline Buenaventura . & Cottage & Scarlet and yellow & May. \\
\hline Chrysolora . . & Early single & Yellow & April. \\
\hline Clara Butt : & Darwin & Rosy salmon & May. \\
\hline Cottage Maid . & Early single & Rose and white & April. \\
\hline $\begin{array}{c}\text { Couronne des } \\
\text { Roses. } . .\end{array}$ & Early double & Rose & April. \\
\hline Crimson King. & Early single & Crimson & April. \\
\hline
\end{tabular}




\begin{tabular}{|c|c|c|c|}
\hline Variety. & Class. & Colour. & $\begin{array}{l}\text { Month of } \\
\text { Flowering }\end{array}$ \\
\hline Dainty Maid . . & Cottage & Lilac and white & May. \\
\hline Didieri alba . . & Cottage & White, sweet & May. \\
\hline Dr. Dalton. & Bizarre & Purple and yellow & May. \\
\hline Dr. Hardy. & Bizarre & Purple and yellow & May. \\
\hline Donders. . . & Darwin & Brownish red & May. \\
\hline Farncombe Sanders & Darwin & Rosy carmine & May. \\
\hline Gala Beauty . & Cottage & Scarlet and yellow & May. \\
\hline Gesneriana lutea. & Cottage & Yellow & May. \\
\hline Heroine. . . & Rose & Rose and white & May. \\
\hline Herschel . . & Cottage & Scarlet & May. \\
\hline $\begin{array}{l}\text { Imperator Rub- } \\
\text { rorum }\end{array}$ & Early double & Scarlet & April. \\
\hline $\begin{array}{l}\text { Inglescombe Scar- } \\
\text { let }\end{array}$ & Cottage & Scarlet & May. \\
\hline Joost van Vondel & Eariy single & Crimson and white & April. \\
\hline Kate Greenaway. & Darwin & Lilac and white & May. \\
\hline Keizer's Kroon & Early single & Scarlet and yellow & April. \\
\hline La Candeur. & Darwin & White & May. \\
\hline La Merveille. & Bronzy salmon & Cottage, sweet & May. \\
\hline Le Rêve. & Early single & Pink & April. \\
\hline Loveliness . & Darwin & Rose & May. \\
\hline Mabel . . & Rose & Rose and white & May. \\
\hline Macrospeila . & Cottage & Cerise, sweet & May. \\
\hline Maiden's Blush & Darwin & Rosy pirı & May. \\
\hline Masterpiece . & Bizarre & Purple and yellow & May. \\
\hline Modesty . . & Rose & Rose and white & May. \\
\hline Nora Ware. & Darwin & Pale lilac & May. \\
\hline Nulli Secundus & Byblœmen & Rose and yellow & May. \\
\hline Ophir d'Or. & Early single & Yellow & April. \\
\hline Parisian Yellow & Cottage & Yellow & May. \\
\hline Picotee . & Cottage & White, pink edge & May. \\
\hline Pink Beauty . & Early single & Pink and white & April. \\
\hline Pride of Haarlem & Darwin & Rosy carmine & May. \\
\hline Prince of Austria. & Early single & Orange, sweet & April. \\
\hline Proserpine $\quad$. & Early single & Rose & April. \\
\hline Queen of Whites. & Early single & White & April. \\
\hline Salvator Rosa. & Early double & Rose & April. \\
\hline Sir J. Paxton. & Bizarre & Purple and yellow & May. \\
\hline Talisman . & Byblœmen & Rose and yellow & May. \\
\hline Thomas Moore & Early single & Orange & April. \\
\hline The Sultan. & Darwin & Maroon & May. \\
\hline Tournesol . & Early double & Red and yellow & April. \\
\hline Van Berghem . & Early single & Rose, sweet & April. \\
\hline Vermilion Brilliant & Early single & Scarlet & April. \\
\hline
\end{tabular}




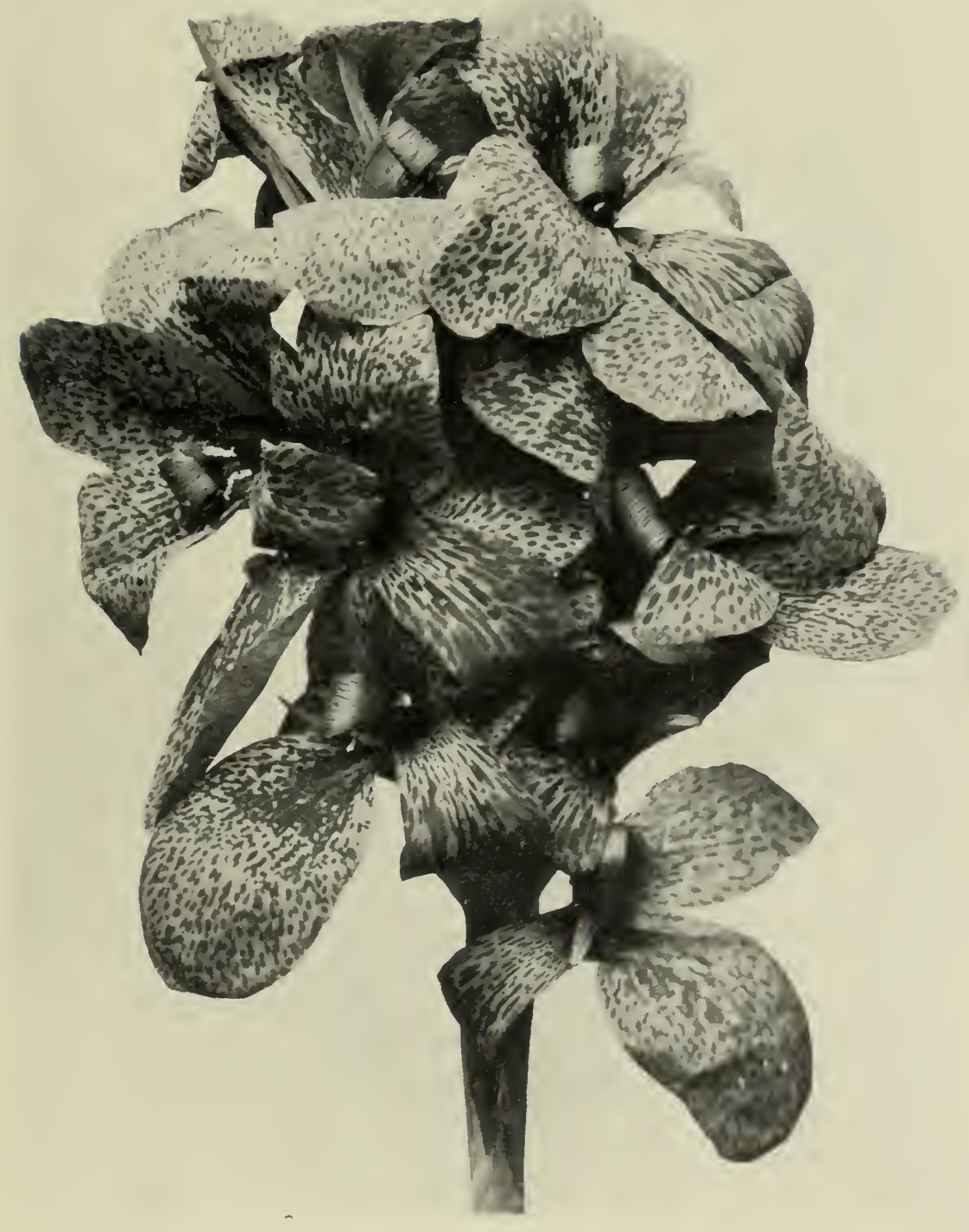

Cancas. 

IN DEX 



\section{INDEX}

\section{A}

Anemones, origin of name, 3 ; principal species, 4 ; Blanda, 5 ; Poppy, 5 ; fulgens, 7 ; Hepatica, 8 ; Hortensis, 9 ; Japanese, 9 ; narcissiflora, IO; wood, IO; Pulsatilla, II ; sylvestris, I I

Annuals, hardy, 47, 48, 49; halfhardy, 50

Antirrhinums. See Chapter XXXIII. Aquilegias. See Columbines, Chapter XII.

Asters, origin of name, I 3 ; perennial, 14; principal species, I7, I 8; soil, I 8 ; propagation, 19 ; for suburban gardens, I9; China, 20; annual types, 2I ; culture of annual, 22

Auriculas, 294, 299

\section{B}

Begonias, early species, 24; early hybrids, 25 ; select varieties, 27 ; cheap, 28; how to start, 28 ; raising from seed, 29; planting, 29; fibrous, 30

Bell-flowers (Campanulas), origin of name, 32 ; Canterbury Bells, 33 ; perennial, 35 ; principal species, 36

\section{C}

Calceolarias, bedding, origin of name, 39 ; early species, 39 ; good varieties, 40 ; propagation, 40
Campanulas. See Bell-flowers.

Canary Creeper, origin of name, 42 ; sowing, 43

Candytufts, 47

Canterbury Bells, 32

Carnations, Picotees, and Pinks, origin of names, $51,52,53$; Clove, 54; various sections of, 57 ; pot culture, 59; select varieties, 6o, $61,62,63$; soil, 64; wireworm, 64 ; leather-jackets, 64 ; planting (illustrated), 65 ; diseases, 66 ; in beds, 66 ; for towns, 67 ; propagation, 67; maggot, 69; Japanese and Indian Pinks, 69; a monthly calendar, 70-76

Christmas and Lenten Roses, poisonous, 78 ; popular name, 78 ; situation for, 79; under trees, 80; planting, $8 \mathrm{I}$; varieties, 82

Chrysanthemums, history, 84 ; early varieties, 87 ; famous growers, 89 ; blue, 90; classification, 90-92; varieties, 93-97; double garden, 97-99; large Daisies, I00; Golden Feather, IOO; Marguerites, IOI ; hardy annual, IOI ; hardiness, IOI ; propagation, IO2 ; soil, IO3; a monthly calendar, IO4-I IO

Clarkias, 49

Clematises, origin of name, I I ; uses of, I I 2 ; popular names, I 12 ; pretty species, I 3 ; mountain, I 3 ; Jackmanii, I 15 ; pruning, I 16 ; beautiful varieties, I 77

Columbines (Aquilegias), origin of 
name, II9; and the poets, 120 ; species and hybrids, I 22 ; propagation, I 24 ; structure of flower, I 25

Cuwslips, 294, 295

Crocuses, origin of name, I26; saffron, I 26-I29; Saffron Walden, I 27 ; Saffron Hill, I28; for rockwork and pots, I30; Autumnblooming, I 3 I ; spring-flowering, I 32 ; cheap Dutch, I 32 ; in grass, I 33 ; birds, I 33

\section{D}

Daffodils and Narcissi, origin of names, I 34; and the poets, I 35 , I 36 ; classification, I 37 ; select varieties, I 38, I 39, I 40 ; hardiness, I 40; in beds, I4I ; and Primroses, I 42 ; after flowering, I 43 ; in town gardens, I43-145; in herbaceous borders, I 45 ; for cheap gardening, I46; the Poet's naturalised, I47; in grass, I 47 ; in pots and bowls, I 48

Dahlias, history, I 53 ; as hardy plants, I 55 ; after flowering, I 56 ; propagation by cuttings, I 57 ; from seed, I 58 ; propagation by division, I 58 ; soil and manure, I 59 ; staking, 160 ; for exhibition, I60; garden, I6I; good varieties, 162

Delphiniums. See Chapter XXVI.

Digitalis. See Foxgloves.

\section{E}

Eschscholtzias, 49

\section{F}

Feverfews (Pyrethrums), origin of name, ${ }^{6} 63$; and Chrysanthemums,
I63; for town and suburban gardens, I65; culture of, I65; best varieties, 166

Forget-me-nots (Myosotis), origin of name, 168 ; various species, 169 ; culture, 170

Foxglove (Digitalis), origin of name, I 7 I ; naturalised, I74; culture of, I 75

\section{G}

Geraniums and Pelargoniums, $1 ; \sigma$; origin of names, 176, I77; hardy, I77; good species, I77; Zonal, I 78 ; winter bloom, I 80 ; propagation, I82; Ivy-leaved, I82; from seed, I83; good varieties, 185

Gladioli, origin of name, 186 ; wireworm, I 88 ; for cutting, I 88 ; beautiful species, I90; classes, I9I ; good varieties, I92; preparing soil, I93; wintering, 194; from seed, 194

Godetias, 49

\section{H}

Hellebores. See Chapter IX.

Hepaticas, 8

Hollyhocks, origin of name, 196, 197 ; disease, 198, 199; culture of, 200 ; Fig-leaved, 20I

Honeysuckle, popular names, 202; and the poets, 202, 203; culture of, 205, 207; good species and varieties, 205, 207

Hyacinths, wild, 208 ; origin of name, 208, 209; white Roman, 209; Dutch, 210; propagation, 210; as pot plants, $21 \mathrm{I}$; in water, 214 ; in bowls, 215; in flower heds, 215 ; in suburban gardens, 216; Grape, 216; good varieties, 217; Hyacinthus candicans, 2 I 7 
Irises, soil, 218; for towns, 218 ; propagation, 219; cheapness of, 219; "Flag," 220; origin of name, 220 ; and the poets, $22 \mathrm{I}$; native, 222 ; pseudacorus, 222 ; Gladwyn, 222 ; snake's head, 223 ; best species, 223-228; German, 225 ; Japanese, 225 ; select varieties, 229-23I

\section{J}

Jasmine, origin of name, 232 ; and the poets, 233 ; species of, 233236

Jonquils, 137

\section{$\mathbf{L}$}

Larkspurs (Delphiniums), origin of name, 237; origin of annual, 238 ; perennial species, 238 ; propagation, 239; soil, 239; cutting back, $24 \mathrm{I}$; seedlings, 24I ; good varieties, 242

Lent Lilies, I 37

Lenten Roses. See Chapter IX.

Lilies (Liliums) and the poets, 244, 245; the Madonna, 246; the scarlet, 247 ; auratum and its varieties, 247 ; the best species, 250259 ; culture in pots, 259 ; propagation, 260; popular names, 260 ; home and imported bulbs, $26 \mathrm{I}$

Lonicera. See Chapter XXII.

Love-in-a-mist, 49

\section{M}

Michaelmas Daisies, I4

Mignonette, 50

Myosotis. See Chapter XVII.
Narcissi. See Chapter XIV.

Nasturtiuns, 44, 45

O

Oxlip, 294, 295

\section{$\mathbf{P}$}

Pronies, early species, 263 ; origin of name, 264 ; soil, 265 ; planting, 266; propagation, 266; species and varieties, 267 ; select varieties, 268

Pansies, origin of name, 27I; and the poets, 27I; popular names, 272 ; wild, 272; Scotch prize, 273 ; propagation, 274 ; best types, 275 ; soil, 275 ; tufted, 276 ; as town flowers, 277 ; Sweet Violets, 278-28I; species and varieties, 28 I ; select varieties, 282,283

Pelargoniums. See Chapter XIX.

Phloxes, origin of name, 285 ; early species, 286 ; early and late, 287 ; annual, 288; propagation, 289; soil, 291 ; for beds and borders, 29 I ; good varieties, 292, 293

Picotees. See Chapter VIII.

Pinks. See Chapter VIII.

Polyanthuses, 294, 295

Poppies, 49

Primroses (Primulas) and Daffodils, I 42 ; origin of name, 294-296 ; and the poets, 297; propagation, 298 ; for beds, 299 ; named border, 300 ; beautiful species, 300 ; green. house, 301

Pyrethruins. See Chapter XVI.

\section{R}

Rose Mallow, 49

Rose of Sharon, I 36 
Roses, old varieties, 305 ; and the poets, 306 ; origin of name, 306 ; some good species, 307; White Rose of York, 307 ; Red Rose of Lancaster, 307 ; Ayrshire, 307 ; Scotch, 307 ; Burnet-leaved, 307 ; Dog, 307 ; Sweetbrier, 308 ; hybrid Briers, 308; Damask, 308 ; Hybrid Perpetual, 308 ; Tea, 309 ; Hybrid Tea, 309; Musk, 309 ; Cabbage, 310; Provence, 310; Austrian Brier, 3 I I ; variegated, 3 I I ; Banksian, 312; Fairy, 312 ; Boursault, 312 ; Seven Sisters, 3 I 2 ; Japanese, 312 ; Cherokee, 312 ; "Sub rosa," 313; gardens of, 314; list of fragrant, 315 ; good Hybrid Perpetual, 317; good Hybrid Tea, 3I7; good Tea, 3r8; for beds, 319; for walls, 319; for pillars, arches, pergolas, arbours, and summer-houses, 321; for banks, 322 ; for standards, 322 ; for indoor culture, 323; soils and manures, 323 ; planting, 325 ; pruning, 326 ; propagation, 329 ; budding, 330 ; from cuttings, 331 ; making pillars and arches, 33I ; exhibiting, 332 ; sizes of show boards, 334; under glass, 334 ; insects and diseases, 335 ; a monthly calendar, 335-338

\section{S}

Snapdragons, 339,340

Stocks, origin of name, 355 ; sec- tions, 358; single and double, 359 ; raising from seed, 359 ; good varieties, $359,360,361$; in beds, 360 ; Brompton, 360

Sweet Peas, history of, 345 ; structure of, 347 ; good varieties, $34^{8}$, 349 ; propagation, 350 ; soil, manure, and planting, $35 \mathrm{I}$; sticks, water, stopping, $35 \mathrm{I}$; exhibiting, 352 ; enemies of, 353

Sweet Williams, 339, 343

\section{$\mathbf{T}$}

Tropœolums, 45

Tulips, the mania, 362, 363; an extraordinary bargain, 362 ; history of, 364 ; origin of name, 364 ; species of, 365 ; early, 366 ; florists', 366 ; late, 367 ; planting, 368 ; in pots, 369 ; good varieties, 369,370

\section{V}

Violas. See Chapter XXIX.

Violets. See Chapter XXIX.

\section{W}

Wallflowers, origin of name, $355-356$; structure of, 356 ; culture of, 357 ; good varieties, 357

Windflowers, 3 



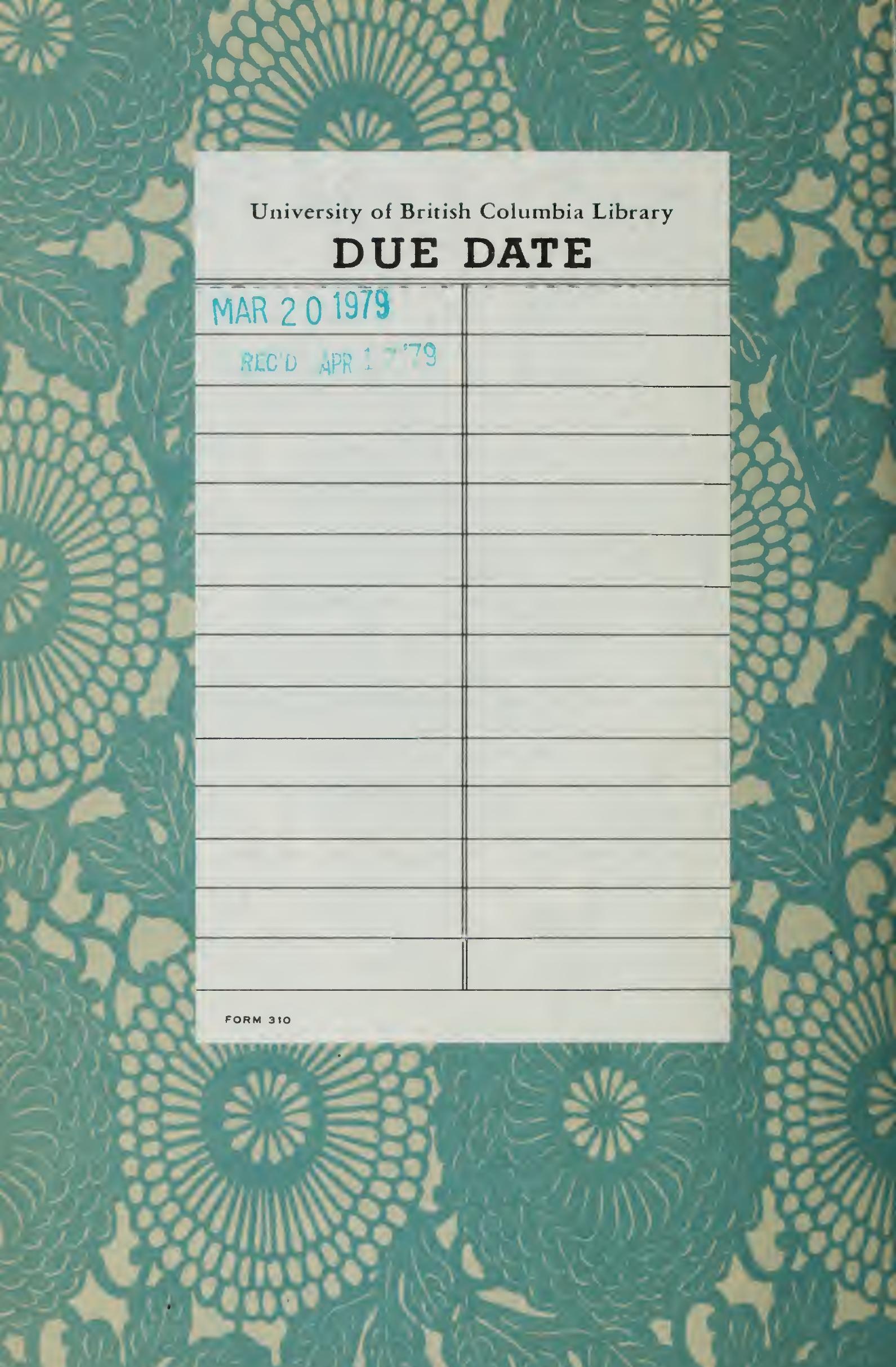




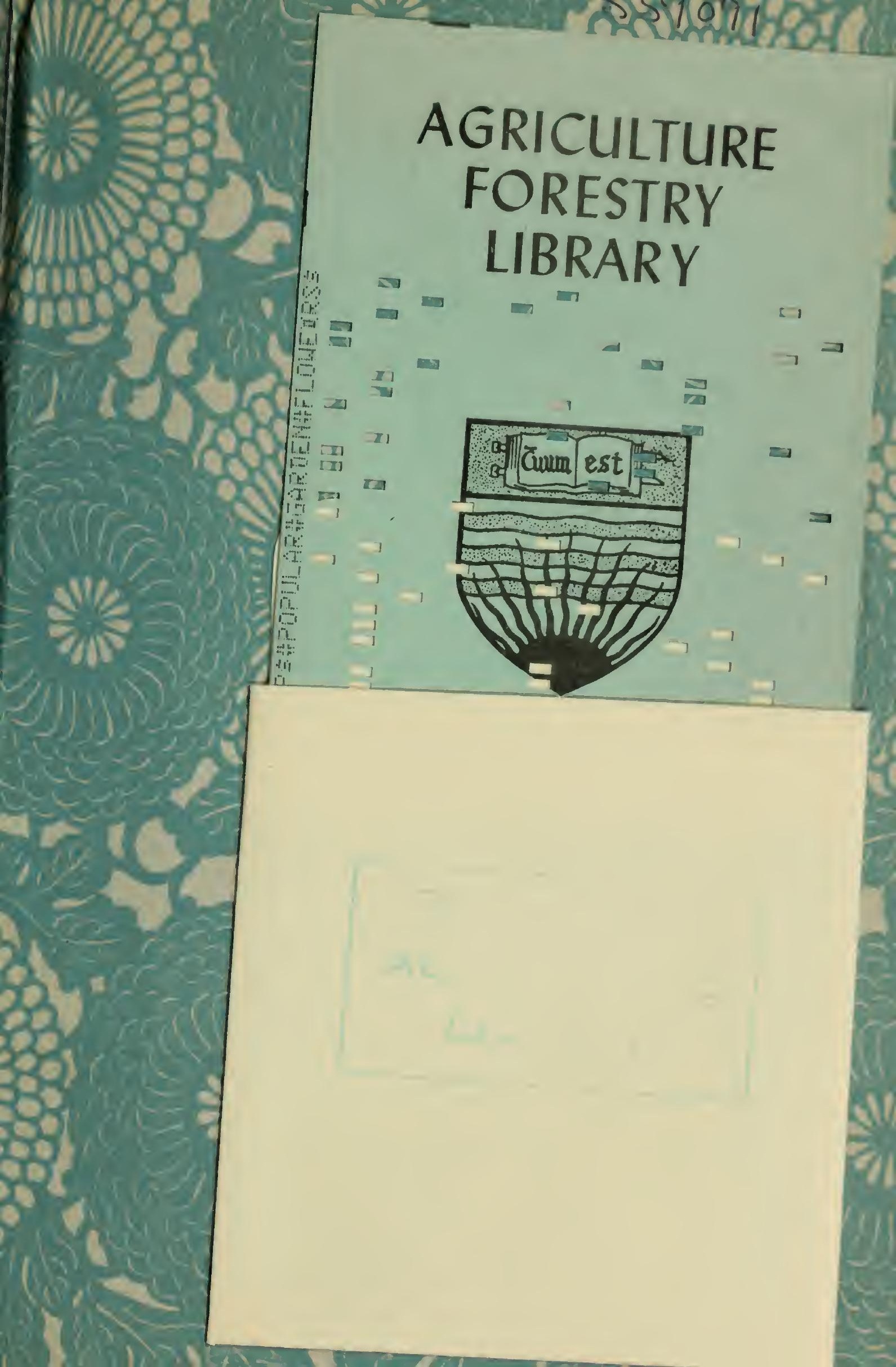


